\title{
URBAN ETHICS
}

CONFLICTS OVER THE GOOD AND PROPER LIFE IN CITIES

Moritz Ege and Johannes Moser

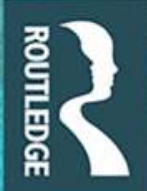




\section{Urban Ethics}

This book delves into the ethical dimension of urban life: how should one live in the city? What constitutes a 'good' life under urban condition? Who gets to live a 'good' life, and whose ideas of morality, propriety and 'good' prevail? What is the connection between the 'good' and the 'just' in urban life?

Rather than philosophizing the 'good' and proper life in cities, the book considers what happens when urban conflicts and urban futures are carried out as conflicts over the good and proper life in cities. It offers an understanding of how ethical discourses, ideals and values are harmonized with material interests of different groups, taking up cases studies about environmental protection, co-housing schemes, political protest, heritage preservation, participatory planning, collaborative art production, and other topics from different eras and parts of the globe. This book offers multidisciplinary insights, ethnographic research and conceptual tools and resources to explore and better understand such conflicts. It questions the ways in which Urban Ethics draw on tacit moral economies of urban life and the ways in which such moral economies become explicit, political and programmatic.

Moritz Ege is Professor of Cultural Anthropology and European Ethnology at the University of Göttingen with a research focus on popular culture studies, urban ethnography, conjunctural analysis, and historical anthropology.

Johannes Moser is chair of European Ethnology and Cultural Analysis at Munich University. His research interests include urban anthropology, everyday culture and community studies. 


\section{Routledge Studies in Urbanism and the City}

\section{Ethnic Spatial Segregation in European Cities}

Hans Skifter Andersen

Big Data, Code and the Discrete City

Shaping Public Realms

Silvio Carta

\section{Neighbourhood Planning}

Place, Space and Politics

Janet Banfield

Urban Neighbourhood Formations

Boundaries, Narrations and Intimacies

Edited by Hilal Alkan and Nazan Maksudyan

\section{Urban Ethics}

Conflicts Over the Good and Proper Life in Cities

Moritz Ege and Johannes Moser

Planning and Managing Smaller Events

Downsizing the Urban Spectacle

Edited by Stefano Di Vita and Mark Wilson

\section{Mega-Events, City and Power}

Nelma Gusmão de Oliveira

For more information about this series, please visit www.routledge.com/ Routledge-Studies-in-Urbanism-and-the-City/book-series/RSUC 


\section{Urban Ethics \\ Conflicts Over the Good \\ and Proper Life in Cities}

Moritz Ege and Johannes Moser 
First published 2021

by Routledge

2 Park Square, Milton Park, Abingdon, Oxon OX14 4RN

and by Routledge

52 Vanderbilt Avenue, New York, NY 10017

Routledge is an imprint of the Taylor \& Francis Group, an Informa Business

(C) 2021 selection and editorial matter, Moritz Ege and Johannes

Moser; individual chapters, the contributors

The rights of Moritz Ege and Johannes Moser to be identified as the authors of the editorial material, and of the authors for their individual chapters, has been asserted in accordance with sections 77 and 78 of the Copyright, Designs and Patents Act 1988.

With the exception of Chapter 11, no part of this book may be reprinted or reproduced or utilised in any form or by any electronic, mechanical, or other means, now known or hereafter invented, including photocopying and recording, or in any information storage or retrieval system, without permission in writing from the publishers.

Chapter 11 of this book is available for free in PDF format as Open Access from the individual product page at www.routledge.com. It has been made available under a Creative Commons AttributionNon Commercial-No Derivatives 4.0 license.

Trademark notice: Product or corporate names may be trademarks or registered trademarks, and are used only for identification and explanation without intent to infringe.

British Library Cataloguing-in-Publication Data A catalogue record for this book is available from the British Library

Library of Congress Cataloging-in-Publication Data

A catalog record has been requested for this book

ISBN: 978-0-367-33842-8 (hbk)

ISBN: 978-0-429-32231-0 (ebk)

Typeset in Times New Roman

by codeMantra 


\section{Contents}

List of figures ix

List of contributors $\quad \mathrm{xi}$

PART I

Configurations of ethics and the urban - concepts and theories

1 Introduction: urban ethics - conflicts over the good and proper life in cities

MORITZ EGE AND JOHANNES MOSER

2 The habitat of the subject: exploring new forms of the ethical imagination

HENRIETTA L. MOORE

3 The city as a setting for collaboration? Tracking the multiple scales of urban promises

ALEXA FÄRBER

\section{PART II}

Shifting ethics of the urban: historical case studies

4 Mégapoles, polyrhythmy, porosity: tracing ideas of Mediterranean urbanity in western scholarly discourse MARTIN BAUMEISTER

5 Urbanity as an ethic: reflections on the cities of the Arab world 
6 The fractious stability of an immoral landscape: the land walls of Istanbul, 1910 to 1980

JULIA STRUTZ AND CHRISTOPH K. NEUMANN

7 "The good, the bad and the ugly": bucharest's urban core as a moral playground

DANIEL HABIT

81968 and beyond: the urban struggle on trial?

ISABELLE DOUCET IN CONVERSATION WITH MAURICE CULOT

\section{PART III}

Building and living ethically - conflicts over housing and architecture

9 Shaping urban ethics: the "making-of" a collective housing project at Berlin's river Spree

MAX OTT

10 Commitment - city - self: ethical self-formations in Munich's young housing cooperatives

LAURA GOZZER

11 Antagonisms and solidarities in housing movements in

Bucharest and Budapest

IOANA FLOREA, AGNES GAGYI AND KERSTIN JACOBSSON

12 Ethical contestation in architecture for a creative Singapore MICHAELA BUSENKELL

\section{PART IV}

Environmental justice, ethics of care and the spectacle of urban sustainability

13 Reimagining urban environmentalisms:

A comparative framework

JULIE SZE

14 Handling waste through consensus, care and community in Auckland, Aotearoa New Zealand 
PART V

Protest between ethics and politics: collective agents of urban change

15 Keep the city clean: the ambivalent ethics of ownership in urban routine and non-violent protest in Moscow

ALEXANDER BIKBOV

16 Guardians of Torfjanka Park: the fight for "our Moscow" and the understanding of "ordinary people" in the current conjuncture OLGA REZNIKOVA

17 "They are stealing the state": commoning and the Gilets Jaunes in France

IDA SUSSER

Index 


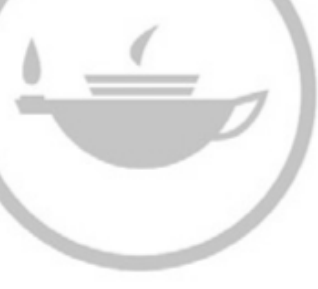

Taylor \& Francis Taylor \& Francis Group

http://taylorandfrancis.com 


\section{Figures}

3.1 Scenes of the promise and the city 50

5.1 Ottoman translation of Ibn Khaldun's Prolegomena 84

5.2 Ottoman translation of "Topographie and Description of Egypt" by Taki ad-Din Ahmed ibn 'Ali ibn 'Abd el-Kadir, also known as Makrîzî

7.1 Abandoned places vs. modernization and gentrification in the Old Town

7.2 Poor building fabric in the Old Town 120

7.3 Romanian folklorism and Orthodox events in the Old Court 122

9.1 The buildings of the housing cooperative Spreefeld 150

9.2 Inside an option space 157

9.3 The spatial arrangements between the cooperative buildings 158

12.1 Esplanade - Theatres on the Bay 198

12.2 Shading shell of the Esplanade 206

12.3 Competition model (DPA) 208

12.4 Section - Esplanade 209

14.1 Communal garbage sorting 233

15.1 Public hearing in Moscow 244

15.2 Protective bar on entrance door 249

15.3 Queue for WWII victory celebrations 253

15.4 Okkupai camp 255

16.1 Confrontation between the "guardians of the park" and orthodox nationalists 263

16.2 Watch shifts in front of the fence 264

16.3 Gathering against the construction of the church 270

17.1 Gilets Jaunes protest 280 


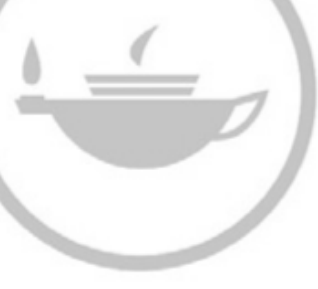

Taylor \& Francis Taylor \& Francis Group

http://taylorandfrancis.com 


\section{Contributors}

Martin Baumeister has been the director of the German Historical Institute in Rome since 2012. From 2003 until 2017, he held the chair in Contemporary European History at the LMU Munich. His current research interests include the history of contemporary Southern Europe and the Mediterranean, and urban history. Among his recent publications: Cities Contested: Urban Politics, Heritage and Social Movements in Italy and West Germany in the 1970s (co-ed. with Bruno Bonomo and Dieter Schott, Campus 2017).

Alexander Bikbov is a sociologist and public intellectual. He is currently a visiting professor at the EHESS, Paris, and a former lecturer at Moscow State University. His primary fields of research are protest movements, sociology of knowledge, historical sociology of concepts and perception of inequalities. Recent publications: "Neo-traditionalist fits with neoliberal shifts in Russian cultural policy" in L. Jonson/A. Erofeev (eds.): Russia - Art Resistance and the Conservative-Authoritarian Zeitgeist (Routledge 2017); and The Grammar of Order: A Historical Sociology of the Concepts That Change Our Reality (Moscow 2016).

Michaela Busenkell is an architecture theorist, curator and publicist. Her research interests concern contemporary architecture in the context of societal relations and transformations. She is currently working for Detail book editorial, an architecture publisher in Munich. Recent publication: “Singapore Puts On a New Face." In: German Architecture Annual 2019, edited by Deutsches Architektur Museum Frankfurt.

Isabelle Doucet is Professor of theory and history of architecture at Chalmers University of Technology, Sweden. Her research focuses on the relationship between architecture, (urban) politics and social responsibility. Since joining Chalmers Isabelle initiated a research project centered on women architects after 1968. She is the author of The Practice Turn in Architecture. Brussels after 1968 (Ashgate 2015) and co-editor of "Resist Reclaim Speculate. Situated Perspectives on Architecture and the City" (Architectural Theory Review, 2018, with H. Frichot). 
Moritz Ege is Professor of Cultural Anthropology/European Ethnology at the University of Göttingen with a research focus on popular culture studies, urban ethnography, conjunctural analysis and historical anthropology. Publications include an article on urban ethics (with Dürr/Moser/Neumann/Winder in City, Culture \& Society 2020), "The Exhaustion of Merkelism: A Conjunctural Analysis" (New Formations 2019, with A. Gallas) and 'Ein Proll mit Klasse'. Mode, Popkultur und soziale Ungleichheiten unter jungen Männern in Berlin (A classy prole. Fashion, pop culture and social inequalities among young men in Berlin) (Campus 2013).

Alexa Färber is Professor of European Ethnology at the Institute of European Ethnology at the University of Vienna. Her research interests concern urban studies, knowledge anthropology and visual research. Recent publications are "How Does ANT Help Us to Rethink the City and Its Promises?" (in: A. Blok, I. Farías, C. Roberts (eds.): The Routledge Companion to Actor-network Theory. 2019) and "Thrift Television: Narratives of Enduring, Saving, and Living Well. A Thematic Introduction" (Culture Unbound 2020, together with A. Podkalicka).

Jeannine-Madeleine Fischer did her PhD on perceptions of pollution and environmental ethics in Auckland, Aotearoa New Zealand at the LMU Munich. Her research interests are urban and environmental anthropology as well as studies on ethics, psychology and medicine. Recently she published together with Eveline Dürr "Tackling Pollution with Care: Everyday Politics and Citizen Engagement in Auckland, New Zealand." In: Setha Low (ed.): Routledge Handbook of Anthropology and the City. London, New York: Routledge 2018.

Ioana Florea is Researcher at the Department of Sociology and Work Science at the University of Gothenburg. She is currently working in the project "Housing, Social Mobilisations and Urban Governance in Central and Eastern Europe." She is also involved as a militant researcher in the housing movements, with which she has completed research on the financialization of housing (The European Action Coalition for the Right to Housing and the City, 2018), forced evictions (The Block for Housing, 2019; The Common Front for Housing Rights, 2019) and on the link between labor exploitation and housing precarity (The Block for Housing, 2020).

Agnes Gagyi is Researcher at the Department of Sociology and Work Science University of Gothenburg. Her research interests concern politics and social movements in Eastern Europe, in the context of the region's long-term world-economic integration. At the University of Gothenburg, she works as member of the project "Housing, Social Mobilisations and Urban Governance in Central and Eastern Europe," looking at urban governance, housing policy and housing protest after 2008. 
Laura Gozzer is Main Researcher in the sub-project "Charity. A praxeological approach to practices of help under urban conditions" of the DFG-founded research group "Urban Ethics" at the Institute of European Ethnology and Cultural Analysis at the LMU Munich. Recent publications: "New Housing Cooperatives in Munich. Two Scenarios for an Ethnographical Class Analysis" (In: The Vulnerable Middle Class? 2019).

Daniel Habit is Senior Lecturer at the institute of European Ethnology and Cultural Analysis at the LMU Munich. In his current project related to the presented chapter he focuses on Bucharest and the development of the urban space since Ceausescu's times. Furthermore, he is interested in moral and legal anthropology, Europeanization and museology. Together with Philipp Schorch, he is currently working on a publication titled Curating Socialist Environments, dealing with different approaches of displaying socialism.

Kerstin Jacobsson is Professor of Sociology at the University of Gothenburg. She works in the field of political sociology, including studies of civil society and social movements in Central and Eastern Europe. Recent articles are: "Performing Resistance: Liminality, Infrapolitics and Spatial Contestation in Contemporary Russia” (Antipode 2019, with C. Fröhlich), and "Mobilizing Grassroots in the City: Lessons for Civil Society Research in Central and Eastern Europe" (International Journal of Politics, Culture, and Society 2019, with E. Korolczuk).

Nora Lafi is Senior Research Fellow at Max-Weber-Kolleg, Universität Erfurt (Religion and Urbanity Research Group (FOR 2779), funded by the German Research Council (DFG)). Her research interests include the urban history of the Ottoman Empire and historical anthropology. Among her publications: "Urban Governance under the Ottomans" (co-ed, Routledge 2014); Urban Violence in the Middle East (co-ed, Berghahn 2015); Understanding the City through Its Margins (co-Ed, Routledge 2018) and Esprit civique et organisation citadine dans l'empire ottoman (Brill, 2019).

Henrietta L. Moore is the Founder and Director of the Institute for Global Prosperity and the Chair in Culture Philosophy and Design at University College London (UCL). A leading global thinker on prosperity, Professor Moore challenges traditional economic models of growth, arguing that to flourish communities, businesses and governments need to engage with diversity and work within environmental limits. Among her recent publications: Still Life - Hopes, Desires and Satisfactions (Cambridge 2011), "Understanding Prosperity in East London: Local Meanings and 'Sticky' Measures of the Good Life" (AnthroSource 2019, with S. Woodcraft).

Johannes Moser is Chair of European Ethnology and Cultural Analysis at the LMU Munich. His research interests include urban anthropology, 
everyday culture, mining communities and methodology. Recent publications are "Urban Ethics - Towards a Research Agenda on Cities, Ethics and Normativity" (City, Culture and Society 2020, with E. Dürr, M. Ege, Ch. Neumann and G. Winder), in: "The Vulnerable Middle Class? Strategies of Housing in Prospering Cities" (Utz 2019, co-ed. with S. Egger 2019), "Protest and Social Creativity" (Narodna Umjetnost 2018).

Christoph K. Neumann is Chair of Turkish Studies at LMU Munich. He works on Ottoman social and cultural history of the 18 th to 20 th centuries, modern Turkish literature, contemporary Turkish political culture and memory politics and the history of Turkish Studies. Among recent publications are "Urban Ethics - Towards a Research Agenda on Cities, Ethics and Normativity" (City, Culture and Society 2020, with E. Dürr, M. Ege, J. Moser and G. Winder), and "Rakı Consumption and Production in Istanbul in the Nineteenth Century and Today" (in: From Kebab to Ćevapčići, ed. by A. Blaszczyk and S. Rohdewald, 2018).

Max Ott is an architect and a member of the Graduate Center Architecture at the Technical University Munich. He is interested in the social and sociopolitical dimension of architecture and urban planning, and in the relationship between architectural space and spatial practice. One of his recent publications on this subject is "A Threshold Space: Connecting a Home in the City with the City" (in: Lenhard, Samanani: Home: Ethnographic Encounters, London/New York, 2019).

Olga Reznikova is Research Assistant at the Institute of Cultural Anthropology/European Ethnology at the University of Goettingen. Her PhD Project about protests in Moscow between 2012 and 2017 is part of the Research Project "Urban Ethics." The research about the protest movement is inspired by theories of critical political economy, moral economies, feminist theory and critical theory of the Frankfurt School.

Julia Strutz is a sociologist (Humboldt University Berlin) and historian (Bilgi University Istanbul), who received her PhD from the Department of Social and Economic Geography at KU Leuven, Belgium, in 2014. As a postdoctoral researcher she conducts research in the fields of memory politics, urban renewal, the urban history of Istanbul and the various ways this history gains importance in heritage and non-heritage contexts today.

Ida Susser, Distinguished Professor of anthropology at Hunter College and CUNY Graduate Center, has conducted ethnographic research in the United States, Southern Africa and Puerto Rico, with respect to urban social movements and the urban commons, gender, the global AIDS epidemic and environmental movements. Important publications: Norman Street: Poverty and Politics in an Urban Neighborhood, Updated Edition (Oxford 2012), Wounded Cities: Destruction and Reconstruction in a Globalized World (Bloomsbury 2003, ed. with Jane Schneider). 
Julie Sze is Professor of American Studies at UC Davis, where she was also the founding director of the Environmental Justice Project for the John Muir Institute for the Environment. She is author of three books, most recently Environmental Justice in a Moment of Danger (UC Press, 2020), and edited "Sustainability: Approaches to Environmental Justice and Social Power" (NYU Press, 2018). 


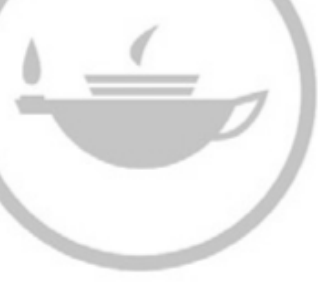

Taylor \& Francis Taylor \& Francis Group

http://taylorandfrancis.com 


\section{Part I}

\section{Configurations of ethics and the urban - concepts and theories}




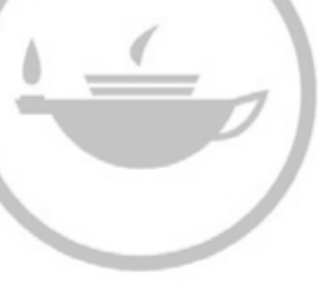

Taylor \& Francis Taylor \& Francis Group

http://taylorandfrancis.com 


\title{
1 Introduction
}

\section{Urban ethics - conflicts over the good and proper life in cities}

\author{
Moritz Ege and Johannes Moser
}

What constitutes a good life in the city, ethics under urban conditions or ethics of urban life? How do and how should people translate normative imperatives and reflections of "the good" into their everyday conduct of life in urban contexts and would that make for a "good" and possibly also emphatically "urban" life? Who gets to live this "good" urban life, who has the resources to engage in such reflections and whose ideas of the "good," of morality and propriety, prevail in these urban ethics?

Questions like these are implicitly and explicitly being asked, debated, negotiated and fought over all around the world. This book and this introduction explore the overarching argument that, across their differences, such questions should also be seen and studied as questions of "urban ethics," as practical negotiations and public debates over the "good" and "proper" or "right" way of living in cities and in urban ways, and that through them, conflicting values and interests are being expressed, addressed, worked through, sometimes neutralized, sometimes transposed and sometimes brought to an escalation. Urban ethics surface in concrete events and movements and in projects that are recognizably "ethical," but they also have a much wider purchase. Focusing on them can help us understand a wide variety of urban situations better in contemporary societies, and also historically.

It is necessary to stress from the start that this is a book of interdisciplinary social and cultural research, not of philosophy. It also is a book devoted primarily to analysis and critical reflection, not toward finding a better and more ethical practice, at least not always and straightforwardly so. Contributions to this volume explore different aspects of the ethical dimension of urban life, of urbanism and urbanity, and the specific ways of articulating and resolving conflicts that it tends to entail. Many of them also ask how this relates to questions of politics and the political. Rather than seeking answers to urban-ethical questions in a normative register, that is, rather than trying to figure out what the "good" and proper life in cities "really" is and should be, the book's contributors - without, of course, denying the importance of ethico-political reflection and action - study ethics as a sociocultural phenomenon that involves discourses, practices and materiality. As sociologist and anthropologist Didier Fassin summarizes a recent 
wave of "moral anthropology" and similar interdisciplinary works, these writings,

rather than defining what is "morality" and verifying whether people's deeds and judgments correspond to the definition, (...) tend to apprehend morality in acts and discourses, to understand what men and women do which they consider to be moral or good or right or generous.

(Fassin 2012b, 6)

This book is written in a similar spirit of inductive, empirical inquiry as that summarized by Fassin. It is scaffolded and supported by theoretical reflections on ethics and the urban and on normative dimensions of urban life more broadly.

Still, "ethics" is a loaded term with contested meanings and borders, and the way the concept is understood inevitably shapes the direction of inquiry. Therefore, it requires at least some initial clarification. To pose a question about urban situations as a question of urban ethics is, in our view, first of all, to ask "how one should live in the city." There are many ways of doing this, many places and positions from which to pose this question, many ways of understanding, for example, the normativity of "should," or the subject of ethics, the "one." In predominantly secular, late- or post-modern contexts, posing such questions usually means envisioning debates about choices that individual subjects should make freely, on their own accord, because they are motivated by a desire to do what is "good" and "right" or "proper" (and perhaps also to live their life so that it will have been a good life). This understanding of ethics prevails, for example, in rhetoric and codes addressed to professionals and experts of all sorts or, in a slightly different sense, in ethical interpellations of good consumers, responsible users of public amenities and so forth. "Ethics," in that sense, is usually understood as running counter to mere self-interest, to a logic of "partisan" political allegiance, to economic rationality/profitability, or mere hedonism, even if all of these orientations could of course also be understood as "ethics."

Such a view is characteristic of many more recent academic accounts of ethics as well. It involves a strong sense of voluntarism and rationalism (see, critically, Holbraad 2018, 33-37), and it often places great importance on individuals" freedom to work on the obstinate "ethical substance" of their inner selves, their habits, desires, interests or even cultural traditions, and to live up to ethical values and virtues despite the draw that other motivations represent (Faubion 2011; Laidlaw 2014). In a sense that is only slightly different, ethics is often also understood as primarily shaped through free societal reflection and debate, as in Habermas's ideal of consensus-seeking discourse ethics (Habermas 1990) and the Kantian tradition of ethics based on duties. There are, of course, many other accounts of ethics in social and cultural research that are much more relational and less rationalistic (in sociocultural anthropology, see only Das 2015; Trnka and Trundle 2014; Zigon 
and Throop 2014), but the former meanings are, in our view, predominant at least within initiatives for getting people to live better lives and, thus, build better cities, which is one important starting point for research on urban ethics.

\section{Ethical events and the promise of open cities}

Munich, in Germany, the city where the research group is based from whose work some of the chapters in this volume stem, is a good place to start looking more closely at public representations of urban ethics - not because it is a particularly "good" city, whatever that would mean, but because it has come to stand for "ethical" action by urban dwellers in a particular way. In the late summer of 2015, this somewhat saturated, economically successful Bavarian city, with its socially liberal tendencies and conservative backbone, became a near-global symbol for welcoming migrants and refugees, a place where many urban dwellers were doing simply the right thing in the face of human suffering and the callousness of European politics - or, from the skeptics' viewpoint, Munich became an example of a symbolic excess, an overreach of ethics, out of touch with (supposed) "popular" morality and realism in immigration matters. ${ }^{1}$ At Munich Central train station, in late summer 2015, thousands of volunteers welcomingly cheered the new arrivals in the trains that had come from Hungary and Austria, many of whom were war refugees from Syria, Afghanistan and Iraq who had crossed the Mediterranean Sea. Volunteers handed out food, clothing, SIM cards and so on, acts which were immediately televised and broadcast, as well as shared on social media. In doing so, these refugees and their supporters became part of an assemblage of actors that temporarily defeated the European Union's border regime, or so it seemed, in what can be seen as a genuinely political act (Hess et al. 2017). In these actions, people signaled that refugees and migrants were indeed welcome, at least in cities like Munich. Some of the activists - if that is the right word, not everyone would subscribe to it - involved had been active in antiracist, anti-border campaigns for many years. Some had been migrants and refugees themselves. Most, however, were neither, and they emphasized that they were motivated primarily, even "compelled," to do what is right and good. ${ }^{2}$ In such statements, there was also something oddly and conspicuously "ethical" about the Munich events. It was not just that these actions were morally good, but that they were exemplary of acting in an ethical way. In that sense, these events were also taking place below, above, beyond and, in a way, against the realm of politics. This has not been lost on high-profile observers either: Sociologist and urban theorist Richard Sennett, in a chapter of reflections on the figures of "Alien, Brother, Neighbor" in his recent Building and Dwelling. Ethics for the City, inspired by philosophers Emmanuel Levinas and Okakura Kakuzo, takes Munich in 2015 as an exemplary case for moments of ethical openness in cities where "the Other appeared as a brother" (Sennett 2018, 122). The fact that these events could be taken 


\section{Moritz Ege and Johannes Moser}

for ethical action and an open city in such an emphatic and exemplary sense probably has something to do with the political context in this specific historical moment, where Europeans acting kindly to people from relatively far away and toward people who were likely to be Muslim in particular seemed increasingly unlikely. It also relates to the voluntary, nonprofessional, nonstate, self-organized nature of many of these acts of support and solidarity, their apparent disconnect from self-interest and their unfolding on a human, person-to-person scale of encounter and care. ${ }^{3}$ Furthermore, Sennett is not alone in using an interpretative framework that is not just about morality and ethics but also about what people think a "city" and "urban" life should be. As researchers in our group discovered, in the rhetoric and the imagery of "welcome," people involved in refugee support initiatives in Munich often referred to the heterogeneity and diversity of urban life and turned it into an ethical argument in a different sense: To live in a city "should" mean to live with strangers, to "tolerate" or even embrace difference and heterogeneity, to create an open city. ${ }^{4}$

Quickly, of course, difficult questions about the nature of a "welcome culture" and its limits arose: About the paternalistic and hierarchical patterns in many practices of aid and support and about their genealogy, about empowerment and disempowerment, representation and misrecognition, about the direct and indirect violence of humanitarianism, on which critical anthropological research has focused so much over the last few years (Fassin 2012a; Ticktin 2011, 2014). By now, an army of critical researchers has descended upon the welcoming and integration initiatives, in Germany and elsewhere, and is thinking through these questions (see e.g. Braun 2017; Hamann and Karakayali 2016; Sutter 2017).

Since then, furthermore, a strong anti-immigrant and anti-immigration backlash has taken place, as Sennett also notes. Not only does this backlash highlight the ways in which urban-ethical interventions are intertwined with political conflicts and confrontations, but it is also noteworthy because configurations of ethics and urbanity are highly relevant in that backlash itself: For many right-wing populists, and some left-wing populists as well, the denunciation of what they consider "rootless," cosmopolitan ethics, as opposed to local moralities, is once more crucial. The concomitant negative stereotypes, such as Gutmenschen (literally "good-humans," do-gooders), Bahnhofsklatscher ("train station clappers") in German, are, among other things, stereotypes of naïve ethical overreach that also have an urban tinge, from "urban liberals" and "urban progressives" to city-dwelling Muslim immigrants whose designation as "urban" (at least in English, not so much in German) carries its own connotations.

In events like these, the openness of cities and the question of how one wants to live in the city become concrete, social, spatial, organizational matters. A more just, more open city becomes a momentary possibility, in events that one can remain true to from there on (Badiou 2012b; Swyngedouw 2017). Our claim is not, of course, that people in Munich are or were 
particularly "good" under some universal or particular ethical standards. But the events have, in our view, underlined the urgency of questions about ethics and urban life, about the potentialities, the limits and the conjunctural contexts of urban-ethical engagements. Subsequent negotiations over the meanings of the Munich events and others like them, in turn, illustrate the diagnostic political potential of a focus on urban ethics. We will not go into these questions further here (see, among others, Ege and Gallas 2019); instead, we will turn to other aspects of urban ethics - first, their widespread organization as "projects," then a broader sense of the normative dimensions of urban life.

\section{Improving urban life: ethical projects, neoliberal governance and post-politics}

The ethical dimension of urban life has long been an implicit concern in writings and research on the city, but it has attracted academic attention in a more direct, explicit sense in recent years (see Amin 2006; Cojocaru 2012; Ege/Moser 2017; Moraitis/Rassia 2019; Mostafavi 2017b; Sennett 2018; Dürr et al. 2020) so that this volume is part of a wider trend and an emerging debate. This new interest is probably no coincidence but a conjunctural effect, not just in the widely diagnosed (and widely criticized) "ethical turn" in all sorts of societal fields, including academic discourse and procedure, ${ }^{5}$ but in cities specifically: While our initial example from Munich refers mainly to an event and its aftermath, many cities today are full of what can be termed "ethical projects," projects for improving not just the quality but the ethical character and the ethical valence of urban life.

Again, our designation of such projects as "ethical" is not intended to suggest that we think that they are necessarily "good." They may well be, they may well not be. The designation is not meant as a normative evaluation, but in order to state, in a descriptive or analytical register, that these projects, regarded in the context of societies' different semantic codes or frameworks, in important ways belong to the code or framework of ethics.

Such "ethical projects" tend to work toward avowed goals, such as ecological ("green") sustainability, social and cultural inclusivity and openness, participation, collaboration, conviviality, consensus- and communitybuilding, and transparency. They represent one very obvious form of engaging in urban ethics. Some of them are large in size and scale, such as newly planned and developed entire "eco-cities" (see Sze in this volume). Most of them are much smaller and more clearly delineated affairs, seeking small- or medium-scale improvements to concrete aspects of urban living, practice-oriented and pragmatic-sounding, self-confidently productive, while, in most cases, opposing more strongly "ideological" mobilizations and schemes for systemic change or, at least, giving them lower priority (Mostafavi 2017a, 11). "Ethical projects" are future-oriented undertakings with a certain amount of pre-planning, self-awareness and intentional 
communication that promise better or more just cities and a better urban life through assemblages of policy, technology, buildings, aesthetics and institutions, and also a ethico-moral sense of "something better." They usually employ non-repressive ethico-political strategies and tactics ("technologies" in Foucauldian parlance) to instigate improvement and change, such as creating affordances, incentives and inspiration, and engaging in persuasion, "nudging" and other "smart solutions" (and win-win models/imaginaries of social change) rather than more confrontational political contestation although this is an ideal type and real cases may very well include elements of the latter as well. Ethical terms are often used quite conspicuously in such projects' public communication (e.g., "green," "good," "open," "fair," "sustainable," "inclusive"); they tend to exhibit something like an ethical surplus. As philosophers have long pointed out, the meanings of the "good" are complex and far from easy to grasp. This is an important point to consider in this case as well: The "hedonic" sense of "good" in urban-ethical projects as enjoyable, the "technical" and "instrumental" sense (as in, for example, long-lasting, well-made), and a more strictly "moral" and "ethical" one, relating to values and a greater good, tend to intertwine and "bleed" into each other, which is most obvious in food-related projects but not only there. Notions of the "good" that are implied in urban-ethical terms such as "quality of life" and "livability" tend to mix those kinds of evaluations as well.

Ethical projects also tend to exude and encourage positive ("warm") affects or sentiments of doing something good and being aware of it on the side of initiators and participants. Among the latter, this often comes about through practices of ethical consumption and, as one could say more critically, a modified form of consumerism (Barnett 2011; Thompson 2012), though the question of how people actually experience and engage in this is largely an open one. At the same time, there are also many non- and anticonsumerist urban-ethical projects, such as non-monetized sharing programs or spectacular versions of publicly owned housing construction, with an "ethical," "participatory" and "smart" surplus. All of them, however, approach issues, concerns, matters, challenges and conflicts of all sorts in some way as questions of urban ethics, such as those posed in the beginning of this introduction. In some cases, this is very much a transformation and a translation, an "ethicization" and a programmatic move away from the political, maybe even its displacement and repression. In others, such as stand-out projects for public housing, the irreducible ethical dimension of life makes itself felt in the context of urban interventions of different types, because to build almost inevitably can also be read as to address the question of how one should live, and becomes amplified.

Exemplary ethical projects include local environmental action, such as recycling schemes (see Fischer in this volume), "social design" innovations with an urban focus, (mobility) device sharing services, pro-bike campaigns with a practical focus and the like, newer forms of building cooperatives (see 
Gozzer and Ott in this volume), urban gardening or beekeeping initiatives, community-based agriculture organizations, local energy initiatives, participatory planning and building processes (see Bikbov in this volume; Baiocchi and Ganuza 2017; Kaltsa 2019), campaigns for better neighborly relations and understanding, and even campaigns against loneliness (Muehlebach 2012). Many of them are situated in fields of urban policy, initiated, funded and administered by various constellations of state agencies, NGOs and similar institutions, and businesses, "top-down" and "bottom up" and many things in between (Crouch 2011), and they can also overlap with fields such as education, political activism and, arguably, advertising and public relations. Ethical projects of similar kinds can also emerge from and be part of the art field, especially in relational/social practice and interventionist projects that problematize and reshape everyday urban life (Bishop 2012; Cruz 2012; N. Thompson 2012). They are prevalent in relatively rich countries, often thriving in middle-class lifestyles where, in an overall context of material abundance (and, possibly, feelings of guilt), they can contribute to an ethicized form of self-fashioning, but that is far from their only site if only because of the work of NGOs, governments and also bottom-up initiatives that address practical problems. "Scaling up" and multiplying projects is a goal of larger-scale initiatives that seek to motivate and guide others to start and direct ethical projects. The "conduct of conduct" works on different levels.

Ethical projects are of course far from new. A historical perspective is indispensable for understanding the difference they try to make and the power relations in which they are embedded, as each of these fields has its own historical genealogies, touching upon different forms of governmentality and expertise, moral and life reform movements, religious/spiritual practices, and so on. In the case of urban-interventionist art, for example, these genealogies involve avant-gardes' discontent with the art/life disconnect, pedagogies of "activation" and emancipation, community-oriented arts close to new social movements, socially engaged architectural practice, political theatre and neoliberal cultural policy oriented toward "relevance" (Bishop 2012), among other strands. How one tells and prioritizes these histories is, of course, a deeply political question (see Doucet in this volume): Are their histories within dissident and emancipatory social movements central? Or those within religions? Or a logic of neoliberalism?

Current academic research on cities is closely entangled in such "ethical projects," be it affirmatively or critically. Many projects for improving urban life are co-developed and/or evaluated by university-based researchers, and research projects with a collaborative bent themselves are usually planned, stylized and carried out as "ethical projects" in the sense under discussion here. In no small part, this is due to funding priorities and procedural rules (such as ethics committees). However, there are elective affinities and convergences in a broader sense as well, coming from different directions, such as political activisms and their "ethicization" of academic work, but also a broader and in some ways quite contradictory logic of governmentality. 
The field of what we term "ethical projects" overlaps in many ways with forms and techniques of neoliberal "governance-beyond-the-state" that grew in states such as the UK in the late 20th century. As Swyngedouw put it, neoliberal governance is not only scaled up to supranational entities, such as the European Union or World Trade Organization, but also downscaled to networks of private, public and third sector actors on a city and neighborhood/community level, "celebrating the virtues of self-managed risk, prudence, and self-responsibility" $(2007,5) .{ }^{7}$ The "re-scaling" of governance toward the city scale (Schiller and Çağlar 2009) also makes questions of politics, ethics and contestation on this urban level (and below) more prominent. Scholars and theorists critical of "ethicization" have stressed that these consensus-oriented techniques, many of which gained prominence during the 1990s and 2000s, the heydays of "Third Way" neoliberalism, are part and parcel of a landscape that can be described as post-political and post-democratic (Swyngedouw 2007, 2009; Wilson and Swyngedouw 2014). If civil society takes the role of participant and co-initiator of ethical projects that can be regarded as part of a wider hegemonic bloc, rather than challenging that bloc more directly, "real" political conflict and contestation are foreclosed, as are discussions over systemic alternatives. In ethical/moral frameworks, where "the ethical stance" is taken for "the ultimate horizon of and for political action" (Swyngedouw 2017, 56), movements for more radical change tend to be cast as completely beyond the pale, outside "reasonable" morality (Mouffe 2005). Some would argue that mutual recognition actually becomes more difficult when conflict and competition are "moralized," as moral statements also assign worthiness and unworthiness of respect (see Bogner 2011; Luhmann 2008a). As some of the chapters in the volume show, many "ethical projects" can indeed be analyzed in a similar way, and such diagnoses can be useful starting and reference points for understanding "ethical projects" and for articulating critique.

All this ethics talk and the prominence of ethical projects that appear in many cities stand in a strange contrast to the violence and brutality and also the banality of much of actual urban life (Bauman 2003; Simone 2015). This does not necessarily make for a particularly original or even critical observation, as diagnoses of an alarming status quo are often the very starting point of such initiatives: It is this contrast that makes them "promising" (and, potentially, "cruelly optimistic"; see Färber and also Moore and Sze in this volume). Capitalist urbanization continues at a rapid pace; most readers will have read statistics hundreds of times by now, according to which over half of the world's population are now living in cities and that, by 2050, two-thirds of the world's inhabitants will live in cities. But for multitudes, while images of "the good life" are constantly promised and broadcast, urbanization remains far from delivering lives where people can truly flourish, by their own standards or those of outside ethicists. Devastating effects of climate change destroy livelihoods; the growth of cities goes along with deep poverty and social polarization, a lack of rights of the newly urbanized 
and a decline of living conditions and increasing dependency in rural areas. In many parts of the world, it is authoritarian nationalism that makes promises for countering the effects of neoliberal globalization that resonate with multitudes and escalates ethnic tensions and racist structures. While functionalist planning and architecture of the modernist and Fordist era in Europe provoked a radical critique of banal and alienated life (Boltanski and Chiapello 1999; Lefebvre 2014), today's inner-city gentrification is criticized not only for the displacement it creates but, again, also for the banal consumerism (Harvey 2013; Susser and Tonnelat 2013) and the "bad" architecture it encourages.

Faced with such bleak diagnoses, many small-scale "ethical projects," with all their avowed goodwill, and even scenarios of a "good city" or a "just city" (Fainstein 2010) or "a just distribution justly derived at" (Harvey 2009) more broadly, may also seem irritatingly detached from "what is really going on." They can also become a subject of ridicule in popular culture and elsewhere (see e.g. Habit in this volume). This is, at least partly, because it tends to remain unclear what kind of model of urban change they stand for: Is the plan for those projects to somehow add up and for people to then just act "better," following the examples of groups of pioneers and regulators? Social and behavioral science and political theory of various types would obviously encourage us to be skeptical here. In that context, the ways in which (and the extent to which) urban political movement activism also shares in "ethicized" rhetoric and forms of contention become particularly relevant for a diagnostics of the present (see the chapters by Bikbov, Reznikova, Susser, and Florea/Gagyi/Jacobsson in this volume; also Dean 2014 and Swyngedouw 2017).

All of this should sensitize us to ethical projects' contexts, their limits, their potential unintended effects and their problematic relationship to politics and the political. Still, to simply dismiss ethical projects lock, stock and barrel as embodying neoliberal ideology would surely be too easy as well. We use the term "ethical projects" broadly and heuristically here, not as a clear-cut analytical term in a strong sense or as part of a strict allencompassing typology. ${ }^{8}$ It is useful, first of all, for pointing out a family resemblance of tendencies and overlapping traits in ethicized and ethicizing forms of problematizing urban lives (again, see programmatically, Moore's contribution) and to ask questions about their effects within specific contexts, while also taking account of larger forces that, in many ways, shape them, such as those pointed out by the literature on the post-political city. While similar issues arise and comparable dynamics are at play in many ethical projects, which are worth pursuing, as the contributions show, we do not intend to argue that these projects and their meanings, effects and dynamics are ultimately all the same. Different kinds of subjectivities, spaces, publics and connections can also arise in them (Mouffe 2017, 226). Taking up critical analyses such as those of the post-political city, we intend to raise a series of questions and invite comparisons and theorizations. 


\section{Beyond presentism: ethics and the normative dimension of urban life}

When it comes to the kinds of projects outlined here, or events like those in Munich in 2015, their "ethicity," their belonging to a realm of ethics, is fairly easy to make out, and the case why they can be usefully studied in terms of urban ethics is relatively straightforward. The latter also suggests relatively clear historical periodizations, as the "post-politics" debate has shown: Here, similar to other fields, the "ethicization" of political language and forms regarding urban life is closely tied to a time after the fall of "really existing" socialism in Eastern Europe (and its transformation into, broadly speaking, state capitalism in China and Vietnam) and the rise of neoliberalism. Given the individualistic vocabularies and voluntaristic imaginations of action in which urban-ethical questions are often embedded today, there is an obvious elective affinity between them and recent decades of neoliberal governmentality and the rule by technocratic experts, in one way or another (Clarke and Newman 2017; Collier 2017).

However, it needs to be stressed that questions of urban ethics also have a far wider scope; they are relevant in different historical conjunctures and sociocultural contexts far beyond and above these recent "ethicizations." Within very different historical conjunctures and societal contexts, cities have been spaces of moral regulation (Hunt 1999; Ruppert 2016), sites of reforms and disputes that "moralize" urban life, of ethical utopias small and large (Sennett 1990, 2018), and of the myriad forms of subjectivation that, following Foucault, we have come to call ethical as well (Collier and Lakoff 2005; Faubion 2011; Foucault 1985). Furthermore, "good" urbanity and "urbanity" as an ethic, a guiding principle, ambition, a virtue and perhaps also a duty that is closely intertwined with forms of governance are recurrent themes in a wide variety of contexts, as many contributors to this volume show. Globally, this involves different trajectories of constructing urbanity through normative ethics (see e.g. Lafi, Baumeister, Habit, Neumann/Strutz and others in this volume on the medieval Arabic, modern Mediterranean, 20th-century Romanian and 20th-century Turkish context).

Taking this perspective and using such a wider sense of urban ethics, many of the chapters in this volume, particularly its second section, study ethics as a ubiquitous dimension of urban life, thought and discourse. In that sense, urban ethics represent a plane of interpellations, negotiations and confrontations. The latter cohere around questions about the good and proper/right life and good urban subjects, which concern matters of planning and building but also literary, including essayistic, writing and, of course, the practices of everyday life. In approaching urban ethics in this way, these chapters explore and uncover their forms and effects in a variety of historical eras and different sociocultural and religious contexts and traditions. We can tie this back to the arguments of social theorists such as Andrew Sayer (2011), who challenge cultural and social research to pay 
closer attention to the normative dimension of everyday life, rather than, for example, reduce it completely to ideologies, social processes, the logic of practice or political antagonisms. In the context of our discussion, we of course need to "urbanize" these arguments. It also incurs the risk of adding to "ethicization" and "moralization," but this is a risk worth taking.

In a lot of the related historical literature, however, a terminology that revolves around morality, moral reform, moral panics, moral economies and so forth is predominant rather than a language of ethics. This volume departs from that tradition by making urban ethics, not morality, the central term. In analyzing urban ethics in this wider sense, it is helpful to consider the work of anthropologists Stephen Collier and Andrew Lakoff, who reformulated Michel Foucault's work on ethics and the subject in their remarks on "regimes of living," and distinguish different components of ethics. In Foucault's later-phase works, in which he genealogically traces the history of sexuality to late Roman antiquity, Greek sources and others (far from late-modern neoliberalism!), the basic ethical problematization can be formulated as the question "How should one live?" (Collier and Lakoff 2005, 22). Ethical practice engages with that question. It relates to "moral codes" dominant in a society during a particular time, but it is not exhausted by them; rather, ethics consist of the ways in which people apply, adapt, reflect or reject these codes in conducting their lives. This is the basic conceptual distinction between morality and ethics in that intellectual tradition.

Similarly, we suggest that urban ethical matters, in that wider sense, are attempts to formulate answers to the question: "How should one live in the city?" Through urban ethics, people do so practically and theoretically, implicitly and explicitly. Following Foucault and Collier and Lakoff, this question has the following components (Collier and Lakoff 2005, 22): (a) Imaginations of practices and virtues deemed good and right or proper ("how"), (b) types of normativity involved, that is, the norms, values, virtues and incentives working on what Foucault calls the "ethical substance" ("should") (Foucault 1985, 275), and (c) actors and the imagined models of the ethical subject ("one"/"we"). We can add (d) imaginations of "good" urbanity/cityness and urban forms of life ("live in the city") to this, in order to "urbanize" the ethical question. These components can play out in quite different ways in terms of both the contents and the forms of ethics, as we will see below.

Given these stipulations, ethics can be understood as the ways in which individuals engage with and relate to moral codes, as socially legitimated and, in that sense, normative "good" behavior and "proper" (or "right") conduct of life. Ethical practice is a form of subjectification or subjectivation, of becoming a type of subject. It is also a form of subjection that relates individuals and groups' regimes of living to broader configurations of power and rule. In that sense, we can also see discourses and infrastructures that work toward achieving certain forms of subjectification and ethical practice in cities as urban-ethical discourses, devices and so forth. For Foucault, famously, governmentality consists of creating and shaping rooms for 
freedom and ethical choice, the "conduct of conduct," indirectly directing the way others conduct themselves; that is, the power of governmentality always also moves in the medium of ethics. Again, social actors themselves may or may not label this explicitly as "ethics" or as "ethical," but, in engaging with how one should live in the city, they refer to values, virtues and the conduct of life and, by that, contribute to urban ethics.

For actors in urban settings, the relevance of the question: "How should one live in the city" (and potentially also how to live it "in an urban way"), in the past and present, can be a matter of the "conduct" of everyday life and of a variety of discourses and institutions that touch upon this conduct. Seen from this angle, urban ethics are not only an experts' debate, a matter of planning, public policy, project design, professional ethics codes and commissions, or high-minded discourse. They also involve ambitions and moral sentiments about urban life that people take to be deeply individual and personal, and they play out in microlevel interactions in the everyday and mundane, as well as during high-profile events. Ethics, in this wider sense, points beyond so-called rational discourse; it involves affect, habit, imagination and embodied practice, which often remain implicit in lived practice, gestures and silence.

This is relevant in all sorts of regimes, not just neoliberal, but, for example, in socialisms, in early liberal capitalism and before (Weber), in all sorts of religious contexts, and in relation to nationalism. In acknowledging this, we also need to keep in mind the variability of Foucault and Collier and Lakoff's "components" (ethical substance, types of normativity, ethical subjects) and the wide range of forms that the components of ethics as a practice, in that sense, can take. Different forms of normativity can structure textual and speech forms, rhetoric, discourse - authoritative "descriptions" that are really ideological calls to duty for a higher, national good, for example (see the chapters by Strutz/Neumann and Busenkell in this volume), the explicit proclamation of rules that people should follow within a specific moral economy (see Lafi in this volume) or interpellations of self-motivating, constantly self-improving subjects (see Gozzer, Färber, Fischer and Ott in this volume). As theorists of urban planning and design (Mostafavi 2017a; Sennett 2018), along with theorists of the materiality of the urban social (Blok and Farias 2016), would argue, this is a matter not only of discourse in a textual sense but also of the affordances of architectures and infrastructures of all sorts that are irreducible parts of these discursive normativities and have wills of their own. ${ }^{9}$ Similar differentiations could be made regarding the meanings of the "ethical" in the context of practices such as prayer, preaching, asceticism, learning and teaching, meditation, self-reflection, self-disciplined consumption, enforcing rules for debate, self-surveillance (analog or digital) and also playing games, organizing pleasures of different kinds, or engaging with art and popular culture. Practices and relations, then, can be "ethical" and "ethicized" in very different ways and to different degrees. 
It could be argued that there is a contradiction in claiming, as we have done, that, on the one hand, urban ethics involves a problematization of the given forms of urban life and, therefore, are a step away from the routines and out of the "natural attitude" of everyday life, in Husserl's (1913) sense, and, on the other hand, that ethical normativity pervades everyday existence and societal and technological arrangements in general, which would mean that it does not require any form of rupture or distancing. Within the (sociocultural) "anthropology of morality," this has indeed been a crucial topic of contention (Das 2015; Lambek 2015; Venkatesan 2015; Zigon 2007). We will not solve this conundrum here, but, in our view, it is productive to take a more pragmatic and heuristic approach to the conceptual distinction between morality and ethics, and to ask at what point in thinking through what people do this distinction actually becomes a problem - because the distinction does become meaningful repeatedly and is, therefore, difficult to ignore. This has a conceptual and a methodological side: As Andrew Sayer puts it, a distinction like Foucault's "makes sense," but it is just one such distinction within philosophical debates and their histories, and a fairly restrictive one at that. ${ }^{10}$ Different ones may prove useful in other contexts. In actual analyses, furthermore, one usually always deals with morality and ethics at the same time. Returning to Fassin, it is worth taking seriously his methods-oriented argument that qualitative researchers, such as ethnographers (and, we could argue, historians and literary scholars), in their research, encounter concrete, normatively charged statements and feelings about the good and proper way of living one's life that people make or have in actual life. The "contours" (Fassin 2012b, 9) of and the boundaries between the ethical and the political and ideological, as well as those of ethics and morality, will necessarily be much less sharply drawn on that basis than those that philosophers or conceptually oriented sociologists arrive at through thought experiments, deductive reasoning or laboratory experiments. This does not mean that they are meaningless, but they are a tool for developing diagnoses and arguments, not a goal in themselves.

Therefore, in many of the chapters in this volume, related dynamics and types of normativity will also come into view, such as moralities in different understandings and "moral economies," that is, references to an older economic order where values such as justice and respect are taken to have played a more significant role (Edelman 2012; Götz 2015). This is because, in a more general sense, these analyses always also want to better understand the ways in which conflicts over the "good" and "right" or "proper" conduct of life in cities can be seen as an arena where other conflicts, for example, those over rights to specific spaces or over the power to represent others, are played out. Negotiations in a moral and ethical register, a register of negotiating, regulating and performing urban life, can become particularly useful for different actors when legal or political means seem out of reach or are more difficult to apply, at least initially, as Strutz and Neumann have argued. In a wide variety of circumstances, then, distinctions between morality and ethics or homologous 
terms become entangled in such conflicts. This can also be framed as a hierarchical distinction between those who "just follow" conventional morality (or break it in simple ways) and those with a reflexive, more complex ethical life. ${ }^{11}$ The ways in which these distinctions and societal hierarchies and differentiations are situationally assembled and resonate with more structural hierarchies are certainly worth exploring further (see Reznikova in this volume).

And lastly, in this context: How do the city and concepts of the urban figure in these ethical negotiations? What difference does urbanity make in negotiating and enacting ethics? The chapters will take different approaches to answering these questions. In a general sense, the "urban" in urban ethics can be conceptualized in three different ways: First (a), urban ethics can be understood as a matter of ethics "in the city." This means treating the city as a backdrop for ethical experiences and negotiations. Or it can be understood (b) as ethics "under urban conditions": In a long tradition of urban and anti-urban discourses, aspects of anonymity, heterogeneity and population density, for example, have been treated as detrimental to ethical motivations and behavior, but they have also been seen as conducive to a more reflexive distance from conventional moralities. This again illustrates the fundamental entanglement of ethics and the urban and of urban ethics and relationships of power. In a third (c), and, in our view, quite important sense, "urban ethics" refers to the ethics of "the urban," of urbanism, urbanity or Urbanität (see Baumeister and Lafi in this volume), that is, to ethical postulations according to which people "should be urban and make use of the potentials that are specific to cities" and, thus, to urbanism. These views of what it means to be emphatically urban, of how "truly" urban lives are to be lived, have frequently had a strong normative side. Some of them privilege the educated, the rich and/or the "civilized," particularly when ideals of urbanity and modernity are articulated (see Habit and Strutz/Neumann in this volume), such as in colonial and quasi- and postcolonial situations. Other "urban-ethical projects," however, attempt to use the potentials of the city and, for more subversive, even counter-hegemonic, purposes, for example, in the sense of the Situationist International in Europe in the 1950s and their successors (Debord 1972; Stracey 2014), or in those explored by Henrietta Moore's chapter on African cities today. In that sense, urban ethics function not only as ways of negotiating and settling conflicts in urban settings, but they also take issue with urban conditions. Urban ethics can be employed to create a discursive space in which the potentials and restrictions of urban life are debated and challenged practically and in which creativity in shaping the social and spatial fabric of cities becomes possible.

\section{Overview of the chapters}

The chapters in the book come from two different contexts. Seven of them stem from the first three years of work of the interdisciplinary research group 'Urban ethics. Conflicts over the 'good' and 'proper' conduct of life 
in 20th and 21st century cities" funded by the German Research Foundation (2015-2017; ${ }^{12}$ second installment 2018-2021), based at universities in Munich, Göttingen and Regensburg (Strutz/Neumann, Habit, Fischer, Ott, Gozzer, Busenkell and Reznikova), of which the authors of this introduction are members as well. The other nine contributions come from international experts who work in similar fields and geographic areas (Moore, Färber, Baumeister, Lafi, Doucet, Sze, Florea/Gagyi/Jacobsson, Bikbov and Susser); their perspectives implicitly and explicitly challenge and add to the "urban ethics" approach, while, of course, also presenting these authors' research independently of it.

The book is divided into five sections. In the first, in this introduction and the chapters by Henrietta Moore and Alexa Färber, concepts and theories of urban ethics and normativity take center stage. Building on her seminal work on the ethical imagination, Moore's article explores evocations of the good life in the city and the complexities of ethicization on different levels, for the middle-class and the poor, in cities such as Nairobi, combining an overview of urban-ethical projects of various types with reflections on the promises of the urban in a wider sense, stressing that the ethical imagination is also a form of creativity, social diagnostics and world-building. Promises - the promise of the city and promises in more specific urban situations - are also the focus of Färber's reflections. Observing that collaborative projects of various kinds, including those in academic research and the arts, come with a series of such promises, Färber uses snapshots from fieldwork in Hamburg, Germany, to decipher the forms of these communicative acts and their ethical force.

The second section encompasses five historically oriented studies that explore specific configurations of ethics, urbanity and conflicts, taking methodological approaches that reach from intellectual history to historical anthropology and architectural criticism. Mediterranean urbanity, as Martin Baumeister argues in his chapter, is a protean concept that haunts normative discourses of Western urbanity and has long been crucial for wider discourses of identity and alterity. He focuses particularly on the ethical implications of Mediterranean urbanity in writers like Lefebvre and more recent Southern European "militant Mediterraneanists" who construct a distinctive, transhistorical Mediterranean urban ethic. This view, as Baumeister argues, often overlooks actual historical developments and seldom manages to avoid the dangers of conceptual essentialism, of reifying ethics. A distinct ethic of urbanity is also at the heart of Nora Lafi's chapter on cities of the Arab world, particularly Aleppo, Cairo and Tunis, from medieval times to the 19th century. The main focus of Lafi's extensive work with primary sources are the "Hisba" treatises for the regulation of markets, which provided possibilities for ethical negotiations and moral economies in a context of Islamic theology, societal heterogeneity and, as time went on, Ottoman Imperial rule. Under European colonialism, these kinds of negotiation and, thereby, a long-standing ethic of urbanity were cut off, so that the reconstruction of this urban ethic also challenges Eurocentric accounts of 
urban history and of the role of ethics in cities in a more general sense. Geographically and historically bordering on Lafi's work, Julia Strutz and Christoph K. Neumann, in their research on the uses of the Byzantine land wall in late- and post-Ottoman Istanbul, are, however, less interested in positive ethical prescriptions for urban life, but more interested in narratives of immoral landscapes, on a discourse-analytical and micro-historical level. Strutz and Neumann ask what these discourses reveal about the (shifting) constructions of "ethical subjects" of modern Istanbul, their national, religious and urban reference points - and about the violence against marginalized urban dwellers who are considered "bad" and "immoral" in that context. The section continues with another study of an urban area in (post-Ottoman) Southeastern Europe, Daniel Habit's chapter on the "Centrul Vechi," the old town in Bucharest, and the moral valuations as a "good" or "bad" space that it was given by different actors, especially after World War II, when the legitimacy of feudal and national histories shifted quickly and the discrepancies between official socialist ethics and the realities of material lack and black markets dominated urban dwellers' lived experience. Using a variety of sources, including oral histories and participant observation, Habit also shows how recent urban activism and the work of NGOs intervene in a situation dominated by fast gentrification and displacement, as well as weak urban planning institutions after the collapse of the Ceauşescu regime, thereby situating recent ethicizations in a broader historical narrative. Isabelle Doucet's contribution, which concludes this section and leads into the next one, focuses on the genealogy and the contentious politics of post-modern, neotraditionalist architecture and planning in Western Europe since the 1960s. Rooted in urban activism and the critique of the demolition of historic neighborhoods and functionalist worldviews, these tendencies in architecture are often seen as promoting a particularly ethical, "livable" and also democratic form of urbanism. Over the years, they have provoked harsh criticism from different quarters as well, as Doucet illustrates in her reflections and through an interview and discussion with a main protagonist of the "Reconstruction of the City" paradigm, Maurice Culot, and his early work in Brussels. The chapter and interview historicize this overall program of urban reconstruction, which surfaces in other contributions to this volume as well, and highlight its shifting political ambiguities.

In Section three, the case studies are primarily contemporary and revolve around a common topic, the area of building and dwelling, a major arena of conflicts and negotiations in cities today. In doing so, they, too, stress the ethical implications and functions of architecture (Harries 1996). The first two of them take a closer, critical look at housing in sought-after cities. They are about urban-ethical projects in the sense outlined above, about construction projects that promise fairer, more neighborly, more communal, but still "urban" and "diverse," rather than financially and culturally exclusive ways of living. More concretely put, Max Ott's and Laura Gozzer's chapters portray recent housing projects in German cities in which, broadly speaking, 
middle-class residents try to bypass the regular housing market and institute new "moral economies": A site of self-organized, collective housing in Berlin in Ott's case, legitimized partly through the "creative city" discourse, and a new wave of housing cooperatives in Munich in Gozzer's. In these studies, both of which are based, among other sources, on interviews, we are introduced to the cooperative members and architects' self-professed ethical motivations and to ambiguities that a more structural view reveals. However, in different ways, both authors suggest that it would be too easy to seek the truth of these projects in "real" materialist strategies "behind" ethical rhetoric. Ott, an architect, puts particular emphasis on the role of space and materiality in social creativity, whereas Gozzer, a cultural anthropologist, stresses particularly the confluence of the ethical and the political in participants' narrations. The approach taken in the subsequent chapter by sociologists Ioana Florea, Agnes Gagyi and Kerstin Jacobsson is quite different, more strongly oriented on the macro and meso levels, and situates ethical projects more systematically in a political-economic context. Here, we return to Bucharest, which in the study is compared to Budapest. Recent waves of financialization have affected the housing markets in these two cities quite differently; interclass alliances and practices of solidarity within social movements antagonistic to the status quo also take divergent paths, partly due to their entanglement with political actors, as the analysis of these local "fields of contention" shows. The last chapter of this section takes us to Singapore. Like in the Berlin study, the focus here is on construction projects for a "creative city" but under very different parameters. Michaela Busenkell, also an architect, investigates the forms and politics of large-scale, cityinitiated cultural buildings that were meant, from their inception in the 1990s on, to foster an audience with broad cultural interests that will ultimately, in the government's view, contribute to a more service and creative sector driven economy. In that context, prescriptions for the "good" and "right" way of living in the city take shape as technologies of governance and subjectivation. They also, however, surface in debates about local or regional aesthetics, in architects' professional practice, and through public contestations of "good" architecture that can articulate with broader political challenges as well as with a paternalistic recuperation of these challenges by the state.

Section four is dedicated to the ways in which the global concern with urban sustainability, surely one of the most pressing issues of our time, becomes entangled with problematic forms of ethical self-fashioning in the context of specific types of urban-ethical projects and may, thus, undermine its own goals. Julie Sze draws on her research in Shanghai and New York City to argue that "sustainability" has become a "plastic word" and that a spectacle of sustainability, especially in the context of larger-scale development projects, in many cases adorns upper-class lifestyles. It produces commodities that satisfy subjects" "eco-desire," rather than truly confronting accelerating ecological collapse. In contrast to these capitalist dynamics, she calls for an "ethical and justice-oriented urban sustainabilities framework" 
and a different imagination of temporality that she sees foreshadowed in the work of some of the local organizations and coalitions in her Brooklyn case study. Jeannine-Madeleine Fischer's Auckland-based case study starts with the similar observation that desires for ethically better, more ecological ways of living in the city are widespread. City administrations' "ethical projects," in this case for better recycling schemes, are part of transnational policy exchanges and compacts. They make wide-ranging promises, but on the ground, a basically neoliberal institutional setup that relies on active local citizens' self-organization, as Fischer shows, on the one hand, contributes to changing the semantics of waste and strengthens an ethics of care that is social and environmental but, on the other hand, also reinforces informal and material hierarchies between "good" and "bad" neighborhoods and urban dwellers, and, in some ways, aggravates, rather than alleviates, environmental and social injustice.

Section five moves on to the world of activism, protest and urban social movements. Their relationship to urban ethics as they have been discussed so far is complex: On the one hand, collective agents of urban change also often formulate visions of better, more just cities and they "prefigure" new forms of living in and making use of the city, be it in earnest or playful ways. The "right to the city" is a genuinely political demand, but it also clearly has an ethical dimension. On the other hand, the antagonistic or agonistic character of such movements can also be seen as pointing "beyond" the consensus-oriented dynamics of many late-modern "ethical projects," and it can be argued that this has increasingly been the case in the context of square-occupation protests since 2011. Again, the chapters confront such diagnoses of political situations on a larger level regarding the specific case studies of movements with their complex histories, dynamics and contradictions. Two of them focus on Moscow, a context of an authoritarian state and relatively new movements toward electoral democracy and the empowerment of local citizenry. Both chapters, however, take a cautiously pessimistic view of what has become of these movements' transformative potentials over the last few years. Alexander Bikbov places the emergence of protests against different kinds of construction projects in the context of Muscovites' selfunderstanding as owner-citizens that is encouraged through different types of "ethical" participation schemes introduced by the city government. A similar ethic of ownership and "civilized" metropolitan respectability, he argues, also structured anti-government protests and prevented their radicalization. Based on a long-term ethnographic study of one particular protest aimed at stopping the construction of a church in a local park, Olga Reznikova describes processes of political and ethical negotiation on the ground and situates them in the wider context of struggles over space, power, secularity and the meanings of the political. Discovering their common ownership of spaces like this park, she argues, protesters performatively create new public spaces that can be starting points for broader emancipatory processes. At the same time, her research also illustrates quite graphically that the emphasis 
on a "good city" for people with "local roots" merges in many cases with exclusivist notions of legitimate belonging that theorists of open cities and movements for antiracist justice would have good reasons to reject. Such ambiguities and problems are also at the heart of Ida Susser's directly-from-thefield reflections on the protest by the "Gilet Jaunes" (Yellow Vests) in France, particularly in Paris. Susser, who has studied urban protest movements and processes of commoning ethnographically over four decades, argues that these protests are part of the formation of a new sociopolitical formation, a class, in E.P. Thompson's sense of the term, that is not adequately captured by current terms such as "precariat" or "multitude." Reclaiming the right to state-organized social support and protection is one of the movement's central overall themes. At this point in time, however, the political alliances that this movement will form with the conventional political Left and Right, as well as with other movements, are still far from clear. The same is true regarding the Gilet Jaunes' attitudes to questions of migration and diversity and to environmental policy, especially within a context of political populism where "anti-moralists" of different stripes seem ready to make common cause. Clearly, the Gilets Jaunes are one example of a movement that challenges a type of urban thought and practice centered around questions of a "good life in the city" and incremental "ethical projects." At the same time, in doing so, with all their contradictions, they also expand and newly pose the question of urban ethics by asking very bluntly what a more just city and a more just relationship between a capital and the rest of a country would look like, and by making strong demands. The contours of urban ethics and their relationship to politics in different senses of the term are constantly shifting, but ethical problematizations of urban life will surely not go away in the foreseeable future.

\section{Acknowledgments}

We would like to thank Simon Zeitler and Philip Saunders for their tremendous help in putting together this volume and also present and past members of the urban ethics research group who are not among this volume's authors (Raúl Acosta, Marie Aschenbrenner, Eveline Dürr, Simone Egger, Michael Grieser, Guido Hausmann, Clemens van Loyen, Ursula Prutsch, Eva-Maria Richter, Evelyn Schulz, Gordon Winder, Sophie Wolfrum) and our interlocutors in a wide range of places for their thoughts and contributions that in one way or another found their way into these reflections. Faults and misconceptions are of course solely our own.

\section{Notes}

1 Munich has a recent history of other "ethical" acts that is worth remembering in this context: In 1992, 400,000 people took to the streets and lit candles in an act of protest against a wave of right-wing anti-immigrant violence that swept 
the country at the time (and was seen mostly as taking place outside the city, especially in East Germany); the Munich Lichterkette (chain of lights) became the iconic case of liberal (rather than more radical anti-fascist) protest.

2 Surely, similar, less publicized events took place in many locations: In Turkey, on Greek and Italian islands, along the so-called Balkan route, and in many towns, small communities and large cities all over.

3 A detail that Sennett mentions as strikingly ethical, though hardly a typical one, is people leaving packages of gifts on tables in order to avoid the situation where donors would play a role of benefactors.

4 In that context, a "good" city must also be taken to be an emphatically "urban" city, in the sense of accepting and embracing difference (Moser 2018).

5 For critical reviews of ethical turns, see Badiou (2012a); Bogner (2011); Fassin (2012b); Garber, Hanssen, and Walkowitz (2000); Holbraad (2018); Luhmann (2008b); Mouffe (2005); Rancière (2006).

6 Mostafavi, whose volume on Ethics of the Urban is highly relevant to this discussion, suggests that urban-ethical interventions are limited in their scope because of the difficulties of more systemic political interventions under current circumstances: "In the absence of a holistic and integrated approach, what remains is the tactical and the strategic, which can at least demonstrate a fragment of what is possible now" (Mostafavi 2017a, 11). While his focus is on urban design and planning projects, similar logics are at play in urban-ethical projects in other fields as well. Overall, Mostafavi argues for urbanistic projects (design, architecture, planning) that are both emphatically "ethical," which he defines as based on values such as justice, that is, in a slightly different and less sociological sense than we do, and "agonistic," open to conflicts among participants but, out of necessity, somewhat distant from broader political plans and a logic of antagonism. This is a productive position in many ways, especially given the actual need for all sorts of practical interventions (see also Kaltsa 2019), but it runs the risk of underestimating the force of neoliberal logics and a type of "passive revolution" recuperation within processes of ethicization and the framework of ethics. It also too easily identifies, in our view, interventions that are ultimately still led by expert professionals with views of politics and the political such as those advocated by Mouffe (2005), Badiou (2012b) or Rancière (2006) and downplays the friction between these positions. Reflections on the potentials of "ethical" architectural and planning projects and procedures and their challenges to older models of architecture also predominate in Urban Ethics under Conditions of Crisis (Moraitis/Rassia 2019), an edited volume that was published briefly before this book went to press.

7 Theorists of contemporary governmentality see such projects as intrinsically linked with ethics because they concern the ways in which individuals approach, direct, stylize and conduct their own lives (on "ethopower" see Rose 2000; for a slightly different but relevant approach, see Clarke 2013), their "work" on the self (ethics in Foucault's sense), and governmental "conduct of conduct."

8 It may well be that using concepts and theory in this way is part of the disciplinary baggage that comes with ethnology (roughly, sociocultural anthropology) and cultural studies.

9 This, however, also raises a series of theoretical and methodological questions when it comes to how ethics and its subjects are imagined, and requires further conceptual and empirical work, as quite obviously notions of distributed agency complicate anthropocentric theories of ethics.

10 Sayer $(2011,17)$. See also Laidlaw $(2014,4)$; Sayer quips that speaking about ethics in academic circles just "goes down much better" than using the term "morality." The relative and contextual nature of these distinctions is also exemplified by Koutsoumpos (2019), who uses "urban ethics" to refer to habituated 
senses of the good and bad - and "urban morality" for rule-based, discursive, rational approaches embodied in, for example, top-down urban planning. This is in important ways different from how the terms are used here, but, as Sayer would put it, it also "makes sense" and enables important analytical work, in that case in urban planning history and theory. In theoretical terms, it should also be pointed out that ethics (and morality) cannot be understood as a societal "system" or "domain," such as politics or law, as sociologists as diverse as Fassin and Luhman have stressed (Fassin 2012b, 15; Luhmann 2008a).

11 The focus on ethics in this particular sense has been theorized extensively by sociologists of reflexive modernization and "life politics" since the 1980s who have strongly contributed to that hierarchization as well (Beck et al. 1994).

12 Project number DFG-FOR 2101; the Berlin and Singapore projects were associated with the group. On the overall approach (see also Dürr et al. 2020; Ege/ Moser 2017).

\section{Bibliography}

Amin, Ash. 2006. "The Good City.” Urban Studies 43, nos. 5-6: 1009-23.

Badiou, Alain. 2012a. Ethics: An Essay on the Understanding of Evil (Radical Thinkers). London/New York: Verso.

Badiou, Alain. 2012b. The Rebirth of History. London/New York: Verso.

Baiocchi, Gianpaolo, and Ernesto Ganuza. 2017. Popular Democracy: The Paradox of Participation. Stanford, CA: Stanford University Press.

Barnett, Clive, ed. 2011. Globalizing Responsibility: The Political Rationalities of Ethical Consumption. RGS-IBG Book Series. Chichester/Malden, MA: WileyBlackwell.

Bauman, Zygmunt. 2003. City of Fears, City of Hopes. London: Goldsmith's College.

Beck, Ulrich, Anthony Giddens, and Scott Lash. 1994. Reflexive Modernization: Politics, Tradition and Aesthetics in the Modern Social Order. Stanford, CA: Stanford University Press.

Bishop, Claire. 2012. Artificial Hells: Participatory Art and the Politics of Spectatorship. London/New York: Verso Books.

Blok, Anders, and Ignacio Farías, eds. 2016. Urban Cosmopolitics: Agencements, Assemblies, Atmospheres. Questioning Cities. New York, NY: Routledge.

Bogner, Alexander. 2011. Die Ethisierung von Technikkonflikten: Studien zum Geltungswandel des Dissenses. 1st edition. Weilerswist: Velbrück Wiss.

Boltanski, Luc, and Eve Chiapello. 1999. Le Nouvel Esprit Du Capitalisme. NRF Essais. Paris: Gallimard.

Braun, Katherine. 2017. "Decolonial Perspectives on Charitable Spaces of 'Welcome Culture' in Germany." Social Inclusion 5, no. 3: 38.

Clarke, John. 2013. "In Search of Ordinary People: The Problematic Politics of Popular Participation” Communication, Culture \& Critique 6, no. 2: 208-26.

Clarke, John, and Janet Newman. 2017. "People in This Country Have Had Enough of Experts': Brexit and the Paradoxes of Populism." Critical Policy Studies 11, no. 1, January, 1-16.

Cojocaru, Mara-Daria. 2012. Die Geschichte von der Guten Stadt: Politische Philosophie zwischen urbaner Selbstverständigung und Utopie. Edition Moderne Postmoderne. Bielefeld: transcript. 
Collier, Stephen J. 2017. "Neoliberalism and Rule by Experts." In Assembling Neoliberalism, edited by Vaughan Higgins and Wendy Larner, 23-43. New York: Palgrave Macmillan US.

Collier, Stephen, and Andrew Lakoff. 2005. “On Regimes of Living.” In Global Assemblages. Technology, Politics, and Ethics as Anthropological Problems, edited by Aihwa Ong and Stephen J. Collier, 22-39. Malden, MA: Blackwell.

Crouch, Colin. 2011. The Strange Non-Death of Neoliberalism. Cambridge: Polity Press.

Cruz, Teddy. 2012. "Democratizing Urbanization and the Search for a New Civic Imagination.” In Living as Form: Socially Engaged Art from 1991-2011, edited by Nato Thompson, 56-63. New York/Cambridge, MA/London: The MIT Press.

Das, Veena. 2015. "What Does Ordinary Ethics Look Like?" In Four Lectures on Ethics. Anthropological Perspectives, authored by Michael Lambek, Veena Das, Didier Fassin, and Webb Keane, 53-126. Chicago, IL: HAU Books.

Dean, Jodi. 2014. "After Post-Politics: Occupation and the Return of Communism." In The Post-Political and Its Discontents: Spaces of Depoliticisation, Spectres of Radical Politics, edited by Erik Swyngedouw and Japhy Wilson, 261-78. Edinburgh: Edinburgh University Press.

Debord, Guy E. 1972. Internationale Situationniste: 1958-69. Amsterdam: Van Gennep.

Dürr, Eveline, Moritz Ege, Johannes Moser, Christoph K. Neumann, and Gordon Winder. 2020. "Urban Ethics: Towards a Research Agenda on Cities, Ethics, and Normativity." City, Culture and Society 20 (March), doi: 10.1016/j.ccs.2019.100313.

Edelman, Marc. 2012. "E. P. Thompson and Moral Economies." In A Companion to Moral Anthropology, edited by Didier Fassin, 49-66. Malden, MA: John Wiley \& Sons, Ltd.

Ege, Moritz, and Alexander Gallas. 2019. "The Exhaustion of Merkelism: A Conjunctural Analysis.” New Formations 96, no. 96: 89-131.

Ege, Moritz, and Johannes Moser. 2017. "Urbane Ethiken. Konflikte um das gute und richtige Leben in Städten." Österreichische Zeitschrift für Volkskunde 3/4, no. 120: 237-49.

Fainstein, Susan S. 2010. The Just City. Ithaca, NY/London: Cornell University Press.

Fassin, Didier. 2012a. Humanitarian Reason: A Moral History of the Present Times. Berkeley: University of California Press.

Fassin, Didier. 2012b. "Introduction." In Moral Anthropology: A Critical Reader, edited by Didier Fassin and Samuel Leze, 1-18. Milton Park/New York: Routledge.

Faubion, James D. 2011. An Anthropology of Ethics. New Departures in Anthropology. Cambridge: Cambridge University Press.

Foucault, Michel. 1985. The History of Sexuality, Vol. 2: The Use of Pleasure. New York: Pantheon.

Garber, Marjorie, Beatrice Hanssen, and Rebecca Walkowitz. 2000. The Turn to Ethics. New York and London: Routledge.

Götz, Norbert. 2015. “'Moral Economy': Its Conceptual History and Analytical Prospects.” Journal of Global Ethics 11, no. 2: 147-62.

Habermas, Jürgen. 1990. Moral Consciousness and Communicative Action. Studies in Contemporary German Social Thought. Cambridge, MA: MIT Press.

Hamann, Ulrike, and Serhat Karakayali. 2016. "Practicing Willkommenskultur: Migration and Solidarity in Germany.” Intersections 2, no. 4: 69-86. 
Harries, Karsten. 1996. The Ethical Function of Architecture. Cambridge, MA: MIT Press.

Harvey, David. 2009. Social Justice and the City. Rev. ed. Geographies of Justice and Social Transformation 1. Athens: University of Georgia Press.

Harvey, David. 2013. Rebel Cities: From the Right to the City to the Urban Revolution. Paperback ed. London: Verso.

Hess, Sabine, Bernd Kasparek, Stefanie Kron, Mathias Rodatz, Maria Schwertl, and Simon Sontowski. 2017. "Der lange Sommer der Migration. Krise, Rekonstitution und ungewisse Zukunft des europäischen Grenzregimes." In Der lange Sommer der Migration, 2nd edition, edited by Sabine Hess, Bernd Kasparek, Stefanie Kron, Mathias Rodatz, Maria Schwertl, and Simon Sontowski, 6-24. Grenzregime 3. Berlin/Hamburg: Assoziation A.

Holbraad, Martin. 2018. "Steps Away from Moralism." In Moral Anthropology: A Critique, edited by Bruce Kapferer and Marina Gold, 27-48. Critical Interventions, Volume 16. New York: Berghahn.

Hunt, Alan. 1999. Governing Morals: A Social History of Moral Regulation. Cambridge Studies in Law and Society. Cambridge/New York: Cambridge University Press.

Husserl, Edmund. 1913. Ideen zu einer reinen Phänomenologie und phänomenologischen Philosophie. Halle: Niemeyer.

Kaltsa, Maria. 2019. "Urban Ethics and Dystopia*: Is Architecture as We Know It Under Strain?" In Urban Ethics under Conditions of Crisis. Politics, Architecture, Landscape Sustainability and Multidisciplinary Engineering, edited by Konstantinos Moraitis and Statamina Th. Rassia, 61-80. Singapore/Hackensack/London: World Scientific Publishing.

Koutsoumpos, Leonidas. 2019. "Morality versus Ethics in the Urban Development of Exarcheia." In Urban Ethics under Conditions of Crisis. Politics, Architecture, Landscape Sustainability and Multidisciplinary Engineering, edited by Konstantinos Moraitis and Statamina Th. Rassia, 199-225. Singapore/Hackensack/London: World Scientific Publishing.

Laidlaw, James. 2014. The Subject of Virtue: An Anthropology of Ethics and Freedom. New Departures in Anthropology. New York: Cambridge University Press.

Lambek, Michael. 2015. "Living as If It Mattered." In Four Lectures on Ethics. Anthropological Perspectives, authored by Michael Lambek, Veena Das, Didier Fassin, and Webb Keane, 5-52. Chicago, IL: HAU Books.

Lefebvre, Henri. 2014. Critique of Everyday Life: The One-Volume Edition. London: Verso.

Luhmann, Niklas. 2008a. "Paradigm Lost: Über die ethische Reflexion der Moral [1990]." In Die Moral der Gesellschaft, edited by Detlef Horster, 253-69. Frankfurt am Main: Suhrkamp.

Luhmann, Niklas. 2008b. "Politik, Demokratie, Moral [1997]." In Die Moral der Gesellschaft, edited by Detlef Horster, 56-162. Frankfurt am Main: Suhrkamp.

Moraitis, Konstantinos. 2019. "Informal Ethics, Ethics of Transformation: Political and Landscape Urbanity." In Urban Ethics under Conditions of Crisis. Politics, Architecture, Landscape Sustainability and Multidisciplinary Engineering, edited by Konstantinos Moraitis and Statamina Th. Rassia, 3-30. Singapore/Hackensack/London: World Scientific Publishing.

Moraitis, Konstantinos and Stamatina Th. Rassia (eds.). 2019. Urban Ethics under Conditions of Crisis. Politics, Architecture, Landscape Sustainability and 
Multidisciplinary Engineering. Singapore/Hackensack/London: World Scientific Publishing.

Moser, Johannes. 2018. "Protest and Social Creativity: An Art and Activist Network Furthers Debate on Problems of Urban Living Space." Narodna Umjetnost 55, no. 2: 165-77.

Mostafavi, Mohsen. 2017a. "Agonistic Urbanism." In Ethics of the Urban: The City and the Spaces of the Political, edited by Mohsen Mostafavi, 9-16. Zürich: Lars Müller Publishers.

Mostafavi, Mohsen, ed. 2017b. Ethics of the Urban: The City and the Spaces of the Political. Zürich: Lars Müller Publishers.

Mouffe, Chantal. 2005. On the Political. Thinking in Action. London/New York: Routledge.

Mouffe, Chantal. 2017. "Radical Politics as Counter-Hegemonic Intervention: The Role of Cultural Practices." In Ethics of the Urban: The City and the Spaces of the Political, edited by Mohsen Mostafavi, 209-12, 225-31. Zürich: Lars Müller Publishers.

Muehlebach, Andrea. 2012. The Moral Neoliberal: Welfare and Citizenship in Italy. Chicago, IL: University of Chicago Press.

Rancière, Jacques. 2006. "The Ethical Turn of Aesthetics and Politics." Critical Horizons 7, no. 1: 1-20.

Rose, Nikolas. 2000. "Community, Citizenship, and the Third Way." American Behavioral Scientist 43, no. 9: 1395-411.

Ruppert, Evelyn S. 2016. The Moral Economy of Cities: Shaping Good Citizens. Toronto: University of Toronto Press.

Sayer, Andrew. 2011. Why Things Matter to People: Social Science, Values and Ethical Life. Cambridge: Cambridge University Press.

Schiller, Nina Glick, and Ayse Çağlar. 2009. "Towards a Comparative Theory of Locality in Migration Studies: Migrant Incorporation and City Scale.” Journal of Ethnic and Migration Studies 35, no. 2: 177-202.

Sennett, Richard. 1990. The Conscience of the Eye: The Design and Social Life of Cities. New York: Knopf : Distributed by Random House.

Sennett, Richard. 2018. Building and Dwelling: Ethics for the City. London: Allen Lane, an imprint of Penguin Books.

Simone, AbdouMaliq. 2015. "The Urban Poor and Their Ambivalent Exceptionalities: Some Notes from Jakarta." Current Anthropology 56, no. 11: 15-23.

Stracey, Frances. 2014. Constructed Situations: A New History of the Situationist International. London: Pluto Press.

Susser, Ida, and Stéphane Tonnelat. 2013. "Transformative Cities: The Three Urban Commons." Focaal 2013, no. 66: 105-21.

Sutter, Ove. 2017. "'Welcome!' - Emotional Politics and Voluntary Work with Refugees." Journal for European Ethnology and Cultural Analysis 2, no. 1: 5-25.

Swyngedouw, Erik. 2007. "The Post-Political City." In Urban Politics Now, edited by BAVO. Reflect. Amsterdam: Netherlands Architecture Institute.

Swyngedouw, Erik. 2009. "The Antinomies of the Postpolitical City: In Search of a Democratic Politics of Environmental Production." International Journal of Urban and Regional Research 33, no. 3: 601-20.

Swyngedouw, Erik. 2017. "Insurgent Urbanity and the Political City." In Ethics of the Urban: The City and the Spaces of the Political, edited by Mohsen Mostafavi, 47-74. Zürich: Lars Müller Publishers. 
Thompson, Nato. 2012. "Living as Form.” In Living as Form: Socially Engaged Art from 1991-2011, edited by Nato Thompson, 16-33. New York/Cambridge, MA/ London: The MIT Press.

Thompson, Stacy. 2012. "The Micro-Ethics of Everyday Life. Ethics, Ideology and Anti-Consumerism." Cultural Studies 26, no. 6: 895-921.

Ticktin, Miriam. 2011. Casualties of Care: Immigration and the Politics of Humanitarianism in France. Berkeley: University of California Press.

Ticktin, Miriam. 2014. "Transnational Humanitarianism." Annual Review of Anthropology 43, no. 1: 273-89.

Trnka, Susanna, and Catherine Trundle. 2014. "Competing Responsibilities: Moving Beyond Neoliberal Responsibilisation." Anthropological Forum 24, no. 2: $136-53$.

Venkatesan, Soumhya. 2015. "There Is No Such Thing as the Good: The 2013 Meeting of the Group for Debates in Anthropological Theory." Critique of Anthropology 35, no. 4: 430-80.

Wilson, Japhy, and Erik Swyngedouw. 2014. "Seeds of Dystopia: Post-Politics and the Return of the Political." In The Post-Political and Its Discontents: Spaces of Depoliticisation, Spectres of Radical Politics, edited by Japhy Wilson and Erik Swyngedouw, 1-22. Edinburgh: Edinburgh University Press.

Zigon, Jarrett. 2007. "Moral Breakdown and the Ethical Demand: A Theoretical Framework for an Anthropology of Moralities." Anthropological Theory 7, no. 2: $131-50$.

Zigon, Jarrett, and C. Jason Throop. 2014. “Moral Experience: Introduction.” Special Issue: Moral Experience. Ethos 42, no. 1: 1-15. 


\title{
2 The habitat of the subject Exploring new forms of the ethical imagination
}

\author{
Henrietta L. Moore
}

\section{The city as a form of life}

African cities are often portrayed as places of impoverishment, deepening inequality and exclusion (Pieterse 2011), but they are also sources of aspiration and hope. The great, gleaming, glass towers of contemporary Nairobi, Accra, Addis Ababa and Kinshasa are home to visions that transcend the limitations of contemporary circumstances to usher in a future that can be more perfectly realized. Even in the earliest days of colonial rule, these cities were envisaged as places of hope, freedom and self-realization. Such projects of self-transformation persisted despite exclusion, immiserization and political inequities. "Going to town" has long held a particular lure.

The urban has frequently figured as the source of the good life in many different historical periods and for various reasons. The new materialities of urban living bring forth new potentialities for being and for personhood, quite literally, new ways of living, of being oneself. Urban worlds are made and unmade. Africa's modern cities have little resemblance to their colonial forbears (cf. Edensor and Jayne 2012), even if many remain indelibly marked by the restrictions on movement and residence of their majority black populations. Contemporary cities bring new questions about difference and diversity, practical interrogations about how to get along with others. The consequence is a series of embedded ethical repertoires that are shaped not only by local context and urban form, but also by translocal and international connections and dislocations of various sorts.

Africa's rapid urbanization, where more than $50 \%$ of the population will be urban by 2050 (UN Habitat 2010), is characterized by high degrees of informal employment, fragmented infrastructure and weak urban governance. Recent commentators on African urbanism have emphasized the importance of understanding African urban form and process in their own terms and not as a failed variant of western models of urbanization (Parnell et al. 2009; Parnell and Pieterse 2014; Pieterse 2011; Robinson 2006). This is part of a broader critique that sees dominant theoretical frameworks rooted in Euro-American exceptionalism and unable to analyze the rapidly burgeoning cities of the Global South (e.g., Robinson 2013; Roy 2009; Watson 2009). 
Many commentators emphasize the fluidity of contemporary African cities, where residents inhabit urban spaces as a means to access local economic and social advantages, a gateway to further opportunities or even a mechanism for providing for a longer-term future envisaged elsewhere (e.g., Landau and Freemantle 2016). These subjective understandings of the city, with their particular forms of interconnected agency, spawn different modalities for managing difference, different ways of envisioning what the city is for and how to live with others and variable mechanisms for building relations, networks and institutions. However, one shared feature is the persistent nature of a series of queries: "what is a city for", "of what does it consist" and "what forms of life are properly urban?"

Such queries are always locally and historically embedded, but they press upon the larger question of what it means to live with others, and whether and how it is possible to live well with them. These practical concerns are matters of ethics in the largest sense of bearing on relations with self and others. Whilst context - historical, built environment, politics, economics are always paramount, relations with others are never constrained to the immediate, the material and the known. It is a feature of social life that our most intimate relations are animated by visions of the world outside them, just as our connections with the global and the intricacies of international capitalism take form within the specifics of daily history, work, intimacy and leisure. Making sense of the urban and those who inhabit it is, therefore, always a question of what academics - in a probably mistaken set of binary terminologies - have come to term the local and the global (Moore 2011).

The fact that local context is enlivened by distant dispositions and invocations reminds us that there is no easy overlap between the local and the cultural. If this is the case, then what are ethical debates about? They cannot be simply about shared moral frameworks. In this chapter, I propose that ethics are indeed about the self in interaction with others, but that we need to approach this terrain through what I term the ethical imagination (Moore 2011). The ethical is never just a matter of voluntarism or of the determinations of historical and cultural formations. Consequently, an exploration of the ethical must proceed via circuitous routes through discursive forms and consciously motivated reflection, as well as through sets of practices, fantasized interconnections and objects, and emerging institutions. What holds these topographies and scales together is the ethical imagination, the thread of the self living in interaction with others.

Delving into the ethical through the ethical imagination opens ethics up to the possibility of change and transformation. Such transformations are historically situated but more powerfully driven by interactions with and within the matrices of subject formation that such interactions drive. In this chapter, I explore how the ethical imagination develops as a response to certain challenges and, most specifically, to the challenge of the urban as a form of living. 


\section{The ethical imagination and problematization}

The ethical imagination may be minimally defined as the forms and means through which individuals imagine their relations to themselves and to others. Consequently, it can be envisioned as both the mechanism and process through which individuals produce different kinds of knowledge of and specific ways of connecting to the world, themselves and others. New relations and forms of knowledge produce, in their turn, new forms of desire, hope and satisfaction, as well as new forms of failure, pain and trauma. The ethical imagination - understood as ways of experiencing, feeling, thinking and living the relation to self and of self to others - works to animate the fantasies, practices, ideologies and institutions that organize people's world. However, the ethical imagination should not be taken as a fixed mechanism, process or structure but rather as a form of engagement, a lived relation, that may be very explicitly worked out or labile, inchoate, partial and temporal. It inheres in both affect and cognition, in performative agency and in institutions. While it is engaged with normative practices and distributions of power and resources, it is also open to possibilities, new encounters and new ways of thinking and feeling, simultaneously reliving old histories and producing new fantasies. It is the fundament of subjective, social and political transformation (Moore 2011, Ch. 1).

Ethics always has a history, and one which is embedded in time and space. The ethical is not a matter of individual subjectivity or voluntaristic orientations but is part of deeply sedimented ways of acting and being that are widely shared. Key to ethics is the question: "how should I live," and within that, a further inquiry which we might gloss also in the form of a question: "who am I for myself and for others?" However, ethics is not about living up to a given exemplar or set of ideals, although it is very often presented as a matter of adherence to moral codes. It is, rather, a labor that seeks to address the query: "how should I live" with myself and with others? Any life, whatever it consists of, is necessarily a shared one, and the self in its relations to others is the "very stuff" of ethics (Foucault 1997, 300).

The question of how we deal with each other is part of a larger problematic about how we understand what it means and entails to share the world with others, both those close to us and those very far away, our intimates and those we will never know. Foucault argues that ethics involves a relation with self, not merely self-awareness, but a regard for self-formation and attention to the ways in which it is possible and desirable to constitute oneself as an "ethical subject" (Foucault 1984, 28-30). Foucault envisages a certain freedom for the subject through and within this process of self-formation. This form of freedom is best understood as a series of possibilities and potentialities. The acting subject, while engaged with the normative and distributions of power, is never fully bound to identities, forms of the self or external powers, cultural conventions and historical determinations. What remains open, connects to the contingency of the present (Foucault 1984, 46, 88) and 
the alterity of the future, and is often most fully present in the moments and structures of daily encounters and engagements (Moore 2011, 22-9).

Consequently, the ethical imagination is one of the primary sites of cultural invention precisely because it deals with the self in its relationships with others, both proximate and distant, and with the historical potentialities for social transformation that are thrown up in our many and varied encounters. In such contexts of encounter, the ethical imagination is brought into play by the advent of new information and ideas, new ways of being and acting, new forms of representation and their mediation. However, it does not always involve conscious thought and is not always based on a privileging of language and ostensible meaning. While we must always have regard for the kind of interpretive talk the ethical imagination makes possible - for example, new languages of description or new frameworks - we need to attend equally to the importance of affect, performance and the body, and its engagement with the nonhuman, the machinic and the organic. Attachment, identification and fantasy are vectors of the ethical imagination and often proceed through forms of unknowing and types of incomprehensibility.

It is a paradox that forms of unknowing can engage the ethical imagination every bit as much as explicit ideologies and well-worked out theories. Forms of identification inevitably vary, but hopes, desires and satisfactions work most often through the relays and connections they establish between pleasure and identification. Fantasy plays a key role in creating and maintaining forms of identification and belonging through establishing new possibilities for connection. These connections do not need to be based on language or on explicit meanings. In any event, cultural meaning is necessarily underdetermined. It is meaning's ambiguity and indeterminacy, its debt to affect and unknowing, which provide the core conditions not only for subjectification, fantasy and identification, but for self-other relations, the making of connections, cultural sharing and, ultimately, social and political transformation. If cultural meanings were fixed, not open to interpretation, without ambiguity, then subjectification would not be possible. Human beings would be too overdetermined to become human subjects. It is a feature of human subjectivity that we are born into and make ourselves under conditions that we may then choose to transform. In this sense, culture provides for historical possibilities; it is the radical potentiality within subjectivity. The ethical imagination links human subjectivity and agency to the forms of the possible, and it does so primarily through a refiguring of self-other relations - where others are not just other humans but also aspects of the object world, the nonhuman and the inhuman (Moore 2011, 19-21).

Self-formation necessarily takes place in historically given contexts, where specific ethical problems arise and provide the conditions for the "problematization" of self. Such problems or difficulties pose challenges for both politics and self-formation and self-understanding. Consequently, the experiences we have of ourselves at specific historical conjunctures always involve certain forms of problematization that "define objects, rules of 
action, modes of relation to oneself" (Foucault 1998, 318), and bear on the question of how we are constituted as subjects of our own knowledge, the kinds of selves we are for ourselves and for others. Foucault's overall interest is in how particular forms of knowledge or problematization involve necessary intersections between the development of a specific politics, a form of government of the self and the elaboration of an ethics in regard to oneself and others. This provides the basis of the tripartite elements of his analysis: Knowledge, power and ethics. Key to the notion of problematization is that it emphasizes where, when and how something begins to stand out from the general terrain of human life and experience, how and when it emerges as an object of thought, the whys and wherefores of questioning "its meaning, its condition and its goals," and the necessity of reflecting on it as a problem, a challenge or a conundrum (Foucault 1998, 117).

In order for something to be problematized, a constellation of factors must have come together to provoke queries, anxieties, explorations or difficulties in relation to it. Such factors will inevitably be the result of specific social, economic and political processes; but while these factors may initiate or provide the conditions for the initial problematization, they do not and cannot determine its form and character. This is because problematizations are never simply the direct consequence or expression of socioeconomic and political determinants or events but rather a series of historically specific responses that take a variety of forms and are frequently contradictory and conflicting. What makes this variety of responses possible is the general terrain or character of what is problematized and the way in which it actively nourishes various responses in their diversity and in spite of their contradictions.

It is problematisation that responds to these difficulties, but by doing something quite other than expressing them or manifesting them: in connection with them, it develops the conditions in which possible responses can be given; it defines the elements that will constitute what the different solutions attempt to respond to.

(Foucault 1998, 118)

So, while problematizations are certainly instigated by social, economic and political changes, they cannot be reduced to or seen as a direct expression of them. One of the reasons for this is that people's own theories of change, self-formation and self-other relations, their ethical imaginations, play a major role in developing the very conditions in which their possible responses to the challenges and difficulties they perceive can develop and find form. A second reason is the issue of diversity. Problematization works through what Foucault terms the politics of truth, the manner in which the truth of any matter comes to be understood at certain historical moments and in certain places, by certain people. Any such truth will inevitably be contested, and it is the diversity of response that signals the emergence of problematization. In simple terms, one could say that without diversity and 
contestation there is no problem. A third reason is that problematization militates against closure; it works to signal the limits of the ethical. It allows for multiple mechanisms for subjectification and objectification, creating a cross-spectrum of knowledgeable subjects and, as such, it has the capacity to expand, alter and transform the parameters of subjectification and world views or perspectives (Faubion 2001, 99). Problematization, however, is always more than a work of thought or reflection. It also involves affect, emotion, the placement of the body, fantasy and relations with objects, technologies and the material world (Moore 2011, 19-21). While it works to present the world anew or sometimes merely to offer new possibilities and potentialities, it is not in itself a necessarily ethical practice (Faubion 2001, 97). What problematization does is to open up a space for the ethical imagination, repurposing existing spaces with new ethical imperatives and desires and sometimes creating new spaces for the ethical.

In the broadest sense, ethics is about the relationship of a social self to its environment, including the others (humans, as well as materials, objects, the nonhuman and the inhuman) who inhabit that environment. In what follows, I suggest that the urban as a form of living has emerged as a problematization itself, as a way of being that is an object of thought, and around which a politics is coalescing and taking shape. This is most particularly the case in the context of massive inequalities, fragile livelihoods, immiserating growth, and anthropogenic and demographic change, accompanied by the accelerating speed of urbanization all around the world but most particularly in the Global South. The key questions here, as I suggested earlier, are "what form of life is proper to the urban" and "how can we live well with others?"

What might I mean by suggesting that the urban is a problematization? The first point would be to emphasize that there are several thematic complexes within the broad terrain of the urban which shape it as an ethical terrain: how should we share with others; how much inequality is tolerable; how should people be provided for; what level of consumption is compatible with moral life; how should we respond to climate change; what are the moral responsibilities proper to sustainability? From one perspective, we could just say that these are the challenges of contemporary living, of being alive at this time on this planet, and they are not particularly urban in character. However, to respond in this way misses the point, for the urban is already one kind of response to these challenges, one set of intersecting materialities within which humans try to formulate and enact their responses, one mode of living which performatively engages not just with conceptions of being and personhood proper to a performative response, but also with sensations, affect, experiences, material forms, spaces and temporalities.

To speak of the urban as a problematization is already to refer to the diversity of understandings, lexicons, activities and experiences that constitute the phenomenon. It marks not so much a known terrain of action, thought and affect, as a thread or vector connecting scale, form and topos. In such contexts, it is not surprising that one form which the problematization of the 
urban has taken is an academic one based on the ethicization of the urban realm. This - along with many other engagements and manoeuvers - allows the repurposing of ethical imperatives regarding knowledge and knowledge acquisition, perhaps even a new space for the ethical. It is also one way in which an analytics of the urban engages the ethical imagination, and how the latter produces the former as a space for the ethical.

This reflects, in many ways, a turn to the ethical that is not just about academic life, but is also about a particular form that the ethical imagination is taking in the contemporary moment, with discussions on everything from planetary politics and environmental degradation to consumption and trade, and how to build sustainable cities. These ideas about how to formulate ethical responses to global challenges are connecting agents across many different spheres from science policy to governments, trade activists, property developers, car manufacturers, producers, consumers and other social economic and political actors across huge distances. This ethical turn is often less about saving the planet and ethical consumption, and more about how to refigure consumption, ecology and the planet as spaces for the ethical. We all recognize that unless we refashion these spaces as objects of our ethical concern, we will very likely not make any progress in tackling the huge challenges ahead of us.

\section{Imaging others: livelihoods and inequalities}

Cities are, of course, one solution to the question of how we live with others. They are heterogeneous landscapes with many categories of others and many modalities for managing the forms of difference they contain and shape, and out of which they are fashioned. When we explore what shapes encounters with others, it is evident that the material circumstances of urban life, the political economy within which these materialities are set, and the fragility and uncertainty of navigating these complex terrains shape both livelihoods and the inequalities through which they are constituted.

African cities currently face low productivity, dismal job creation, high informality, huge infrastructure and service gaps, and increasing inequalities. They are also vulnerable to climate change, cause significant environmental damage and have weak institutional systems and forms of governance. What to do about this situation is compounded by many challenges, but one of them is the inadequate nature of our theories of development, structural transformation and urbanization. What is now abundantly clear is that Africa is not following the historic path of the Global North, and growing urbanism is not fueled and propelled by growing industrialization and large-scale formal employment. While significant gross domestic profit growth has been recorded for several African countries in recent years, this has not meant better quality of life for the majority of residents. Starting in the 1980s, the International Monetary Fund strictures and World Bank structural adjustment loans disproportionately affected the poor and deepened inequalities. Privatization of health care and education and paying for 
transport, food, housing, water and energy have made survival extremely difficult for low-income city dwellers. The jobless growth of recent decades has only intensified the problems of how to make a living.

The urban is a challenge to living for many people, and the politics of the relationship between livelihoods - ways of living - and social inequalities maps out the possibilities of encounters with others. This is often captured well by popular music in Africa. It is well recognized that hip-hop embraces issues of inequality, corruption, housing, unemployment, political critique and more (e.g., Koster 2013), and there is a considerable body of work on the relationships between music and identities (e.g., Ntarangwi 2009; Wanjala and Kebaya 2016; Weiss 2009). However, music also provides a soundscape of the city. It demonstrates how residents alter urban spaces and make the city work for them, providing a space within which to make sense of the urban and the others who inhabit it. This is more, however, than a form of narrativization, a way of reflecting the realities of social and economic inequalities. It is also a space for ethical judgment, and a sensory and affective form of engagement with the urban, an instance of engagement with the ethical imagination.

Sasa ni lunch time, tufunge makazi

Twende kwa chakula, tuje tena saa nane

Wengine wanakwenda kulala uwanjani

Kumbe shida ndugu, njaa inamwumiza

It's now lunch time, let's take a break

Take a meal and return at $2 \mathrm{PM}$

Others go to sleep in the parks

Because of problems brother, hunger is ravaging him.

Gabby Omolo: Lunch Time (Ogone 2014, 184)

The song depicts the public park as a place for those who cannot afford to eat lunch to go and sleep, and to try and assuage both the pains of hunger and the larger problems within which it is embedded (Ogone 2014, 184). Music is part of the experience and effective negotiation of urban life, and it effectively ties forms of subjectivity to lived engagement with the materialities of the urban form.

Watu wa Industrial Area, watoroka maharagwe

Waenda hotelini, kwa chapati na ng'ombe

Na wengine nao, wale mishahara juu

Siku hiyo wote, kwa hoteli za wazungu

The people of the Industrial Area abandon beans

They go to hotels for chapati and beef

And others who earn high salaries

That day they all go to European hotels.

Gabby Omolo: Lunchtime (Ogone 2014, 189) 
The industrial laborers in Omolo's song eat beans, except at the end of the month when they get their salaries and go to eat beef. Those with larger salaries go to European establishments. The spaces of the city, and movement through them, are marked out by inequalities of work and consumption. In Kenya, the phrase "they have eaten" always refers to the benefits of proximity to power and most often to a particular understanding of the nature of the political. The idiom of food, thus, ties livelihoods to political economy and to politics.

Intersections between infrastructure, work, public welfare and urban poverty within African cities are leading to new forms and ethics of the self. New modes of self-care, self-governance and self-stylization are shaping the possibilities for subjective agency within the newly emerging forms of urban politics. Specific configurations of inequality, responsibility, mobility, care and competitiveness emerge and remerge, some of them reprising older versions and some inclining to the shifting nature of ongoing uncertainties and new dispositions. People need cash for daily necessities, and a culture of entrepreneurialism, "fend for yourself," "everyone can be a business person," has long been a form of self-realization and self-stylization crucial to people's efforts to turn to informality and petty business to manage joblessness and poverty, combined with insecure living.

Ama twende ghetto tufungue kibanda

Tuwauzie kahawa, nakuonyesha itawabamba

Si dalasini, si karafuu

Tutawachanganyishia zote waskie nafuu

Kisha ikishawabamba, si unjaua nini itafuata

Kuwasanyia njumu na mambota

Washindwe ni mogoka imeshika ama ni kuota

Wakishika ujanja, car wash tunaanza

Kwa ile hali ya kuosha, rim inapotea

Side mirror inapotea, tenje inapotea

Makarao wakikuja, gari inabembea

Or we go to the ghetto and open a kiosk

To sell to them coffee, I tell you it will please them

Not cinnamon, not clove

We mix for them all so that they feel "relief"

Then after it has taken effect, you know what will follow

Collecting their shoes and watches

They will wonder if it is khat

that made them high or they are dreaming

When they become wise, we open a car wash

In the process of washing, the rim disappears

The side mirror disappears, the music system disappears

When the police come, the vehicle is wobbling. 
The song creates the familiar figure of the hustler, who is both creative and cunning, knowledgeable about how to operate in the urban realm and who knows how to handle the city by dreaming up different ways of scamming others (Ogone 2014, 188). The space of the ghetto is reported in the song as outside the space of governance, a place forgotten by the authorities and rarely visited by the police. This is sometimes portrayed in the academic literature as an actual example of the hustler outwitting the police through a series of moves, where power is wielded by those who can turn their hand to any job, recreate their identities at will and become as changeable as the city itself. This rather overstates the case. This is much more a form of selfstylization. It both emphasizes a form of neoliberal subjectivity in the guise of heroic resistance and provides an attempt to characterize the nature of subjective engagement with the urban, and to reflect on the way relations of proximity with others are both actual and fantasized. The hustler - allied to his original American roots - is an acknowledged form of self-creation and aspiration: a figure acting as a means to garner respect but also for commenting on the selves of others, and on the networks of connection and interaction that make the city work, the relation of self to others.

In this sense, music provides an embodied and sensate means of engaging the ethical imagination, scoping spaces for social critique and critical reflection (Ntarangwi 2009). Songs often work by reworking the rhythms of the city, as in the Zimbabwean artist Synik's description of how the city of Harare got its name in Hamurarwe (there is no sleep).

\section{Harare}

Let me break down the etymology

"Rara" means "to sleep"

And over here that's a luxury

With mad levels of unemployment in the economy

For typical residents, hustling is one of the qualities.

Synik: Hamurarwe (Ncube and Chipfupa 2017, 113)

The very name of the city reflects its restless and unreasonable demands. While music can often be about resilience, aspiration and hope in trying conditions, it is not the only ethical space that engages with the relationship between informality, vulnerability and entrepreneurship. Personal aspirations and self-understandings for the poorest in African cities are frequently engaged with a series of more developmentally oriented discourses that once again tie subjective experience to others who are both proximate and very distant. In its broadest sense, development has always been about the inculcation of new regimes and practices of self-government. However, in the absence of formal employment opportunities in African cities, current development efforts are focused on how to draw the poor into economic growth and poverty reduction via business and microenterprise (e.g., Meagher 2016). This shift from employment to entrepreneurship makes much 
of conjuring individual entrepreneurial talent out of economic and social disadvantage (Dolan and Rajak 2016, 514).

The trajectory of much policy and scholarship in relation to the bottom of the pyramid - as this group of youths, women, migrants and urban poor have come to be known - focuses on breaking down the barriers between formal and informal employment, and striving not toward redistribution but toward inclusive markets. Aid agencies, non-governmental organizations (NGOs), international organizations and multinational corporations have rolled out distribution systems not only for consumer goods but also for development goods, such as water filtration systems and financial services. There has undoubtedly been benefit here for some, but this new capacity to deliver profits under the cover of social purpose has seen many social enterprises and NGOs pulled into last mile distribution systems that, in the powerful words of Catherine Dolan and Dinah Rajak, recast geographies of poverty as unmet consumer needs (Dolan and Rajak 2016, 518; Thieme 2015). This repurposing of entrepreneurship is not only remaking capitalism but reworking subjectivities and agency for the people it engages, turning their personal assets and capabilities into income-generating possibilities, and creating new practices of self-governance and self-realization.

The remaking of the agents of development has a long history in Africa but has always been powerfully shaped by notions of poverty and vulnerability arising in policy and academic domains. Many African countries have rolled out social safety nets and forms of public welfare in recent decades designed to support the poorest and most vulnerable in society. The evidence suggests that these can make a significant difference to the quality of life, health and education (e.g., Fisher et al. 2017), but even when they are unconditional, they may still have a powerful impact on practices of self-formation and selfgovernance (cf. Beegle et al. 2018; Devereux et al. 2017). Part of this connects to the way that beneficiaries perceive possible requirements, such as punctual behavior, monitoring and evaluation, and continuous behavior, including immunization and primary school attendance for children in participating households. Self-formation and self-stylization can be the unintended consequences of participation in schemes where beneficiaries are acutely aware of the practical necessities of conforming to conceptual and practical distinctions demarcating the vulnerable from the non-vulnerable, the extreme poor from the poor. This is often made most evident by the fact that members of the local community, such as healthcare workers, headmen and NGO employees, may be the ones conducting surveys, gathering evidence for inclusion and monitoring compliance (e.g., Rohregger et al. 2018). In Kibera, Nairobi's largest slum, for example, cash transfer programs support vulnerable children, and reimagining the self through the notion of vulnerability becomes a source of potential support and employment. The result is that local networks of support and/or resource allocation can be repurposed and shot through with ideas and demands that impact people's intimate lives and, yet, arise in very distant locations. Even locally implemented national welfare and social 
support schemes may engage the ethical imagination, reworking the interconnections between self and others in ways that inflect local relationships with distant requirements for specific types of agency and self-management.

Accessing resources is key to survival in the city, and this applies to the newly emerging middle class of African cities, as well as the very poor. Insecurity, the threat of not managing, of losing traction, is the shadow hanging over the young professionals, the data engineers, software developers, journalists, cultural managers and others who have emerged in the city in response to new types of knowledge and work, new technologies, and a huge globalized aid and development industry. Nairobi, for example, is the home to many international institutions and agencies, religious organizations, local NGOs and international donors, as well as philanthropists of all kinds. Poverty amelioration is not only an urgent necessity but also a source of huge funding and employment. For deliverers and beneficiaries alike, the causes, consequences and costs of poverty are linked to particular forces, agencies, materialities and subjectivities in the world. It is also one of the most frequent and familiar ways in which ordinary people's lives are affected by global flows of knowledge, technology and finance. In such contexts, new practices of self-governance emerge.

The urban face of organizations such as UN Habitat - ironically enough - is part of this production of new forms of self-stylization: Individuals who govern themselves in the name of freedom, choice, making good and getting on. Such individuals are also engaged in intimate relationships with many of their fellow citizens who depend on them for forms of care and sustenance. Their employment in the industry of aid and development and its many offshoots may involve them in delivering benefits to those less fortunate than themselves, as I have already suggested, reimagining their co-residents in terms of vulnerability, poverty and need; or they may employ them directly as gardeners, nannies and home helps. A particular relationship to politics and livelihoods shapes both the actual and the imagined nature of inequalities. The character of self-other relations shifts as older ideas of kinship and responsibility give way to ideas that are global in their circulation about the challenges of poverty, climate change, food insecurity, public health and well-being.

Middle-class Kenyans are generous donors to charities that support those in need in Kenya and beyond. Being a donor is a powerful aestheticization of self. It is also a very good example of the interconnection between ethics and forms of governmentality, as well as a fine exemplar of the ethical as "the strategies that individuals in their freedom can use in dealing with each other," as Foucault would put it. The ethical imagination here produces a new form of urban politics based on forms of subjectivity that create new forms of self-governance and new relationships of care for self and others but are not necessarily shaped by any particular political outlook or project. Rather, they create spaces for self-realization that shape day-to-day interactions at the very local level but are also animated by imagined forms of subjectivity and forms of social collectivities that are not only distant but 
also very abstract. These imagined relationships to others are connected to fantasized relationships to such things such as the global economy, new technologies, self-enterprise, skills development and a world where international institutions, like the UN, are both mysterious actors and local employers. This produces individuals who not only make a living out of helping others, but who are also invested in their own "development." Urban politics is located and newly purposed in these new forms of subjectification. Differentiated access to employment and other forms of support reworks the way belonging and identities are imagined in the city, setting up new answers to the questions "what is a city" and "what forms of life are properly urban"?

Livelihood strategies of various kinds connect individuals and communities divided by class and location and the relationship between production and consumption is a powerful space for the ethical. Fair trade and several other initiatives to monitor and limit the impact of well-off consumers on producers less well provided for have a long history in terms of Global SouthNorth relations (e.g., Dolan 2005, 2007). However, ethical consumption is an emerging space for middle-class consumption in African cities, where it is associated both with a class-based aestheticization of self, and with various mechanisms for demarcating new spaces for ethics and care that signal local class distinctions, as well as participating in global discourses and international connections (e.g., Hughes et al. 2015; McEwan et al. 2015). Recent research with shoppers in informal craft markets and trading spaces in Cape Town found that shoppers - many of whom were white - understood craft production as a survival strategy, while some liked the idea of supporting what they termed local talent, initiative and creative capacity. "I like to support craft producers ... I feel I'm contributing to livelihoods by buying these products - the money goes straight to the producer" (Daya 2016, 131). Some shoppers reported a sense of shared responsibility, locale and solidarity in the context of disadvantage in South Africa. This extended to incorporate a larger sense of Africanness and shared African identity. The value of these encounters for purchasers came not just from the intrinsic nature of the objects but from a wider sense of the human connection of production and the sense of skill, achievement and aesthetics. Craft producers themselves recognized these forms of appreciation, and both sides were engaged in forms of mutual recognition and care based on attentiveness to others that did not necessarily involve conscious reasoning and motivation (Daya 2016, 132-3). This does not imply these forms of recognition and care were always or necessarily progressive, good or benevolent, nor that they stood outside politics. They were clearly shot through with relations of power and particularly with that specific form of violence that underpins all forms of philanthropy and ethical benevolence in the context of the operations of racial difference. What is important about the self-other relation here is that consumption provides the space for the ethical imagination to emerge as a form of care, and its potency is derived both from intimate face-to-face interactions and from imagined relationships, such as nationality or shared Africanness. 


\section{The future urban}

As an object of thought and a site of practice and attachment, problematization can be seen at work in reflections, images, cultural forms, scientific theories and political engagements. It is a feature of problematizations that they often work across domains and involve various kinds of objects, rules of action, modes of relation to oneself, materialities and affects (Foucault 1998, 318). They are made up of conscious and unconscious forms of reasoning, encounter and attachment, as I suggested earlier, and involve elements of the human and nonhuman worlds (cf: De Boeck and Plissart 2014).

One aspect of the problematization of the urban that is particularly pressing is its futuricity, its visions of the new, the transformative, the hopefully technologized, all the promises of modernity and more. Such visions are always shot through with their opposites - decay, death, destructiveness and this is inevitable, because the urban has now become the space par excellence where we question our ability to survive the anthropogenic threat we pose to the planet, ourselves and others. The urban is more than a built environment or a set of infrastructures and livelihoods; it is also an experience to be lived, enjoyed and/or suffered. But more than the actuality of experiences, it is also an experience of what is yet to come, what is hoped for, aspired to and imagined as possible. The experience of the urban is here and now but also one of anticipated futures, possibilities and relationalities. It is a space where a lot of people congregate with different ideas, beliefs, interests and behaviors. It is a place full of others and their fantasies. It is inherently familiar and unstable, a place of escape and rekindled hope.

\section{Kijana amekatia mama}

Mama mzungu, sasa anaishi majuu...

Kila mtu kwa mtaa anasaka

Hata five years old

Anauza Karanga

Mimi sihitaji visa

Mimi ni vulture

Natumia tu mabawa

A young man seduces a woman

A white woman, he now lives abroad

Everyone in the estate is a seeker

Even a five-year-old

Sells peanuts

I do not need a visa

I am a vulture

I just use wings.

Colonel Mustafa: Mtaani dot com (Ogone 2014, 191) 
Filip De Boeck writes of how the inhabitants of Kinshasa disbelieve the future being developed for their city but are nevertheless drawn in. They do not trust the government, and they know that they will never have rights to this future world, but they dream: C'est beau quand-même, ça fait rêver! [It is so beautiful, it makes one dream] (De Boeck 2011, 320); just as others dream of a visa for Europe, of making good and turning out a success. The dialectical interplay of internalization and objectification through which subjectivity is constituted plays out in the heterogeneous space of the urban made up of a range of competing identities, modes of self-fashioning and complex desires for pleasure, fantasy and freedom. The ethical imagination is a space where the self is at risk, where the engagement with others and their fantasies and desires offers - however fleetingly - a space where the self reflects on itself, imagines itself as other and engages with a world of possibilities.

In addition to access to jobs, housing, education, infrastructure and opportunities, the imagined cityscapes of Nairobi and other African cities raise issues about the social, ethical and material entities, experiences and affects these cities of the future are thought to harbor. What kinds of thought, action and behavior will be proper to them (Van den Broeck 2018, 211-2)? The uncertainties of these envisioned spaces are unsettling, even anxiety producing, but they are also exciting, animating and vital. They hold out a future for living, however imperfectly realized. Jan Van den Broeck has written about Konza Technology city, a proposed master-planned new town some 60 kilometers from Nairobi on the Nairobi-Mombasa highway. It currently exists as a series of fenced-off grasslands and billboards over which a series of court cases are playing out over land ownership. The urban is a promise, both anticipated and delayed. Local people imagine that they will be excluded from this new world when it arrives, but the lure of possibilities still works its magic and possibilities are familiar territory. Current housing in the area is made up of different types of dwellings in an oscillating state of completion, renovation and decay, as families strive to make their life circumstances more durable, stable and comfortable with the few resources at their disposal. When the new technology city arrives, it will not be made up of such flimsy structures. It will make a definitive claim in its materiality for the future of the area (Van den Broeck 2018, 215-7). For the moment, however, the future has not arrived.

The materiality of the built environment and even future versions of that environment intersect with affective experiences both real, hoped for and fantasized. Fantasy, in this sense, has both a materiality and a history. It is the product of social, economic and political circumstances, but not determined by them. It is a functioning aspect of problematization that allows for anticipations to drive forward engagements across several modalities and spatial and temporal scales. Narrativization is a key element but not the only one. From the process of house building for local residents to the imagined towers of a technological future and everything in between, the built environment acts as an instantiation of the present and the anticipated forms of the future. 
The urban is one way to cultivate the future, to elicit the forward nature of what could be (Van den Broeck 2018, 220). These forms of the future conditional connect - without specifying a particular trajectory or a set of distinct goals that make up a world view (Van den Broeck 2018, 220) - to the practices of interrogation, engagement and elicitation of the ethical imagination: who am I for myself and others; what do I want; what can I hope for; what must I do? Simone's argument that urbanism is "not a destination but always a work in progress" partakes of the same future conditional $(2013,245)$.

The urban is made up of not only specific cities, places and spaces, with their particular demographies and histories, but also disparate circulations, fragmentations of ideas, images, affects, soundscapes, theories, spheres of action and longings. What the anthropologist Aihwa Ong has called in the context of Asia "the worlding of cities":

This art of being global ignores conventional borders of class, race, city and country. There are promiscuous borrowings, shameless juxtapositions and strategic enrolments of disparate ideas, actors and practices from many sources circulating in the developing world and beyond. We identify urban modelling, inter-referencing practices and new solidarities as the flamboyant features of worlding cities.

(Ong 2011, 23)

Whatever the criticisms of this particular argument about Asian urbanism may be, the phrase "the worlding of cities" is a felicitous one for exploring the problematization of the urban and the specific forms it takes in certain places and spaces. The urban as problematization is not a theorization of the urban but a critical reflection on how engagements with imagining, enacting, reworking, decoding the urban through the ethical imagination are shaping the urban itself, through the actions of city dwellers and those of diverse others. New forms of the urban and of urban coexistence are coming into existence alongside the urban as a new site of problematization. This is shaping new forms of urban politics for a whole variety of actors, entities and institutions, and most certainly for scholars, policy makers and ordinary citizens of every kind. It is also widening the sources of inspiration for theorizing the urban and questioning the privileging of certain forms of urbanity, modernity and ways of living (Robinson 2013, 660). These new forms of the ethical imagination stretch across power hierarchies and wealth distributions, linking the dynamic, provisional, precarious worlds of ordinary citizens with transnational capital, donors, traders, religious organizations, governments and academic theorists.

The academic literature has already played a very significant and distinctive part in this process by creating, exploring and initiating new relationships between urban life and ethics. The move to ethicize the domain of the urban, as part of the larger turn to ethics in the social sciences and humanities, has been truly formative. This has been driven in part by social, economic and 
political changes that have highlighted the impact of immiserating growth, inequality and precarity on the lives of ordinary people in cities across the world. It has also been driven by the logical developments of theorizing in and around political economy, feminist theory and postcolonial scholarship. However, the problematization of the urban does more than merely express or represent these conditions, determinants and events. It provides, through the ethical imagination, the conditions under and through which diverse responses to these externalities can be posited, developed and interrogated.

The problematization of the urban connects forcefully to the new forms of subjectivity and care for the other that are emerging in the context of major planetary challenges, including climate change, environmental degradation and new forms of vulnerability for humans and nonhumans. These new forms of subjectivity and self-other relations are beginning to reshape the urban as various actors seek to improve climate change adaptability, resilience, energy and water management, and the urban agriculture of cities, alongside smart and eco-transport systems, retrofitted housing and much more. It is sometimes mistakenly imagined that such concerns and actions are features predominantly of the cities of the Global North, but this is not the case. Discussions on food quality, human rights, water and land access, energy rights and pollution are reworking the relationship between urban life and ethics, creating new forms of the possible and of politics. The super diversity of cities in Africa raises pressing issues around migration, ethnicity and the alternative lifestyles of diverse others who are exploring and developing ideas about religious affiliation, ecology and urban food security. These explorations may engage with specific ideologies and life projects, but, on a more general level, they are driven by the new demands of living together at scale and the necessity of finding ways to live well together.

Ethics as a diverse form of knowledge production - including academic discourse - takes shape through the ethical imagination creating both new subjectivities and new spaces for the ethical. The ethical imagination works to govern the forms of self-other relations through which subjects come to govern themselves. This is as true of academics as it is of all other city dwellers. It does not mean that there is a single ethics specific to urban living or that the purpose of ethicization is to arrive at consensus or even accommodation. The ethical imagination can also be used effectively to exclude others, narrowing the spaces of self-other relations and renationalizing sentiment. The ethical imagination is not, in and of itself, necessarily a morally good project. The work of the ethical imagination, in its engagement with the urban, is to create spaces within which the limits of the ethical can continue to be contested and developed. The problems of human societies are increasingly made intelligible as ethical problems, as they should be, as individuals and communities around the world struggle to make sense of how it is possible to live together on a single planet and how it might be possible to reimagine the relationships between selves and others, to open them up to new possibilities and to the alterity of the future. 


\section{Bibliography}

Beegle, Kathleen, Maddalena Honorati, and Emma Monsalve. 2018. "Reaching the Poor and Vulnerable in Africa through Social Safety Nets." In Realizing the Full Potential of Social Safety Nets in Africa, edited by Kathleen Beegle, Maddalena Honorati, and Emma Monsalve, 49-86. Washington: World Bank. doi: 10.1596/978-1-4648-1164-7

Daya, Shari. 2016. "Ordinary Ethics and Craft Consumption: A Southern Perspective." Geoforum 74: 128-35.

De Boeck, Filip. 2011. "Spectral Kinshasa: Building the City through an Architecture of Words." In Urban Theory beyond the West: A World of Cities, edited by Tim Edensor and Mark Jayne, 311-327. London: Routledge.

De Boeck, Filip, and Marie-Françoise Plissart. 2014. Kinshasa: Tales of the Invisible City. Leuven: Leuven University Press.

Devereux, Stephen, Edoardo Masset, Rachel Sabates-Wheeler, Michael Samson, Althea-Maria Rivas, and Dolf te Lintelo. 2017. "The Targeting Effectiveness of Social Transfers." Journal of Development Effectiveness 9, no. 2: 162-211.

Dolan, Catherine S. 2005. "Fields of Obligation: Rooting Ethical Sourcing in Kenya Horticulture." Journal of Consumer Culture 5, no. 3: 365-89.

Dolan, Catherine S. 2007. "Market Affections: Moral Encounters with Kenyan Fairtrade Flowers." Ethnos 72, no. 2: 239-61.

Edensor, Tim, and Mark Jayne, eds. 2012. Urban Theory beyond the West: A World of Cities. London: Routledge.

Faubion, James D. 2001. "Toward an Anthropology of Ethics: Foucault and the Pedagogies of Autopoiesis." Representations 74: 83-104.

Fisher, Eleanor, Ramlatu Attah, Valentina Barca, Clare O’Brien, Simon Brook, Jeremy Holland, Andrew Kardan, Sara Pavanello, and Pamela Pozarny. 2017. "The Livelihood Impacts of Cash Transfers in Sub-Saharan Africa: Beneficiary Perspectives from Six Countries." World Development 99: 299-319.

Foucault, Michael. 1984. The Foucault Reader. Edited by Paul Rabinow. New York: Pantheon Books.

Foucault, Michael. 1998. Ethics: Subjectivity and Truth. Edited by Paul Rabinow. Volume I. New York: New Press.

Harrison, Philip. 2006. "On the Edge of Reason: Planning and Urban Futures in Africa.” Urban Studies 43, no. 2: 319-35.

Hughes, Alex, Cheryl McEwan, and David Bek. 2015. "Mobilizing the Ethical Consumer in South Africa." Geoforum 67: 148-57.

Koster, Mickie Mwanzia. 2013. "The Hip Hop Revolution in Kenya: Ukoo Flani Mau Mau, Youth Politics and Memory, 1990-2012." The Journal of Pan African Studies 6, no. 3: 82-105.

Landau, Loren B., and Freemantle, Iriann. 2016. "Beggaring Belonging in Africa's No-man's Lands: Diversity, Usufruct and the Ethics of Accommodation." Journal of Ethnic and Migration Studies 42, no. 6: 933-51.

McEwan, Cheryl, Alex Hughes, and David Bek. 2015. "Theorising Middleclass Consumption from the Global South: A Study of Everyday Ethics in South Africa's Western Cape." Geoforum 67: 233-43.

Meagher, Kate. 2016. "The Scramble for Africans: Demography, Globalization and Africa's Informal Labour Markets.” Journal of Development Studies 52, no. 4: 483-97. 
Moore, Henrietta L. 2011. Still Life: Hopes, Desires and Satisfactions. Cambridge: Polity Press.

Ncube, Gibson, and David Chipfupa. 2017. "Outspoken Cynics? Rethinking the Social Consciousness of Rap and Hip-Hop Music in Zimbabwe.” Muziki 14, no. 1: 103-22.

Ntarangwi, Mwenda. 2009. East African Hip Hop: Youth Culture and Globalization. Urbana: University of Illinois Press.

Ogone, James Odhiambo. 2014. "Framing the Urban Hustler: Space, Identity Discourse in Kenyan Popular Music." Journal of Pan African Studies 6, no. 9: 179-200.

Ong, Aihwa. 2011. "Introduction: Worlding Cities or the Art of being Global." In Worlding Cities, edited by Ananya Roy and Aihwa Ong, 1-26. Oxford: Wiley-Blackwell.

Parnell, Susan M., and Edgar Pieterse. 2014. Africa's Urban Revolution. London: Zed Books.

Parnell, Susan M., Edgar Pieterse, and Vanessa Watson. 2009. "Planning for Cities in the Global South: An African Research Agenda for Sustainable Human Settlements." Progress in Planning 72, no. 2: 233-40.

Pieterse, Edgar. 2011. "Grasping the Unknowable: Coming to Grips with African Urbanisms." Social Dynamics 37, no. 1: 5-23.

Robinson, Jennifer. 2006. Ordinary Cities: Between Modernity and Development. London: Routledge.

Robinson, Jennifer. 2013. "The Urban Now: Theorising Cities beyond the New." European Journal of Cultural Studies 16, no. 6: 659-77.

Rohregger, Barbara, Katja Bender, Bethuel Kinuthia, Esther Schüring, Grace Ikua, and Nicky Pouw. 2018. The Politics of Implementation or Why Institutional Interaction Matters: The Role of Traditional Authorities in Delivering Pro-Poor Social Policies in Kenya. Bohn: IZNE Working Paper 18/2. Accessed September 8, 2019. https://pub.h-brs.de/frontdoor/deliver/index/docId/3661/file/IZNE_WP_1802.pdf

Roy, Ananya. 2009. "The 21st-Century Metropolis: New Geographies of Theory." Journal of Regional Studies 43, no. 6: 819-30.

Simone, AbdouMaliq. 2013. "Cities of Uncertainty: Jakarta, the Urban Majority, and Inventive Political Technologies." Theory, Culture and Society 30, no. 7/8: 243-63.

Thieme, Tatiana A. 2015. "Turning Hustlers into Entrepreneurs, and Social Needs into Market Demands: Corporate-community Encounters in Nairobi, Kenya." Geoforum 59: 228-39.

Wanjala, Henry, and Charles Kebaya. 2016. "Popular Music and Identity Formation among Kenyan Youth." Muziki 13, no. 2: 20-35.

Watson, Vanessa. 2009. "Seeing from the South: Refocusing Urban Planning on the Globe's Central Urban Issues.” Urban Studies 46, no. 11: 2259-75.

Weiss, Brad. 2009. Sweet Dreams and Hip Hop Barbershops: Global Fantasy in Urban Tanzania. Bloomington: Indiana University Press. 


\title{
3 The city as a setting for collaboration? Tracking the multiple scales of urban promises
}

\author{
Alexa Färber
}

The relationship between collaboration and the promise is not self-evident. While promises do not evocate collaboration in any sense, we can imagine that collaboration brings with it certain promises: Hence, collaborative working relationships promise to achieve special results and collaboration takes place in relationships, which may, in turn, be based on specific promises, such as reliability or equality. In this regard, the expectations attached to collaborative work, as it is put forward, for instance, in method books for ethnographic research, point to the fact that working together promises to provide a positive difference compared to working individually. In this vein, "collaborative ethnography" is achieved, among other factors, when specific scripts or protocols enable equal distribution of roles and tasks and a certain transparency about it. Accordingly, an underlying ethics of equality is translated into a detailed set of rules that should explicitly guide (interdisciplinary) teamwork and lead to better success. More importantly, the higher ethical standard of collaborative ethnography is based on the required recognition of the research contribution of the ethnographic counterparts (Rappaport 2008, 2). This extended understanding of cooperation should be shown in all stages of collaborating (Lassiter 2005, 16). The aim is to achieve a coproduction of theory that "shifts control of the research process out of the hands of the anthropologist and into the collective sphere of the anthropologist working on an equal basis with community researchers" (Rappaport 2008, 5). In short, collaborative ethnography's working ethos promises two things simultaneously: the exchange and translation of different approaches into a better ethnographic result and a kind of equality of socially different partners within knowledge production. The latter represents a strong ethical and political claim that has its roots in the postcolonial debate in anthropology, which wanted to break with the discipline's colonial heritage and the power relations enacted in fieldwork.

The merged promises of academic differentiation, on the one hand (coming to better results than other forms of ethnographies), and an equation or alliances, on the other hand (conducting fieldwork under new ethical standards), can, of course, be problematized, for instance, as being difficult to monitor: How do we know what is a better ethnography if we cannot directly compare 
the results of a collaborative work with an individual ethnography? The ethically framed promise of equality in research relationships through collaboration also seems to point to neoliberalizing models of work and subjectivation that bear many inequalities (Färber 2009). Hence, more recent calls for collaborative methodologies are also skeptical about reproducing these competitive and, at the same time, ethically informed promises of collaboration in anthropology and idealizing its outcome (Sánchez Criado and Estalella 2018). There is a need to understand the conditions for this idealizing.

Against this backdrop, the chapter's reflection is twofold: On the one hand, it takes the resemblances of the promise and collaboration as a tool to problematize idealized understandings of both. On the other hand, I ask: What are the conditions for the promissory potential of collaboration? In order to organize this problematization and to find answers to these questions, I turn to the city as a setting for promissory collaboration. Therefore, analytical perspectives from several fields of research are brought together: Collaboration appears as a recurrent topic in the perspective of an anthropology of knowledge that has a sensibility for everyday socio-material practices of collaboration (Groth and Ritter 2019; Sánchez Criado and Estalella 2018). From the perspective of a contemporary urban anthropology, the city comes into play as an unstable notion that allows one to conduct research in urban fieldsites and about the city and its qualities as a multiple object. Finally, acknowledging a special interest in the performative power of articulations and materializations of promises (Ahmed 2010; Berlant 2011) "in" and "of" the city, this chapter is part of a reflection that aims at conceiving the entanglement of the city and the promise. I have argued elsewhere that the notion of the city as a "promissory assemblage" (Färber 2019) might serve as such a concept.

Referring to material from two different fieldsites (Hamburg and Berlin), I will problematize the conditions for collaboration and its promises in the city in three steps: I first refer to different scenes of promises in the city to show the diversity of possible settings. Although located on different scales, these promises may be experienced as intertwined in the everyday. I will briefly introduce the concept of the city as a "promissory assemblage" to capture this interrelatedness. Second, I will turn to concepts of the promise as speech acts and objectifications, with a special interest in their affordances and looseness. These qualities of the promise of the city will be exemplified with Berlin's post-1989 contradictory attractiveness. I reconsider the promises of collaboration in a third step. Here, the city as a "promissory assemblage" helps again to explain the diverging forces at work when it comes to the promises of collaboration within these urban settings. Overall, this contribution aims at challenging the promises attached to a fixed notion of collaboration by questioning, among other things, their ethical claim. It does not give an account of a finished study of these questions. Rather, it is part of a broader conceptual work testing how to explain the potential of the promise as an analytics for the quality of the social "in" or "as" cities as well as the disputed attractiveness of cities - with a special 
focus here on collaboration as an everyday practice that raises some ethically loaded expectations.

\section{Scenes of the promise and the city}

Five psychologists ask: "Why do 'urban promises' exert such an attractive force over people across the world?" (Cardoso et al. 2017, 4) in their study "The City as a Self-Help Book: The Psychology of Urban Promises." They offer the following answer:

We ... argue that people "believe" in the promises of cities for similar reasons that they "believe" in self-help books - lack of statistical intuition to evaluate risk, reliance on exceptional cases, overconfidence about themselves and their environment, illusory cause-effect attributions, and rationalization of failures. These features of cognition are some of the heuristics and biases affecting decision-making under uncertainty.

(Cardoso et al. 2017, 5)

Although this is not the conceptual language of choice for an urban anthropologist, the authors of this study are interested in a similar problem regarding the entanglement of the promise and the city, that is, how can we make sense out of the incoherence of urban promises and the disparities they seem to produce?

Regarding the reflexive construction of the city, that is, when actors refer to some kind of essence of the city in order to develop an argument (an individual narrative about the city, a plan or a political strategy for its future), urban promises typically appear as promises of urbanity - imbued with ethical imaginations of freedom, equality (access to infrastructures, to consumption and, most important, to work) and, therefore, care and opportunities. Concerning these cultural representations, urban anthropology may add insights into the lived disparities they entail. Differentiating promises "in" the city from promises "of" the city, the latter being general ("The city as a promise") or specific ("promised city xy"), we can ask for not only their content but also their different everyday settings.

As a possible research perspective in urban anthropology, the notion of the promise first appeared to me in 2014 during a piece of "speed research" I conducted in Hamburg's huge inner-city urban development area HafenCity, together with my colleagues Cécile Cuny, sociologist and photographer at the École d'Urbanisme de Paris, and Sonja Preissing, then a $\mathrm{PhD}$ candidate at the University of Cologne. We made two itinéraires or "go-alongs" (Kusenbach 2003; Petiteau and Renoux 1993) through HafenCity, each one with a photographer as our ethnographic counterpart, over two days. These two photographers had collaborated (together with seven other colleagues) in 2009 on an assigned project that resulted in a photo book on public space in Hamburg's emerging new district (Bruns-Berentelg 2010) that had, until then, earned more critique than applause. During the two itinéraires, we had asked each of the 
photographers about their experience of that collaborative project: how they had organized it practically, what their memories of challenges in collaborating were and where this project led them to individually. We were less interested in the result of their work than in the way they had worked together.

We encountered a couple of more or less explicit promises, especially during one of the go-alongs: Maria NIFI Xerisoti, one of the two photographers, told us a story that relates the promise and the urban development site in multiple ways. It was a story she had noted six years earlier while she filled out a form that all participating photographers should use in order to provide information about their photographs (e.g., time, weather, location). As a preparation for our meeting, she had reread these notes and found a conversation between an elderly couple that she had overheard at the time and considered interesting for us. With great enthusiasm about this find, she had asked us to hold on and listen while she read from her notes (Figure 3.1).

"ALEXA: Ok, you wanted to say something else.

MARIA: No, exactly, no. (she goes through her notes) I wanted, ... here! (starts reading) A couple in the Viewpoint looks at the display.

THEN THE WOMAN SAYS: "The building, it's all really ugly, too much concrete. You had told me, 'You will like it here!'?! "Yes, I couldn't remember very well."

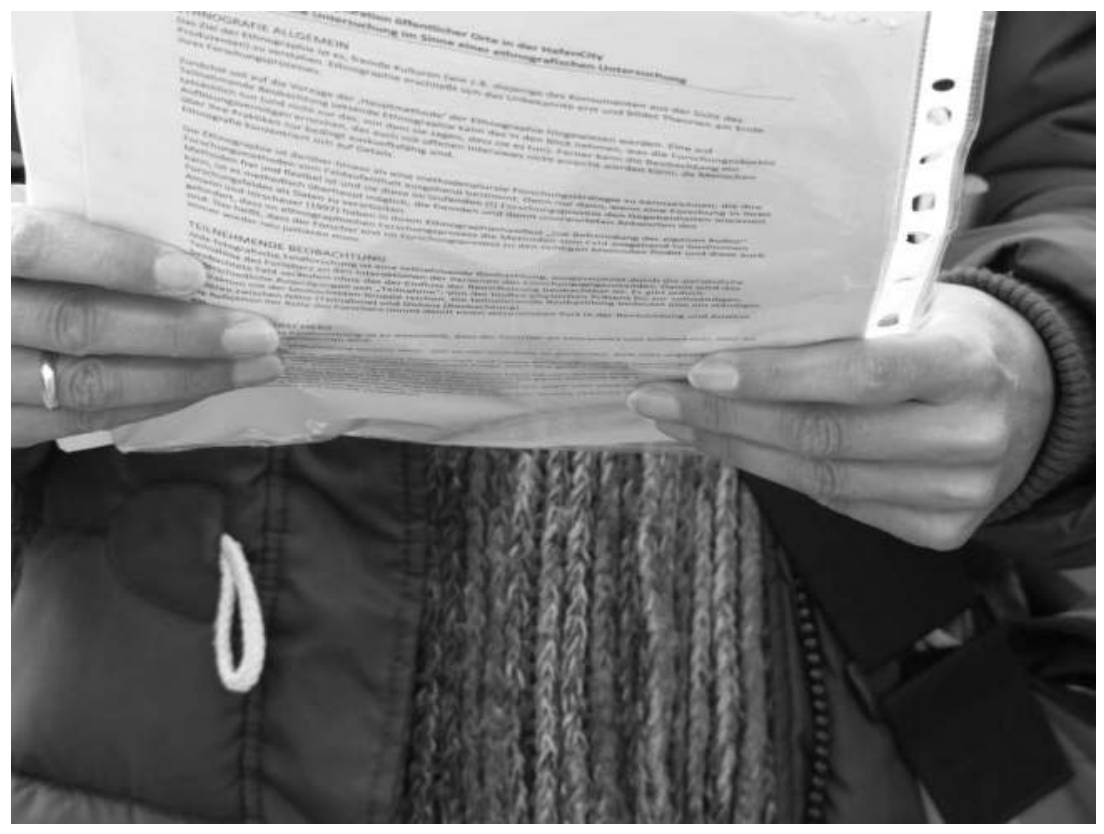

Figure 3.1 Scenes of the promise and the city. (Sonja Preißing) 
This transcript can hardly convey the loosening effect created by this quote and our amusement about it, as Cécile, Sonja and I realized on several occasions when we quoted it, in turn, to others. However, we liked the story and its comical dimension that had driven Maria first to write it down and then to read it to us. Comical because of the everyday "sound" of the back and forth between the elderly couple about an expectation that was awakened elsewhere and then disappointed on the spot. You had told me it is this way - and now it is different! A disappointment that results from a neglected everyday promise.

The fact that Maria chose to recall or "reenact" the articulation of the neglected promise is quite telling regarding one quality of promises: They lend themselves to be narrated after the fact. Not only the woman reminding her confident husband that he had promised something recalls a promise. Maria did the same - with another purpose. I quote it because it illustrates something else again: The narrative force of promises.

If promises lend themselves to being told and retold, we should be able to encounter these narrated promises all over the city in the shape of everyday talk, media representations and materializations. This is where my attention shifted after this first encounter: Once sensitized for promises in urban situations, other observations started to resonate and made me curious about the potential of promises for urban studies. I recalled students that, at different times, had become interested in a certain urban area in Hamburg because they had heard of a metro station that had been promised decades ago and was never built. On a different scale (because of the sheer size and degree of popularity of this infrastructure project), the construction site of Berlin Brandenburg airport (BER) produces a seemingly endless follow-up of (broken) promises that are of lasting media interest for being scandalized. Again, on an even larger-scale level, the unlikely growth of cities through migration could be traced back to, for example, the promise of more individual opportunities. The productive force of these and other promises, which are, for example, materialized as infrastructures, job markets or the multiplicity of possible subjectivities, can be conceptually grasped with assemblage theory. While the notion of urban assemblages directs our attention to the emerging, multiple and virtual modes of existence of the city (Farías 2010), to conceive of the city as a "promissory assemblage" helps to qualify the specific modality and the quality of attachments within and to these assemblages (Färber 2019). The city as a "promissory assemblage" allows one to think across different scales and points to the temporality of "future perfect" (Hetherington 2016) that has consequences on the endurance towards unfulfilled promises.

The city as a "promissory assemblage" helps us to analyze the centralizing dynamic, the "triumphalism of the urban" (Roskamm 2017, 9), which also provokes skepticism and fear. It is addressed in not only academic but also public discourse, especially in light of the allegedly relentless expansion of cities, a related overconsumption of resources and ongoing social segregation. Promises not only arouse positive expectations; they may be experienced as threats. 


\section{Different modalities of and attachments to promises: practices and objects of desire}

The equation of the city and the promise could easily be reproduced - and the rankings of cities that are published year by year are only one way to do so. The unfulfillment of these promises attached to, let us say a city that contains opportunities for specific job markets, will be lamented by all those whose expectations were not met after they had gone to that very city. Those who believe in urban promises, despite knowing better, may be qualified as "overconfident" regarding their expectations and the choices (i.e., moving to another city) they derived from that (Cardoso et al. 2017) - and this might perhaps hold true for the husband in Maria's story. Nevertheless, I propose another approach that takes a closer look at the different modalities of the promise and, subsequently, the way they entangle the city and collaboration. In order to do so, we may distinguish the promise as a practice, such as a speech act, and the promise as an object of desire.

In the most basic sense, the promise as a practice - to promise to do something - relates a promisor and promisee to each other. As a culturally modulated way of relating to each other, the promise has been studied from diverse perspectives, cf. philosophy, literature, rhetoric, law (Schneider 2005a). It is mostly its performative nature that is put forward in this literature. The performativity of the promise, as an illocutionary or commissive act (Austin 1962, 99, 156f.), is not primarily thought of as leading to the fulfillment of the promise but as a social bond with a certain quality.

Promises, therefore, produce a form of connection that is expected as rather reliable - although this is not necessarily the case and, as Austin puts it, only "plain-thinking" people would really believe "that our word is our bond" (Austin 1962, 10). However, the relationship between promisor and promisee is often evaluated according to the (improbable) fulfillment of the promise and, accordingly, gets attached to values such as reason and/ or rationality, responsibility, reliability and trustworthiness. This "intuitive judgment" is, according to Alan Habib, one reason why promises "are of special interest to ethical theorists, as they are generally taken to impose moral obligations. Thus an explanation of how such promissory obligations come about and how they function is necessary for a complete moral theory" (Habib 2008).

Although it is not the aim of this chapter to contribute to a "complete moral theory," this background may serve as a reminder about the ethical dimension and everyday moral affordances comprised in promises. This is, perhaps, one reason for its narrative force: The (necessary) problematization of ethical standards in everyday moral implications.

There are also multiple ways of de-fulfilling the promise by fulfilling it in a literal sense and not regarding its meant result (i.e., to drown somebody without killing him/her). Manfred Schneider explains that the existential and clever everyday de-fulfilling of promises implicates, among other 
things, more detailed regulatory efforts - all installed more or less in vain (Schneider 2005b). The promise that is not binding juridically but morally relates promisor to promise enhances creative evasive maneuvers. From Schneider's deconstructivist reading, we may retain that the relationship of promisor and promisee is precarious, productive and an object of reordering and/or re-regulating. It provides a difference in time and order between before and after the promise was uttered. In the end, the promise remains a quite elusive social bond to be monitored by those who are involved. However, it provides rich narrative material.

This leads to the second conceptual quality of promises as designating and materializing an object of desire. Two recent problematizations of the promise as a cultural form in late capitalism point out the disparity it entails: Sara Ahmed derives her interest in promises from the future-oriented expectations they raise. These are imbued with the desire, for example, for happiness:

The slide between the "I promise to" and "the promise of" is how promises are distributed, or shared. The promise of happiness is what makes some things promising, as if to share in things is to share in happiness. When something promises happiness, we have an idea of that thing as being promising. In receiving that something, we imagine the good things that will follow.

(Ahmed 2010, 30)

Conceived as such, happiness is, in her words, "crucial to the energy of 'forward direction' of narrative" (Ahmed 2010, 32), which could count as another vigor of the narrative force of the promise. While Sara Ahmed is mostly concerned with the diverse emotions attached to the convergence of happiness with the promise and its narrative force (Ahmed 2010, 236), Lauren Berlant distinguishes her approach from that of Ahmed: With the notion of "cruel optimism," she is "seeking out the conditions under which certain attachments to what counts as life come to make sense or no longer make sense, yet remain powerful as they work against the flourishing of particular and collective beings" (Berlant 2011, 13) Attachment for her "is a structure of relationality" (Berlant 2011, 13). Regarding Berlant, we can think primarily of connections that have limiting effects "as soon as the attachment becomes an end in itself" (Kemmer 2020, 177). Through the promise, we get attached to objects we desire, even though these might not be realized or we know will not add to our well-being, even to the contrary. Berlant encourages us to consider the multiplicity of contradictory qualities involved in promises and understand their enigmatic incoherence:

All attachments are optimistic. When we talk about an object of desire, we are really talking about a cluster of promises we want someone or 
something to make to us and make possible for us.... To phrase "the object of desire" as a cluster of promises is to allow us to encounter what's incoherent or enigmatic in our attachments ... as an explanation of our sense of our endurance in the object.

(Berlant 2011, 24)

The sense of endurance not only reminds us of the argument of the psychological study quoted above. The city could be thought of as one of these ambivalent objects of desire, provoking this incoherent and enigmatic attachment, articulated and/or contained by a cluster of promises. I encountered multiple expressions of this endurance in my research on the cultural transformation of Berlin after 1989, a kind of "nevertheless-ness" as expressions of defiance. Against the backdrop of intensive globalization of cities and their economies, it was interesting to analyze what the specific responses of the paths taken were in this city that had been divided for 30 years, during which specific everyday urban cultures and scenes had emerged. Would Berlin become a world city with the same globalized urban cultures as many so-called global cities in the decade before?

At the heart of that study about Berlin's possible "world-cityness," I observed and analyzed a moment in time, the beginning of the new millennium, that may count as a conjuncture, in the sense that economic and cultural disparities seemed to culminate. Attempts to organize this tension around the topos of Berlin as a "Creative City" materialized in a range of political goals, public-private initiatives, collective and individual engagement of actors in transnational cultural production, and historically rooted and locally invested alternative scenes (Färber 2014). The encompassing mode of subjectivity that was addressed and that resonated the "nevertheless-ness" was the entrepreneurial self (Bröckling 2007), enabled through its diverse rootings that ranged between migrant economies, DIY cultures and governmental self-employment programs.

Actually, it was the specific imaginary of Berlin as the city of bohemian, alternative lifestyles and weak economic power that offered the cultural reference where economic weakness and failure could be considered a resource. A whole range of expressions was created to articulate defiance in the "urban imagineering," understood as a distributed representational work with Berlin as its object (Färber 2011, 2014): The cultural articulation of the "city of imperfection" (Klein 2005, 255) enabled (successful) role models to appropriate this material and imagery space of Berlin in an essentially bohemian way. They came together here in Berlin as the "world club of international losers" (Litichevsky 2003, 20), such as self-labeled "universal dilettantes" (Lange 2005, 58), "urban dossers" (Bunz 2006) or "digital bohemia" (Friebe and Lobo 2006), that try to "get things done without any self-discipline" (Passig and Lobo 2008). These expressions - discursive and non-discursive - were modes of making sense of a paradox that was all too apparent: The tension between a stagnating economic situation that most 
citizens of Berlin found themselves in after 1989 "and" a thriving cultural sector that overshadowed these disparities (Graw 2014; Krätke 2004). This attitude or bearing reflects what Berlant pointed out as individual "striving and hopelessness," and that Berlin as a city had become an object of desire by the very work of a cluster of promises.

\section{Non-collaborative aspects of promissory collaboration in urban project work}

Collaboration and the promise do not relate to each other in the same way. They resemble each other in some respects. They are both basically relational concepts: The promise relates the promisor or the promised object to the promise, whereas collaboration relates different people to each other in a specific venture. We (may?) also have similar intuitive ethical judgments regarding reliability with respect to promises and to collaboration: Despite knowing better, we (want to) believe in promises coming true, similar to the expectation that those involved in collaboration will relate to each other seriously. Besides this resemblance, collaboration today is attached to certain positive expectations that it will make a difference to other modes of relating to each other. More specifically, collaboration brings with it certain promises about its results, rewards and social quality._As I have argued above, it is this idealization that deserves analysis and problematization. I will make suggestions regarding collaboration in urban settings in the following section.

Urban planning is an example of processes where multiple different professions collaborate and where, under the premises of the participatory planning paradigm, the range of actors that should be involved has grown to include nonprofessionals, such as local residents and businesspeople (see also the contribution of Bikbov in this volume). Gisa Weszkalnys traces the different practices that constitute the future building site of the inner-city area of Alexanderplatz in post-1989 Berlin "as a project" in her anthropological study of the planning process: "Meetings as well as the writing of documents, the drawing of plans and timetables, the setting of boundaries, the arrangement of tracks and pipes, and the selection of street lamps and paving materials, quite literally assembled Alexanderplatz" (Weszkalnys 2013, 98-9). While these practices refer to the genuinely interdisciplinary work of urban planners, other situations were explicitly meant to involve local inhabitants and, thus, responded to the ethically charged demands of the participatory planning paradigm - creating an "expert public" and a self-conscious positioning as citizens (Weszkalnys 2010). In order to distribute planning agency in these complicated collaborative situations, plans "arrange and distribute ... and gather up a welter of disparate knowledges and regulations" (Weszkalnys 2013, 101-2). These material devices are a condition or active part of the collaboration.

However, Weszkalnys' study is also an example of the volatility of urban planning. Together with social anthropologist Simone Abram, she points to 
the "elusiveness of promises" in urban planning (Abram and Weszkalnys 2013). They understand these elusive promises as unfolding "gaps," gaps that in the anthropological study of urban planning turn out to be gaps "between ideal, ideology and practice" and "fill themselves with things unplanned, unexpected and inexplicable, and with things that get overlooked and forgotten" (Abram and Weszkalnys 2013, 23). This spatialized thinking underlines the fundamental inconsistency of promises in the everyday of planners or citizens - be it to promise something or to believe in the promise of something. It also includes, in addition to the promisor and promisee, the multiple actors involved in situations that are "attuned" by the promise; that is, they are under the impression of the promise.

Studies of the articulation of the world-cityness of Berlin as a Creative City at the turn of the millennium mentioned above have shown that the conditions for its ambivalent attractiveness lay in the long-lasting imaginary of the city's bohemian, subcultural character (Lindner 1993; Schwanhäußer 2010; Stahl 2014). More specifically, different actors had made it their project to become part of this invention of the Creative City in the early years of the new millennium: From individual cultural entrepreneurs and all sorts of cultural institutions and media, to the city's administration and political representatives (Krätke 2004; Lange 2007; McRobbie 2016).

In addition to these actors, the plausibility of Berlin as a Creative City relied on all sorts of materializations: The "gap" opened up by the promise of the Creative City was filled with actors from the realms of politics, economy, media and culture and with, for example, statements and articles, reports, statistics, marketing campaigns, wasteland, literature, films and journals.

All these studies put an emphasis on the risks taken and the individual handling of the risk. In other words, they criticized how, despite a high degree and awareness of self-exploitation, individuals became attached to the promises of the Creative City, such as becoming successful entrepreneurs in the creative sector and reaching some kind of self-realization (McRobbie 2009; Steyaert and Beyes 2009). Engaging in this highly competitive field of a creative economy that, as a single sector, has only just been outlined by the administration and scientists, that is, by being made measurable (Färber 2008, 2014; Lange 2009), articulated the enigmatic incoherence of the attachment to the promise of the Creative City. These self-aware reflections stressed the aspects of endurance involved in this attachment. In other words, these close readings of how economic crisis and cultural production were articulated at that time allowed the detection of their stabilizing impact on the ambivalence between economic weakness, precarious urban realities and parallel attractiveness.

Acknowledging this simultaneous elusiveness and effectiveness of cityrelated promises is one step towards becoming sensitive to the idealizing aspects of collaboration and the expectations it raises. A closer look at the practices involved in the collaborative photo assignment in HafenCity highlights even non-collaborative moments in collaborating. 
Looking back at the assignment mentioned above in the context of the urban development site HafenCity, the photographers presented collaboration as the opposite of autonomy: During our go-along, we were, on the one hand, told by our two interview partners about the instructions for collaborative work, such as taking pictures from exactly the same places and perspectives each time, plus specific hours for taking these pictures. This information should be recorded in a form that could later be made available for the publication. However, these rules and material devices that should maintain the collaboration and help to care for it were experienced as not very inspiring. This is why one of the photographers tried to broaden the scope of the collaborative work and develop individual photographic projects simultaneously.

In our analysis, it was the temporality of working together in a project that urged and allowed for other temporalities to include a kind of autonomy from the project: Time was doubled and stretched. It was doubled in the sense that one did something else simultaneously (on one's own, not necessarily coordinated) while following the instructions; it was stretched in the sense that one did something else simultaneously that would possibly become part of a future project (Cuny et al. 2019, 70ff). With these temporal adjustments, the agreement regarding the rules of working together made it possible not to restrict collaboration to collaborating. Here, we get a sense of the conditions of the looseness of collaboration and its promise.

Analyzing the conditions for collaboration under the impression of the promise leads one to question the quality of collaboration as something stable, as attached to well-intended, socially ready for collaboration participants only. Instead, it brings forward the multiple temporalities of collaboration as an everyday practice that is complicated in the way that the future is already imagined as, for instance, "future projects," and prepared through non-collaboration in collaboration. It is no coincidence that we were able to observe non-collaborative aspects of collaboration and to analyze the specific time-space as one condition for both collaboration and non-collaborative practices in the context of project work. To work in projects can count as one of the time-spaces most susceptible for handling this elusiveness of promises in collaboration. Projects have a specific temporality because they are always determined, although they often take longer than expected. They also bring together people who are supposed to work together for exactly that period of time. Expectations are somewhat increased and explicitly addressed regarding a project because projects often only come about if they have been applied for - that is, presented based on a proposal - and approved beforehand. They have given a promise, so to speak, that, if approved, attunes the time-space to the specific group of people that collaborates in this project.

Set under the impression of the promise, this single situation may resonate with others that, for instance, apply for the same funding scheme or work within a similar collaborative paradigm. The projects and their promises 
may even amplify each other in a way that they reproduce similar ideas of the future of cities. HafenCity remains the controversial urban development site it has always been, but we can see from such a cluster of urban planning promises, to stay in this context, how the city emerges as an object of desire. However, is it necessarily this ambivalent object of desire that creates attachments of endurance? Are there other ways of relating to the promised city?

\section{Outlook}

In this chapter, I have drawn connections between unequal elements that articulate the city at different scales and in multiple settings. I took a closer look at different modalities of the promise, its ethical dimension and the place of collaboration in the setting that it offers. I tried to problematize collaboration and its slightly idealized perception with insights gained from conceptually analyzing the promise. I exemplified both the promise and collaboration regarding their special relationship to the city. Some of the insights from one case served as questions for the other. In this sense, the destabilizing potential of temporality in collaboration allowed the acknowledgment of the multiplicity of being detached in collaborating. This observation shed light on the incoherence of promises. The settings were specified as time-spaces of project work in the city and with the city as its object to analytically recognize this inconsistency of collaboration and (its) promises.

With the aim of strengthening the analytical potential of these different elements and in order to draw connections between these different settings and scales, I have proposed the concept of the city as a "promissory assemblage" (Färber 2019). Conceiving the city as a "promissory assemblage" should allow us in further research not only to work through multiscalar settings but also emphasize multiplicity and potentiality (Farías and Höhne 2015). The qualification as "promissory" allows that we address the performative power of the promise more precisely as relying on distributed agency, and the presence or absence as a result of the specific temporal and relational structure of the promise and the contradictory qualities found therein. To think of the city as a "promissory assemblage" acknowledges not only these multiple temporalities, its fugitivity, volatility and ephemeral nature but also endurance, duress and the contradictory qualities found in these relationships. They are stable and instable, precise and imprecise, and more and less loose.

Sarah Ahmed (2010) and Lauren Berlant (2011) have both stressed the fact that promises, often materialized as desirable objects, set the scene to narrate - and analyze - situations that people bear, stories of endurance and nevertheless-ness. If the notion of a "promissory assemblage" allows one to think about the simultaneity of different modes of relating to the promise, including looseness in addition to intensive attachment, we would also be able to reconsider endurance. With regard to the looseness of the 
promise regarding, for instance, its improbable fulfillment, and the ways of circumventing it - for instance in collaboration, as shown in the microanalysis of the photo-project - it is necessary to ask whether the stability of attachments has been overrated in the studies of Ahmed (2010) and Berlant (2011). Without already being able to give an empirically saturated answer to these questions, I would like to critically question my own work on Berlin's Creative City world-cityness: Can we also think of "urban dossers," "universal dilletantes" or the "digital bohemia," who are deeply detached from the promise of the Creative City? What were the situations or, more precisely, the projects from which collaborators detached themselves under the impression of the Creative City promise? What were the conditions for being perhaps only loosely attached to those promises? To find out the common features of situations where people detach themselves from promises may be as equally important as countering the idealization of collaborative practices, that is, in the humanities, by way of acknowledging that interand transdisciplinary collaboration is no longer the exception but the rule (Groth and Ritter 2019, 18).

However, there are attempts to conceive of these forms of "strategic detachment" where endurance is not a thing that people bear but becomes an "act of endurance" that even enables one to put the promise in a position of "stand by" (Kemmer 2020; Kemmer et al. forthcoming) - and reduce its enduring impression. Any analysis of everyday situations that complicates the quality of time, space and social bond will then be able to challenge idealized visions of the promise, collaboration and probably the relatively stable set of (moral) values derived from them.

\section{Bibliography}

Abram, Simone, and Gisa Weszkalnys, eds. 2013. Elusive Promises. Planning in the Contemporary World. New York: Berghahn Books.

Ahmed, Sara. 2010. The Promise of Happiness. Durham, NC/London: Duke University Press.

Austin, John L. 1962. How to Do Things with Words. Oxford, Clarendon Press.

Berlant, Lauren G. 2011. Cruel Optimism. Durham, NC: Duke University Press.

Bröckling, Ulrich. 2007. Das unternehmerische Selbst. Soziologie einer Subjektivierungsform. Frankfurt am Main: Suhrkamp.

Bruns-Berentelg, Jürgen, Angelus Eisinger, Martin Kohler, and Marcus Menzl. 2010. HafenCity Hamburg: Neue öffentliche Begegnungsorte zwischen Metropole und Nachbarschaft. Berlin: Springer Verlag.

Bunz, Mercedes. 2006. "Meine Armut kotzt mich an." zitty 4: 17-9.

Cardoso, Rodrigo V., Evert J. Meijers, Maarten van Hamm, Martijn J. Burger, and Duco de Vos. 2017. The City as a Self-Help Book: The Psychology of Urban Promises. IZA Discussion Papers 10693. Berlin: Institute of Labor Economics (IZA).

Cuny, Cécile, Alexa Färber, and Sonja Preissing. 2019. "Autonomie und Zusammenarbeit. Zur zeitlichen Dimensionierung kooperativer Fotografie- und Stadtforschung." In Zusammen arbeiten. Praktiken der Koordination und Kooperation 
in kollaborativen Prozessen, edited by Stefan Groth and Christian Ritter, 51-77. Bielefeld: Transcript.

Färber, Alexa. 2008. "Flourishing Cultural Production in Economic Wasteland. Three Ways of Making Sense of a Cultural Economy in Berlin at the Beginning of the Twenty-first Century." In Creative Urban Milieus. Historical Perspectives on Culture, Economy, and the City, edited by Martina Heßler and Clemens Zimmermann, 409-29. Frankfurt am Main/Chicago, IL: Campus Verlag.

Färber, Alexa. 2009. "Das unternehmerische ethnografische Selbst. Aspekte der Intensivierung von Arbeit im ethnologisch-ethnografischen Feldforschungsparadigma." In Horizonte ethnografischen Wissens. Eine Bestandsaufnahme, edited by Ina Dietzsch, Wolfgang Kaschuba, and Leonore Scholze-Irrlitz, 178-202. Köln: Böhlau Verlag.

Färber, Alexa. 2014. "Low-budget Berlin: Towards an Understanding of Lowbudget Urbanity as Assemblage." Cambridge Journal of Regions, Economy and Society 7: 119-36.

Färber, Alexa. 2019. "How Does ANT Help Us to Rethink the City and its Promises?" In The Routledge Companion to Actor-network Theory, edited by Anders Blok, Ignacio Fárias, and Celia Roberts, 264-72. London: Routledge.

Färber, Alexa, and Brike Otto. 2016. "Saving (in) a Common World: Studying Urban Assemblages through a Low-budget Urbanities Perspective." In Urban Cosmopolitics. Agencements, Assemblies, Atmospheres, edited by Anders Blok and Ignacio Fariás, 25-43. London: Routledge.

Farías, Ignacio. 2010. "Introduction: Decentring the Object of Urban Studies." In Urban Assemblages: How Actor-network Theory Changes Urban Studies, edited by Ignacio Farías and Thomas Bender, 1-24. London, Routledge.

Farías, Ignacio, and Stephan Höhne. 2015. "Humans as Vectors and Intensities: Becoming Urban in Berlin and New York City." In Deleuze and the City, edited by Hélène Frichot, Catherine Gabrielsson, and Jonathan Metzger, 22-44. Edinburgh: Edinburgh University Press.

Friebe, Holm, and Sascha Lobo. 2006. Wir nennen es Arbeit. Die digitale Bohème oder: Intelligentes Leben jenseits der Festanstellung. München: C.H. Beck Verlag.

Graw, Isabelle. 2014. "The Myth of Remoteness from the Market: Notes on Berlin's Rise as an Art Metropolis.” Texte Zur Kunst 24: 34-59.

Groth, Stefan, and Christian Ritter, eds. 2019. Zusammen arbeiten. Praktiken Der Koordination und Kooperation in kollaborativen Prozessen. Bielefeld: Transcript.

Habib, Alan. 2008. "Promises." Stanford Encyclopedia of Philosophy. Accessed September 12, 2019. https://plato.stanford.edu/entries/promises/

Hetherington, Keith. 2016. "Surveying the Future Perfect: Anthropology, Development and the Promise of Infrastructure." In Infrastructures and Social Complexity: A Companion, edited by Penelope Harvey, Capser Bruun Jensen, and Atsuro Morita. 40-50. London: Routledge.

Kemmer, Laura. 2020. "Free Riding Rio: Protest, Public Transport and the Politics of a Footboard." City \& Society 32, no. 1: 157-181.

Kemmer, Laura, Annika Kühn, Birke Otto, and Vanessa Weber. Forthcoming. "Standby Infrastructures." ephemera: theory \& politics in organization.

Klein, Christian. 2005. "Vom Glück des Scheiterns. Lebens- und Gesellschaftskonzepte in Kästners 'Fabian' und Regeners 'Herr Lehmann'.' In Scheitern und Biographie. Die andere Seite moderner Lebensgeschichten, edited by Stefan Zahlmann and Sylka Scholz, 255-64. Gießen: Psychosozial-Verlag. 
Krätke, Stefan. 2004. “City of Talents? Berlin's Regional Economy, Socio-Spatial Fabric and 'Worst Practice' Urban Governance." International Journal of Urban and Regional Research, 28: 511-29.

Kusenbach, Margarethe. 2003. "Street Phenomenology: The Go-Along as Ethnographic Research Tool." Ethnography 4: 449-79.

Lange, Bastian. 2005. "Culturepreneurs in Berlin: Orts- und Raumproduzenten von Szenen.” In Hotel Berlin - Formen urbaner Mobilität und Verortung. (Berliner Blätter 37), edited by Alexa Färber, 53-64. Berlin et al.: LIT Verlag.

Lange, Bastian. 2007. Die Räume der Kreativszenen. Culturepreneurs und ihre Orte in Berlin. Bielefeld: Transcript.

Lange, Bastian. 2009. "Governance und Netzwerke der Kreativwirtschaft.” In Governance der Kreativwirtschaft: Diagnosen und Handlungsoptionen, edited by Bastian Lange, Ares Kalandides, Birgit Stöber, and Inga Wellmann, 47-60. Bielefeld: Transcript.

Lassiter, Luke Eric. 2005. The Chicago Guide to Collaborative Ethnography. Chicago, IL: University of Chicago Press.

Lindner, Rolf. 1993. "Berlin. Zone in Transition." Anthropological Journal on European Cultures 2, no. 2: 99-111.

Litichevsky, Georgy. 2003. "Berlin - Hauptstadt des dritten Jahrtausends.” In Berlin Moskau / Moskau Berlin 1950-2000: Kunst aus fünf Jahrzehnten, edited by Berliner Festspiele, Pawel Choroschilow, Jürgen Harten, Joachim Sartorius, and Peter K. Schuster, 18-22. Berlin: Nicolai.

McRobbie, Angela. 2009. "Reflections on Precarious Work in the Cultural Sector." In Governance der Kreativwirtschaft. Diagnosen und Handlungsoptionen, edited by Bastian Lange, Ares Kalandides, Birgit Stöber, and Inga Wellmann, 123-38. Bielefeld: Transcript.

McRobbie, Angela. 2016. Be Creative! Making a Living in the New Culture Industries. Cambridge: Polity Press.

Passig, Kathrin, and Sascha Lobo. 2008. Dinge geregelt kriegen - ohne einen Funken Selbstdisziplin. Berlin: Rowohlt.

Petiteau, Jean-Yves, and Bernard Renoux. 1993. "Le Grand Desbois, Itinéraire d'un Docker à Nantes." Annales de la Recherche Urbaine 55-56: 126-39.

Rappaport, Joanne. 2008. "Beyond Participant Observation: Collaborative Ethnography as Theoretical Innovation." Collaborative Anthropologies 1: 1-31.

Roskamm, Nicolai. 2017. Die unbesetzte Stadt: Postfundamentalistisches Denken und das urbanistische Feld. Gütersloh: Birkhäuser.

Sánchez Criado, Tomás, and Adolfo Estalella. 2018. "Introduction. Experimental Collaboration." In Experimental Collaboration. Ethnography through Fieldwork Devices, edited by Tomás Sánchez Criado and Adolfo Estalella, 1-30. New York/ Oxford: Berghahn.

Schneider, Manfred. 2005a. "Dem Versprechen ent-sprechen. Kontraktuelle Sprachmanöver." In Die Ordnung des Versprechens, edited by Manfred Schneider, 395-419. München: Wilhelm Fink Verlag.

Schneider, Mandfred, ed. 2005b. Die Ordnung des Versprechens. München: Wilhelm Fink Verlag.

Schwanhäußer, Anja. 2010. Kosmonauten des Underground. Ethnografie einer Berliner Szene. Frankfurt am Main: Campus.

Stahl, Geoff, ed. 2014. Poor, But Sexy. Reflections on Berlin Scenes. Bern: Peter Lang. 


\section{Alexa Färber}

Steyaert, Chris, and Timon Beyes. 2009. "Narrating Urban Entrepreneurship: A Matter of Imagineering." In Governance der Kreativwirtschaft. Diagnosen und Handlungsoptionen, edited by Bastian Lange, Ares Kalandides, Birgit Stöber, and Inga Wellmann, 207-22. Bielefeld: Transcript.

Weszkalnys, Gisa. 2010. "A Citizenly Engagement with Place.” In Stoffwechsel Berlin. Urbane Präsenzen und Repräsentationen, edited by Alexa Färber, 112-27. Berlin: Panama Verlag.

Weszkalnys, Gisa. 2013. Berlin, Alexanderplatz. Transforming Place in a Unified Germany. New York: Berghahn Books. 


\section{Part II}

Shifting ethics of the urban

Historical case studies 


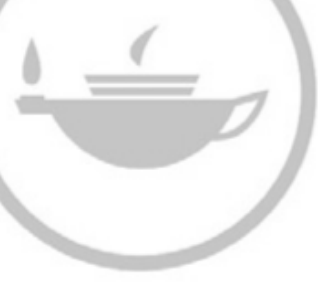

Taylor \& Francis Taylor \& Francis Group

http://taylorandfrancis.com 


\title{
4 Mégapoles, polyrhythmy, porosity
}

\author{
Tracing ideas of Mediterranean \\ urbanity in western scholarly \\ discourse
}

\section{Martin Baumeister}

Urbanity, urbanité, urbanità, urbanidad, Urbanität - all these concepts refer simultaneously to ideas and ideals of urban life and behavior, how a good life in the city ought to be, and urban form and space, how a city should be built and organized. Notwithstanding the terms' nuances in meaning and use in the different languages quoted here - and, one may add, of course, more examples from other languages - there is one common semantic core stemming from its etymological origin and shared historical trajectories. No single clear definition of the rather vague concept of urbanity and its equivalents in other languages exists, but one may define some of its basic features, such as its normative character, changing meanings and connotations over the course of time depending on different political, social and cultural contexts, and rootedness in specific Western traditions and discourses.

"Urbanity" became a key concept in 20th-century political and academic debates about the modern metropolis, urbanistic discussions and town planning. It, on the one hand, echoed in former uses and meanings going back to ideas of urbanitas in classical antiquity, the Renaissance and Enlightenment and, on the other hand, assumed new semantic and moral values while referring to urban modernity. "Urbanity" now relates to rapidly changing modern cities and metropolises, often in the sense of a backward-looking utopia, which contrasted an ideal past of urban life and forms with current decay, loss and destruction of what was considered as the "true" essence of the urban. Accelerated change fostered a sense of the past, according to, for example, the American sociologist Richard Wohl, who compared the city with "a palimpsest, marked with hasty erasures, corrections, rebuilding, and redirection. Each city is the sum of its history" (Wohl 1955, 53). It was in this situation, particularly in the recurrent evocation of a deeply felt "urban crisis" due to profound transformations of cities in postwar Europe and North America, that "urbanity" moved to center stage. ${ }^{2}$ As a core concept of 20th-century urbanism in debates about urban crisis and renewal, it bundled different, at times contradictory, ideas about the "good city" and "good urban life," depending on varying political, social or economic interests and constellations, but it was always imbued with historical notions related to a 
strongly Occidental imagination going back to the classical Mediterranean world as the quintessential site of origin of Western civilization.

This particular legacy is one of the main reasons why the French historian Denis Bocquet can affirm that "[u]rbanity as a value has always been marked by a certain Mediterranean nostalgia, and historians have illustrated how Mediterranean metropolises have constituted central paradigms in the evaluation of what makes a city urban" (Bocquet 2013, 237f.). This chapter uses Bocquet's affirmation as its starting point. First, it will look for the "Mediterranean flavor" inherent in the ideas of urbanity in the context of urban debates in the 20th-century Western world. Second, it will consider how elements of the idea of a "Mediterranean urbanity" contributed to defining a particular type of city in the Mediterranean region, one of whose characteristics is "the high value given to urbanity" (Bocquet 2013, 237). Finally, it will ask briefly for a reevaluation of this idea to consider Mediterranean cities as laboratories for discussing and realizing "good" urban life.

\section{A Mediterranean flavor}

"Urbanity" as an ideal of classical Greek and Roman antiquity referred to a cultivated elite of privileged free citizens compared to an unfree population of slaves, the rustic population of the countryside and uncivilized barbarians. The classical urbanitas was rediscovered and revitalized at courts in medieval Europe as an aristocratic form of refined cultivated manners as well as in urban contexts, such as Italian Renaissance cities, as an ideal of social and political emancipation of an emerging middle class in autonomous political communities. Urbanité romaine was defined in the Encyclopédie, edited by Denis Diderot and Jean-Baptiste d'Alembert in 1765, as la politesse de langage, de l'esprit \& des manières, attachée singulièrement à la ville de Rome (D.J. 1765, 487), that is, ancient Rome, while, in parallel with the transformation of Paris into a modern metropolis, what Walter Benjamin called "the capital of the 19th century" (Benjamin 1977), the concept related increasingly to the dynamics of modern urban life without completely losing its connotations of classical Roman urbanitas. Elements of the classical urbanitas also survived in 20th-century thought about the city and ideals of urban life. Lewis Mumford defined the city as the very essence of human culture in the introduction of his highly influential study "The Culture of Cities," published for the first time in 1938:

The city is the form and symbol of an integrated social relationship: it is the seat of the temple, the market, the hall of justice, the academy of learning. Here in the city the goods of civilization are multiplied and manifolded; here is where human experience is transformed into viable signs, symbols, patterns of conduct, systems of order. Here is where the issues of civilization are focused: here, too, ritual passes on occasion into the active drama of a fully differentiated and self-conscious society. (Mumford [1938] 1970, 3) 
Mumford, a New Yorker, conceived of the city as an archetypical polis-like spatial sample embodying a well-ordered, integrated, political, social and cultural entity, which seemed rather distant from the realities of the modern metropolis or industrial city as the emblematic urban phenomena of his time.

The international elite of modern architects organized into the Congrès Internationaux d'Architecture Moderne in their eighth meeting in 1951 during a discussion on the issue of urban public space had to confront the deeply changed situation for modern architecture in the postwar world. In their deliberations about the future of "the heart of the city," the architects evoked the classical Mediterranean tradition of the Greek agora, the Roman forum and the medieval Italian piazza as models for the creation of a free space in the center of the city, serving as a site for social encounters and leisure (Tyrwhitt et al. 1952). ${ }^{3}$ The Congrès Internationaux d'Architecture Moderne's references to classical urban tradition, however, remained on a rather abstract, formal level, while the architects were envisaging new forms of public space for consumerist societies, "including shopping malls, renewed downtowns and theme parks, that came to characterize urbanism in the rapidly decentralizing cities of the 1950s and later" (Mumford 2000, 215). At the same time, "urbanity," charged with many reminiscences of the classical urbanitas, was also relaunched as a polyvalent slogan in the criticism of functionalist urbanism that was proclaimed by the Congrès Internationaux d'Architecture Moderne and their followers. The landscape architect and city planner Christopher Tunnard teaching at Yale University in 1953, for example, made a sweeping condemnation of technocratic urbanism:

"Utilitarian" city planning can never accomplish its purpose [...] It does not include the architectural solution. Who cares about the plan of the Piazza or Piazetta? The plan only provides open spaces; it is the architecture that brings everything to life [...] All the great town-planning schemes of the past have been successful because of their architecture, but we have forgotten this elementary fact. Ensembles of great architecture! Settings for the human drama.

(Tunnard 1953, 223)

Like Mumford, Tunnard saw the city as a stage for social life, but, contrary to his compatriot, referring to the model of historical European cities such as Rome and Venice, he celebrated the crucial role of monumental buildings and the aesthetics of "great architecture" in shaping human life in the city.

The rise of urbanity as a key concept in urbanist debates in West Germany is generally attributed to an often-quoted lecture given at the general assembly of the Deutscher Städtetag (the Association of German Cities) in Augsburg in 1960 by the economist Edgar Salin. He defined his topic as a mindset or kind of habitus, as the "education [Wohlgebildetheit] of body, soul and spirit [...] as well as the fruitful participation of the human being as a polis being [Polis-Wesen] in his own [...] political sphere" (Salin 1960, 14). ${ }^{4}$ 
The perfect ideal of urbanity for Salin had been reached by the polis of Athens in the era of Pericles but could never be realized again. Evoking "the clarity of southern light" (Salin 1960,13) but neglecting the highly exclusive character of the Athenian democracy, he advocated a strictly political understanding of urbanity, characterized by the free autonomy of the citizens and municipal democracy. In Salin's elitist view, deeply imbued by a neohumanist ethos, urbanity was incompatible with the age of masses. In 1970, he declared the death of urbanity, whose last remnants or first new beginnings in Germany had vanished, he maintained, under the terror and in the gas chambers of the "Third Reich" (Salin 1970, 874).

At the same time as Salin was proclaiming that urbanity - in his view a moral or spiritual quality - could not be created by politicians, architects or planners, the term emerged as a key concept used by experts who focused on spatial dimensions of urban development and defined the crisis of the city as one of urban form resulting from functionalist planning. Following Jane Jacobs's plea for urbanity as an objective for urban planning (Jacobs 1961), the West German sociologist Heide Berndt, for example, complained about the loss of urbanity that, in her view, was due to "a lack of spaces which by their design invite urban behavior and are able to integrate urban ways of life, diversity and the heterogeneity of social functions" (Berndt 1984, 471). In the 1980s and 1990s, the sociologists Hartmut Häußermann and Walter Siebel $(1987,1992)$, in the face of the deep transformation of cities following the industrial revolution and the triumph of capitalism, argued for a historization of the concept of urbanity, criticizing an approach which focused exclusively on architecture and urban form. They deemed the traditional ideas of urbanity were obsolete but tried to revitalize the concept by redefining classical political ideas of urbanity in a democratic sense. For them, the term meant more than a stimulating design of urban spaces and a variety of cultural offers: "Urbanity refers always to an idea of the right life. It is also characterized by the economic, social and political opportunities which a city offers to each citizen" (Häußermann and Siebel 1992, 6).

Häußermann and Siebel's quest for a "new urbanity" (1987) represented only one aspect of a concept that continuously absorbed different meanings comprising social, cultural, moral and political aspects and oscillating between two dimensions, referring to a series of characteristics of city dwellers as a mindset or way of life and/or to the organization of urban space, the role of architecture and its aesthetic values. "Urbanity," in this sense, was always a relational category, marking a counterpoint to the rural world but, as far as modernity is concerned, to particularly urban phenomena, such as segregation and inequality, urban sprawl or suburbia.

\section{Varieties of Mediterranean urbanity}

Considering the (Euro-)Mediterranean area, the concept of urbanity, due to a relatively late wave of urbanization far into the 20th century, is deeply 
marked by the contrast between the rural and the urban and by the central role of history. In the postwar years, from the 1950s to the 1970s, the countries bordering the Mediterranean Sea were experiencing a deep transformation from more or less agrarian to predominantly urban societies, while old metropoles, such as Barcelona, Rome, Athens, Istanbul or Cairo, grew exponentially due to mass immigration (Leontidou 1990). Simultaneously, one could observe two opposing tendencies regarding the role of cities and urban society in scholarly attempts to conceptualize the Mediterranean as a particular area, just when, in parallel, the concept of urbanity became crucial in Western urban debates. At the end of the 1950s, a new academic discipline, Mediterranean Anthropology, began to be established by social anthropologists from an Anglo-Saxon background, who applied their methods and approaches, developed in a non-European colonial context, to a region which, in many aspects, was considered the cradle of modern Western culture and which these scholars now conceived as a stable archaic world, characterized by a set of apparently premodern values, such as honor, shame and "amoral familism" (Davis 1976). Historians, however, had a rather different outlook on the region. In 1949, Fernand Braudel had published the first edition of his monumental thèse on La Méditerranée et le monde méditerranéen à l'époque de Philippe II [The Mediterranean and the Mediterranean World in the Age of Philipp II], where he studied the Mediterranean of the 16th century as an espace mouvement, an urban civilization woven together by routes and cities, which were nodal points in a dense network of interconnections and exchanges. Braudel was particularly interested in the economic and communicative functions of cities; he didn't care much about urban centers and metropoles as focal points and hotspots of a specific culture and way of life:

The human unity of the Mediterranean lies in this space filled with routes, with lines and centers of power. Whatever its form, its architecture or civilization that illuminates it, the Mediterranean town creates routes, and is simultaneously created by them.

(Braudel 1966, 254) $)^{5}$

In an important reconceptualization of the Braudelian Mediterranean, the British scholars Peregrine Horden and Nicholas Purcell called this phenomenon "connectivity"; towns, for them, were crucial elements of a connectivity of micro-regions which, in their interpretation, form the whole of the Mediterranean (Horden and Purcell 2000).

Braudel's vision of the Mediterranean urban world implied a rather emphatic idea of a Mediterranean civilization beyond its sober functionalism, characterized by the primacy of the city. Other historians, such as Maurice Aymard, argued that the Mediterranean was the region where modern urbanism, with Hippodamus of Miletus in the 5th century BC, had its origins. He highlighted the square, piazza, plaza - a recurrent element of discourses 
on urbanity - as the true center of social life, an essential characteristic and constant element of the Mediterranean city since the times of the Greek agora and the Roman forum, "the site of the encounters and the words, of the citizens' meetings and mass demonstrations, of the solemn decisions and the executions" (Aymard 1987, 144, 152 f.). There are some attempts to create a typology of the Mediterranean cities according to their respective historical, political and cultural settings, such as the Greek polis, the Roman, Arab and the Byzantine city, or the medieval city states (Guarracino 2007, 60-7, referring to the Italian American medievalist Roberto S. Lopez), but Denis Bocquet rightly maintains that "Mediterranean cities, in their diversity, [...] can't be reduced to a static category or type," however general it would be (Bocquet 2013, 235).

History, a past in the sense of a longue durée, is a crucial element in conceiving an ideal type of Mediterranean city and the idea of urbanity as one of its aspects, but one always ends up in the dilemma of how to reconcile historical change with a supposed timeless essence of the Interior Sea. This becomes particularly clear in the French concept, coined by the historian of classical antiquity Claude Nicolet, of mégapole méditerranéenne, which is not to be confused with the term mégalopole (Nicolet et al. 2000). Mégapoles are cités-monde, exceptional, quasi eternal "world-cities" in a very specific sense, which cannot be reduced to their period of splendor but have survived the vicissitudes of history:

The mégapole is a Mediterranean peculiarity because it owes its existence to the longue durée and memory. The urban history of the Mediterranean hereby becomes an espace-temps, a self-centred space-time, charged with an immeasurable energy: Even destroyed civilizations re-emerge, just like the erased Hellas, successively covered by Rome, the Barbarians, Christianity, Byzantium, Ottoman, Mongol, Arab and Turkish Islam, in order to reappear in 19th century neo-Hellenism and nowadays one of the symbols of Europe.

(Ilbert 2016, 909)

History is dissolved in myth: The mythical past, the urban imaginary, defying destruction and oblivion, becomes a constitutive element of Mediterranean mégapoles such as Rome, Alexandria, Venice or Constantinople-Istanbul, characterized, according to Ilbert, by their size, the duration and continuity of their past, and their urbanity, still more by la fonction catalysatrice de l'urbanité, that is to say that leur environment "fait monde" (Ilbert 2016, 910). In this context, the concept of urbanity in all its vagueness refers to the mégapoles méditerranéennes as models of civilization, in analogy to Paul Valéry's well-known dictum of the Mediterranean Sea as a dispositif [...], une véritable machine à faire de la civilisation $(1951,317)$.

Urbanity, as one of the core elements of the concept of mégapole, appears as a rather abstract matrix of a general form of (Western) civilization beyond 
the reality of a concrete urban society or space. Something similar occurs in the equation of mégapole and cosmopole, as suggested by Robert Ilbert (2016, 909), who builds on a long tradition of associating the Mediterranean with particular traditions of cosmopolitanism. This is particularly true for port cities, which can be seen as the quintessential model of the Mediterranean city, "vectors of the transmission of ideas," according to David Abulafia (Mucem 2017, 30) and "visible expression of the Mediterranean space" (Borne 2017, 353). Port cities, such as Barcelona, Tanger, Genoa, Alexandria, Izmir, Beirut or Istanbul, are considered cradles of proto-globalization and, therefore, the origins of cosmopolitanism have been attributed to them as well (Driessen 2005, 2016, 313). The prototype of this "Mediterranean cosmopolitanism" are Ottoman port cities during the reform era of the Empire in the 19th and early 20th centuries, enjoying a privileged relative autonomy, which opened a formalized access to municipal institutions for notables, elite minorities from different religious, cultural and ethnic backgrounds, accentuated cultural difference and maintained urban coexistence at the same time (Ben-Yehoyada 2014, 115 f.; Lafi 2013). This ancien régime type of imperial cosmopolitanism, embodied in the millet system, was not so much a sublime ideal but rather a mundane administrative practice related more to a model of "a continuously renewed contiguity of established, recognized and often responsible groups" (Ilbert 1991, 20) than to the idea of a melting pot. It changed under the impact of European colonialism and came to an end with the triumph of nationalism and the nation state (Giaccaria 2019, $94 \mathrm{ff}$ ). The cosmopolitan imagination about the Mediterranean, beyond political and social realities, "elitist in its formulation and content" and privileging "formal labels over content," was part of a broader Mediterranean discourse emerging in the context of European colonialism (Giaccaria 2019, 87, quoting Will Hanley); it erased the memory of practices and experiences of shared governance and of dealing with diversity developed in the Ottoman Empire by Western visions of cosmopolitanism where coexistence was identified with multicultural tolerance. On the one hand, the effect of recent European conceptions of cosmopolitanism on the Mediterranean was "not a mere revival of ancient philosophical ideals but rather part of a more complex process of reading societies that had been subjected to domination" (Lafi 2013, 328). On the other hand, the image of the Ottoman port cities as the Mediterranean opposite of nationalism "became an object of paradoxical nostalgia for a moment that emblematized a certain image of modernity - urbaneness, refinement, and inter-cultural co-existence and conviviality" (Ben-Yehoyada 2014, 116).

While Naor Ben-Yehoyada has used the oxymoronic formula of "nonModern modernity" for the case of Mediterranean cosmopolitanism in the 19th and early 20th centuries (Ben-Yehoyada 2014, 116), other scholars have tried to categorize aspects of what they consider as traits of a specific Mediterranean urbanity also in other forms of contrast to dominant ideas of modernity. One of the most influential thinkers in current debates of urban theory, the 
French philosopher and sociologist Henri Lefebvre, goes so far as to attribute a specific capacity of resistance against capitalist modernity to Mediterranean cities. He stresses the deep historical roots and traditions of Mediterranean cities, particularly as prototypes of city-states, whose origins often date back to Ancient Greece. In an article published together with Catherine Régulier, the late Lefebvre distinguished Nordic cities, according to him, communities guaranteed by contractual, juridical relations, by oaths, pacts and charters, from the Mediterranean cities which "appear to have always lived and still live within a regime a compromise between political powers" (Lefebvre and Régulier 2000, 233). Lefebvre and Régulier perceive a "Mediterranean pulse," a kind of rhythm of street life, of the façades of the buildings, of the interchange between public and private, between outside and inside (Sarkis in Ben-Yehoyada 2013, 66). According to them, Mediterranean cities are characterized by a certain theatricality: Urban space "becomes the site of a vast scene-setting [...] where are shown all social relations and their rhythms. Rituals, codes and relations become visible and are acted out" (Lefebvre and Régulier 2000, 236). However, the two authors define what they call their "polyrhythmy" as the main feature of Mediterranean cities, a result of their social segmentation and fragmentation, and also a way of coping with it. In this view, Mediterranean cities are made of a series of enclaves - ethnic or similar - that are more connected to corresponding enclaves in other Mediterranean cities than to each other (Sarkis in Ben-Yehoyada 2013, 66): "The very idea of centrality is refused because each group, each entity, each religion and each culture considers itself a centre [...] The polyrhythmy of Mediterranean cities highlights their common character through their differences" (Lefebvre and Régulier 2000, 239). Polyrhythmy facilitates the resilience of Mediterranean cities, notwithstanding their weakness, across historical time:

All the conquerors have conquered the cities, but all the cities have resisted. How and why? In our view, by times and rhythms. Which underscores the solid and consistent character of urban times in the Mediterranean in relation to politically dominated space.

(Lefebvre and Régulier 2000, 238)

Even in modern mass tourism, which has become essential for many Mediterranean regions and cities, Lefebvre and Régulier discover a dimension of continuity, because "in a curious way" it "prolongs the historical problematic of conquest" (Lefebvre and Régulier 2000, 238).

Iain Chambers (2008) has taken up Lefebvre and Régulier's idea of the resilience of the Mediterranean city in his interpretation of Naples as a configuration of modern life of its own. Chambers uses the metaphor of a "porous modernity," borrowing an image coined by Walter Benjamin and Asja Lakis that refers to the spongy tufo, the tuff, as the typical rock of the city under the volcano (Benjamin and Lakis 1972). Chambers sees the city's "porosity" in its capacity to soak up external elements, to embody and incorporate 
foreign elements and external pressure while maintaining its initial form (Chambers 2008, 81), an argument that follows Lefebvre and Régulier's idea of the Mediterranean's extraordinary power of resilience and persistence against the forces of historical change. Naples appears as the opposite to the "modern myth of the rational organization of urban space, production, labor and profit" that "continues to be interrupted, decomposed, and deviated by innumerable pockets of social resistance, mercantilism, barter, corruption, and crime" (Chambers 2008, 73-4). For Chambers Naples is connected to other non-Occidental cities "in its uneven rhythms and volatile habits" and, echoing the idea of the mégapole, to an "emerging metropolitan worldliness" (Chambers 2008, 86). Naples, according to the British professor of cultural and postcolonial studies teaching in the regional capital of Campania, questions the traditional Western understanding of urban life, architecture and planning. Varying Baudelaire's famous definition of modernity as le fugitif, le transitoire, le contingent (Baudelaire 2010), he analyzes Naples as a model of a non-Western modernity:

Participating in progress without being fully absorbed in its agenda, Naples [...] reintroduces the uneven and the unplanned, the contingent, the historical. Viewed and, above all, lived in this manner, the interrogation posed by Naples returns the question of the city to the relationship between politics and poetics in determining our sense of the ethical and aesthetic.

(Chambers 2008, 81)

He explicitly addresses the ethical dimension of urbanity, urbanism and urban culture in this rather general, impressionist way. He proposes an alternative form of urbanity which is far away from classic ideas of urban decorum, refinement and equilibrium and established ideas of respectability and order by presenting Naples as an emblematic city, as the representation of a "porous" modernity. With Lefebvre and his intellectual comradein-arms, the Italian sociologist Franco Cassano, the advocate of "Southern thought" as a radical alternative to Western modernity (Cassano 2012; Cassano and Fogu 2010), Chambers shares a "rhapsodic," romantic view of a timeless Mediterranean culture, ${ }^{6}$ which is able to resist all the blows and impacts of history, as well as the idea of the city as an embodiment of Southern culture, a variety of "Mediterraneanism" - an essentializing, homogenizing and exoticizing view of the Mediterranean - turned positively. Chambers sees Naples as a "critical city," "perhaps emblematic of the city in crisis, of the city as crisis" (Chambers 2008, 80, author's emphasis). His idea of crisis, however, is more metaphysical than historical, "leaving us with a profoundly metropolitan interrogation of the enigma of what Heidegger once called the nebulous quality of life" (Chambers 2008, 80).

Chambers does not grasp the deep sense of urban crisis linked with the profound, almost violent, transformations of Mediterranean cities and 
cityscapes in concrete historical moments. Like other South European cities, Naples after the Second World War was heavily affected by mass immigration, "informal" urban sprawl beyond legal regulation, speculation and corruption. ${ }^{7}$ Later on, Euro-Mediterranean cities had to confront the strong repercussions of the so-called financial crisis of the 2010s. It is these trajectories that the Greek geographer Lila Leontidou (1993) explains in a strictly binary model, opposing (Euro-)Mediterranean cities to what she sees as the mainstream Anglo-American model. As a general cultural background for this opposition, she hints at the "classical" historical argument, explicit, or at least implicit, in all attempts to conceptualize a general type of Mediterranean city, "the complex interweaving of traditional, modern and postmodern conditions," the coexistence of many levels and cultures in Southern European cities (Leontidou 1993, 961). However, above all, she stresses a particular Southern urbanism, a pro-urban ideology which identifies the city with progress and cultural life, bringing forth "urban eutopias," sites of well-being and good life, contrary to a supposed Northern anti-urbanism, wherein cities are "dismal and violent dystopias" and the "rural idyll" is privileged (Leontidou 1990, 257-9, 2014, 558). "Southern urbanism" entails some essential characteristics of Mediterranean cities, of Southern cultures and ways of life. It constantly brings out people into the streets and piazzas, creating a vibrating urban public sphere. It inspires informality and spontaneity, which comprise a massive demand for the "right to the city" (Leontidou 1990, 2010) and which, in the context of the crisis of the 2010s, have been the objective of a fierce offensive, of "quasi-Orientalist" attacks from the North, from European power elites (Leontidou 2014). This sense of "Southern urbanism" shares some core elements with Lefebvre and Régulier's "rhythmanalysis" of Mediterranean cities and Chambers' formula of an alternative "porous modernity." It stems from the claim of the "subversive function of Mediterranean cities on all levels, from the epistemological and theoretical to the political one, and from the socio-cultural to the quotidian one, [...] unbearable to North European dominant classes" (Leontidou 2014, 554). Informality, concerning practices of land use, housing and petty economic activities beyond legal regulations, is all-pervasive in Southern cities involving all social groups, and, as Leontidou maintains, contributes to the emergence of urban social movements. Spontaneity, in Antonio Gramsci's understanding as unmediated popular action, implies "la joie de vivre [...] embedded in Mediterranean urban eutopias" (Leontidou 2014, 558, author's emphasis), ${ }^{8}$ in a Lefebvrian exaltation of the festival, l'usage éminent de la ville (Lefebvre 1968, 11).

Similar to Chambers and Cassano, Leontidou is undoubtedly a "militant Mediterraneanist" who struggles against a marginalization and denigration of the Mediterranean, which she and her comrades-in-arms, in a larger perspective, link with the "Global South" in terms of negative difference compared to the Modern (Giaccaria and Minca 2010, 355-7). Her Mediterranean eutopia is constructed against the menace of a hegemonic North: It is the cradle and the powerhouse of popular creativity and revolt against the 
exploitative "rationality'-as-austerity," against the EU democratic deficit and the Southerners' "othering" by the North (Leontidou 2014, 561). Her idea of "Southern urbanism," highlighting informality and spontaneity, has a lot in common with other scholarly attempts to conceptualize a distinct Southern and/or Mediterranean type of city or urban qualities expressing particular ideals of urban life and form similar to those discussed above. Examples are the mégapole as a classic Mediterraneanist matrix and cosmopolitan port cities as peculiar historical settings of dealing with diversity, both varieties of a Eurocentric universalism where the city appears as a model and core of a (Western) civilization, and Southern "polyrhythmy" resisting Northern, respectively, Western standardization and "porosity" as a capacity of selfassertion by soaking up foreign pressure and influences. These qualities, together with informality and spontaneity, according to the school of militant Mediterraneanists, constitute an "alternative modernity" which fuels a political project against neoliberal capitalism and offers its own urban "eutopia." At the same time, however, the protean Mediterranean urbanity as a promise of beauty and "authentic" good urban life is appropriated by the capitalist economy in the form of Mediterranean "façades," of a "Mediterraneanization" of city centers far beyond Southern Europe with cafés, bars and artificial beaches for urban leisure and consumerism (Kaschuba 2017), and "Mediterranean" architecture as a globalized artificial eclectic architectural style sold to inhabitants of North American suburbia or gated communities in Istanbul (Sarkis in Ben-Yehoyada 2013, 80).

\section{Re-considering a protean concept}

All these concepts suffer from the shortcomings of the ideas of urbanity and the Mediterranean simultaneously: Their implicit or explicit normativity, the tendency to essentialization, be it by the abstraction from social, political, cultural or economic contexts and conditions, be it by the transformation of history into timeless myth and, finally, moral "hypertrophy," a way of emphatic ethical-political overcharging, evident, for example, in declaring the Mediterranean mégapole as something like the "navel of the world" or in identifying the Mediterranean with the "Global South" as a whole. A common main deficit, moreover, is a certain Western bias, while "West" and "North" coincide on the dominant Occidental moral maps. This tendency characterizes even the militant Mediterraneanists' claim for an 'alternative modernity." They, although referring to the South as a whole, do not consider adequately in their Euro-Mediterranean narrowness de facto, either the Eastern or the Southern shore of what Romans called Mare Nostrum. There is no real alternative to widen the perspective beyond Eurocentric fixations and limitations. The best example, up to now, is the recent reevaluation of the concept of Mediterranean cosmopolitanism by stressing Ottoman traditions and practices against Western visions and ideas. This points to another challenge: The need to historicize what seems like 
a timeless essence of Southern urbanity and urbanism, which also entails considering the fragmented, multifaceted world of Mediterranean cities and cityscapes. Finally, one must take seriously the relational character of the ideas of urbanity and the Mediterranean, which must be understood in their "liquid" spatialities against the "ossified geographies of the Mediterraneanist tradition" (Giaccaria and Minca 2010, 360). This is how Mediterranean cities could be (re-)discovered as fascinating laboratories for theorizing and analyzing "good" urban life and forms as well as politics and practices to implement and realize them.

\section{Notes}

1 See Sonne (2014) for an instructive outline of the concept's history. Sonne discusses, among others, the texts by Berndt (1984), Häußermann and Siebel (1987, 1992), Mumford (1970), Salin (1960), Tunnard (1953) and Wohl (1955) quoted below; see Binder (2006) on the emergence of "urbanity" as a key concept in urbanistic debates of the 1960s and 1970s; see Ege (2018) for a critical reassessment of the normative implications of "urbanity."

2 See Weaver (2017) for the changing meanings and uses of the term "urban crisis" in postwar North American and European debates.

3 See particularly: Giedion, S. "Historical Background to the Core." and CIAM 8. "Discussion on Italian Piazzas." Ibid., 17-25, 74-81.

4 This quote, as well as other quotes from foreign languages, has been translated into English by the author of this article if not marked otherwise.

5 The English translation is from Mucem $(2017,26)$.

6 Peregrine Horden defines the "rhapsode," "a descendant of the romantic Mediterraneanist of the nineteenth century," as one of four alternatives of writing history of the Mediterranean after Braudel and the critique of "Mediterraneanism" in the age of postmodernism (Horden 2005, 28). Concerning the critique of "Mediterraneanism," see the writings of Michael Herzfeld (1987, 2005).

7 The most famous denunciation of corruption in the urban development of Naples as an emblematic case of postwar Italy is Francesco Rosi's film from $1963 \mathrm{Le}$ mani sulla città (Hands over the City). Castells (1977) uses the concept of "urban crisis" in a seminal study referring to the dynamics of mass urbanization and urban social movements in Southern Europe in the 1960s and 1970s.

8 Leontidou $(2014,560)$ refers to Gramsci (1971).

\section{Bibliography}

Aymard, Maurice. 1987. “Espacios.” In El Mediterráneo, edited by Fernand Braudel, 135-57. Madrid: Espasa-Calpe.

Baudelaire, Charles. [1863] 2010. Le peintre de la vie moderne. Paris: Éd. Du Sandre.

Ben-Yehoyada, Naor. 2013. "The Sea of Scales and Segments. Interview with Hashim Sarkis and Michael Herzfeld." New Geographies 05: 59-80.

Ben-Yehoyada, Naor. 2014. "Mediterranean Modernity?" In A Companion to Mediterranean History, edited by Peregrine Horden and Sharon Kinoshita, 107-21. London: John Wiley \& Sons.

Benjamin, Walter. 1977. "Paris, die Hauptstadt des XIX. Jahrhunderts [1935]." In Walter Benjamin. Illuminationen. Ausgewählte Schriften 1, edited by Siegfried Unseld, 170-84. Frankfurt am Main: Suhrkamp. 
Benjamin, Walter, and Asja Lakis. 1972. "Neapel (1925)." In Walter Benjamin. Gesammelte Schriften, vol. IV.1, edited by Tillman Rexroth, 307-16. Frankfurt am Main: Suhrkamp.

Berndt, Heide. 1984. "Urbanität.” In Handwörterbuch zur Kommunalpolitik, edited by Rüdiger Voigt, 468-72. Opladen: Westdeutscher Verlag.

Binder, Beate. 2006. 'Urbanität als 'Moving Metaphor'. Aspekte der Stadtentwicklungsdebatte in den 1960er/1970er Jahren." In Stadt und Kommunikation in bundesrepublikanischen Umbruchszeiten, edited by Adelheid von Saldern, 45-63. Wiesbaden: Franz Steiner.

Bocquet, Denis. 2013. "Challenges to Urbanity in Contemporary Mediterranean Metropolises. New Urban Forms, Dynamics, Boundaries and Tensions." New Geographies 05: 235-43.

Borne, Dominique. 2017. "L'Europe réinvente la Méditerranée (1815-1945).” In Histoire de la Méditerranée, edited by Jean Carpentier and François Lebrun, 307425. Paris: Éditions du Seuil.

Braudel, Fernand. 1966. La Méditerranée et le monde méditerranéen à l'époque de Philippe II. Vol. I. Paris: Armand Colin.

Cassano, Franco. 2012. Southern Thought and Other Essays on the Mediterranean. New York: Fordham University Press.

Cassano, Franco, and Claudio Fogu. 2010. "Il pensiero meridiano oggi: Intervista e dialoghi con Franco Cassano." California Italian Studies 1, no. 1: 1-14. Accessed June 15, 2019. https://escholarship.org/uc/item/2qf1598v.

Castells, Manuel. 1977. Ciudad, democracia y socialismo: la experiencia de las asociaciones de vecinos en Madrid. Madrid: Siglo XXI.

Chambers, Iain. 2008. Mediterranean Crossings. The Politics of an Interrupted Modernity. Durham: Duke University Press.

D.J. [Louis de Jaucourt]. 1765. "Urbanité romaine.” In Encyclopédie ou Dictionnaire raisonné des sciences, des arts et des métiers. Vol. XVII ${ }^{\mathrm{e}}$. Venerien-Z, edited by Denis Diderot and Jean Le Rond d'Alembert, 487-8. Neuchâtel: Samuel Faulche [Paris: Briasson].

Davis, John. 1977. People of the Mediterranean: An Essay of Comparative Social Anthropology. London: Routledge \& Kegan Paul.

Driessen, Henk. 2005. "Mediterranean Port Cities: Cosmopolitanism Reconsidered." History and Anthropology 16: 129-41.

Driessen, Henk. 2016. “Cosmopolitisme.” In Dictionnaire de la Méditerranée, edited by Dionigi Albera, Maryline Crivello, and Mohamed Tozy, 313-6. Arles: Actes Sud.

Ege, Moritz. 2018. "Urbane Ethiken und das Normative der Urb-anität - ein Diskussionsbeitrag." In Andere Urbanitäten. Zur Pluralität des Städtischen, edited by Brigitta Schmidt-Lauber, 169-92. Cologne: Böhlau.

Giaccaria, Paolo. 2019. "Cosmopolitanism. The Mediterranean Archives." In The Mediterranean Other - the Other Mediterranean, edited by Medardus Breh1, Andreas Eck1, and Kristin Platt, 79-103. Paderborn: Ferdinand Schöningh.

Giaccaria, Paolo, and Claudio Minca. 2010. "The Mediterranean Alternative." Progress in Human Geography 35, no. 3: 345-65.

Gramsci, Antonio. 1971. Selections from the prison notebooks, edited by Quentin Hoare and Geoffrey Nowell Smith. New York: International Publishers.

Guarracino, Scipione. 2007. Mediterraneo. Immagini, storie e teorie da Omero a Braudel. Milan: Bruno Mondadori. 
Häußermann, Hartmut, and Walter Siebel. 1987. Neue Urbanität. Frankfurt am Main: Suhrkamp.

Häußermann, Hartmut, and Walter Siebel. 1992. Urbanität. Vienna: Magistrat der Stadt Wien.

Herzfeld, Michael. 1987. Anthropology through the Looking Glass: Critical Ethnography in the Margins of Europe. Cambridge: Cambridge University Press.

Herzfeld, Michael. 2005. "Practical Mediterraneanism. Excuses for Everything, from Epistemology to Eating." In Rethinking the Mediterranean, edited by W.V. Harris, 45-63. Oxford: Oxford University Press.

Horden, Peregrine. 2005. "Mediterranean Excuses: Historical Writing on the Mediterranean since Braudel." History and Anthropology 16, no. 1: 25-30.

Horden, Peregrine, and Nicholas Purcell. 2000. The Corrupting Sea. A Study of Mediterranean History. Oxford: Blackwell.

Ilbert, Robert. 1991. "De Beyrouth à Alger: la fin d'un ordre urbain." Vingtième Siècle 32: 15-24.

Ilbert, Robert. 2016. "Mégapole.” In Dictionnaire de la Méditerranée, edited by Dionigi Albera, Maryline Crivello, and Mohamed Tozy, 908-11. Arles: Actes Sud.

Jacobs, Jane. 1961. The Death and Life of Great American Cities. New York: Random House.

Kaschuba, Wolfgang. 2017. "Die Stadt, ein großes Selfie? Urbanität zwischen Bühne und Beute." Aus Politik und Zeitgeschichte 48, November 24. Accessed June 15, 2019. https://www.bpb.de/apuz/260060/urbanitaet-zwischen-buehne-und-beute.

Lafi, Nora. 2013. "Mediterranean Cosmopolitanism and its Contemporary Revivals. A Critical Approach.” New Geographies 05: 325-33.

Lefebvre, Henri. 1968. Le droit à la ville. Paris: Éd. Anthropos.

Lefebvre, Henri, and Catherine Régulier. 2000. "Rhythmanalysis of Mediterranean Cities [1986]." In Writings on Cities, Henri Lefebvre (author), 228-40. Oxford: Blackwell.

Leontidou, Lila. 1990. The Mediterranean City in Transition: Social Change and Urban Development. Cambridge: Cambridge University Press.

Leontidou, Lila. 1993. "Postmodernism and the City: Mediterranean Versions." Urban Studies 30, no. 6: 949-65.

Leontidou, Lila. 2010. "Urban Social Movements in 'Weak' Civil Societies: The Right to the City and Cosmopolitan Activism in Southern Europe." Urban Studies 47: 1179-203.

Leontidou, Lila. 2014. "The Crisis and Its Discourses. Quasi-Orientalist Attacks on Mediterranean Urban Spontaneity, Informality and Joie de vivre." City 18, nos. 4-5: 551-62.

Mucem [Musée des civilisations de l'Europe et de la Méditerranée]. 2017. Cités, villes, mégapoles en Méditerranée. Cities, Towns, Megacities in the Mediterranean. Marseille: Éditions du Mucem.

Mumford, Eric. 2000. The CIAM Discourse on Urbanism, 1928-1960. Cambridge, MA: MIT Press.

Mumford, Lewis. [1938] 1970. The Culture of Cities. San Diego: Harcourt Brace Jovanovich, Publishers.

Nicolet, Claude, Robert Ilbert, and Jean-Charles Depaule, eds. 2000. Mégapoles méditerranéennes. Géographie urbaine rétrospective: actes du colloque organisé par l'École française de Rome et la Maison méditerranéenne des sciences de l'homme, Rome, 8-11 May 1996. Paris: Maisonneuve et Larose. 
Salin, Edgar. 1960. "Urbanität.” In Erneuerung unserer Städte. Vorträge, Aussprachen und Ergebnisse der 11. Hauptversammlung des Deutschen Städtetages. Augsburg, 1.-3. Juni 1960, edited by Deutscher Städtetag, 9-34. Cologne: Kohlhammer.

Salin, Edgar. 1970. "Von der Urbanität zur 'Urbanistik"” Kyklos. Internationale Zeitschrift für Sozialwissenschaften 23: 869-81.

Sonne, Wolfgang. 2014. "Urbanität." In Urbanität und Dichte im Städtebau des 20. Jahrhunderts, Wolfgang Sonne (author), 14-36. Berlin: DOM publishers. Accessed June 15, 2019. https://www.stadtbaukunst.org/cms/upload/texte_zur_ stadtbaukunst/Sonne_Urbanitaet.pdf.

Tunnard, Christopher. 1953. The City of Man. A New Approach to the Recovery of Beauty in the American Cities. New York: Charles Scribner's Sons.

Tyrwhitt, Jacqueline, Josep Lluís Sert, and Ernesto Nathan Rogers, eds. 1952. The Heart of the City: Towards the Humanisation of Urban Life. London: Lund Humphries.

Valéry, Paul. 1951. Regards sur le monde actuel et autres essais. Paris: Gallimard.

Weaver, Timothy. 2017. "Urban Crisis: The Genealogy of a Concept." Urban Studies 54, no. 9: 2039-55.

Wohl, R. Richard. 1955. "Urbanism, Urbanity, and the Historian." The University of Kansas City Review 22: 53-61. 


\section{Urbanity as an ethic \\ Reflections on the cities of the Arab world}

Nora Lafi

\section{Introduction}

The object of this chapter is to discuss the relationship between ethics and urbanity. The choice has been made to focus on the example of a set of cities of the Arab world between the medieval and Ottoman periods in order to challenge some persisting culturalist clichés affecting the notion of urbanity and to take part in ongoing discussions on the way for scholars to tackle this question. This discussion is based upon the examination of original sources and various manuscripts from the cities of Aleppo, Cairo and Tunis. The intellectual context of scholarly discussions on urbanity is often that of the influence of three major impulses. The first pertains to attempts by architects and planners to create the conditions of a harmonious life. It spans from the effort of the utopian socialists of the 19th century (Moret 1998) to the garden city movement of E. Howard and to Le Corbusier. This vision was strongly contested for its failures and ambiguities in the 1960s by Jane Jacobs and her followers (Cunningham 2010). The second can be qualified by right-wing conservative and derives from visions announced by Jean Giraudoux in the 1940s. Urbanity for him pertains to order: The educative role of a well-ordered architecture and respect for other people and one's self (Chombard-Gaudin 1993). This vision of urbanity was developed in the context of racist and colonialist visions of society and urbanity and linked explicitly to the so-called Western world. In reaction to such visions, Henri Lefebvre and then David Harvey subsequently developed a notion of urbanity linked to the concept of right to the city. Urbanity was seen not as an order imposed from above but as a capacity of mobilized inhabitants to challenge this order from below (Bocquet 2012). Current research tends to focus on urbanity through the lens of a critical examination of the commodification of public spaces (Beuscart and Peerbaye 2003; Boudreau 2010; Hanningan and Richards 2017). Others insist on urbanity as a spatialization of ethical values, in an effort to go beyond the conservative connotations of urbanity seen as an ethic (Zijderveld 1998). The problem, however, with this later vision is that focusing on the case of European cities, it consolidates culturalist clichés that tend to assume that cities outside of this cultural area 
and its "Western" extensions were not able to develop forms of urbanity. The intent here is to refuse this assumption and, thus, look for the historical roots, characteristics and developments of urbanity, seen as the spatialization of ethical values, in cities of the Arab world. The aim indeed is to examine how concretely urbanity was the result of the implementation of a set of principles and attitudes in the public space of cities that pertain to civic and ethical values, considered not just as invariants coming from above but also as shared and constantly locally negotiated civic values. A particular attention will be dedicated to the notions of Hisba and maslaha al-amma (common goods). Urbanity is more than the mere point of encounter of topdown visions of order and the adaptive, resistance and creative capacities of the inhabitants. It pertains to the organization of cities according to shared principles of civic common good, with an accent on the preservation of public spaces in which diversity and social or commercial vitality could develop.

\section{Islamic roots: the Hisba}

In a medieval Islamic context, ethics were conceptualized through the notion of Hisba, from the verb hasaba, which means "to count, to verify" in Arabic. Religious precepts of Koranic essence, work ethics, commercial ethics and civic life were mixed into this notion, which was also the result of a process of historical sedimentation of previous mediations, accommodations, expertise and jurisprudences. The concept of Hisba also encompassed many dimensions of public morality (Ghabin 2009; Moukheiber 2002). The Hisba was one of the key elements of the urban civic organization. The general moral framework of the Hisba was that of a Koranic principle (Koran, Surat 104) that commands right and forbids wrong: Al-'mr bi-l-ma'rûf wa'lnahhî 'an al-munkar. This principle was at the heart of all ethical developments in an Islamic context, for individuals and for society in general. It was supposed to inspire regulations in all sectors of society, including governance, commercial and work relationships. It was not per se, however, a concrete set of rules of a theological nature, but rather a spirit, a framework, a guidance and an inspiration.

Medieval Islamic societies have long been analyzed under the light of the ubiquity and centrality of the social value of religion as a universal organizational principle. Since the 1970s, however, scholarly discussions have contested the importance of this dominant interpretive key (Lapidus 1975). Attention to the notion of Hisba and its ethical dimension allows one to reflect on this dimension: Morality and ethics have always had a strong religious connotation in such societies, similar probably to all medieval social organizations, but this does not necessarily mean that religion was the only organizational principle. Work and communal relationships, governance principles or commercial ethics, for example, were also spheres in which social norms, both explicit and implicit, were produced. The study of this moral economy, in a meaning echoing the notion proposed by Edward 
Palmer Thompson (1971), based on goodness, fairness and justice ('adala), and of its complexity according to this diversity of basic elements is a key to a more nuanced understanding of the functioning of medieval Islamic urban societies and the societies that historically derived from them. Coming back to the roots of these social organizations is a way to challenge orientalist and culturalist visions that tended to insist on the exclusivity of religion as a source of regulation. The concept of Hisba itself and the practicalities of its implementation have for decades been the object of historiographical controversies. Whether it is an adaptation to an Islamic context of previous rules pertaining to market order and commercial life or a translation into the concrete world of cities of Islamic theological principles? The weight of this interpretive dichotomy has long forbidden the development of analyses that could avoid civilizational topoi. On the one hand, Hisba seems to be the heir of previous imperial Phoenician, Roman and then Byzantine regulations. The possible link between the charge of Agoranomos and the one of Muhtasib, market inspector in charge of the application of the principles of the Hisba, has often been underlined (Berkey 2003; Buckley 1992; Foster 1970; Sauvaget 1947). However, the Hisba was more than just a sum of practical rules: It embodied a whole sphere of ethics. Some, on this basis, have contested the consistence of the Byzantine administrative heritage. The object of the present chapter's examination is not to solve such controversies but rather to analyze the complexity of ethics in the Middle Ages in their relationship to urbanity. A form of practical administrative continuity does not impede a philosophical reframing (Rau and Rüpke 2020).

Numerous Hisba treatises, comprising legal considerations, practical instructions on how to behave in society (good neighborliness, fairness in commercial interactions, harmonious intercommunal coexistence) and philosophical reflections, were written during the medieval era (Garcia Sanjuan 1997). Such treatises were collections of judicial expertise, sums of economic and commercial moral principles, and morale treatises organizing social life, governance and the use of public space. From weights and measures to equity or from fair prices to social justice, Hisba treatises were the expression of a will to apply a general morality to public life. Hisba treatises were indeed treatises of ethics. This general morality of Koranic essence included a dimension of accommodation into social practices. This accommodation was a negotiation, with numerous mediation processes and philosophical, theological and practical debates, accumulated over time. There is no ontological stability in the historical corpus of Hisba treatises but rather an accumulative and reflexive process of constant renegotiation and adaptation. There was no mechanical link between theory and practice or between theology and practice but rather the creation of a sphere of accommodation inspired by religious principles, at the core of which was the notion of goodness. It is in that sense that urbanity in medieval Islamic cities was an ethic. Hisba treatises, as a literary genre, functioned with a dimension of accumulation: Most of them referred to previous treatises and recopied part of their 
heritage. However, as handbooks, they were also anchored in a strong pragmatic dimension: Writers reflected on cases they had had to deal with as part of their job as a qâdî (judge) or muhtasib (market and street regulator). Chapters were also sometimes dedicated to public life and private customs. Depending on the context and on the political orientations and sensibility of those in charge of the redaction of Hisba treatises, urbanity could be defined more from a top-down normative perspective or more under the form of an accommodation between a religious and philosophical corpus and daily practicalities. European Orientalists, since the times of Tychsen and De Sacy, have developed a strong interest for such Hisba treatises. Ignaz Goldziher (1894) and, subsequently, Maurice Gaudefroy-Demombynes (1938) published various treatises and also produced extensive catalogues and typologies. This domain of study developed considerably between the 1930s and the 1960s (Clerget 1934; Colin and Lévi-Provençal 1931; Garcia Gomez 1957; Husni Abdelwahab 1967; Talbi 1954). Since the 1980s, a strong renewal has occurred (Abu Zid 1986; Buckley 1999, Cook 2000; Essid 1995; Holland 1982; Izzi Dien 1997). What the now vast panorama of available Hisba treatises illustrates is that the authors of such works were generally no strangers to the world they described. They were, indeed, themselves practitioners and were even often themselves muhtasib or qâdi, that is, persons in charge of the implementation of the very principles they wrote about. Ethics and real life belonged to the same dimension and were intimately interconnected. This is part of the definition of urbanity as an ethic. Hisba treatises were handbooks. This shows how Hisba and the moral economy in commerce, governance, social relationships and work ethics that it expressed was not a principle that just came from above (Koranic principles, State power, social hierarchies). It also represented a dimension of confrontation with daily practices: How to behave in society, how to guarantee the fairness of transactions, how to guarantee both hygiene, order, justice and equity. A figure such as Taqiyy al-Dîn Ahmed b. 'Alî al-Maqrîzî in Cairo at the turn of the 14th and 15th centuries (Ahmad Said 2014; Raymond and Wiet 1979; Shatzmiller 1994; Zin Hum and Madîha Charkawi 1998) is an example of this entanglement between practice and theory. A friend and colleague of Ibn Khaldun, al-Maqrîzî had many occupations in the governance of the city during his career, including a time as muhtasib. At the end of his life, he was a central figure in the civic life of the city and, as such, in charge of the writing of the chronicle, the civic annals of the medieval municipality. Such a figure illustrates how civic life on the scale of the city and market supervision were linked and how the practice of writing (a Hisba treaty, a civic chronicle) was linked to the practice of very precise professional and civic charges. It tells a lot about the nature of ethical reflections. The career of 'Abd al-Rahmân b. Nasr al-Shayzarî (1999) as muhtasib, but also physician or qâdî (judge) during other phases of his life, in Aleppo in 1169 also illustrates such entanglements between theory and practice (Behrnauer 1860) (Figure 5.1). 


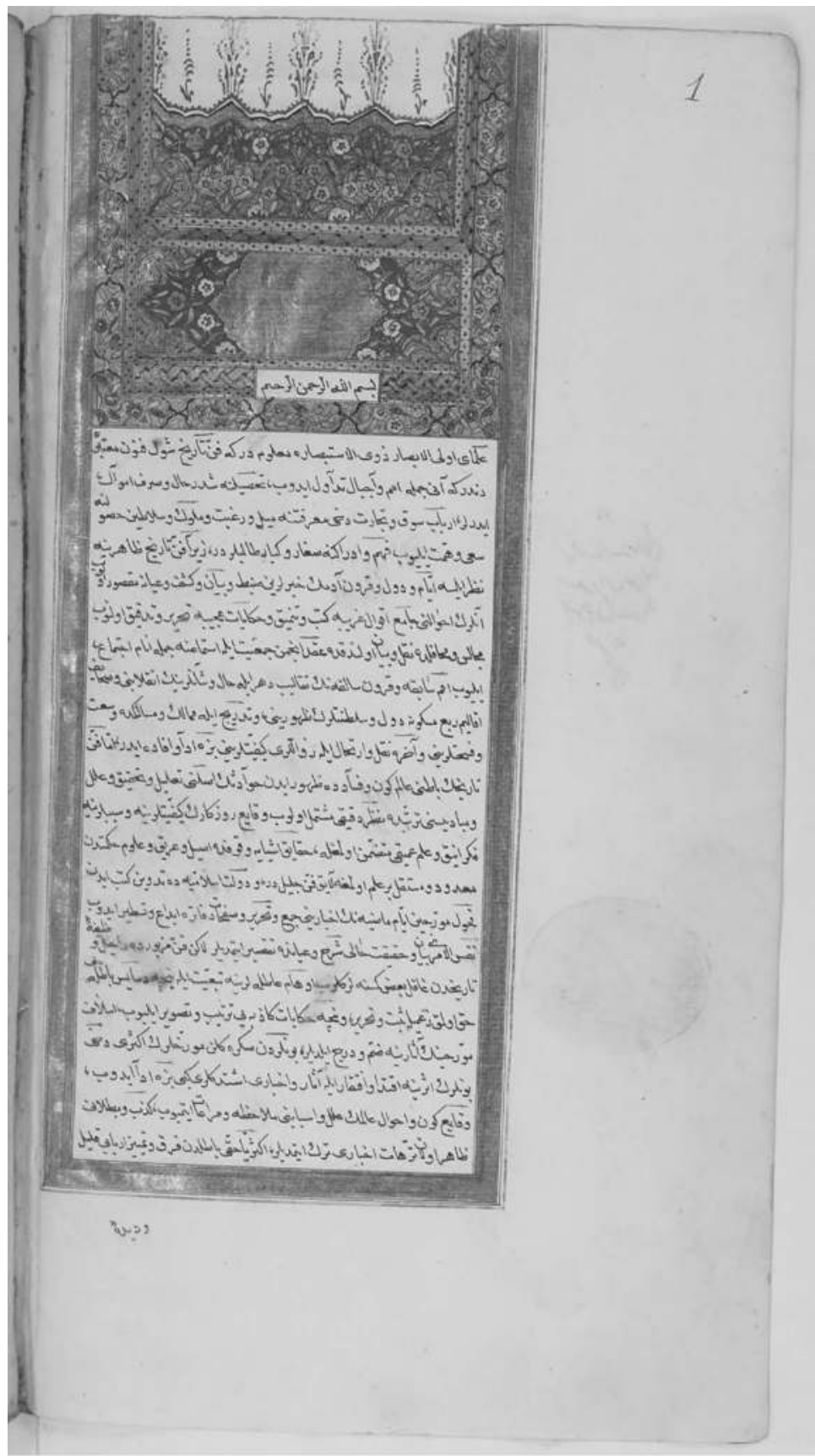

Source gallica.bnf.fr / Bibliothèque nationale de France. Département des manuscrits. Supplément turc 1412

Figure 5.1 Mohammed Sahib Pirizade (1748), Ottoman translation of Ibn Khaldun's Prolegomena ربخلا و عادتبحلا ناوىدو ربعلا باتو و 
The biographies of the authors of medieval Hisba treatises, from A1Andalus to Mamluk Egypt, generally invite one to consider theory and practice as linked dimensions. Ethics were both shaped and mirrored in such treatises. Urbanity was a social construction that came from both ethical principles and accommodations from daily life. Treatises of ethics included discussions on cases taken from real-life disputes or conflicts. The figure of the muhtasib was itself the result of a mediation between central power and local notabilities. For Lévi-Provençal, the late insertion of the Hisba sphere into that of the central government was the result of the wish to control guilds and merchants better (Lévi-Provençal 1955). This also represented an effort to control the local civic dimension. Local notables, however, also maintained a strong influence on the designation of the muhtasib and on the very definition of Hisba. The muhtasib represented both the local urban elites (from a sociological point of view) and the central power (as his charge had been inserted into the State framework) in late medieval Cairo. Representatives of the Hisba in late medieval Aleppo and Tunis had similar roles.

What is to be found in Hisba literature are generally rules oriented toward the defense of the public interest (al-masâlih al-'amma, for Ibn Khaldun and most of his successors). This public interest is intended as the pursuit of a standard quality for the products which were sold in the market. It also encompasses the supervision of the activities of craftsmen and merchants. The quality of work in an Islamic society responded to criteria of common good. The purpose of Hisba was the defense of the general equilibrium of the system and the prevalence of an ethic oriented toward the notion of good. The general Koranic philosophy of justice in society was supposed to be at the heart of all rules. The Hisba was the expression of an ethic of the quality of work, good governance and the fairness of commercial relationships. The muhtasib dealt, with the help of dedicated personnel, with the implementation of the principles he was in charge of on a daily basis (Shoshan 1981). He was, indeed, a mediating figure between the authority of the diwân and the world of craft and trade. Hence, the centrality of the ethical notion of Hisba in urbanity. Hence, the both ethical and practical aspects of urbanity: Respect of public spaces, enforcement of the rules against encroachments, functioning of public amenities, fairness of commercial transactions and communal coexistence in the public space.

This strong civic link between society and space constitutes the core of a possible definition of urbanity and ethics that could challenge Eurocentric visions and historical perspectives limited to modern times. Urbanity was an expression of the very nature of cities as civic collective bodies. It represented the spatialized manifestation of the civic dimension in everyday life. The civic sphere was at the core of the very organization of urban society (Lafi 2019). It was in the hand of local notables, whose definition could vary from city to city, but who generally belonged to the most powerful guilds and families. Their legitimacy as notables was defined not only from the top but also due to their influence on the population in their respective neighborhoods. The notables controlled the medieval forms of municipal power. 
A civic chronicle (yawmiyât or hawadith), written by the secretary (kâtib) of the medieval municipal council, played the role of public annals. Moral values and duties were attached to the exercise of these powers, and ordinary people had access to forms of protest when notables did not respect the civic and moral pact. Such forms of protest could go from informal encounters with the chief of the neighborhood, the chief of the guild, the head of the confessional community or the chief of the city to formal petitions. Through the petitioning system, all inhabitants were entitled to have their rights respected, or at least to claim for justice ('adala). When such mediations failed, riots and rebellions could happen. They were the sign of a rupture of the pact of governance. The pact of urbanity had been broken as the ethical guidelines has not been followed. Urbanity, in other words, was defined much more at the ethical level than just at the legal one.

The principles of the Hisba were spatialized through the competences of the notables and their institutions in the urban space: Public infrastructures, often under the form of civic waqfs (endowments), control of building rights, building safety, public space, market order, security, confessional balance and factional cohabitation. These elements of medieval origin were reinterpreted in classical Ottoman times and remained constitutive of urbanity, defined as the manifestation of a set of constantly renegotiated ethical values in the urban space, aiming for public and common good as well as for patterns of living together.

\section{Urban ethics and the construction of the local dimension of Ottoman imperiality}

This whole medieval system was submitted to a process of reform and reinterpretation with the integration of the Arab world into the Ottoman Empire, mostly in the early 16th century, which can be read as the negotiated construction of the Ottoman imperial sphere of governance (Barkey 2008; Inalcik 1973; Lafi 2019). In this context, ethics and the organization of governance, social control, commerce, work and production in general, and all these negotiated features constitutive of the local forms of urbanity, appear as the elements of a broader mediation process between local societies and the imperial apparatus. The integration into the Ottoman Empire was in no way a one-way process. It represented more of a process of accommodation and mediation, with phases of confirmation (and reinterpretation) of previous practices and theories. It knew phases of conflict and a whole process of ideological reframing. One of the first results of the negotiation of the integration of cities into the Empire was the writing of local charters (qanunname) in which imperial authorities recognized previously acquired collective rights and the existence of collective entities, such as confessional communities, professional communities and city assemblies. In Aleppo, this negotiation reinforced the local power of notables and redefined their role in governance in the context of the integration into the Empire and of the redefinition of the ideological narrative of power (Lafi 2018). A whole set of 
urban competences remained in the hand of the notables as defined in medieval times and of the medieval municipal institutions that they controlled. Hisba, reinterpreted in this new configuration, remained the ethical inspiration of the whole system in this process of construction of the Ottoman old regime. In this context, the nature of ethics as a sphere of negotiation and translation of morality into actual practices (and not only a fixed set of values) was reinforced. On the scale of the empire, the integration of the Arab provinces even reinforced the role of Hisba as the main ethical guidance of governance (Cebeci 1987). Hisba offered reference both to religious principles common to Muslim local notables (that also considered the diverse local forms of communal and confessional diversity) and to the State apparatus and aspects of practicality adapted to local negotiations. Hisba was also the result locally of multiple layers of sedimentation of negotiations that were constitutive of the collective identity of urban societies. The reinforcement of ihtisab (a principle of governance deriving from Hisba and organizing civic life) in the capital city, Istanbul, is to be analyzed in this context (Mantran 1957). The ethical principles of the Hisba in cities of the Arab provinces provided the sphere of negotiation between imperial authorities and local élites, with a process of consensus building around the notions of good governance, justice, coexistence and fair commercial conditions. The muhtasib Zain al-dîn Barakât ibn Mûsâ played a crucial role in the transition from Mamluk to Ottoman rule in Cairo, as Gaston Wiet (1945) studying the chronicle written by the local notable and member of the civic assembly Ibn Iyâs underlined. The medieval competences of the muhtasib in Tunis were progressively absorbed by the mayor of the Ottoman old regime municipality (sheikh al-madina), a fact that reinforced the role of local notables in governance and also embodied the pact of imperiality between local élites and the Empire. Hisba remained the reference ethical principle of market regulation and the governance of urban amenities. It also remained the inspiration for the whole system of local governance, confirming urbanity in its civic and ethical definition. Ethics kept their medieval base, but the whole framework acquired a new ideological meaning (Rafeq 1991). The morality had the same base, but the interaction between the moral economy and power had been reframed. Cities, including Tunis and Aleppo, were ruled by old regime municipalities in the hands of local notables, to whom the empire had delegated many functions. Confessional communities were represented. Ethics, derived from the Hisba but reinterpreted in the framework of the construction of Ottoman imperiality, constituted the moral horizon of all social transactions and the interaction between society and the urban space.

Most of the rules governing labor, social and political relationships were confirmed, as well as most of the values of ethical and moral dimensions. The old regime Ottoman imperial system was not just a continuation of the medieval situation, however. Its construction was the occasion of a new negotiation with local societies that, in return, shaped the Empire itself. This is why ethics were so central. The result of all these local processes of negotiation 
in the specific Ottoman old regime framework was not a unification of local practices under a common imperial umbrella. This conception would be totally anachronistic. It was, rather, the construction of a sphere of imperial knowledge and a sign that the imperial structure was active in dealing with local forces for the definition of forms of imperial belonging. The main questionings were about the Ottoman regulation of local economic and social life, the changes in guild relationships introduced by the extension of the imperial horizon and by new trade and production activities, and the link between professional belonging and civic life. The new pact of governance, in which ethics were key, also regulated the relationship between confessional communities, recognized as collective bodies, and the Empire. From a spatial point of view, urbanity, as inspired by Hisba principles, allowed for the coexistence between confessional communities (Jews, Christians of various Churches, Muslims of various schools of Koranic interpretation) and an organization of daily life that favored interaction, security and regulated behaviors. All this, of course, as archival sources illustrate, was not without breaches and incidents. All incidents, from commercial disputes in the public space to confessional tensions or acts of violence in the public space, however, were dealt with and interpreted according to the frame of reference of Hisba ethics. The system, as described by E. Çelebi, an imperial inspector who traveled the whole region in the 17th century (Dankoff 2004; Dankoff and Kim 2011; Kreiser 1988), was no longer the medieval one: Guilds had new functions, figures and codes, notables had newly defined urban governance functions, and confessional communities had been newly defined in reference to older privileges. There were elements of Anatolian influence in the Arab world, but the contrary is also true. Most of all, Hisba principles served as a sphere of accommodation. This is not to be seen as a mechanical process. One should not have a static vision of the situation, with two separated worlds, imperial and local, in contact: They were, instead, interconnected and ethics constituted a constructed system of common reference. The codification of work, governance, diversity and commerce also knew new steps and new scales, with the possibility of recourse to the imperial dimension through the petitioning system (Baldwin 2012; Ben Basat 2013; Lafi 2011). Complainants in petitions often used references to Hisba principles in order to justify their claims morally. A whole definition of urbanity as an ethic can, thus, be read in the documents denouncing the breaches to this order (BOA Ottoman Archives, petitions). Many situations, though, were still dealt with at the microscale of the interaction between local life and ethics.

The moment of the transition between the Ottoman old regime and the period of modernization known as the Tanzimat, starting in the 1830s (Ortayl 2000), represented again a phase of redefinition of the ideological and practical framework for governance. Here again, urbanity, as an ethic inspired and regulated by Hisba principles, played a role. In contrast to the culturalist interpretations that prevailed until recently and to "insisted on reforms being imports from Europe, a consensus has now been reached 
among historians around the necessity of reevaluation of the influence of inherited features from the Ottoman old regime and Islamic thought in the modernization effort of the Tanzimat era (Lafi 2019). The modernization process of the Ottoman empire was in no way only an import of European influences and solutions of practical modernization of the State apparatus. As the work of Osman Nuri Ergin (1883-1961) illustrates (Ergin 1922), there was a profound link with the previous system. His study of the creation of modern municipalities in the Ottoman Empire during the second part of the 19th century is also the work of an expert of Hisba-related notions and the system of urban governance that derived from them. His whole career illustrates the intimate relationship between modernity and heritage. The ethics of modernization were referred to the heritage of Hisba in the Tanzimat period. Ergin's madaniyya, a definition of urbanity in an institutionally modernized context, is an echo of Hisba. Contrary to interpretations of reforms being only an import, one can now say that a form of ethics was common in the ideological and practical definition of urban modernity. This does not mean that inspiration from abroad was absent or that all issues were resolved by this ethical inspiration. As a civic sphere anchored in early modern times, the new regime system stumbled on the question of the invention of a fair modern notion of equality, as the old regime system was a form of regulated inequality. It also stumbled on the question of possible divergent manifestations of urbanity, outside the dominant system, and on the relationship with Europe, in the context of growing pressures of colonial nature (Lafi 2016a). Modernity was in no way a neutral feature, as pressures by European consuls altering the spirit of the reforms in late Ottoman Tunis illustrate (Lafi 2017a). In late Ottoman times, urban modernization was as much a reform of the previous system as an import of foreign ideas. Modern municipalities (belediye or baladyyia) were created on the basis of existing municipalities of the old system (Kaya 2007; Lafi 2005; Ökmen and Yilmaz 2009). They posed the question of the transcription into a modern system of values attached to the very ontology of the old. Hence, the growth of tensions of geopolitical instrumentalizations of modernization processes also in the context. Urbanity was still ethically defined according to Hisba principles, but the negotiation of its practical dimension was supposed to happen according to new logics of administration. The reforms, promoting a more bureaucratic definition of authority, abolished ihtisab and were partially inspired by the Hisba. The new municipalities, also inspired by Hisba principles (Akgündüz 2005), had difficulties defining the very status of notables, the status of individuals according to their confessional identity and the relationship between ethics and the urban space. Instruments of mediation inherited from the old regime, such as petitions, were used, however, as channels of mediation (Ben Basat 2013; Lafi 2019). In some situations, such as those in Tunis in the 1850s, as a reaction to European interference, conservative forces tended to interpret Hisba as only a source of inspiration for a newly defined vice squad (Kerrou 2002) (Figure 5.2). 


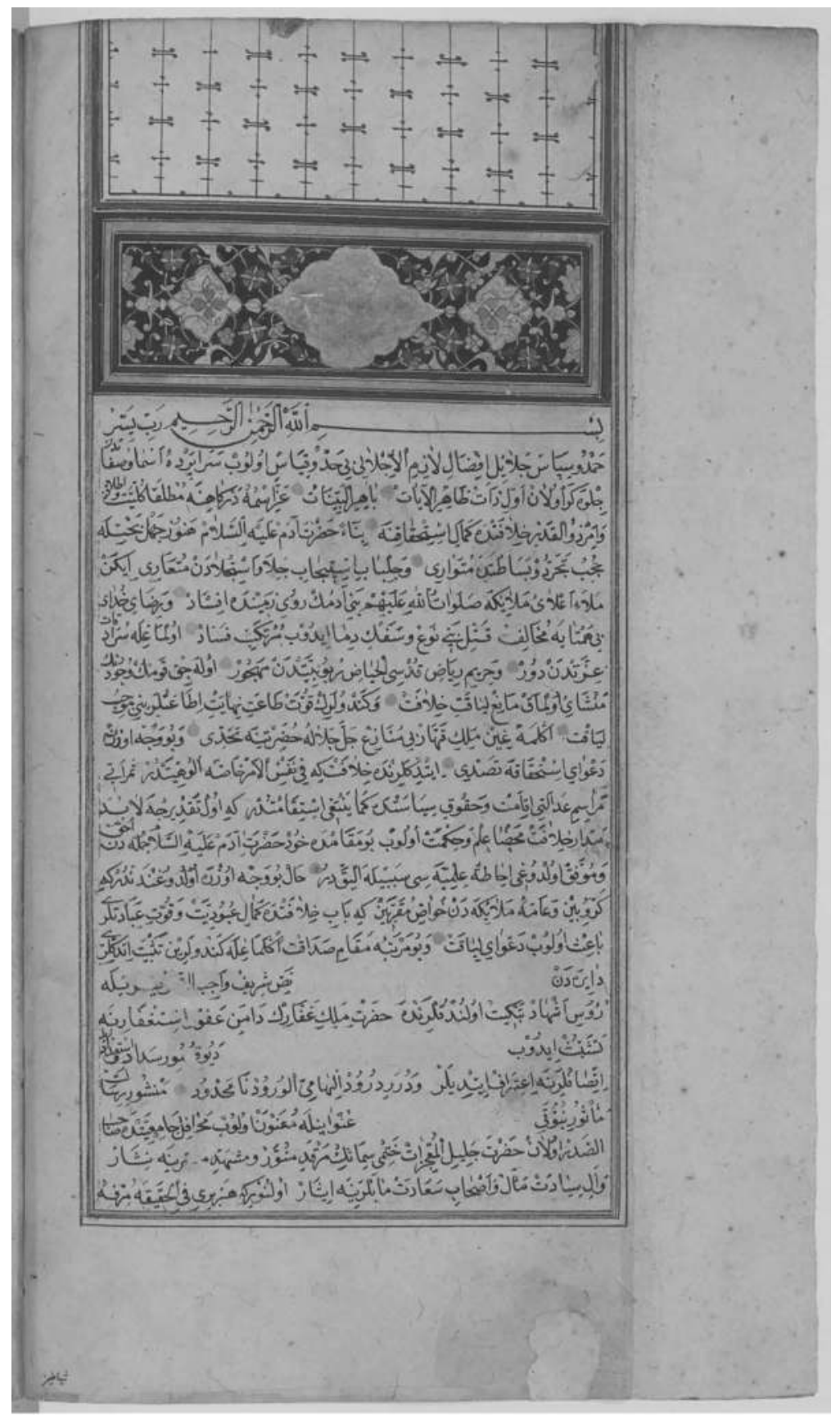

Source gallica.bnf.fr / Bibllothèque nationale de France. Département des manuscrits. Supplement turc 216

Figure 5.2 First Ottoman translation (1550-1570) of رطخلا ركذ ىف رابتعال| و ظعاوملا باتك راثالا و (Topographie and Description of Egypt), by Taki ad-Din Ahmed ibn 'Ali ibn 'Abd el-Kadir also known as Makrîzî. 


\section{Conclusion: the ambiguous colonial and postcolonial rediscovery of the Hisba}

Between 1798, with the French occupation of Ottoman Egypt, and the French occupation of Ottoman Algeria in 1830, the end of the 19th century with the French occupation of Ottoman Tunisia and the British occupation of Ottoman Egypt, the Italian occupation of Ottoman Tripolitania and Cyrenaica in 1911-1912 and then the aftermath of World War I with the French occupation of Ottoman Syria and the British occupation of Ottoman Palestine and Iraq, almost all the former Ottoman provinces of the Arab world came under violent colonial occupation. Depending on the date of the occupation and the degree of previous European interference with modernization processes in the provinces, this came in the context of more or less advanced Ottoman reforms that reinterpreted the ideological and practical heritage of Hisba. In a colonial context, urban order was defined according to other principles, mostly the imposition by colonial authorities of new regimes of property and governance. Urbanity in its civic definition was canceled. A symbol of this dead end can be seen in petitions sent in vain by inhabitants of occupied provinces to the new rulers: They were never considered (Ben Bassat 2017). As for Iraq, Palestine and Syria in the 1920s, the petitions sent to the League of Nations in Geneva also illustrate this dimension (Archives of the League of Nations, Mandates).

Colonial scholars, however, developed a strong interest in the Hisba. Some treatises, originating either from al-Andalus, from North Africa or from the Middle East, were republished and translated. The vision that emerged from such initiatives reinforced the dichotomy between past systems and modernity that was, by essence, a European prerogative. Hisba became the object of historical studies or, for its relevance in societies of the time, the object of a reification that cut off such societies from modernity. In contrast to the late Ottoman form of modernity that retained an ethical link to the heritage of the Hisba sphere as part of the definition of modern urbanity, these evocations of the Hisba and the way they were instrumentalized in a colonial context tended to reinforce the perception of an ontological incompatibility between ethics of Islamic essence and the modernization of societies. Later attempts by Islamists to reconnect with the Hisba (Barr 2014; Thielmann 2003) were also biased, partially due to this colonial intellectual legacy: Hisba was again a dimension cut off from the present, an object of a rediscovery as a static tradition and an object of a reification as a sphere pertaining to static visions of religion and its influence in society. This is why scholars currently need to reinterpret this concept with critical eyes. Conceiving urbanity as the spatialized expression of a civic sphere in which the ethical dimension plays a central role, as it embodies a kind of social pact, is a way to relativize visions of ethics in an Islamic context that are only based upon the reading of religious principles. It is also a way to challenge a Eurocentric vision that speculates on the incapacity of local societies to have developed a notion of urbanity historically. What urban ethics illustrate is the 
existence of a profane sphere of ethics. This sphere, of course, has intense religious contents, as in all old regime societies and probably in many modern societies, but it cannot be reduced to this dimension. Urban ethics were also the result of a social construction, based upon a pact of governance between rulers and ruled, notables and neighborhood factions, the Empire and local élites and various components of society, such as guilds and confessional communities. The reading of the impact with modernity allows one to nuance existing visions of modernity itself as not only an import from Europe, not only a new system of values but a reformed system that elaborated on earlier forms. The new ethics had a lot to do with the former. However, the process of modernization introduced various ambiguities: About the position of individuals in society in late Ottoman times and about the perversion of the colonial context. When reflecting today on ethics in the region, all these dimensions should be considered in order to avoid clichéd visions. In 2011-2012, for example, some of the developments of the revolts against dictatorships in Tunisia and Egypt illustrated the strength of expressions of urbanity that could be traced back to old systems, with conceptions of ethics but also of the destruction of ethics that morally justify revolt that were also linked to old logics (Lafi 2016b, 2017b).

\section{Bibliography}

Abu Zid, Sihem Mustafa. 1986. Al-Hisba fî̀ Misr al-Islâmiyya min fath al 'arab ilâ nihâyat al-'asr al-mamlûk. Cairo: Al-Hay'a al-Masriyya.

Ahmad Said, Najwân. 2014. Al Hisba fî̀ Misr 'asr salatîn al-mamâlîk. Dirâsa fî altârîkh al-iqtisâdî wal-ijtimâ' $̂$ (648-923h./1250-1517). Elharam: Ein For Human and Social Studies.

Akgündüz, Ahmed. 2005. Osmanlı Devletinde Belediye Teşkilâtı ve Belediye Kanunları. Istanbul: Osmanlı Araştırmaları vakfı.

Baldwin, James. 2012. "Petitioning the Sultan in Ottoman Egypt." Bulletin of the School of African and Oriental Studies 75, no. 3: 499-524.

Barkey, Karen. 2008. Empire of Difference. The Ottomans in Comparative Perspective. Cambridge: Cambridge University Press.

Barr, Mohamad Musa Mohamad Ahmad (ed.). 2014. Nizâm al-hisba fî al-islâm. Dirâsa fî Islâh al-mujtama' [Hisba Organization in Islam. Studies for a Reform of Society]. Cairo: MAUB.

Behrnauer, Walter. 1860. "Mémoire sur les Institutions de Police chez les Arabes, les Persans et les Turcs.” Journal Asiatique 16: 114-90, 347-92.

Ben Bassat, Yuval. 2013. Petitioning the Sultan: Protests and Justice in Late Ottoman Palestine (1865-1908). London: Tauris.

Ben Bassat, Yuval. 2017. "Petitioning the Sultan When the Sultan No-longer Reigned: A View from Post-1908 Ottoman Palestine." New Perspectives on Turkey 56: 87-103.

Berkey, Jonathan. 2003. "The Muhtasibs of Cairo under the Mamluks: Towards an Understanding of an Islamic Institution." In The Mamluks in Egyptian and Syrian Politics and Society, edited by Michael Winter and Amalia Levanoni, 245-76. Leiden: Brill. 
Beuscart, Jean-Samuel, and Ashveen Peerbaye. 2003. "Urbanité(s)." Terrains et Travaux 5, no. 2: 3-6.

Bocquet, Denis. 2012. "Urbanisierung ohne Urbanität: Deutung eines missverstandenen Begriffs auf heutiger Sicht." Informationen zur Modernen Stadtgeschichte 2: 41-7.

Boudreau, Julie-Anne. 2010. "Reflections on Urbanity as an Object of Study and a Critical Epistemology.” In Critical Urban Studies: New Directions, edited by Jonathan Davis and David Imbroscio, 55-71. Albany: SUNY Press.

Buckley, Ronald. 1992. "The Muhtasib." Arabica 39: 59-117.

Buckley, Ronald. 1999. The Book of the Islamic Market Inspector. Oxford: Oxford University Press.

Cebeci, Dilaver. 1987. “Osmanlı Devletinde Ihtisab Ağalığı.” Türk Dünyası Araştırmalarl 49-51: 171-220.

Chombard-Gaudin, Cécile (ed.). 1993. Jean Giraudoux et le Débat sur la Ville. Paris: Grasset.

Clerget, Marcel. 1934. Le Caire: Étude de Géographie Urbaine et d'Histoire Économique. Cairo: Schindler.

Colin, Georges-Séraphin, and Evariste Lévi-Provençal. 1931. Un Manuel Hispanique de Hisba. Paris: Leroux.

Cook, Michael. 2000. Commanding Right and Forbidding Wrong in Islamic Thought. Cambridge: Cambridge University Press.

Cunningham, Frank. 2010. "Triangulating Utopia: Benjamin, Lefebvre, Tafuri." Cities 14, no. 3: 268-50.

Dankoff, Robert. 2004. An Ottoman Mentality: The World of Evliya Çelebi. Leyde: Brill.

Dankoff, Robert, and Sooyong Kim. 2011. An Ottoman Traveller. Londres, Eland, 482p.

Ergin, Osman Nuri. (1922), Mecelle-I Umûr-i Belediyye. Târîkh Tachkayilât Belediyye. Istanbul: Jama'iyat 'Umûmyya Baladiyya. Matbaha Osmaniyya (Imprimerie ottomane).

Essid, Yassine. 1995. A Critique of the Origins of Islamic Economic Thought. Leyde: Brill.

Foster, Benjamin. 1970. "Agoranomos and Muhtasib." Journal of the Economic and Social History of the Orient 13: 128-44.

Garcia Gomez, Emilio. 1957. "Unas 'Ordenanzas del zoco' del siglo IX: traduccion del mas antiguo antecedente de los tratados andaluces de 'hisba' por un autor andaluz." Al-Andalus 22, no. 2: 253-316.

Garcia Sanjuan, Alejandro. 1997. "La organización de las oficios en al-Andalus a través de los manuales de Hisba." Historia, Institutiones, Documentos 24: 201-33.

Gaudefroy Demombynes, Maurice. 1938. "Sur quelques ouvrages de Hisba." Journal Asiatique 230: 449-57.

Ghabin, Ahmad. 2009. Hisba, Arts and Crafts in Islam. Wiesbaden: Harrassowitz.

Goldziher, Ignaz. 1894. "Die Handwerke bei den Arabern.” Globus 46: 203-5.

Hanningan, John, and Greg Richards. 2017. The SAGE Handbook of New Urban Studies. London: SAGE.

Holland, Muhtar. 1982. Public Duties in Islam: The Institution of the Hisba. Leicester: Islamic Foundation.

Husni Abdelwahab, Hasan. 1967. "Aslu-1-hisba bi Ifrîqiyya.” Hawliyyât al-jâmî'a al-Tûnusiyya 4: 5-23. 
Inalcik, Halil. 1973. The Ottoman Empire: The Classical Age. New-York: Praeger.

Izzi Dien, M. Yûsuf. 1997. The Theory and the Practice of Market Law in Medieval Islam: A study of Kitāb Nișāb al-Iḥtisāb of 'Umar b. Muhammad al-Sunāmī (fl. 7th-8th/13th-14th century). Warminster: E.J.W. Gibb Memorial Trust.

Kaya, Kemal. 2007. "Tanzimat'tan Önce Belediye Hizmetleri ve Voyvodalar.” In Ankara Üniversitesi Dil ve Tarih-Coğrafya Fakültesi Tarih Bölümü Tarih Araştırmalarl Dergisi, 101-12.

Kerrou, Mohamed. 2002. "Le mezwâr ou le censeur des mœurs au Maghreb.” In Public et Privé en Islam, edited by Mohamed Kerrou, 311-41. Paris: Maisonneuve et Larose.

Kreiser, Klaus. 1988. Çelebi's Book of Travels. Leiden: Brill.

Lafi, Nora. 2005. Municipalités méditerranéennes. Les réformes urbaines ottomanes au miroir d'une histoire comparée (Moyen-Orient, Maghreb, Europe méridionale). Berlin: K. Schwarz.

Lafi, Nora. 2011. "Petitions and Accommodating Urban Change in the Ottoman Empire.” In Istanbul from a Distance, edited by Elisabeth Özdalga, Sait Özervarlı, and Feryal Tansuğ, 73-82. Istanbul: Swedish Research Institute.

Lafi, Nora. 2016a. "Well-Managed Cities: Old Regime Urban Planning Practices in Ottoman North-Africa and Their Reform during the Tanzimat Era." In Urban Planning in North-Africa, edited by Carlos Nunes Silva, 23-30. London: Routledge.

Lafi, Nora. 2016b. "Urban Open Spaces and the Revolutionary Events of 2010-2011 in Tunis: A Tentative Typology." In Städtische öffentliche Räume / Urban Public Spaces, edited by Christoph Bernhardt, 279-91. Stuttgart: Frantz Steiner Verlag.

Lafi, Nora. 2017a. "Policing the Medina: Public Order in Tunis at the Time of the Tanzimat (1857-1864)." Journal of the Ottoman and Turkish Studies Association 4, no. 1: $55-71$.

Lafi, Nora. 2017b. "The 'Arab Spring' in Global Perspective: Social Movements, Changing Contexts and Political Transitions in the Arab World (2010-2014)." In The History of Social Movements in Global Perspective, edited by Stefan Berger and Holger Nehring, 677-702. New York: Palgrave.

Lafi, Nora. 2018. "Organizing Coexistence in Early Ottoman Aleppo: An Interpretation of the 1518, 1526 and 1536 Tahrîr Defteris and the 1536 Qanunname." In Human Mobility and Multiethnic Coexistence in Middle Eastern Urban Societies 2, edited by Hidemitsu Kuroki, 103-20. Tokyo: ILCAA.

Lafi, Nora. 2019. Esprit civique et organisation citadine dans les villes de l'empire ottoman (XVe-XXe s.). Leiden: Brill.

Lapidus, Ira. 1975. "The Separation of State and Religion in the Development of Early Islamic Society.” International of Middle-East Studies 6, no. 4: 363-85.

Lévi-Provençal, Evariste. 1955. Trois traités hispaniques de Hisba. Cairo: Institut français d'archéologie orientale.

Mantran, Robert. 1957. "Un document sur l'ihtisab de Stamboul à la fin du XVIIe." In Mélanges, edited by Louis Massignon, 127-49. Damascus: Institut français de Damas.

Moret, Frédéric. 1998. Les Socialistes et la ville. Grande-Bretagne-France (18201850). Lyon: ENS Editions.

Moukheiber, Karen Raif. 2002. al-Hisba or al-Amr bil ma'ruf wal nahy an al-munkar: A Forging Principle for an Islamic Way of Life. M.A. Thesis, American University, Beirut. 
Nasr al-Shayzarî, Abd al-Rahmân. 1999. Nihâyat al-Rutba fî̀ Talab al-Hisba (The Utmost Authority in the Pursuit of Hisba), published (with introduction and notes) by R. P. Buckley as The Book of the Islamic Market Inspector. Oxford: Oxford University Press (1999). Journal of Semitic Studies Supplement 9.

Ökmen, Mustafa, and Abdullah Yilmaz. 2009. "Klasik Dönemden Tanzimat'a Osmanlı Kenti Ve Yerel Yönetimler.” Dulumpinar Üniversitesi Sosyal Bilimler Dergisi 23: 91-112.

Ortayl1, Ilber. 2000. Tanzimat Devrinde Osmanll Mahallî Idareleri (1840-1880). Ankara: Türk Tarih Kurumu.

Rafeq, 'Abul-Karim. 1991. "Craft Organization, Work Ethics, and the Strains of Change in Ottoman Syria." Journal of the American Oriental Society 111, no. 3: 495-511.

Rau, Susanne and Rüpke, Jörg. 2020. "Religion und Urbanität: wechselseitige Formierungen als Forschungsproblem.” Historische Zeitschrift 310, no. 3: 654-680.

Raymond, André, and Gaston Wiet. 1979. Les marchés du Caire: traduction annotée du texte de Maqrîzî. Cairo: IFAO.

Sauvaget, Jean. 1947. "Décrets mamlouks de Syrie." Bulletin d'études orientales 12: $1-56$.

Shatzmiller, Maya. 1999. Labour in the Medieval Islamic World. Leiden: Brill.

Shoshan, Boaz. 1981. "Fâtimid Grain Policy and the Post of the Muhtasib." International Journal of Middle East Studies 13: 181-9.

Talbi, Mohammed. 1954. "Quelques données sur la vie sociale en Occident musulman d'après un traité de Hisba du XVe siècle.” Arabica 1: 294-306.

Thielmann, Jörn. 2003. Nasr Hamid Abu Zaid und die wiedererfundene hisba: Saria und Qânûn im heutigen Ägypten. Würzburg: Ergon.

Thompson, Edward Palmer. 1971. "The Moral Economy of the English Crowd in the Eighteenth Century." Past and Present 50: 76-136.

Wiet, Gaston. 1945. Journal d'un bourgeois du Caire, Chronique d'Ibn Iyâs traduite et annotée. Paris: SEVPEN (Armand Colin-EPHE).

Zijderveld, Anton. 1998. A Theory of Urbanity: The Economic and Civic Culture of Cities. New Brunswick: Transaction.

Zin Hum, M., and Madîha Charkawi. 1998. Bil-Khittat al-Maqrîziyya. Cairo: Matbouli. 


\title{
6 The fractious stability of an immoral landscape
}

\author{
The land walls of Istanbul, \\ 1910 to 1980
}

\author{
Julia Strutz and Christoph K. Neumann
}

In 1925, Ahmed İhsan, a well-known and well-connected Turkish journalist, published an article in Servet-i Fünun, the journal publication he edited from 1891 until his death in 1942. He wrote:

Once again it was time for a journey to Europe. The most grievous, monotonous hours of these travels that I have made I-do-not-know-howmany-times, are always those stretching from the departure in Istanbul to the border. (...) there are just deserted quarters, sheds raised by a number of creatures that one might rightfully doubt to be human, gypsy tents in foul water ... these [people] grin with sordid, rotten teeth at those passing by in the train; and this causes a condescending demeanour in the Western Europeans looking of the windows and a mood of gloom in the children of our fatherland like me. So I had taken to read a book in order to avoid seeing these ugly things. Just beside me somebody burst out:

"Look, look, they are demolishing this filthy crap!"

You cannot imagine the deep breath I took ... Yes, from Kumkap1 as far as to Yedikule the arms of civilisation belonging to our Republic knock down these disgusting huts glued to the age-old Byzantine fortification walls like squalid ticks, shattering them to the ground and driving out the vicious and wretched dwelling in them. This was really a great felicity for me because for perhaps thirty years I have waited on and on for such a radical, surgical pick-axe. Now I feast my eyes on the sight: Oh, arm of civilisation, demolish and burn down! Not only here, where foreigners pass by, but in the most remote corners of the fatherland: destroy the contaminated nests of ignorance from the old period that have left a feculent stain on the Turkish name due to a faulty and false concept of compassion!

The train leaves Yedikule; and for a moment, I had a look on the street going from there to Edirnekapı. In what a miserable state are this road and its environs, where the Turk has written one of the most sublime pages of his history! It is hard to imagine that a car passes through it, so bad a street it is; and on both its sides surrounded by holes of 
rubbish! Ruined tombs with decrepit walls ... Oh, arm of civilisation, come, instead of the pick-axe of demolition that you have swung on the other side, send here a building hand, show that we know to respect our dead and to protect the monuments that are heirlooms of our history. "May Istanbul be a city of tourists, may the foreigners come and understand us!" we say and do not consider that in all the guidebooks printed for foreign travellers visiting Istanbul a principle suggestion is to visit the walls of Istanbul. As Istanbul's transfer from the Byzantines to the Turks has divided even the history of the world in two parts, these imposing walls have great historical value; and every foreigner goes to see the old wall-towers when he comes to Istanbul - however using which street? And what will he see around the walls? Dear mister mayor, direct your car here only once and you will confess that at this place where the most sublime page in Turkish history has been written, a beautiful metallic road and modern cleanliness constitute a necessity. The pick-axe of destruction has to arrive with the instruments of creation.

([Tokgöz] 1341)

Ahmed İhsan's text contains a number of elements one frequently encounters in Turkish texts on Istanbul in the 20th century: First, a situation described as disrepair, lack of order, decay and underdevelopment; second, the emotions triggered by this appearance; third, a relationship established between the condition of Istanbul and Turkish national identity; fourth, the eye of foreigners as a perspective assumed by the author, then the dismay about inhabitants not worthy of the city in which they life; and finally the importance and desirability of modernity. All these elements combine to form a paradigm of looking at the city. The issue at stake in the discourse formed by this paradigm is Istanbul and the question of how life in this city should be.

\section{Terms and concepts: ethics of urban heritage and moral landscapes}

In this chapter, we look specifically into ethics as assemblages of techniques that form the ethically good Istanbulite (Foucault 1997). The role that space has in subject formation remains largely unexplored, even if Foucault constantly used spatial metaphors in his own writings and called for taking space seriously (Foucault 1980, 69; Soja 1989). In this chapter, we concur with Huxley that "spatial rationalities postulate causal qualities of 'spaces' and 'environments' as elements in the operative rationales of government, and these postulates can be examined as truths having histories" (Huxley 2007, 194). Huxley distinguishes between three different forms of spatial rationalities offering distinct patterns of analysis for the role of space in ethics: First, the panopticon or the artificial towns of the 18th century are examples of a dispositional and/or geometrical rationality, where a "sort of spontaneous policing or control was carried out by the spatial layout of the town itself" 
(Collier 2009; Foucault 2003, 251). Spatial dispositions, such as borders, orders, voids and visibilities, are, thus, understood as means to exercise control and discipline; they provide for correct comportment (Huxley 2006, 774).

Second, generative or biomedical spatial rationalities imagine specific areas or even whole cities as unhealthy social bodies in need of a cure. Exemplary for generative spatial rationality is the utopia of the sanitary city, where regulative technologies of sanitation, such as plumbing, airing and physical exercise, are employed differently from, but often in combination with, the dispositional rationalities that order and control (Huxley 2006, 780).

Third, vitalist or evolutionary spatial logics are expressed in discourses of "progress" and "evolution" through which humanity is to reach higher stages of "development." While dispositional and generative spatial rationalities draw on specific spaces, Huxley proposes that vitalist spatial rationalities are directed to a "general bio-social and non-material environment, which can be shaped to foster the progressive development of humanity, race or nation" (Huxley 2006, 781). The locus of these imaginations is very often a certain city with its specific urbanity and urban life.

We concentrate on the 6.5-kilometer-long strip of the so-called land walls between Yedikule and Ayvansaray1. They were built in order to delimit the city and defend it against aggressors from the landside.

Characteristic for the land walls is not only their relatively good state of preservation but also their "thickness." Their depth measures about 70 meters, including double ramparts and a moat. This feature creates opportunities for invisibility and illicit activity. The thick wall is a shelter for street kids, glue-sniffers and the homeless, a home for the poor, a hideaway for couples, a business opportunity for drug traffickers and storage space for junk dealers (Dorso 2003, 14). The fertile ground of the former moat is perfect for growing vegetables and has housed gardens for centuries that fed the city (Shopov and Han 2013). Despite the obvious dependence of urban society on activities located there, since late Ottoman times the land walls have come to be regarded as a place where the "bad citizen" dwells. Therefore, they are an "immoral place" (Dorso 2006).

These considerations triggered the idea to look at the land walls as an (im) moral landscape. With the term "moral landscape," we draw on a wide debate in social geography that uses landscape to describe the representation of a place that is perceived as a whole. Very simply put, landscape is "what you see," is a view, but is yet bounded (Setten 2004). The concept of landscape is often used to analyze the relationship between subject and object, culture and nature (Matless 1992; Wylie 2009). Landscapes are "constructs of the imagination projected onto wood and water and rock" (Schama 1995). Yet, landscapes always remain cultivated or are civilized nature. In their criticism of landscapes, John Berger (1972) and Raymond Williams (1973) have shown landscapes to be a way of reproducing a way of seeing and of aesthetics that are part of a Western class project. In this capacity, a landscape is not a fixed image; it is a social relationship permanently negotiated and in motion. 
Landscapes as social imaginations often articulate value judgments. The study of these values uses the concept of moral landscape. ${ }^{1}$ Moral judgments, to begin with, may derive from the aesthetics of a landscape - whether "intensely humanized" and, therefore, pointing toward a good future like 16thcentury New England (Lowenthal 1999), or a nostalgic, scenic aesthetics of ruins (harabe estetigi) ${ }^{2}$ that was adopted at least by some conservationists as moral landscape for the Istanbul land walls in the early 1990s. Qualifying landscapes as moral or immoral, thus, provokes questions of what is made visible, what and who is hidden, who has access and what kind of action is possible and permitted. Matless (1992) points to the relatedness of this reasoning to Foucault's analysis of knowledge and power and helps to turn the concept into an analytical, rather than only an empirical, tool. Moral landscapes are results of, and result in, negotiations over good conduct that shape bodies and the good subject.

Remembering the lead-in quote from Ahmed İhsan's 1925 article, it becomes clear that the spatial qualities of Istanbul's land walls did not operate as a means to effectively exercise control over good moral conduct. The land wall's dispositional-geometrical spatial rationality (1) does not create borders, voids or visibility as means to exert or instill discipline. To the contrary, the wall guarantees invisibility and creates a void in the middle of the city that appears to be exempt from state control. Similarly, the walls display the very opposite to a generative spatial rationality (2) that would engender a healthy urban citizenry. The land walls are represented and regarded as a habitat of the unhealthy, the parasitic and the dangerous, where much more was to be knocked down by the "surgical pick-axe." Ahmed İhsan's last resort is to call for the vitalist (3) imagination of an arm of civilization that would indeed heal the walls and with them society as a whole. The land walls of Istanbul constitute the contrary of a landscape of urban morality: An immoral landscape nobody wants to possess either as heritage or as habitat.

\section{0-1953: ethics of civilization: demolishing the abject or participating in universalism}

Ahmed İhsan relates the walls to two historical turning points. On the one hand, he describes the Ottoman conquest of Istanbul as dividing world history into two - he takes the walls as the lieu de mémoire for the transition from the medieval age to modernity. This break is mirrored by a second one, namely, the very moment of Ahmed İhsan's writing: In his rendering, this is the time when the young Republic as a civilizing force brings an end to decay and negligence. The expectation that now is the time of change, the moment when a just and adequate handling of the walls, of Istanbul's past and future glory will begin, is voiced throughout the century.

This created a situation of multiple ambivalences. Practically superfluous, the walls could be either demolished or assigned a value fitting to the civilization promised by the Kemalist "New Turkey." They had to be embraced 
as a monument of universal civilizational history, and their preservation was to be a proof that a progressive Turkey had embraced a state-of-the-art policy of historical memory. What made matters worse was the question of the "Western" view, of both international public opinion and the "foreign gaze" internalized by many members of the late Ottoman and Republican elite, a gaze that proposed a Western view of antiquity as the cradle for world civilization, meaning that it was also valid for Turkey. This was an argument to increase accessibility, cleanliness and visibility of historic monuments. The size of the walls, moreover, made demolition, renovation and infrastructural development costly to a degree that stifled many initiatives. Finally, the people living along them were not fitting the expectations especially of the "young" republican ideology.

When Ahmed İhsan wrote about the walls, he no longer regarded them as being of any immediate practical use. Having been built in late antiquity and reinforced in Byzantine times, they had been employed by the Ottomans mainly as a means to control access to the capital. After 1453, the walls had never been adjusted to new fortification technologies. The control of access to the city was terminated when the Ottoman internal travel license system was abolished after the Constitutional Revolution of 1908 (Mürur Tezkeresi n.d.; Y1lmaz 2014). Consequently, the walls had ceased to be an instrument of administration or defense.

Throughout the second half of the 19th and the beginning of the 20th centuries, city walls all over Europe were demolished after losing their conventional functions. Indeed, Istanbul had shared this trend. As a military installation, the walls were regarded as the property of the military; and the proposal was to sell them and use the receipts for the construction of "civilized and modern" boulevards or or the building of barracks for the First Ottoman Army stationed in the capital. While the assertion that the walls had a negative effect on the aesthetic of the city might have been virtually consensual a few decades earlier, in 1909, such a position no longer met with general approval: Now historical value counted (Çelik 1986, 170). Therefore, a similar project in the following year claimed to confine the scope of destruction to only those parts of the walls that could not be regarded a historical monument. This project was also rejected, as the walls as a whole constituted a historical monument (Sarımeşe 2018, 89-91).

Ironically, understanding the walls as historical and, thus, without need to be of any immediate use, exacerbated the problem of their preservation: The Ministry of War now denounced any responsibility for the walls. As a historical monument, the walls belonged to the scope of responsibility of the municipality and the imperial museum - two institutions with a much slimmer budget than the military.

Not surprisingly, the demolition of the walls was repeatedly publicly discussed without leading to a conclusion in the years to come. While the walls facing the Sea of Marmara were regarded as practically redundant and, in fact, severely damaged when the coastal road was built in the 1950s, to build 
an avenue along the land walls (or perhaps two, one on each side?) was regarded more appropriate and would make the area accessible to tourists. ${ }^{3}$ Such a road, even if it did not initially take on the form of a broad avenue, was actually constructed in the second half of the 1930s (Kandemir 1936). However, the fundamental indecision about the value of the walls prevailed. As late as 1941, Henri Prost, the architect charged with designing a new master plan for Istanbul, considered tearing down the walls, sparing only the monumental gates (Cumhuriyet 1941, 1945b; Pérouse 2014, 231). Prost may have been encouraged by a plan drawn by Aziz Ogan (1938), one of the leading archaeologists and preservationists, on behalf of the Society of Preservation of Old Monuments in 1938. This design, apparently preserved only as a copy of the key plan, ${ }^{4}$ envisaged tearing down large portions of the land walls while others would be repaired.

Even if the commitment for the preservation of the walls prevailed on the declaratory level, they actually continued to decay. By 1945, no solution seemed to be feasible and the same Aziz Ogan had expressed his helplessness - but still admonished the municipality to work on the advice of experts such as himself (Cumhuriyet 1945a; Ogan 1941). ${ }^{5}$

\section{Good and bad Istanbulites}

While the value of the monument was regarded as debatable, the real immorality came with the people living on and around it. The dubious pedigree of the structure combined with the despicable character of its inhabitants to depict the immoral landscape of the land walls.

The questions how the good inhabitant of Istanbul behaves and who indeed has the right to claim he or she was a real Istanbulite (Istanbullu) were fiercely debated throughout the century. The main issue is the equation of "city" with "civilization," often substantiated with the philological argument that the words medeniyet ("civilization") and medine ("city") both have the same (Arabic) stem (e.g., Karpat 1976, 244). The city-civilization nexus worked as a mechanism for the exclusion of Armenian, Orthodox, Catholic, Protestant or Jewish inhabitants (because they were not part of "our" Muslim civilization) but also of rural immigrants and the poor (as not sophisticated or "civilized" enough).

Very little has been written about the process that first constructed a group subsumed under the name "non-Muslims" and then turned them into foreigners in their city of birth - even though they made up half of the inhabitants as late as the 1930s. Genocide, population exchange and successive waves of dispossession and persecution were accompanied by a deeply paradoxical process of othering: While the cultural practices associated with the imagined universal civilization of Europe and Christianity were adopted by the Kemalist elite as modern civilization, those citizens of the country who might have been regarded as representatives of this modernity were forced to disappear. 
During and after the First World War, the walls were one of the prime habitats, harbors and points of arrival for the hundreds of thousands of refugees from Russia, the Balkans and Anatolia. In 1920, even a conservative estimate counted 100,000 refugees in Istanbul, who, thus, made up every eighth to ninth inhabitant of the city. Little is known about the living conditions of those who did not find a place in a shelter organized by international charity organizations, religious communities or the Turkish government and had to live in abandoned and destroyed buildings. A survey compiled by a number of American charity organizations active in Istanbul reports that a dungeon, which was part of the sea walls near Kumkap1, was indeed inhabited by the poorest of Armenian refugees (Johnson 1922, 299). The notion that the land walls were a place where refugees lived continued well into the 1930s. As late as 1937, Yunus Nadi, editor-in-chief of the daily Cumhuriyet, suggested using the "exuberantly available land" outside the walls to house another 500,000-600,000 refugees (Nadi 1937).

The quarters between Kumkap1 and Yedikule, with their churches, school buildings and hospitals, bear witness to a vivid Armenian cultural life even today. After the genocide, a number of institutions offered shelter in the area around Yenikapı and at the land walls to the survivors forced to leave Anatolia. In 1918/1919, the Armenian Hospital Surp Pırgiç, situated just outside Yedikule in front of the land walls, housed several hundred Armenian orphans. Another shelter was established in the neighborhood of Samatya that borders on Yedikule from inside the walls (Suciyan 2016, 44).

While Armenian, Greek Orthodox, Jewish and even Turkophone Muslim inhabitants were rarely mentioned by visitors, a smaller group was always noticed: The Roma. Indirectly, as by Ahmed İhsan in the article quoted at length, or explicitly, they are often described in racist terms. The Roma and often together with them all the inhabitants of the area turned into a herd (sürü) of gypsy kids who are seen as insolent (sırnaşık), immodest (arsiz), offensive (mütecaviz) and annoying (musallat) (e.g., Kandemir 1936). But even authors such as the famous poet and writer Ahmet Hamdi Tanpinar or the socialist and early feminist Suad Derviş did not avoid the othering of the poor (without mentioning their ethnic background). Tanpınar compared them to a sponging illness that had spread, because "in the times of decline [meaning the late Ottoman Empire] our civilisation, our religion and the state authority's ethics have been very obedient towards the poor" (Tanpınar 1946). Derviş, after having been assaulted at the walls, left the area not to return for a long time and called for more control of the area (Derviş 1935b, see also 1935a).

\section{The symbolic turn of 1953: from universalist to Ottomanist and Islamic nationalism}

From the mid-1940s onward, with the integration of Turkey into the Western side of the Cold War and the end of high-Kemalist "revolutionist" topdown transformation of Turkish society, the collective memory of the city 
and, with it, the land wall's historical significance began to undergo a slow process of redefinition. After the victory of the Democratic Party over the Republican People's Party in the general elections of 1950, the political elite reconfigured. While the secularist and statist Kemalists lost their grip on power, rural landowners and businessmen, often with a provincial background or an education in engineering, formed the government. Against the radically secular Kemalists, their populist nationalism embraced Islamic heritage.

The Republican People's Party had already attempted to appease popular feelings. It convened the Advisory Commission on Monuments and $\mathrm{Mu}-$ seums (Eski Eserler ve Müzeler Birinci Danışma Komisyonu) in 1945. It is impossible to overrate the impact of the radical recommendations issued by this convention of the most important heritage protectors of the country. It constituted the basis for a positive reevaluation of Ottoman heritage. The commission recommended holding celebrations of the 500th anniversary of the conquest of Istanbul on May 29, 1953.

When ambitious plans to celebrate the conquest (Özcan 2013) faltered for budgetary reasons, an Association of the Conquest of Istanbul (Istanbul Fetih Cemiyeti) was formed and entrusted with the preparations of the celebration. This Association quickly engaged in building an active network of conservative-nationalist scholarship about Istanbul (Tağmat 2014). The anniversary was eventually celebrated as a restaging of the conquest. The land walls at the Topkap1 (Romanos Gate) were shelled with artificial gunfire, dummies of stones crumbled and an actor posed as the soldier Hasan Ulubatl1, who climbed a tower of the wall to fly the Ottoman flag, where he was "martyrized" (art. "Fetih Bayram1," DBİA 3: 305-7). For this occasion, the tower in question had been renovated in what appears to be the first of the few restorative initiatives of the land wall completed before 1980 (Anon. 1957, 16; art. "Sur Onarımları" DBİA 7: 79-80). ${ }^{6}$

An interpretation became dominant regarding the celebrations of 1953 that achieved the integration of İstanbul's city walls into the nationalist narrative. This narrative makes the walls into the locus of conquest. They mark the victory of the Turks. The walls, as the promotional brochure The Book of Istanbul published by the Tourism Directorate of Istanbul in 1957 states, "are no longer Byzantine walls. The Byzantine Wall is nothing more than a name. All of these walls are a Turkish monument as the Turks have with pride preserved and sustained them" (Anon. 1957, 16). ${ }^{7}$

The conquest of Istanbul turns into an epochal change. The national time of the Kemalist project focused on the founding of the Republic as moment of national (re-)birth; the conquest now took its place center stage just beside it. Istanbul was reimagined as the center of the Islamic-Turkish Ottoman civilization (Çınar 2001, 387). The discourse prevails until today and oscillates between aggressive-nationalist tones and more humanist-nationalist versions.

The new importance given to the preservation of Ottoman heritage had a truly dialectic relationship to both the industrialization of the country and 
the large-scale urban transformation projects undertaken in Istanbul. From the mid-1950s onward, Prime Minister Adnan Menderes promoted and enforced the demolition of large chunks of Istanbul's historical building stock in order to build streets suitable for car traffic (Ünsal 1969). The land walls were pierced at three locations by arterial roads, most dramatically at the Topkap1, where 50 meters of the walls were demolished (Menteşe 1955, 36). The demolitions were celebrated as miracles of engineering. Quite remarkably, no-one appears to have objected to these measures - at least not in a way that has left traces in the public memory. The simultaneity of protection and demolition is, thus, characteristic of this period: Some monuments were carefully renovated, especially those that could be connected to an Islamicnationalist historical narrative and those situated at the side of new arteries, while even higher numbers of monuments were completely demolished. In the parlance of the time, "with its walls, its streets and its squares," Istanbul was to become a "modern historic city" (Anon. 1957, 16).

The renovation of the walls, proposed the Islamist-nationalist architect Turgut Cansever, was to demonstrate the Ottoman achievement "to turn Istanbul into the biggest center of human history that ensured the coexistence of Ottoman, Byzantine and Roman remains" (Cansever 1962, 173). The Mayor of Istanbul, Haşim İşcan, in a speech at the anniversary of the city's conquest in 1964, praised the noble-hearted (alicenap) behavior of Mehmed the Conqueror, who allowed the Byzantines to continue the unhindered practice of their religion. This stated an example to humankind that resembled the spirit of the United Nations (Ulunay 1964).

Much of this nationalist discourse, thus, takes place in an ethical register: The noble-hearted, civilized, disciplined Turk, the brave, strong soldier is the proposition of a decidedly good (historical) subject that citizens should look up to and try to become themselves.

\section{The authentic peasant as deserving poor and urban threat}

The re-configuration of the walls as a dignified monument that belonged to the noble Turks, however, stood in sharp contrast to the everyday perception of the social and spatial realities around the wall. "Wrong" people continued to live their "bad" life there. The "bad city" in this assemblage was still the artefact of non-Muslims, even if the number of Christians and Jews living in Istanbul continued to decline dramatically. The Roma, however, stayed on. They represented the non-national subject perceived as dangerous. They were joined by poor inhabitants who had recently migrated to Istanbul. These were often Turkophone but increasingly joined by Kurdophone and Arabophone internal migrants - all unable to show respect to their national heritage in the eyes of the Istanbulite. However, the agrarian workers arriving in Istanbul during the years of the Cold War could not be identified as easily as outsiders or only temporary inhabitants as the earlier refugees and non-Muslims. 
In the 1950s and early 1960s, the first generation of rural-urban migrants was treated as harmless peasants that, over a short period of time, would adopt an urban lifestyle and become good Istanbulites themselves. As Istanbul began to grow again after four decades of shrinkage, it slowly became clear that the newcomers would change the character of Istanbul very much - detrimentally, as most commentators of the time agreed (Akbulut and Başlik 2011, 5-21).

The migrants did not attain the attributes considered as signifying "Istanbulishness," which would typically include discarding their rural accents, changing their appearances, especially the veil, going to the movies and concerts, dining at tables (not on the low tables on the ground) or putting on makeup (Erman 2001, 989-91). Even leftist authors, such as the writer and activist Çetin Altan, while pretending to understand the poor, was alarmed by their cultural disorientation: They played an Americanized Italian song with a Turkish lute (Altan 1961). The authentic Istanbulite, who just had constituted him- or herself in a Muslim-only citizenry, thus, used migrants as an "absolute other" to evidence "the refinements and distinctions of being an Istanbulite" and their "moral superiority" (Öncü 1999, 97).

In most descriptions of the inhabitants of the wall, however, the ethnicity of the subject is not made as explicit as their ethics. This can be demonstrated by the representation of Kazlıçeşme, an area in front of the land walls, where the tanneries of Istanbul were located. This area turned into an industrial cluster specializing in leather and textiles, with slaughterhouses, hide and leather traders, shoemakers and companies dealing in chemicals. Until the mid-1950s, businesses were mostly owned by Greek Orthodox and Jewish businessmen; their disappearance was something glossed over. The only printed source devoted to the daily life in Kazlıçeşme tells stories of rough men, carousal, female sex workers and bar fights (Yelmen 2006). As had been envisaged since the late 1970s (Gönültaş et al. 1979), the last 200 leather factories in Kazliçeşme were displaced to the outskirts of the city and their original facilities demolished in 1990. Outside the compound, especially in areas close to the land walls, an informal auxiliary industry of slaughterhouses and animal markets existed, grew and informalized with industrialization. Newspapers in the 1960s and 1970s repeatedly report about horses and donkeys being slaughtered in secret corners of the wall (Gürsoy 1973; Ulunay 1967). A regular waste dump was located just outside Edirnekapı until 1968 (İsvan 1975).

The consequences of the intensive industrialization and urbanization of Turkey since the 1950s were earlier and perhaps more clearly visible along the lands walls than at other places. Small manufacturing enterprises sprung up in high density in the neighborhoods inside the land walls. Outside the walls, informal housing was newly constructed, notably the settlement of Zeytinburnu, inhabited mainly by textile workers (Hart 1969).

The fact that construction up to 500 meters outside of the wall had been prohibited meant that houses would usually not be built according to regulations and in the density of residential areas. The large number of graveyards 
in front of the land walls and the ring road that was built along the walls stretching all the way from Golden Horn to the Sea of Marmara, however, helped to reinforce the spatial function of the walls as a border and a gap.

The transport infrastructure, built on the orders of Prime Minister Menderes, also brought massive disadvantages to the wall. After the demolitions in intra muros Istanbul, quite a large number of those who had lost their homes tried to live in the spaces available along the wall. The ring road attracted traffic that turned the intersection at Topkapi into an agglomeration of formal and informal, local, regional, national and international bus stations with their auxiliary businesses. Topkapı had been the point of arrival for rural-urban migrants since the 1960s and developed into a service hub to satisfy their specific needs. Next to Istanbul's biggest informal market for (second-hand) consumer goods (Strutz 2019), the area along the wall between Topkapı and Edirnekapı serviced the bus stations with spare parts and repair shops. The mold of the walls was used to store trucks and busses for disassembling, repair and resale (Olker 1968).

The industrialization of the immoral landscape "walls" posed new challenges to both heritage politics and the creation of the good subject and citizen. Industry, traffic and housing harmed the land walls and made measures to protect them imperative. In the process, they assumed their old function as borders again. Now, however, they no longer formed a divide between the inner city and (the now industrialized) industrial periphery but as a hub, creating congestion of traffic, people and goods in such way that the name "Topkapı" became proverbial for urban disorder. Simultaneously, the land walls' new materiality was even further detached from imaginations of the good citizen and tourists who would visit the walls and show them due respect. The immoral landscape that once housed the wretched urban poor in the periphery became a void in the city that had once inhabited by unworthy citizens. The industrial subject who now lived in and used the walls was, in its generative spatial rationality, a far fetch from the healthy, authentic bodies Turkish nationalism demanded. The discourse began to criminalize and denounce them as non-nationals. This went hand in hand with criminalization, calls for security measures and exclusion (Öncü 1999, 97).

By the late 1970s, the attempt to invent a national good subject and connect it to the narrative of the conquest had failed, even backfired. As Umut Bugay (1977) wrote in his rendering of the celebrations of the 534th anniversary of the conquest about the rural migrants attending the festivities: "They will conquer Istanbul. They are waiting with wife and children as if they had set up a commander's tent. (...) Without making a sound, they have already conquered Istanbul."

\section{A generation later: a landscape of a new moral?}

Well into the 1990s, the rural migrants to Istanbul were regarded as a threat to public order and urban lifestyle (Erman and Eken 2004, 59; Yonucu 
2008, 59). This has changed under the first municipal (since 1994) then national (since 2002) regime of the Party of Justice and Development which very much relied on this stratum of society. Sustained growth and the commercialization that comes with a neoliberal economy have changed conditions in Turkey dramatically.

This went hand in hand with a fully new materiality of the walls. The late 1980s and 1990s saw a massive renovation of the land walls that was heavily criticized by archaeologists for being in fact more destructive than protective. The outcome is a wall with clear-cut limestone blocks, cleaned of the marks of centuries. Green lanes and flowerbeds are kept neatly on the outside of the walls, while the popular neighborhoods on the inside have been demolished and partly replaced by compounds and installations for tourists. In the so-called culture park, built where once the long-distance bus stations were located, the Panorama Museum 1453 inspires citizens and tourists with the reenactment of Ottoman conquest in a sound and visual show (Barlas Bozkuş 2014). The restored walls now constitute a border between the historic city center and its industrial belt that leaves little question as to how to behave. They function materially and discursively as subject formation that is attainable for a larger stratum of society. The land walls have been integrated into the new national narrative, the rhetoric of the conquest, and the land walls seem to be ubiquitous - and, be it as scenography during a rally of Recep Tayyip Erdoğan, little and few continue to disturb this new normality.

\section{Notes}

1 The literature on moral landscape often remains a rather philosophical debate as it disregards its spatial dimension (Clark 1986; Harris 2011). Empirical studies observe the moral charging of certain places as reform schools in the Victorian age (Ploszajska 1994), cooperative housing (Ley 1993) or human-nature relationships in agriculture (Setten 2004).

2 As explicitly formulated in the Conservation Board (Anttlar Koruma Kurulu), Decision 4200 on November 18, 1992.

3 The first such discussion in Republican times took place in 1924 and essentially repeated older arguments ([Eldem] 1341; [İlmen] 1341, the former is actually a reprint of an article published in 1914 ([Eldem] 1332). The most recent as late as 1994, when parts of the Islamist "Party of Prosperity" (Refah Partisi) used them as a case to discuss their own heritage (defaming them as "Byzantine") shortly after winning the municipal elections and Recep T. Erdoğan becoming mayor (Avcu 1994; Üreten 1994).

4 Nazmi Dayan, Aziz Ogan. Istanbul surları imar planı - Istanbul historic city walls zoning plan. Archive SALT Research December 2, 1938, TASUPL0023.

5 On Ogan, see the web exhibition de Tapia and Özdoğan (n.d.). The role of experts and the ethical-symbolic value of professional expertise is a topic the authors will deal in another study.

6 In 1958, the renovation of the fortress Yedikule followed that at Topkap1. Yedikule is an Ottoman structure added to the Byzantine fortification shortly after the conquest that was used as arsenal, prison and security complex. It could, thus, be seamlessly included into a nationalist narrative (Duyuran 1958, 151). The 1950s were a 
timein which thestate budget for restorations (in 1953 and 1955) was doubled, as was staff at museums and monuments (between 1950 and 1957): BCA [Başbakanlık now Cumhurbaşkanlık- Cumhuriyet Arşivi] 030.01.00.00.91.568.11.13 and BCA 030.01.00.00.91.568.11.14, respectively.

7 In 1953, the political aspects of this narrative were felt to be so aggressive toward Greece that Celâl Bayar, the President of State, and Adnan Menderes, the Prime Minister, preferred not to participate in the celebrations.

\section{Bibliography}

Akbulut, Mehmet Rıfat, and Seher Başlık. 2011. "Transformation of Perception of the Gecekondu Phenomenon." METU Journal of the Faculty of Architecture 28, no. 2: 1-44.

Altan, Çetin. 1961. "Mambo İtalyano.” Milliyet August 22, 1961.

Anon. 1957. İstanbul'un Kitabı. İstanbul: İstanbul Vilayeti Neşriyat ve Turizm Müdürlüğü.

Avcu, Arife. 1994. “'Domuzdan Yana Olmayın'” Milliyet, December 27, 1994.

Barlas Bozkuş, Şeyda. 2014. "Rethinking Nationalism in the Case of 1453 Conquest Museum in Istanbul." Global Media Journal: TR Edition 4, no. 8: 1-12.

Berger, John. 1972. Ways of Seeing. London: Penguin.

Bugay, Umur. 1977. "İstanbul'u Fethetmeyen Yok.” Milliyet, May 30, 1977.

Cansever, Turgut. 1962. “Türkiye'de Eski Eserlerin Korunması ile İlgili Çalışmalar Hakkında Rapor." Arkitekt, 4: 173.

Çelik, Zeynep. 1986. The Remaking of Istanbul: Portrait of an Ottoman City in the Nineteenth Century. Publications on the Near East 2. Seattle, London: University of Washington Press.

Çınar, Alev. 2001. "National History as a Contested Site: The Conquest of Istanbul and Islamist Negotiation of the Nation." Society of Comparative Study of Society and History 43, no. 2: 364-91.

Clark, Gordon L. 1986. "Making Moral Landscapes: John Rawls' Original Position.” Political Geography Quarterly 5, no. 4: 147-62.

Collier, Stephen J. 2009. "Topologies of Power: Foucault's Analysis of Political Government beyond 'Governmentality'." Theory, Culture \& Society 26: 78-108.

Cumhuriyet. 1941. "Şehrin Muhtelif İmar Plânları Gözden Geçirildi.” April 30, 1941.

Cumhuriyet. 1945a. "İstanbul Surlarının Perişan Hali." March 19, 1945.

Cumhuriyet. 1945b. "İstanbul Surlar Hakkında Proje.” September 1, 1945.

De Tapia, Aude Aylin, and Başak Deniz Özdoğan. n.d. "Aziz Ogan: Kültürel ve Tarihsel Hazinelerin İzinde bir Arkeolog ve Müzeci.” http://bogaziciarsivleri.boun. edu.tr/. Accessed September 27, 2019. http://bogaziciarsivleri.boun.edu.tr/sergi/ ogan.php.

Derviş, Suad. 1935a. "Edirnekapı Surlarının İçinde Dört Nüfusu Barındıran Mağara." Cumhuriyet June 9, 1935.

Derviş, Suad. 1935b. "Sinanın Güzel Eseri Mihrimah Camisini Böyle Kim Harab Ediyor? Şimdi Tekfursarayı Görmek İçin İlerlerken... 935 Eylûlünde Istanbulda bir Gezinti..." Cumhuriyet September 30, 1935.

Dorso, Franck. 2003. Un espace indécis au coeur d'Istanbul. La muraille de Théodose II en 2001. Les dossiers de l'IFEA. Série Patrimoines au présent, no. 1. Istanbul: Institut français d'études anatoliennes Georges Dumézil. http://www.ifeaistanbul.net/dossiers_ifea/Bulten_Y-1.pdf. 
Dorso, Franck. 2006. "La muraille ignorée ou le paradoxe de l'alliance tourismepatrimoine." Téoros 25, no. 2: 40-6.

Duyuran, Rüstem. 1958. "Yedi Kulenin Restorasyonuna Başlarken.” Arkitekt 4, no. 293: $151-5$.

[Eldem], Halil Edhem. 1332. “Kostantiniye Surlar1.” Servet-i Fünun May 17, 1332.

[Eldem], Halil Edhem. 1341. "İstanbul Surları Meselesi." Türkiye Cumhuriyeti İstanbul Şehremaneti Mecmuası I, no. 5: 105-7.

Erman, Tahire. 2001. "The Politics of Squatter (gecekondu) Studies in Turkey: The Changing Representations of Rural Migrants in the Academic Discourse." Urban Studies 38, no. 7: 983-1002.

Erman, Tahire, and Aslıhan Eken. 2004. "The 'Other of the Other' and 'Unregulated Territories' in the Urban Periphery: Gecekondu Violence in the 2000s with a Focus on the Esenler Case, Istanbul." Cities 21, no. 1: 57-68.

Foucault, Michel. 1980. "Questions on Geography." In Power/Knowledge: Selected Interviews and other Writings 1972-1977, edited by C. Gordon, 63-77. New York: Pantheon.

Foucault, Michel. 1997. "On the Genealogy of Ethics: An Overview of a Work in Progress." In The Essential Works of Michel Foucault, 1954-1984, edited by Paul Rabinow, 253-80. Ethics: Subjectivity and Truth. New York: New Press.

Foucault, Michel. 2003. 'Society Must Be Defended': Lectures at the Collège de France, 1975-1976. New York: Picador.Foucual.

Gönültaş, Güngör, Abdullah Öğülmüş, and Namık Koçak. 1979. "Zeytinburnu Kaymakamı: 'Nüfusun Yarısı Sarılık, Yarısı da Solunum Yollarından Hasta'." Milliyet February 12, 1979.

Gürsoy, Özdemir. 1973. “Hasta At-Eşek Mezbahaları Basıldı.” Milliyet June 8, 1973.

Harris, Sam. 2011. The Moral Landscape: How Science Can Determine Human Values. New York: Free Press.

Hart, Charles W. 1969. Zeytinburnu Gecekondu Bölgesi. İstanbul Ticaret Odası Yayınları. İstanbul: İstanbul Ticaret Odası.

Huxley, Margo. 2006. "Spatial Rationalities: Order, Environment, Evolution and Government.” Social and Cultural Geography 7, no. 5: 771-87.

Huxley, Margo. 2007. "Geographies of Governmentality.” In Space, Knowledge and Power. Foucault and Geography, edited by Stuart Elden and Jeremy W. Crampton, 185-204. Aldershot: Ashgate.

[İlmen], Süreyya. 1341. "Layiha." Türkiye Cumhuriyeti İstanbul Şehremaneti Mecmuasl 1, no. 5: 51-7.

İsvan, Ahmet. 1975. “İstanbul Belediyesi’nin Gelir Darboğazı.” Milliyet July 22, 1975. Johnson, Clarence Richard, ed. 1922. Constantinople To-Day or the Pathfinder Survey of Constantinople: A Study in Oriental Social Life. New York: The Macmillan Company.

Kandemir, [Feridun]. 1936. "Seyahat Acentaları Nasıl Çalışıyorlar? Turizm İşleri Üzerinde Tetkikler, 4.” Cumhuriyet October 26, 1936.

Karpat, Kemal H. 1976. The Gecekondu: Rural Migration and Urbanization. Cambridge: Cambridge University Press.

Ley, David. 1993. "Co-operative Housing as a Moral Landscape: Re-Examining 'the Postmodern City'." In Place/Culture/Representation, edited by James S. Duncan and David Ley, 128-48. London: Routledge.

Lowenthal, David. 1999. "From Landscapes of the Future to Landscapes of the Past." Norsk Geografisk Tidsskrift 53: 139-44. 
Matless, David. 1992. "An Occasion for Geography: Landscape, Representation, and Foucault's Corpus." Environment and Planning D Society and Space 10: 41-56. Menteşe, Ertuğrul. 1955. "İstanbulun İmar1.” Arkitekt 279: 27-38.

"Mürur Tezkeresi." n.d. Dünden Bugüne İstanbul Ansiklopedisi VIII: 327.

Nadi, Yunus. 1937. "Göçmen Politikasında Büyük Ölçülü Hamleler Lâzım.” Cumhuriyet July 21, 1937.

Ogan, Aziz. 1938. "İstanbul Surlarının Mukadderatı Hakkında Eski Eserleri Koruma Encümeni Tarafından Ağustos 1936 Tarihinde Tanzim Edilmiş Olan Esbabı Mucibe Mazbatası ve Layihayi Kanuniyeye Göre İhzar Edilen Plandır." SALT Research TASUPL0023.

Ogan, Aziz. 1941. İstanbul Surları. Yeni Türk: İstanbul Halkevleri Mecmuası.

Olker, Bürhâneddin. 1968. "Edirnekapusu D1şı." İstanbul Ansiklopedisi 9: 4927-8.

Öncü, Ayşe. 1999. "Istanbulites and the Others: The Cultural Cosmology of Being." In Istanbul: Between the Global and the Local, edited by Çağlar Keyder, 95-120. Lanham: Rowmann \& Littlefield Publishers.

Özcan, Ömer. 2013. "İstanbul'un Fethinin 500. Yıldönümünü Kutlama Hazırlıkları.” Türk Yurdu VII, 33, no. 316: 29-35.

Pérouse, Jean-François. 2014. "Henri Prost et Istanbul: le magistère contrarié." In Turcs et Français: une histoire culturelle, 1860-1960, edited by Emmanuel Szurek and Güneş Iş1ksel, 225-38. Collection Histoire. Rennes: Presses Universitaires de Rennes.

Ploszajska, Teresa. 1994. "Moral Landscapes and Manipulated Spaces: Gender, Class and Space in Victorian Reformatory Schools." Journal of Historical Geography 20: 413-29.

Sarımeşe, Fatih. 2018. "18. ve 19. Yüzyıl İstanbul Surlarında İnşa ve Onarımlar.” MA Thesis at Marmara University Istanbul.

Schama, Simon. 1995. Landscape and Memory. London: Harper Collins.

Setten, Gunhild. 2004. "The Habitus, the Rule and the Moral Landscape." Cultural Geographies 11: 389-415.

Shopov, Aleksandar, and Ayhan Han. 2013. "Osmanlı İstanbul'unda Kent İçi Tarımsal Toprak Kullanımı ve Dönüşümeri: Yedikule Bostanları.” Toplumsal Tarih 24, no. 236: 34-8.

Soja, Edward W. 1989. Postmodern Geographies: The Reassertion of Space in Critical Social Theory. London: Verso.

Strutz, Julia. 2019. "Spiriting Off the Bad Urbanite. From the Topkapı Bus Terminal to the Panorama Museum 1453." In Doing Tolerance: Democracy, Citizenship and Social Protests, edited by María do Mar Castro Varela and Barış Ülker. Leverkusen: Barbara Budrich.

Suciyan, Talin. 2016. The Armenians in Modern Turkey: Post-Genocide Society, Politics and History. London, New York: I.B. Tauris.

Tağmat, Çağla Derya. 2014. "Fetih Derneği ve İstanbul'un Fethinin 500. Yı11.” Tarih Kültür ve Sanat Araştırmaları Dergisi 3, no. 4: 46-60.

Tanpınar, Ahmet Hamdi. 1946. "İstanbulun İmar1." Cumhuriyet September 23, 1946. [Tokgöz], Ahmed İhsan. 1341. "[Avrupa Seyahat1]." Servet-i Fünun, Teşrin II [=5. XI.1925 1341.

Ulunay, [Refi' Cevad]. 1967. "Kontrol.” Milliyet July 28, 1967.

Ünsal, Behçet. 1969. “İstanbul'un İmarı ve Eski Eser Kaybı.” In Türk Sanat Tarihi. Araştırma ve İncelemeleri II., edited by Millî Eğitim Basımevi, 6-61. İstanbul: İstanbul Devlet Güzel Sanatlar Akademisi. Türk Sanatı Tarihi Enstitüsü Yayınları. 
Üreten, Orhan. 1994. “Asiltürk Çark Etti.” Milliyet December 28, 1994.

Williams, Raymond. 1973. The Country and the City. New York: Oxford University Press.

Wylie, John. 2009. "Landscape." In The Dictionary of Human Geography, edited by Derek Gregory, Ron Johnston, Geraldine Pratt, Michael Watts, and Sarah Whatmore, 409-11. Malden, MA: Wiley-Blackwell.

Yelmen, Hasan. 2006. "Kazlıçeşme.” In Surların Öte Yanı/The Other Side of City Walls: Zeytinburnu, edited by Burçak Evren, 101-35. Istanbul: Zeytinburnu Belediyesi Kültür Yayınları.

Yllmaz, İlkay. 2014. Serseri, Anarşist ve Fesadın Peşinde: II. Abdülhamid Döneminde Güvenlik Politikalar, Mürur Tezkereleri, Pasaportlar ve Otel Kayıtları Serseri, Anarşist ve Fesadın Peşinde. İstanbul: Tarih Vakfı Yurt Yayınları.

Yonucu, Deniz. 2008. "A Story of a Squatter Neighborhood: From the Place of the 'Dangerous Classes' to the 'Place of Danger'." Berkeley Journal of Sociology 52: $50-72$. 


\section{7 "The good, the bad and the ugly"}

\section{Bucharest's urban core as a moral playground}

\section{Daniel Habit}

Literary descriptions, academic writing and statements of architects throughout the 19th and 20th centuries about the urban shape of Bucharest, a city of over-layered villages, contained expressions such as "irregular," "spontaneous," "random," "rural" and "anarchic." Since the 1870s, urban planners have called for more regulations, geometric control and an urban vision for the city. Bucharest, in their eyes, was too slow to become an urban agglomeration. One of the most important architects of the interwar period, Marcel Iancu, famous for a series of modernist buildings, stated in 1935:

Only barbarian eras, - those of the dark Middle Ages and the architecturally unfortunate 19th century have not acted by means of geometry. The therefore randomly grown cities mean a reduced human consciousness and art. We now live days of authentic formation: times of directives. It's the decisive hour for the skeleton, for the geometrical foundation of Bucharest. Where is the iron fist, the visionary mind and the daring power that we imperiously require?

(Derer 2015, 50)

A few decades later, an "iron fist" struck not only the capital but also cities and other settlements throughout the country. The so-called systematization, a state program implemented in 1974, aimed at the modernization of the rural backwardness of most Romanian villages and the agricultural sector and called for doubling the number of Romanian cities by the year 2000, mainly by resettlement and the destruction of abandoned "useless" villages. Cities, urbanization and the new urban citizens played a major role in this concept of modernization, as they were the key figures of the new vision of society. In addition to its political, social and spatial aspects, this program implies a strong moral component by aiming at the transformation of the rural into the urban - with all its implications. Following cultural anthropologist Jarrett Zigon, the socialist system as an institution (or rather "the" institution) can be seen as "the bearer and securer of the truth or rightness of a particular kind of morality," especially in a totalitarian context with a strict moral code (Zigon 2010, 6). 
The so-called Civic Centers (Centrul Civic) were refurbished as cities played a major role in the moral reframing of society; historic buildings reminiscent of a bourgeois past that had to be overcome were demolished to make space for new, socialist-style buildings, some of them hosting apartments but most were buildings for administrative and cultural functions under the guidance of the party. Bucharest was not specifically a focus of this refurbishment because systematization mainly targeted rural areas. Nevertheless, several newly designed squares, axes and, most importantly, mass housing programs changed the urban fabric. After the earthquake of 1977, however, when almost 33,000 buildings (or 12\% of Romania's dwellings in 1977) were destroyed or heavily damaged and more than 35,000 families were without shelter, state President Nicolae Ceauşescu started one of the most massive urban projects Europe had ever seen (Petrescu 2009; Răuţă 2013; Vossen 2004). This natural disaster helped the communist regime facilitate the subsequent, massive interventions into urban space on several levels. Visits to North Korea and China in 1971, with their state-planned urban design, left a strong impression on Ceaușescu, as did the cult of personality and the choreographed mass mobilization, particularly during a welcome parade in Pyongyang. ${ }^{1}$ The existing urban landscape of Bucharest, with its topology long criticized as premodern, did not fit into his image of a socialist capital and, therefore, he called for a radical redesigning of the pre-existing built environment by superimposing wide and straight boulevards, massive high-rise buildings and monumental squares for political ceremonies.

A series of articles and monographs over the last 30 years, since the "Romanian revolution," have concentrated on the urban project of Bucharest carried out by Ceaușescu, his team of architects and the thousands of more or less voluntary workers - although this last group is as underrepresented in the scientific discourse as are the more than 40,000 citizens who had to leave their homes to make room for the city's conversion. Various disciplines contributed to the discourse on the Casa Poporului (House of the People), respectively Palatul Parlamentului (Palace of the Parliament), as it has been called since 1990, and its surrounding neighborhood. This major project of Romanian socialism and its implications for the urban space have been consistently morally condemned (often in very metaphorical characterizations) regarding its material and social brutality, tremendous costs, disrespect for the urban fabric and the history of Bucharest, and symbolic affirmation of a dictatorial regime - architectural critic Augustin Ioan calls the post-Ceaușescu times "After Armageddon" (Ioan 1997). ${ }^{2}$ The prosecution in the trial of Elena and Nicolae Ceaușescu in 1989 referred to the moral project of systematization and its spatial violence, calling it a pharaonic project carried out by two megalomaniac tyrants in order to satisfy their malicious, criminal interests and to suppress the Romanian people.

Although the Centrul Civic project is mainly interpreted as an idea of a mad dictator and an obedient political class, it should be seen in a wider 
context of the urban development of socialist cities in general and Bucharest more specifically. Regarding to the former, a spatial and moral reconfiguration of urban space in line with the idea of a new society as both a utopia and a concrete manifestation can be found in various socialist countries, to an extreme extent in the socialist "new towns," "they were imagined as free of conflict, as beautiful. They were the spatial site for a new socialist generation that would grow in peace and harmony" (Wakeman 2014, 106; cf. Tsenkova and Nedović-Budić 2013; Verdery 1991). Concerning the latter, the idea of a "modern" Bucharest dates back to the Urban Master Plan of 1935, "thus part of the planning profession regarded Ceaușescu's proposals as a socialist fulfilment of pre-World War II plans for Bucharest. It was an opportunity to finally modernize the capital" (Light and Young 2013, 523).

\section{Centrul Civic vs. Centrul Vechi}

Whereas the Centrul Civic, as the most important landmark of Bucharest, draws a lot of scientific, planning, political and touristic attention, a distinct neighborhood right next to this newly designed area was astonishingly left alone. However, it has been gaining increasing attraction from city hall, citizens and tourists in recent years. The fact that it was left alone was astonishing, as this part of Bucharest, the Centrul Vechi, the Old Town, is located directly adjacent to the newly built Civic Centre and hosts several important Romanian lieux de mémoire in a broader sense, for both the "official" national memory and the specific "countermemory" of Bucharest, its citizens and their "unofficial truth projects" 3 concerning the debate on the historical appreciation of December $1989 .{ }^{4}$ Following the overall topic of this volume, this article tries to contribute to the discussion on urban ethics by focusing on the development of a very specific quarter, the Centrul Vechi, its specific role within the urban context and its changing moral framings, which can be attributed to different stakeholders throughout the last century. The city and, more precisely, this small but symbolically charged area of the city is interpreted as "assemblages of materials and resources, knowledge and understanding from close by and far away, from the present and the past," as geographers Eugene McCann and Kevin Ward outlined in their analysis of urban policies and governance techniques (McCann and Ward 2012, 42). Whereas the urban refurbishment of the Centrul Civic can be seen as an extreme example of top-down rule in an autocratic manner, the spatial governance of the Centrul Vechi followed very different techniques of governmentality. In a more general sense, this perspective adds to a better understanding of urban planning during socialism and its ethical dynamics. ${ }^{5}$

The area in question is located right in the middle of Bucharest, framed by four main boulevards. It contains 48 rather small streets and dead ends. Only four streets in the north are accessible by car; the rest form the only pedestrian area in the Romanian capital, still giving an idea of the unplanned history of the city. The area, also known as Lipscani (the Romanian word 
for the German town of Leipzig), has served as the center of local commerce and trade since Bucharest became the capital of Wallachia in 1659, a momentum that increased the development not only of this area but of the whole city (Enache and Mihaila 2013). ${ }^{6}$ Around 450 buildings, almost half of them labelled as historic monuments, form the Old Town; their diversity, especially regarding architectural style, represents the different ideological mindsets and political-economic conditions Bucharest had to face in the changeful 20th century and at the beginning of the 2000s. Prestigious buildings in the eclectic style of the late 19th century, such as the old building of the Romanian National Bank and its modern neo-classical expansion of the interwar period, the Postal Service Palace, hosting the National History Museum from 1971 or the Municipality Museum, refer to the late 19th century and represent the capital of the Kingdom of Romania under the rule of Carol I. These recently renovated buildings, used as museums and, therefore, accessible to the public, link the present to the royal past and, together with other public buildings, such as the main university, represent the new national consciousness of Greater Romania after World War I when Bukovina, Transylvania, Banat and Partium became part of Romania. Several modernist buildings with Bauhaus reminiscences can be found from the interwar period, explaining why Bucharest, like many other cities around the globe, was labelled the "Paris of the East," a myth that has gained new attention as an "usable past" in the self-culturalization (Reckwitz 2009) of the city in recent years (Popa 2007). ${ }^{7}$

During this formative period in the history of Bucharest, the area nowadays labelled as the "historical center" was actually at the southern periphery of the "modern" city. Situated at the northern fringe of the newly built central market area around Union square, it had lost its function as a trading area. It came "under scrutiny as the crux of corruption, illegal or petty commerce, immorality, and urban chaos - in other words, everything that the urban elites rejected" (Grama 2009, 61). The politically driven remodeling in the postwar era can be interpreted not only as spatial but also as moral ordering, as the architects in charge wanted to clean the run-down premises and erect the modernist future of socialism and its values. Accordingly, not only were the buildings reminiscent of an unwanted past, but the inhabitants and their lifestyles as bohemian artists, capitalist entrepreneurs or smart slackers were also contrary to the ideal of the new socialist citizen. ${ }^{8}$

After 1948, most of the buildings were nationalized and the socialist idea of housing and living that began to shape the urban morphology was also carried out in the Old Town, as blocks of flats were erected at the eastern axis along Brătianu boulevard. But whereas the surrounding quarters, especially south of the Old Town, became heavily affected by the redesign of the city from the 1950s onward, this part was more or less left apart and only refurbished at its margins along the four axes. This happened due to several reasons: "First of all, this area was only slightly affected by the earthquake, especially compared to the destroyed quarter of Uranus, where Ceausescu placed his idea of" (...) 
a palace. Second, urban plans from the 1930s had focused mainly on projects in the neighborhoods south of the river Dâmbovița, whereas the plans of the 1950s concentrated on the remodeling of Union Square, so that the area on the northern shore was not in the center of attention of the urban planners and architects involved. Furthermore, and most important in the moral context mentioned above, despite all socialist plans of establishing a new society, the Romanian regime also claimed a strong historical rootedness, situating itself, the state and the nation in a historical narrative of economic and social struggle and development. This reintroduction of national values as an essential part of the public and intellectual discourse of the Romanian way is described as "indigenism" by cultural anthropologist Catherine Verdery (1996, 127), referring to the ideological construction of a Romanian national identity during socialism, based on a specific protochronism, emphasizing Romania's originality, superiority and distinctiveness and putting Romania at the center of world, just like the glorified kingdom of Dacia that corresponded to the role Ceauşescu envisioned for socialist Romania (Cernat 2012; Niessen 2002). ${ }^{9}$ As the Old Town was considered one of the important landmarks in Romanian history, it helped the regime's narrative that the territory of today's Romania had already played an important rule during the Middle Ages. Therefore, in the early 1970s, architects even modified some 19th-century Old Town neoclassical façades to make them look late medieval, which consolidates official propaganda. It can still be seen in Hanul cu Tei street (Grama 2009, 161). While the Centrul Civic served the regime by showing its planning and building capabilities, restoration in the Centrul Vechi reveals the importance of self-reassurance in history carried out in urban space.

The most important example of this process of historical self-reassurance is the restoration of the so-called "Old Court," an area within the Old Town core where Wallachia's ruling princes had their palace residence from the 16 th to the late 17 th centuries, and its turning into a museum in 1972 . The name of the street where the site is located had already been changed from "King Carol I street" to "Street of 30th of December," reminding people of the abolition of the monarchy in 1947 and the rise of a new, socialist Romania. The first excavations in the center in 1953 still followed the idea of Soviet archaeologists seeking a rewriting of the history of feudalism, as it was carried out all across the Soviet bloc. Later on, in the process of political emancipation from Moscow, the idea of pervasive Slavic influence and history preferred by Russian archeologists was transformed by historians and archaeologists into the interpretation of Romanian supremacy mentioned above (Grama 2012). In accordance with the centralistic organization of the state and society, the Museum, in its own research and studies about the history of the place and the development of Bucharest, represented the court as "the heart of the city," delivering a solid foundation of medieval walls to the regime for its interpretation of history, "a physical mark of a late medieval Bucharest, cleansed of any 'foreign influences' and ready to appear as an authentic and ideologically safe 'old Bucharest' "' Grama 2010, 183). 
The linkage with this historical period and its adoption in both political discourse and the urban fabric revolved around a specific theme: The medieval rulers of the Romanian territories defended their independence by fighting against the Ottoman Empire, whereas socialist Romania had to struggle against the Soviets after Ceaușescu's break with Moscow after his defense of the Prague Spring. This strategy should be seen in the wider context of the regime's historical self-legitimization, which plays out in many fields of cultural production. In practical terms, in this case, it led to a specific form of architectural interference in the Old Town in the 1970s: Some old houses in the neighborhood, dating back to the 18th century, were turned into extensions of the palace through redecorations with closed verandas on the upper floors. In addition to the regime's craving for authenticity and originality, these facades represent the "four fundamental historical myths of the Romanians," as historian Dragos Petrescu calls it, which are "ancient roots, continuity on the present-day territory, unity, and struggle for independence" (Petrescu 2009, 532). The vision of the leading architect at the time, Constantin Joja, therefore, claimed a "unique Romanian urban architecture" (Grama 2010, 179). However, the plans for embellishing the entire quarter were never realized, mainly because of a lack of money and shifting attention toward the new Centrul Civic.

The material remodeling of Lipscani can be seen as a political project that has a strong symbolic side but is also intended to affect the ways urban dwellers conduct and understand their lives, a technique of governance in a Foucauldian sense, carried out by architects and archaeologists, aiming at the establishment of a national past that fits the criteria of the new socialist state. It is part of a (nationalist) "institutional morality" in Zigon's (2010) sense, as mentioned above. Accordingly, the state's ideals of socialist homogenization and national continuity tried to get control over the inhabitants and over space. However, due to the lack of funds and to overall organizational issues, this did not succeed completely. Instead, this former main commercial area became one of the hot spots of the black market in Bucharest. During the 1970s and 1980s, Lipscani was the main area in Bucharest where one could find many things that had long ceased to exist in the empty store windows. Places such as "The Bacani Bazar," "The Bucharest Department Store" or a variety of small shops played an important role in the consciousness of the city. ${ }^{10}$ As there is little scientific literature on black-market situations and atmospheres in Bucharest in the 1980s, popular oral history literature can help to close this gap:

It was the black market that held the country together, kept it afloat by filling its many gaps and rectifying, at a price, its ruinous bureaucracy. It was the system's other self, its shadow aspect. Perhaps the system even owed its survival to it, the way the wall owes its survival to the ivy that sucks it dry before becoming the only thing that holds it up.

(McGuinness 2011, 26) 
Whereas block of flats not only homogenized the society but also facilitated control, the windy roads, old houses and small backyards of the Centrul Vechi made it difficult to control. This led to a spatial coexistence of the national cradle of the socialist state and a site of its obvious failure as provider of goods for the population, turning Centrul Vechi into a microcosm playground of different moralities and urban-ethical strategies - between governance and the social creativity of the informal city. ${ }^{11}$

\section{The old town in transition ${ }^{12}$}

The years after "Ceaușima," as sociologist Vladimir Tismăneanu, evoking the destruction of the Japanese city of Hiroshima, called the reshaping of Bucharest's urban landscape, and the so-called revolution of 1989 can be characterized in terms of a general decline of public space. The Old Town, like many other parts in the city, went through a time of agony as the municipality's emphasis focused on technical and social infrastructure projects that had been neglected during socialist rule (or disregarded, as resources were spent on the House of the People). While there was strong agreement on the need for transformation in many fields, this was impeded by the lack of plans concerning land use and the non-existence of a general Urban Master Plan, the uncertainty of house ownership, the overall lack of regulation, cooperation and coordination among the local authorities and various lobbies with their political and economic agendas, resulting in an irregular urban development and leaving the city with an abundance of liminal spaces (Vossen 2004). ${ }^{13}$ Whereas the socialist years can be characterized by authoritarian overregulation, especially of urban space (whether successful or not), the years after 1990 basically lacked any kind of planning (Figure 7.1).

Starting in the late 1990s, the Old Town found its way back into urban politics when Urban Zoning Plans were established and architectural contests held. At the beginning of the millennium, the "urbanistic ensemble" of the Old Town was declared as a "zone of national interest" by the Government Emergency Ordinance 77/2001, which demonstrates the ongoing importance of this neighborhood for the city administration. The ways in which restoration and revitalization, two of the main goals mentioned in the Ordinance, were realized, however, also show the lack of planning, funding and organization within the administration, as is characteristic for this period of transition of the city. The list of problems identified was and still is extensive: Unclear juridical property questions, an overall precarious infrastructure, real estate and land speculation, poor building stock, misuse of public space for commercial activities, almost collapsing abandoned houses, among them many historic monuments, and the fact that many houses were informally occupied. Between 2000 and 2002, the municipality carried out the program Un Bucuresti Frumos (A Beautiful Bucharest) and invested US\$103,155 in the restoration of facades in the Old Town - approaching the disastrous situation of the fabric and infrastructure in the area as a matter of cosmetic repair, 


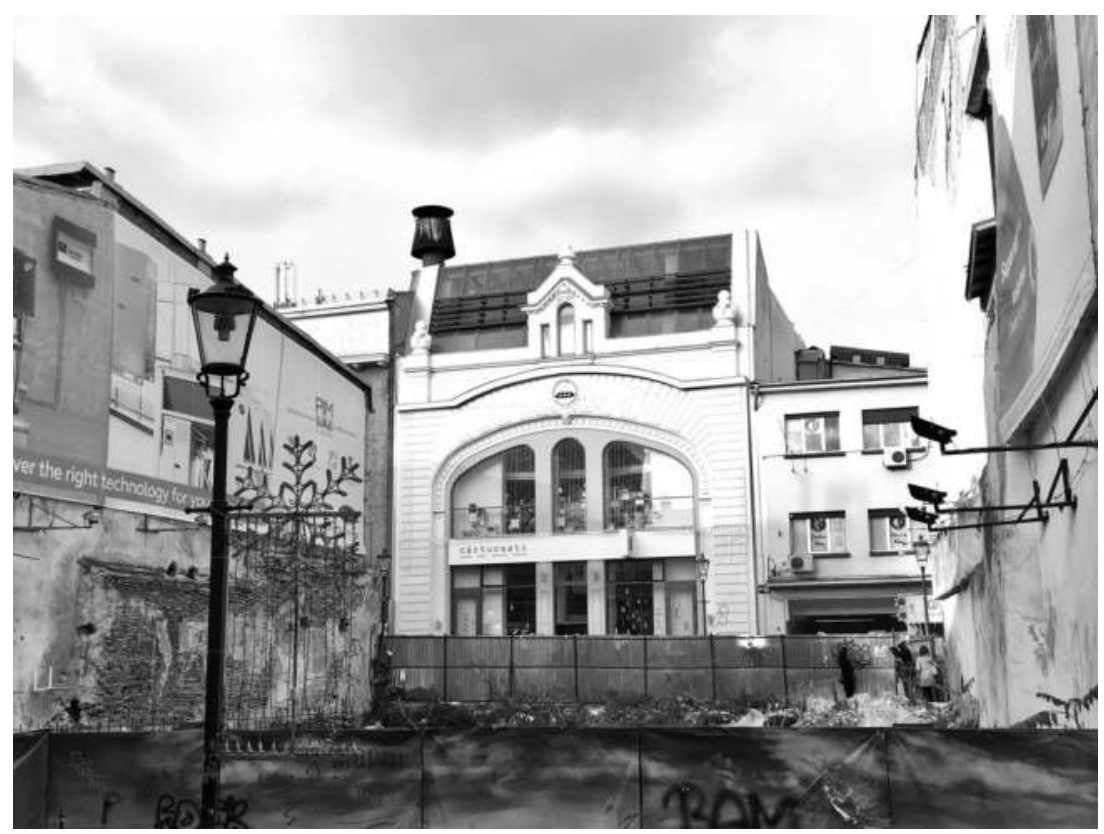

Figure 7.1 Abandoned places vs. modernization and gentrification in the Old Town. (Daniel Habit)

rather than of a sustainable development (Primăria Municipiului Bucureşti 2004). As various plans were made and contests announced but only partially implemented, Augustin Ioan stated in 2006 that "the lack of effective public administration and consistent urban policies has delayed the realization of winning urban design projects from several competitions, leaving downtown Bucharest as a vacant playground for consumerism" (Ioan 2006, 346). Accordingly, in 2006, the area was still a somewhat anonymous place in the process of reconfiguration, an "obsolete area buried in oblivion" (Dumitrache and Nae 2013, 194), with badly paved streets, collapsing facades, empty or occupied houses, a malfunctioning sewage and garbage system, and inhabited by a sizeable number of stray dogs, turning the place into a combat area between humans and animals at night (Figure 7.2). ${ }^{14}$

In the following years, Lipscani went through a phase of massive restoration by the authorities and investment from the private sector, turning the area first into an ongoing site of construction and then into a monofunctional space of consumption and entertainment, reminiscent of Marc Augés concept of the "solitary contractuality" that is inherent in nonplaces, in contrast to the more organic sociality of lived places (Augé 1995). This development, oriented on profit margins and consumers' per capita expenditure, was carried out through a close cooperation between city hall 


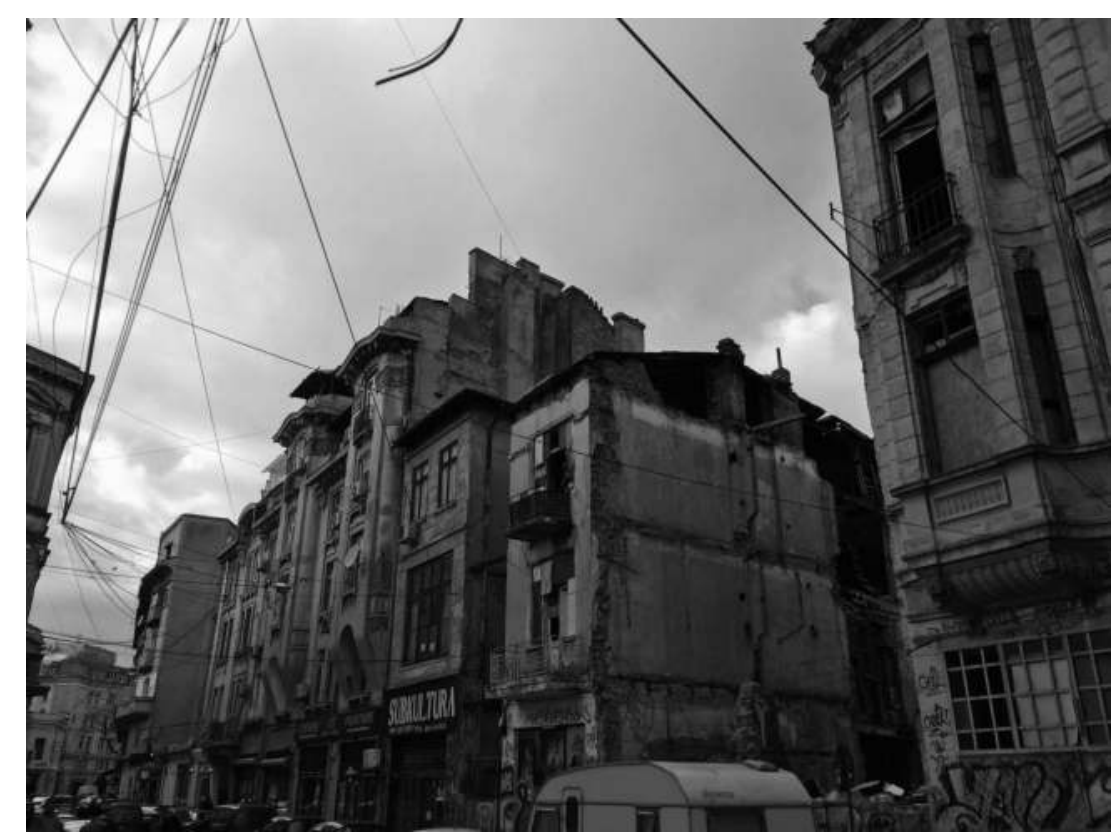

Figure 7.2 Poor building fabric in the Old Town. (Daniel Habit)

and private investors, often in the form of private-public partnerships that employed different tools but followed the overall vision of a "new" Old Town. ${ }^{15}$ According to the municipality's plans, the new City Centre should contribute to the "quality of urban life." Therefore, one of the first strategies carried out by the municipality focused on a "cleansing" of the area, by getting rid of everything and everyone that did not fit into the parameters of a new center, including people, animals, history or, to be more precise, the supersession and displacement of disruptive inhabitants (many of them belonging to Roma communities, living in abandoned buildings), solving the stray dog problem (by castration or euthanasia) and, coming back to the Court Museum, by symbolic renaming. Its socialist reference had been gotten rid of in 1990 by naming it after interwar Prime Minister Iuliu Maniu, and, in 2007, when Iuliu Maniu received his own boulevard, it was named Strada Franceza, in a politically neutral act, demonstrating again a shift in official historic (self-)references. ${ }^{16}$ Accordingly, the nearby Church of Saint Anthony, one of the oldest religious buildings in Bucharest, was restored. After the fall of socialism, the strong historical link between the Orthodox Church and the nation was reconstructed and brought to new prominence "by transferring the responsibility of all social evils to socialism and by portraying the church as an anti-socialist Messiah" (Novac 2012, 82). The Orthodox Church has been gaining increasing influence and state funding 
especially in recent years. The restoration of all eight orthodox churches in the Old Town, which is by now mostly complete, and the inauguration of the "People's Salvation Cathedral," one of world's largest Orthodox Churches, next to the Palace of Parliament, in 2018, illustrate the strength of a "post-secular turn" described by Jürgen Habermas and others (Habermas 2006; Stan and Turcescu 2007) in Romania. Religion and its materialization gained increasing attention in the public sphere. Other measures contributed to a further self-culturalization of the city, perhaps most prominently the restoration of the so-called Arcub (City Hall Center for Cultural Projects), the former Gabroveni Inn, dating back to 1739. It was turned into a performance and exhibition hall oriented toward performances and exhibits by renowned artists attended mostly by well-off, culturally interested citizens, whereas the creative industries and subcultural movements are more likely to be found in other areas of the city. ${ }^{17}$

The second strategy, carried out by private investors, quickly commodified the area through consumer culture and a focus on "experience economy." In 2007, 12 gastronomic places were to be found, some of them using abandoned places, respectively places with unclear ownership, simply by putting up a fridge and some music equipment. In 2018, 164 bars, restaurants, clubs, coffee shops, nightclubs and other venues were waiting to be visited. Eight hostels, nine hotels and more than 150 apartments rented out through Airbnb offer accommodation for tourists, contributing to community displacement and the gentrification of the area in general. ${ }^{18}$ As rents increased enormously, the competition among the venues is hard, leading to a quick turnover of places, owners and employees. Many of the places share a similar gastronomic concept (such as pub, trattoria or bistro), concentrate on a stereotypical "Romanian" cuisine with folkloristic ambience, standardized global types of ethnical food (Argentinian steak house, Japanese sushi bar, Greek taverna) or are run as franchises. Although prices are quite high for Romanian standards, most of the places make their profit primarily on weekends when the area is filled up with an amusement-seeking audience using the area as a stage for sociability. Other than the rather cosmetic improvements by the municipality, the development of the area was left to private investors that easily adopted the customers' apparent desires for a consumable Old Town as it can be found in many other European cities. Although local authorities developed plans of action, they were blindsided by the normative force of the factual and, therefore, soon primarily concerned with the post-factum legalization of the damage done, forbearing obvious misconduct such as missing papers, legislations, emergency exits, ignored hygienic standards and noise regulations (Totelecan 2015) ${ }^{19}$ To some extent, this situation of uncontrolled development and a lack of standards changed after the so-called Colectiv tragedy in 2015, when a fire in a night club killed 64 people. ${ }^{20}$ As a result, more emphasis was put on safety-law enforcement and the adoption of standards, resulting in shut-downs of bars and restaurants. As interview partners stated in 2016/17, these measures followed rather 


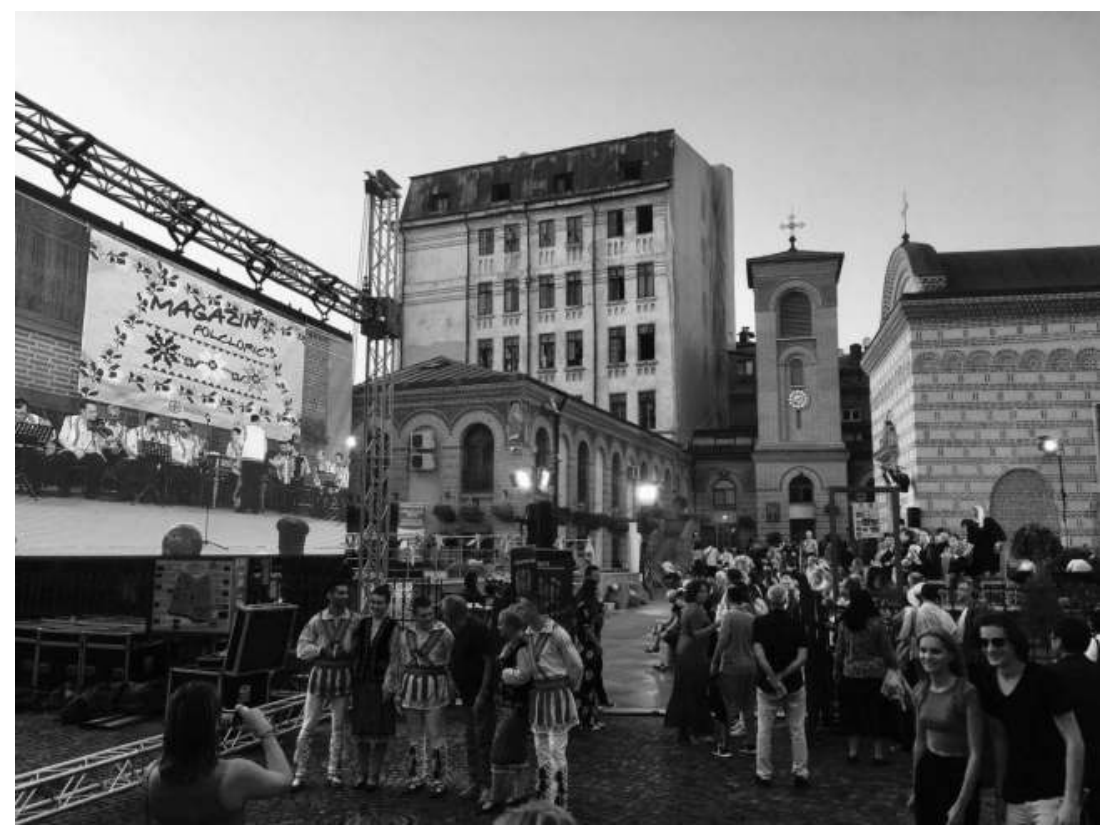

Figure 7.3 Romanian folklorism and Orthodox events in the Old Court. (Daniel Habit)

arbitrary parameters and were easy to bypass within an often corrupt and public administration system lacking checks and balances (Figure 7.3). ${ }^{21}$

In recent years, several NGOs that campaign for the built environment in Bucharest have raised their voices against the economically driven developments in the building sector, employing a strong rhetoric of explicitly moral statements and judgments and calling for a more ethical city. New office buildings, by their sheer appearance, are taken to exemplify "both the corruption in the municipal offices (which issue illegal construction permits that affect the historical substance of the city) and the questionable decisions (in terms of collective profit and public good) of the city's administration" (Ghyka 2015, 150). Not only are they heavily violating and ignoring the urban fabric with its historical monuments, they are also reminiscent of the demolitions and redevelopments during socialist times. Neoliberal, market-driven interventions into urban space were accompanied by a growing number of protests from civil society, which gained increasing attention and visibility in the discourse on the development of the city. This also led to disruption in the political system by the establishment of new parties, proclaiming, among other goals, a better life in the city on various levels. ${ }^{22}$ In the case of the Old Town, for example, the association of architects stated that the "Lipscani area is representative of the multitude of approaches that lead to the general depreciation of the artistic and architectural character of the area as a 
whole" (Ordinului Arhitecţilor din România 2016, 42). Other urban activists documented illegal demolitions of historic buildings, protested against evictions or found creative ways to condemn corruption and the general spatial violence carried out by both the municipality and the private sector. ${ }^{23}$

\section{Conclusion}

The Old Town of Bucharest illustrates the ongoing negotiation of several aspects of urban ethics, as this chapter tries to show through a historical and phenomenological approach. A focus on urban ethics can help decipher several aspects of urban history that are often ignored or kept apart. Rather than delivering a comprehensive analysis, the chapter has tried to show the potential of this critical approach to spatial configurations, its linkage to morality and politics, always implicitly "asking what has been gained and what has been lost in this process of making it what it is" (Fassin 2012, 15). Different discursive conceptualization and attributions of the "good" and the "bad" (and, as many statements showed, the ugly) in the urban center reveal the dominant political and economic climate in different phases, conflicts over institutional moralities and strategies of governance associated with them, the intertwining of ethics and aesthetics, and also the clash of planning strategies, ideologies and realities on the ground. Strategies of appropriation, which I was only able to mention here cursorily, show creative ways of coping with this unique area that served as a playground for moral evaluations and prescriptions by various stakeholders over the last decades and with the interventions into it. Following Jarrett Zigon (2010), the social reality of the Old Town is assembled by its built materiality and the changing moral attributions to it. The stakeholders engaging with it in different forms, with different motivations and sorts of capital, thus, contribute to "a multitude of multi-aspectual moral and ethical assemblages" (Zigon 2010, 13) that have been part of the history of modern Romania since the end of World War I. Despite its singularity among the different quarters of Bucharest, all of which have their very specific local history, order and logic, the Old Town and its development - from the reenacted cradle of the nation and the moral burden that went along with it during socialism, to a fallow land inhabited mostly by outsiders, invisible to much of mainstream urban society during transition, and then a commodified, monofunctional destination for the urban middle class and tourists - represent the development of many crucial aspects of the whole city in a nutshell. It reveals the complexity of almost all dominant discourses on the "good" and "proper" life in the city and the diverse and contradictory transformation of the city including its spatial violence.

\section{Notes}

1 Rare footage of these celebrations is to be found on YouTube; see https://youtu. be/r9xbVr8qq5A. 
2 Communist poet Stefan Augustin Doinas, for example, describes the largest building in Europe in the following way:

Every metropolis is a labyrinth that has its devouring monster. In Bucharest, however, this monster seems to have appeared in the form of a dictatorial couple very keen on building its Daedalus type of habitat, the People's House, like a memento for the next generation that speaks against the lack of measure and grotesque.

(Harhoiu 2001, 18)

3 Geographer Craig Young and Duncan Light highlight the different sites and forms of memory and countermemory in the Romanian capital in their article on "multiple and contested geographies of memory," stressing the importance of the University square for the everyday memory of the "revolution" (Young and Light 2017). As political scientist Lavinia Stan shows in her work, these "unofficial truth" projects play an important role in the ongoing negotiation of the "revolution" and include "the unauthorized release of secret information, a citizens' opinion tribunal, and numerous art, theater, movie, and literature projects focused on the communist past" (Stan 2012, 208).

4 Romanian society still struggles over the definition of the events of December 1989 more than 30 years later. Possible explanations in the media and in political and scientific discourses describe them as a people's revolution, a counterrevolution, a coup d'état carried out by Ceaușescu's opponents within the Romanian Communist Party or a terrorist act and a betrayal supported by foreign forces (Petrescu 2014).

5 This analysis is based on a subproject of the interdisciplinary research group "Urban Ethics. Conflicts around good and right urban lifestyle in the 20th and 21st centuries (2015-2018)" (FOR 2101 HA 2727/7-1, funded by DFG). The research focused on urban ethics in Bucharest and was conducted under the supervision of Guido Hausmann.

6 Some street names in the area preserve the names of old guilds and merchant activities, such as Saddlers' Street (Strada Șelari), Furriers' Street (Strada Blănari) or Milliner's Street (Strada Șepcari).

7 However, this part of the architectural history of the city was systematically denied during socialism, "precisely because the official endorsement of architecture as yet another form of producing a national socialist heritage could not allow for any resemblance with earlier, 'bourgeois' representations of 'the national past' " (Grama 2010, 100). In the context of the touristic commodification of the city since the 2010s, this special period, respectively, its mythological exaggeration, can be found in various fields of cultural production and from official stakeholders.

8 As several authors have underlined, the reference to Paris followed not only architectural citations but was also based on sociocultural and mental links, such as the adoption of certain habitual everyday rituals (Majuru 2014; Smochină 2012).

9 As Verdery and others pointed out, this idea of linking the Romanian socialist system to the past has to be seen as an essential part in the context of Ceaușescu's reconfiguration of Romanian society,

years of trying to build up a state resting on a teleology of progressive change and an ideology of internationalism had ended in the realization that the state could adequately construct itself only in terms of what it had at first denied: a teleology of national continuity and an ideology of national values, premised on internal uniformity.

(Verdery 1996, 131; cf. Gabanyi 2000; Tomiţă 2007) 
10 Two other important landmarks for the socialist time have to be mentioned here, as they contributed greatly to the atmosphere of the area, implying the two sides of possible entertainment: First, the Caru cu Bere beerhouse, founded in 1879, served those who could afford to go there during socialist times, mainly the nomenclature. "Eating in these places was almost the same as saying that you are very well seen by the Communist Party, if not a full-blown nomenclature member" (Totelecan 2015, 8). Second, Club A, a club founded by architectural students during the time of ideological liberalization in 1969, offered one of the few places for subcultural activities in the city.

11 As Grama states:

As much as the state officials initially tried to change the site and its people by opening the Old Court Museum and systematically bringing in delegations of workers and pioneers from all over the country to see the historical walls of Bucharest, networks of illegal commerce continued to prosper on the nearby streets. By the 1980s, the state officials gave up, allowing the provincial visitors who came to the Old Court Museum for their share of national history to acquire, under the knowing eyes of the police, also their share of black-market goods from next door.

(Grama 2009, 180)

12 Material, especially for this chapter, relies on empirical data drawn from firsthand observation, in-depth interviews, life stories and institutional reports gathered over years of fieldwork conducted individually in 2007/2008 and between 2014 and 2017.

13 As geographer Joachim Vossen shows, the socialist regime left a large number of projects, mainly in the building sector, unfinished. In 1990, more than 30,000 apartments were in the phase of construction. Even in 2019, some "left-over" spaces of state-socialism" (Light and Young 2010) are to be found in Bucharest, such as the fallow land behind the new National Library (a project started in the 1980s) or the still standing ruins of Casa Radio, planned to serve as the museum of the Romanian Communist Party, which are an ongoing object of speculation.

14 According to estimates, more than 100,000 stray dogs lived in the streets of Bucharest at that time. As social anthropologist Ger Duizings states,

they attack much more ferociously when it gets dark, one of the most fascinating aspects of the urban night in Bucharest and an interesting inversion of the usual (daytime) patterns. Although dogs are normally diurnal animals, stray dogs come alive especially during the evening and the night. It is then that they feel unhindered and unthreatened by people. The night is when the day turns black and this is the moment they feel they can strike back.

(Duizings 2011, 148; cf. Karamaniola 2017)

The deadly attack on a 68-year-old Japanese businessman in 2006 is still part of the communicative memory in 2018 concerning the transition period of the Old Town.

15 This close cooperation is to be found in the municipality's plans for the restoration of the area, where the private sector and its local investments are emphasized and tourists are to be addressed: "In the area there are also special values of cultural, historical, architectural heritage, the proximity to the historical center offering a potential with tourist valences" (Primăria Municipiului Bucureşti 2002, 30).

16 This reconfiguration of time and space can take place during all the different changes in the political system. In contrast to urban planning or the symbolic teardown of obnoxious statues, these changes within the urban topology can 
be interpreted as political propaganda with a high external effect, "through renamings, the new regime proclaims the beginning of a new era while demonstrating both its resoluteness and its self-confidence, renaming streets is both a celebration of triumph and a mechanism for settling scores with the vanquished regime" (Azaryahu 1996, 318). A total of 288 street names in Bucharest were changed after 1990, compared to cities like Moscow (153) or Berlin (80).

17 Subcultural-orientated interviewees showed their widespread disapproval when asked about this institution and the development of the Old Town in general. Nevertheless, the place plays an important role as a cultural landmark within the self-culturalization of the city, as can be seen in the (unsuccessful) application of Bucharest for the title of European Capital of Culture 2021.

18 Although there is no exact number of the apartments on Airbnb available, the number has increased in the few last years. The vast majority of apartments in Bucharest are inhabited by their owners and a rental market is almost nonexistent. More and more apartments are available for short-term rent because many highly qualified Romanians have left their country in recent years. According to the Romanian fiscal code, there is a $16 \%$ tax on the income gained through rental, but as the state has no possibility of controlling this informal economy, the tax refunds are negligible (Treapăt et al. 2018).

19 As Romanian geographer Totelecan points out,

in fine-tuning with the global route of money, images, goods and desires and on behalf of the welfare through development, the warfare like interventions upon the former built environment wiped out the local history of the place, and made it ready to deliver "bread and circuses" on daily basis.

(Totelecan 2015, 8)

20 The approximately 400 visitors to the concerts tried to escape through the only working exit, creating a stampede. The tragedy led to a series of protests beginning on November 3,2015, leading to a series of resignations of politicians on all levels, sentences against those responsible and ongoing shifts in the political system (Rammelt 2017). Bucharest-based British journalist Craig Turp stressed the importance of these developments, calling it a paradigm shift within Romanian society; the fire at the Club Colectiv "will in future be a reference point for historians of modern Romania every bit as important as the earthquake of 1977 or the revolution of 1989" (Turp 2015).

21 In an interview with a firefighter, he said that he would not let his children go to Centrul Vechi because of the lack of an evacuation plan. Crowded and narrow streets occupied by terraces and garbage, blocked by concrete street pillars (which were placed in order to fight the volume of traffic), a lack of water hydrants and emergency exits would turn the whole area into a high-risk district.

22 Civic activist Nicușor Dan founded the party "Save Bucharest Union” on July 1, 2015, based on the activities of the NGO "Save Bucharest Association." Following their success in the local elections, the party transformed into "Save Romania Union" and currently constitutes the third largest political party in the Romanian Parliament.

23 For example, www.observatorulurban.ro, http://fcdl.ro, or www.piatadespaga. ro; the latter provides an open street map where citizens can mark cases of corruption.

\section{Bibliography}

Augé, Marc. 1995. Non-Places: Introduction to an Anthropology of Supermodernity. London: Verso. 
Azaryahu, Maoz. 1996. "The Power of Commemorative Street Names." Environment and Planning: Society and Space 14, no. 3: 31-30. doi: 10.1068/d140311.

Cernat, Vasile. 2012. "Ethnic Conflict and Reconciliation in Post-Communist Romania." In Peace Psychology in the Balkans: Dealing with a Violent Past while Building Peace, edited by Olivera Simic, Zala Volčič, and Catherine R. Philpot, 17-34. New York: Springer.

Derer, Hanna. 2015. "Building Urbanity in Bucharest." sITA studii de Istoria şi Teoria Arhitecturii 3: 48-63.

Duizings, Ger. 2011. "Dictators, Dogs, and Survival in a Post-Totalitarian City." In Urban Constellations, edited by Matthew Gandy, 145-8. Berlin: Jovis.

Dumitrache, Liliana, and Mariana Nae. 2013. "Urban Regeneration and Affective Connections to Place in Bucharest City Centre." Analele Universitatii Bucuresti: Geografie 2013: 187-202.

Enache, Christina, and Marina Mihaila. 2013. "A Discussion about New Bucharest ShoppingScapes." AE Revista Lusofona de Arquitectura e Educacao 8/9: 521-39.

Fassin, Didier. 2012. "Introduction: Toward a Critical Moral Anthropology." In A Companion to Moral Anthropology, edited by Didier Fassin, 1-17. Chichester: Wiley-Blackwell.

Gabanyi, Ute. 2000. The Ceauşescu Cult. Bucharest: The Romanian Cultural Foundation Publishing House.

Ghyka, Celia. 2015. "Urbanity and Civil Society. The Rise of a New Urban Generation in Bucharest during the 2000s." sITA studii de Istoria şi Teoria Arhitecturii 3: $149-59$.

Grama, Emanuela. 2009. "Letters, Plans, and Walls: Architects and Archaeologists in the 1960s Bucharest." Anthropology of East Europe Review 27, no. 2: 56-67.

Grama, Emanuela. 2010. "Searching for Heritage, Building Politics: Architecture, Archeology, and Imageries of Social Order in Romania (1947-2007).” PhD diss., University of Michigan. Accessed May 28, 2019. http://deepblue.lib.umich.edu/ handle/2027.42/78818.

Grama, Emanuela. 2012. "Impenetrable Plans and Porous Expertise: Building a Socialist Bucharest, Reconstructing Its Past (1953-1968)." EUI Working Papers, Max Weber Programme 2012/2013. Florence: European University Institute.

Habermas, Jürgen. 2006. "Religion in the Public Sphere." European Journal of Philosophy 14, no. 1: 1-25. doi: 10.1111/j.1468-0378.2006.00241.x

Harhoiu, Dana. 2001. Bucharest: A city Between Orient and Occident. Bucharest: Editura Simetria ArCuB.

Ioan, Augustin. 1997. “Dupã Armaghedon.” Secolul XX, nos. 5-7: 268-76.

Ioan, Augustin. 2006. "Urban Policies and the Politics of Public Space in Bucharest." In The Urban Mosaic of Post-socialist Europe: Space, Institutions and Policy, edited by Sasha Tsenkova and Zorica Nedović-Budić, 337-48. New York: Springer.

Karamaniola, Lavrentia. 2017. "Bucharest Barks: Street Dogs, Urban Lifestyle Aspirations, and the Non-Civilized City." PhD diss., University of Michigan. Accessed May 18, 2019. http://hdl.handle.net/2027.42/138453.

Light, Duncan, and Craig Young. 2013. "Urban Space, Political Identity and the Unwanted Legacies of State Socialism: Bucharest's Problematic Centrul Civic in the Post-socialist Era." Nationalities Paper 41, no. 4: 515-35. doi: 10.1080/00905992.2012.743512.

Light, Duncan, and Craig Young. 2017. "Memory, Commemorative Landscapes and Transistional Justice." In Justice, Memory and Redress in Romania. New 
Insights, edited by Lavinia Stan and Lucian Turcescu, 145-65. Cambridge: Cambridge Scholars Publishing.

Majuru, Adrian. 2014. Stadt der Verlockungen. Das vormoderne Bukarest zwischen Europa und Orient. Berlin: Timme.

McCann, Eugene, and Kevin Ward. 2012. "Assembling Urbanism: Following Policies and 'Studying Through' the Sites and Situations of Policy Making." Environment and Planning 44: 42-51. doi: 10.1068/a44178.

McGuinness, Patrick. 2011. The Last Hundred Days. London: Bloomsbury.

Niessen, James P. 2002. "Naţionalismul românesc: o ideologie a integrării şi mobilizării." In Naţionalismul est-european în secolul al XX-lea, edited by Peter F. Sugar, 226-50. Bucharest: Curtea Veche.

Novac, Sergiu. 2012. "Post-Secular Bucharest? The Politics of Space in the Case of the 'Cathedral of National Redemption'." JB StadtRegion 1: 81-98. doi: 10.3224/ jbsr.v7i1.04.

Ordinului Arhitecților din România. 2016. Raportul pentru București. Bucharest: Filiala Teritorială București a Ordinului Arhitecților din România.

Petrescu, Dragoş. 2009. "Building the Nation, Instrumentalizing Nationalism: Revisiting Romanian National-Communism, 1956-1989.” Nationalities Papers 37, no. 4: 523-44. doi: 10.1080/00905990902985728.

Petrescu, Dragoş. 2014. "The Revolution of 1989 and the Rashomon Effect: Recollections of the Collapse of Communism in Romania." In Remembering Communism: Private and Public Recollections of Lived Experience in Southeast Europe, edited by Maria Todorova, Augusta Dimou, and Stefan Troebst, 533-48. Budapest: Central European University Press.

Popa, Maria Raluca. 2006. "The 'Wounded' City: Remembering Socialist Restructuring and Reinventing Bucharest after 1989." New Europe College Yearbook 2016: 313-57.

Primăria Municipiului Bucureşti. 2004. "Program de dezvoltare a Municipiului Bucuresti 2000-2008.” Bucuresti: Primăria Municipiului Bucuresti. Accessed May 4, 2019. http://www2.pmb.ro/primarul/prioritati_proiecte/proiecte_2000_2008/ docs/22-33.pdf.

Rammelt, Henry. 2017. "How Romania is Developing Its Own Culture of Protest." Euronews, February 6, 2017. Accessed April 18, 2018. http://www.euronews. com/2017/02/06/view-romania-politics-protests-corruption.

Răuţă, Alexandru. 2013. "Civic Centers under Ceauşescu's Rule. The Failure to Articulate a Professional Discourse." sITA - studii de Istoria şi Teoria Arhitecturii 1: 105-19.

Reckwitz, Andrea. 2009. "Die Selbstkulturalisierung der Stadt. Zur Transformation moderner Urbanität in der 'creative city'." Mittelweg 36, no. 2: 2-34.

Smochină, Laura. 2012. "Die Stadt in der rumänischen Literatur.” PhD diss., University of Vienna. Accessed June 6, 2019. http://othes.univie.ac.at/19039/.

Stan, Lavinia. 2012. Transitional Justice in Post-Communist Romania. Cambridge: Cambridge University Press.

Stan, Lavinia, and Lucian Turcescu. 2007. Religion and Politics in Post-Communist Romania. Oxford: Oxford University Press.

Tomiţă, Alexandra. 2007. O istorie "glorioasă:" Dosarul protocronismului românesc. Bucharest: Editura Cartea Românească.

Totelecan, Silviu. 2015. "Eating Out: (Re)searching the Labs of Social(bi)lity." Seria Humanistica 13: 7-28. 
Treapăt, Laurenţiu-Mihai, Anda Gheorghiu, and Marina Ochkovskaya. 2018. "A Synthesis of the Sharing Economy in Romania and Russia." In Knowledge Management in the Sharing Economy. Knowledge Management and Organizational Learning, edited by Elena-Mădălina Vătămănescu and Florina Magdalena Pînzaru, 57-73. New York: Springer.

Tsenkova, Sasha, and Zorica Nedović-Budić, eds. 2013. The Urban Mosaic of Post-Socialist Europe: Space, Institutions and Policy. New York: Springer.

Turp, Craig. 2015. "Romania Has a Prime Minister. What Now?" Bucharestlife, November 11, 2015. Accessed February 17, 2017. http://www.bucharestlife. net/2015/11/romania-has-a-prime-minister-what-now/.

Verdery, Katherine. 1991. National Ideology under Socialism: Identity and Cultural Politics in Ceaușescu's Romania. Berkeley: University of California Press.

Verdery, Katherine. 1996. What Was Socialism, and What Comes Next? Princeton, NJ: Princeton University Press.

Vossen, Joachim. 2004. Bukarest. Die Entwicklung des Stadtraum. Berlin: Reimer.

Wakeman, Rosemary. 2014. "Was There an Ideal Socialist City? Socialist New Towns as Modern Dreamscapes." In Transnationalism and the German City, edited by Jeffry M. Diefendorf and Janet Ward, 105-24. New York: Springer.

Zigon, Jarrett. 2010. "Moral and Ethical Assemblages. A Response to Fassin and Stoczkowski." Anthropological Theory 10, nos. 1-2: 3-15. doi: 10.1177/146349961 0370520 . 


\title{
$8 \quad 1968$ and beyond
}

\section{The urban struggle on trial?}

\author{
Isabelle Doucet in conversation with \\ Maurice Culot
}

\section{Introduction (by Isabelle Doucet) ${ }^{1}$}

The international colloquium La Reconstruction de la Ville Européenne took place in Brussels, Belgium, between November 15 and 17, 1978. It would lead to the Déclaration de Bruxelles, a book including a manifesto published by the Archives d'Architecture Moderne in 1980. The manifesto was signed by the participants of the colloquium, who "proclaimed their conviction that the European city could be repaired" (Barey 1980, 17). These included Pierre Laconte, Jacques Lucan, Jean Castex, Antoine Grumbach, Léon Krier, François Loyer, René Schoonbrodt, Jacques Van der Biest, Fernando Montes, Bernard Huet, Robert Delevoy, André Barey, Maurice Culot, Philippe Panerai, and Pierluigi Nicolin. Resonant with other seminal texts of the time, notably Maurice Culot and Léon Krier's "The Only Path for Architecture" (1978) and their book Counterprojects (Krier and Culot 1980), the Déclaration de Bruxelles manifesto summarized, in just one page (Barey 1980, 17), the main ideas and intentions of these architects. They criticized how, for decades, the cultural heritage and close-knit inner-city neighborhoods of cities had been subjected to far-going destruction, or the threat thereof, for the sake of large-scale urban modernization works. In response, the Déclaration signatories called for the reconstruction and repairing of the European city. They called on architects to support the urban struggles of organized citizens, to integrate the task of urban repairing into their pedagogy, to reconnect knowing and doing in architecture through a focus on construction, and to think of conservation not just for monuments but applied to all of the urban patrimony.

Good cities (livable, democratic) were defined as composed of neighborhoods, streets and squares, rather than a city organized through motorways and functional zoning. It is a compact city, clearly distinguished from the countryside, which is based on mixed use, so that rather than commuting into the city from the suburbs, one instead lives and works in proximity. Functionalist urbanism is rejected, as are industrial methods of production. In addition to this "anti-industrial resistance," architects were to tame their unbridled creativity: "[T]he city and its neighbourhoods can no longer be 
used as a field of experimentation for architects" (Culot and Krier 1978, 351). Instead, architects were called to work with the city that is already there, the historic city that is deemed to be familiar to all.

Under the banner of the Reconstruction of the European City, a movement of like-minded architects emerged across Europe, promoting a specific interpretation of and physical shape for the "good" city. This view of what makes a good city was also a product of May 1968, a time when the architectural profession went through a period of self-reflection regarding the social responsibility of architects, the audiences of architecture (elite customers, those in power or the everyday inhabitants of the city) and the profession's (unavoidable yet questionable) alliance with capitalism. Spurred by the grassroots activism emerging in cities across Europe throughout the 1970s, some architects joined the luttes urbaines (urban struggles) in their cities. The city, thus, emerged as a "revolutionary instrument"; questions regarding urban form were argued to always go hand in hand with the urban struggle (Culot 1980).

In Léon Krier's theorizations of the ideal physical form for the city, the city was modelled on the historic forms and dimensions of "the best and most beautiful preindustrial cities" (Krier 1980). The city composed of streets and squares was to be made of functionally mixed neighborhoods "not to exceed 35 ha and 15,000 inhabitants" (Krier 1980). But even if the shape and appearance of the city would become defined with precision, Should become:

.... For Maurice Culot, the stakes still seemed to be that of the urban struggle. In a compelling paragraph taken from the Counterprojects book that I have also cited elsewhere and find important to include here again, Culot argues that at stake is "the battle to retain the liberating tool which is the city and to maximize its gains to the profit of the working class i.e. the victims in an advanced industrial society" (Culot 1980).

The neotraditional city would travel well as a model for the postmodern city throughout the 1980s and 1990s. This view of the city, often disliked by progressive architects but seemingly embraced in many urban development schemes, was also criticized for having abandoned its grassroots political roots in favor of a more cultural activism. British architect Cedric Price, for example, had already drawn attention to these contradictions in response to Culot's talk in London in July 1976, as part of the Art Net lecture series (Culot 1976). Price argued that the obsession with a return to the European city risked creating a dependency on precisely the kinds of jobs that are the worst paid and most exploited (Price lists, for example, dustmen, sidewalk repairers, bus drivers, milkmen and sewer cleaners).

I publish in this chapter, in translation from French, a conversation with Maurice Culot, who can be considered a protagonist in the promotion of the European postmodern city. Not only was he a co-founder of the Archives d'Architecture Moderne (AAM), which published the Déclaration de 
Bruxelles, and of the Atelier de Recherche et d'Action Urbaines (ARAU), which coordinated and supported the grassroots urban activism of numerous citizen committees in Brussels. Culot was also a teacher at the École Nationale Supérieure d'Architecture et des Arts Visuels (La Cambre) in Brussels between 1972 and 1979, where his students designed numerous counter-projects. Counter-projects are instrumental to the understanding of the activism of the movement (Doucet 2015, 39-78) in that they offered a critique "through" the project of architecture and the city. They, thus, combined critique with alternative proposal. They had, informed by Henri Lefebvre's conceptualization of Le Droit à la Ville (Right to the City) in 1968 , emerged from the grassroots urban politics of numerous action committees in Brussels since the late 1960s. The many counter-projects designed by the members of action committees, the ARAU, AAM and students at La Cambre, intended to serve as tools for provoking debates around the development of the city, initially applied to specific sites and problems but gradually taking the shape of autonomous theoretical exercises, and were never realized. ${ }^{2}$ However, they arguably had a long-lasting effect on urban thinking and urban design in Brussels.

The conversation published here offers a discussion on the origins of the Reconstruction of the European City model at a time when we are still living through the effects and legacies of the movement. The conversation, in my view, also prompts questions regarding the difficulty of discussing urban ethics through not just the theories, ideologies and designs of the urban condition but also the (long-term) effects thereof. The design solutions developed by architects and urban designers - the democratic, livable and reconstructed city that is accessible to all - have become widespread. Now that their historical referencing has become considered reactionary and conservative, it is important to revisit the political ambiguities and aesthetic translations in existence at the origins of the movement. It is equally important to study the (desired and undesired) effects of the just city ideals over nearly five decades. To do so, a more detailed and geographically expanded unpacking of the movement's complex and multifaceted history is, of course, needed. ${ }^{3}$ This conversation with Culot offers a modest attempt to begin revisiting some of the opportunities, struggles and challenges of the Reconstruction of the City approach to urban ethics.

Notwithstanding its informal nature, the dialogue hints at concerns that can be seen as anchor points regarding larger research questions related to urban ethics. It seems to suggest, for example, discussing urban ethics in ideological-conceptual terms symptomatic of the wider efforts of the time toward the Right to the City but also through the specific circumstances of a city. Brussels of the 1970s had undergone decades of destructive urbanism whereby popular neighborhoods had been demolished and their inhabitants expelled. That many other cities underwent similar traumas is evinced by, for example, the efforts to protect the Covent Garden area in London and Les Halles in Paris and, of course, famously by Jane Jacobs's writings 
and activism in New York. The use of the term "Bruxellization" to depict a city falling victim to destructive urban development gives us some indication of the perceived severity of that destruction in Brussels. The reactions against the destruction of the city also took a specific shape in Brussels in that a form of urban activism emerged that combined grassroots urban politics (through numerous citizen action committees coordinated by the ARAU) with historical-cultural activism (AAM) and architecture education (La Cambre). This combined activism resonates with the recommendations formulated by the Déclaration: The struggles of ARAU, the cultural preservation work of the AAM and Culot's teaching at La Cambre mobilizing students to the service of the urban struggle. In the conversation, Culot, moreover, hints at how support for the urban struggle can come from unexpected corners. While the European presence in Brussels was seen as part of the problem - the instalment of the European Economic Community in Brussels resulting in dense residential fabric being erased was criticized explicitly in the Déclaration - it also triggered visibility for the urban struggles. Culot claims that The Bulletin, the journal read by internationals in Brussels, reported on the actions of the ARAU, thus distributing a sense of disapproval with the destruction of the city among its international readership.

The interview also seems to suggest that studying the urban ethics at the basis of the Right to the City struggle means also looking into the practical manifestations, consequences and afterlives of the design solutions formulated in response to this struggle. The Reconstruction of the European City offered a view of the city that received widespread mainstream support, evidenced through international foundations, awards and prominent supporters, such as the Council of European Urbanism, the Foundation of the Urban Environment, the Prix Européen d'Architecture Philippe Rottier and, in the United Kingdom, HRH The Prince of Wales (see Jencks 1988). Ideas connected to the European city found resonance in projects such as Poundbury in the United Kingdom and the New Urbanism in the United States. In the conversation, we talk about the tensions between the original refusal to build (so as to not be complicit with the capitalist forces believed to be destroying the just city) and leading an active architectural firm in Paris. Léon Krier's theories for the city, the Déclaration and the Reconstruction of the European City instigated a widespread image of the postmodern city that is still actively promoted today. ${ }^{4}$ Despite such continued popularity and the growing interest in postmodernism among historians of architecture, the postmodern city, as promoted by the Déclaration, deserves still further critical historical attention. ${ }^{5}$

We can also take from the conversation that the struggle for just, good and livable cities can sprout from a wide range of, sometimes contradictory, positionings, inspirations and desires, and can be informed not only by global influences and intellectual alliances, but also by personal desires and opportunisms. We learn how the Reconstruction of the City, while largely 
associated with Krier's project for the city, developed through a more pluralist set of influences, including the techno-utopias of Archigram. ${ }^{6}$ We have to work carefully through these different and seemingly disparate influences. In our conversation, Culot also points toward personal desires and histories that can accompany urban ethics. Ethical questions become also complicated and personal when architects block the projects proposed by colleague architects, or, when they find themselves accepting project commissions that they would have previously deemed questionable.

For all the reasons above, I feel that the origins, legacies and afterlives of the Déclaration prompt fruitful discussions about what it means to conceptualize urban ethics and design for and build good cities. From the outset, my interest in this movement was motivated by an urge to begin to digest a difficult part of the architectural history in Brussels and its role in European postmodern urbanism. It was also motivated by my fascination with the counter-project that, in combining critique with alternative proposal, potentially offered a compelling tool for activism in architectural culture. This published conversation with Maurice Culot offers a suitable conclusion to that personal scholarly trajectory dedicated to counter-projects in Brussels (Doucet 2013, 2015, 39-78, 2016, 2017). Importantly, it also offers a bridge toward unearthing a broader range of actors beyond the obvious and recognized protagonists (including decision-makers, developers, architecture students, cultural foundations) involved in the advancement of the postmodern city and a wider geographical scope of projects for the postmodern city (see Doucet, Gosseye and Kockelkorn 2019).

\section{An iconography of resistance between Archigram, Léon Krier and François Spoerry (Isabelle Doucet in conversation with Maurice Culot) ${ }^{7}$}

ISABELLE DOUCET: I have studied counter-projects for quite some time now, a tool for activism that has fascinated me for its combination of critiquing a spatial situation with the formulation of an alternative proposal. Counter-projects propose a critique that take place through the project of architecture and the city and constituted a reaction against the demolition of the historical city and the destruction of popular neighborhoods for the sake of large-scale modernization works, including high-rise office towers, urban highways and modern housing blocks. Against this destruction, counter-projects proposed a reconstruction of the traditional city, namely, the city that is already familiar to all and is organized on the scale of streets and squares, and neighborhoods characterized by proximity between work, living and leisure. Of the many counter-projects designed by the members of the ARAU, AAM and also with students at La Cambre, none were realized. But they still had an effect on urban thinking in Brussels in terms of what makes a liveable and democratic city. We could, therefore, begin our conversation 
with the role of Brussels in the development of a certain way of thinking about the city, that is, the European City, its history and the city on the scale of the neighborhood. But also: What is timely about the counterprojects as a tool for critique, especially now that we can observe today a renewed interest in the countercultural and resistant architectural practices of the 1960s and 1970s?

MAURICE CULOT: One of the advantages of Brussels compared to other European cities is its place in the European project. One could argue that even if Europe had not officially decided to adopt Brussels as its capital, it was, in effect, the capital city of Europe. Even if it was only provisional and transitionary, an economically comfortable European population would settle in this city next to an important existing population which had immigrated from the Maghreb countries, Turkey and Arabic countries. To be in this capital city, thus, meant that whatever actions one takes, they will always potentially have a much wider resonance. Many representatives of the international press are present in Brussels. One newspaper that would follow the activities of the ARAU is The Bulletin, the newspaper for English-speaking residents of Brussels. The Bulletin reported on the actions of the ARAU against those implementations of Europe that were to the detriment of living quarters in Brussels. A certain number of European functionaries agreed with the ARAU that one should not destroy neighborhoods and replace them with offices. Thanks to the international press, one was more sensitive to what was happening in Brussels. The so-called Battle of the Marolle of 1969 received, thanks to the European presence in Brussels, a broad international diffusion that it would otherwise not have received. ${ }^{8}$

ISABELLE DOUCET: Was this coverage by the mainstream international press matched by the architectural press? For example, while the intellectual affiliation between counter-projects and Léon Krier is wellknown and documented, the influence of Archigram, and notably Peter Cook, seems less known.

MAURICE CULOT: Absolutely. Even if both influences were there! As for the journals Architectural Design in London and Lotus in Italy, Léon Krier was the connection. He was known internationally and appreciated in France by Bernard Huet [editor of the periodical Architecture d'Aujourd'hui]. It was, in fact, Peter Cook who introduced me to Krier. The ideas of Archigram and Krier are, of course, very different, but I was interested in both. Krier brought a theoretical armature to the Brussels urban struggles; a reflection on the city beyond the everyday struggles. To understand my interest in Cook one has to remember that there was a true obsession with London during the 1960s. We were also interested in Italy, because of the work of Pierluigi Cervellati in Bologna, a city that would become directed by the communists. Cervelatti was one of the first to abandon the practice of tabula rasa for restoring old urban habitats whilst keeping the inhabitants in their neighborhoods. Krier 
and Cervelatti brought serious theoretical and practical elements to the struggle, and Peter Cook arrives with the London fanfare! Ambiance guaranteed!

ISABELLE DOUCET: But Peter Cook and Léon Krier still brought a very different iconography!

MAURICE CUlOT: Yes indeed. Peter Cook and the Archigram members introduced a new iconography that took a bit from everywhere. They appeared as iconoclasts breaking with functionalism. One of the early counter-projects by La Cambre students proposing a bridge in the shape of a woman's body is a direct heritage of the iconography of Archigram. Other approaches were taken from sociology, via René Schoonbrodt [co-founder of the ARAU], who had connections with Manuel Castells and Henri Lefebvre and other European sociologists, who, moreover, also visited Brussels.

ISABELLE DOUCET: You refer to the Projet d'aménagement de la vallée du Maelbeek, a counter-project by students at La Cambre from the early 1970s. The project mobilizes the absurd and surreal to respond to the municipal plans to create an urban highway in a dense neighborhood. Presented in the shape of a woman-as-bridge, the project aimed to show that, no matter how persuasive, one always needs to be cautious with the proposals presented by architects and planners. This project also shows how a first generation of counter-projects, as collected in the 1975 exhibition catalogue Le Bateau d'Élie. Contributions aux luttes urbaines et projets opportunistes, La Cambre 1971-1975, demonstrated a more manifesto-like character than those produced by a second generation of students. With the second generation, projects were more architecturally precise, resonant of Léon Krier's project for the historical city, and these were collected in a second volume, published in 1978, $\mathrm{La}$ Tour Ferrée. Projets dans la Ville. Projets réalisés à La Cambre, Bruxelles, de 1975 à 1978. In addition to these two volumes, these counterprojects were also published in international architecture periodicals.

MAURICE CULOT: Yes, Pierluigi Nicolin, editor in chief of the Milan based journal Lotus, published our projects and texts. Thanks to Peter Cook, I also met Andreas Papadakis who would become a friend and who had Bob Maxwell editing a special themed issue for Architectural Design [see Maxwell 1977]. L'Architecture d'Aujourd'hui similarly realized an issue in 1975 with one of our counter-projects for the Marolles as its cover image.

ISABELLE DOUCET: In the Architectural Design issue you mention, I remember an article reflecting on a talk you gave in London in 1976 at the invitation of Peter Cook. Londoners in attendance allegedly saw affiliations between your actions in Brussels and those by Brian Anson at Covent Garden, where he, together with students of the Architectural Association, supported the local residents in their struggle against modernization plans for their neighborhood. Support for their actions was not 
only justified by the threat posed to the historical market hall of Covent Garden, which was set for demolition, but especially also because the modernization works would cause the displacement of local inhabitants [see also Anson 1981]. The urban struggle in Brussels, on the other hand, also saw itself as specifically "anti-industrial"?

MAURICE CULOT: Yes. Historically Belgium has always had difficulties situating itself culturally, because it is only a small country. One spoke of Belgium in 1900 with the Art Nouveau movement around Victor Horta and Henry Van de Velde, and then again in the 1920s with Victor Bourgeois as part of CIAM and the Modern Movement. And after the war we find personalities such as Lucien Kroll, Charles Vandenhove and Renaat Braem. But these were isolated architects, individuals rather than movements. And then a group like the ARAU arrives, whose actions resonate with what was happening in other cities such as Covent Garden in London and Les Halles in Paris. The struggles in Brussels had an anti-industrial dimension in that they faced the threat of cars and of urban motorways, large-scale corporate projects, banks and insurance companies building offices that led to the displacement of inhabitants. And let us not forget the oil crisis of the 1970s! All that created a particular context whereby industry and its architecture allies were criticized for a lack of ethics and moral principles.

ISABELLE DOUCET: Internationally, however, we can clearly see very different types of reactions and critiques against similar problems. For example, instead of a historical reconstruction project, we find radically different responses in Archigram, Superstudio, Paolo Soleri and others. So why did Brussels choose the route of reconstruction?

MAURICE CULOT: One aspect of the movement was to not be sectarian (as was functionalism). If I take my own example: I worked in the United States for Frank Lloyd Wright and also Paolo Soleri, whose utopias I adored! While I defend the European city, I also adore the anti-city that is Miami! One is capable of sharing that which is subject to a struggle with that which is subject to curiosity. I was first in doing an exhibition on Claude Parent in Brussels and his Oblique Architecture. And I felt that Ron Herron's Walking City was formidable. I admire Le Corbusier the poet, when he designs houses, but I do not follow him when he mingles with urbanism. It has never disturbed me to admire simultaneously things that are also contradictory. Nothing obliges us to have black and white visions. I am, of course, aware that mine has appeared as black and white because, when positioned at the center of a conflict or struggle, nuanced positions stand no chance; you 'must be' black and white. When taking part in a struggle, you cannot say that you like everything. The attitude of combat is structured and does not allow much room for fantasies. And yet, in the eyes of architects, we have been perceived as extremist rather than political. But I can understand this: After all, we prevented the realization of their projects. 
ISABELLE DOUCET: And here we see why your actions caused so much frustration.

MAURICE CULOT: It was a movement of contestation that really managed to cause discomfort, and sometimes anxiety, among certain architects. We still see that today, when people say: "We have Culot, the ARAU and the AAM to blame for all this mess!"

ISABELLE DOUCET: It seems important to articulate the coexistence of counter-projects that were realistic - developed with the action committees and residents - and counter-projects that were more imaginary and provocative. Did this coexistence of different types of projects contribute to the irritations among architects?

MAURICE CULOT: But this coexistence is very much part of the culture of the architect! When one is "in" the struggle, one is still attracted by ludic things. Do not forget the role of education. At La Cambre [where Maurice Culot had studied before becoming a teacher], Robert-Louis Delevoy had opened our minds and encouraged us to travel. It is also thanks to him that I departed for the US. Le Bulletin des Archives d'architecture moderne [Published between 1975 and 1990] reflected this spirit of eclectic curiosity rather well.

ISABELLE DOUCET: Le Bulletin des A AM and other publications by the AAM, as well as the exchanges that took place at La Cambre, also played a role in the international diffusion of ideas. Le Bulletin des AAM, for example, seemed to have been well-distributed. And the AAM published several volumes that were key to the movement, including La Reconstruction de Bruxelles [Brauman, Culot, and Louis 1982], Rational Architecture [Krier 1978], and Déclaration de Bruxelles [Barey 1980] resulting from the international colloquium La Reconstruction de la Ville européenne held at La Cambre in November 1978. It seems that all these activities and publications facilitated the diffusion of neotraditional ideas in Europe, and even beyond. I think, for example, of the New Urbanism in the US, popularized notably by Andrés Duany and Elizabeth Plater-Ziberk.

MAURICE CULOT: The New Urbanism was, in some sense, a recovery of concepts of the European City but applied to the American context. With Léon Krier, we held conferences in the US, where we met vivid opposition from Denise Scott-Brown, who did not accept our criticism of shopping centers. In the US, shopping centers were seen as important everyday social spaces. The conferences in Europe that you mention as well as La Cambre were very important places of encounter, allowing us to invite our international friends, including Bernard Huet, Antoine Grumbach, Pierluigi Nicolin, the members of Archigram, Alvin Boyarsky from the Architectural Association...

ISABELLE DOUCET: May 68 played a role, too. In the history of architecture, we can observe a current interest in May 68, resistance and the countercultures. Do you recognize this renewed interest in the urban struggle and countercultures? 
MAURICE CULOT: May 68, with whatever defects one may allocate to it today, was a movement of incredible liberation. Back then, we were not too worried about the future, about getting a job. In Brussels, where housing was not too expensive, one could live with modest means. In Paris, that would have been very difficult. Today, one could say that there is a resurfacing of resistant architecture, is there not? It was the theme of the last two biennials in Venice where we could see projects and constructions made out of waste and salvaged materials. That is a form of anti-industrial resistance!

ISABELLE DOUCET: Counter-projects were also exhibited at the 1980 architecture biennial in Venice organized by Paolo Portoghesi on the theme Presence of the Past.

MAURICE CULOT: It was Leon Krier who had suggested to Paolo to exhibit our counter-projects behind the Strada Novissima. And I now find it rather amusing to see counter-project being exhibited again in Montreal and at Columbia in New York, almost 40 years later!

ISABELLE DOUCET: You refer to the exhibition L'Architecte, Autrement / The Other Architect, at the Canadian Centre for Architecture, in 2015 [see the exhibition catalogue: Borasi 2015], and which subsequently travelled to New York and the Nieuwe Instituut in Rotterdam, and which indeed included the work of the ARAU. What has changed in these new interests in resistant architecture?

MAURICE CULOT: I think that designers today, such as Philip Starck, are ahead of architects. The British architects of the 1960s, such as Archigram, had a liberal, anarchic, fun and explorative vision. Postmodernism, by contrast, has often become a caricature of itself, with its ridiculous capitals placed on badly designed columns. Contrary to architects, today's designers do not seem to have too much trouble to work with history and the past. Architects, for example, have still not fully explored the possibilities of pastiche. Why do they not explore the past more creatively? Not to copy history but to learn to play, to juggle with it, like designers do so well. Why reject styles when you can study them, learn to understand them and adapt them to actual programs without necessarily literally copying or caricaturing?

ISABELLE DOUCET: How do you see the counter-projects in comparison to other architect-activists of the time in Belgium, such as Lucien Kroll?

MAURICE CULOT: Kroll was seduced by direct participation, such as with the students at La Mémé [Kroll designed student accommodation for the Medical Faculty at the Catholic University of Louvain, in close collaborations with the students and his wife, landscape designer Simone Kroll]. ARAU and the action committees were not preoccupied with the participation of inhabitants in the planning of buildings but only in questions regarding the organization and becoming of the city. Today, in my office Arcas, it happens that I find myself constructing houses 40 kilometers outside Paris, which requires two to three cars per family. 
For that, we sacrifice good agricultural land. That does not make sense! But there is a market for these houses. And as long as politicians do not have the courage to forbid suburban allotments, we will continue building them.

ISABELLE DOUCET: Does that not disturb you, doing these kinds of projects? Is it possible to reconcile work in an office with activism? Do you still find openings for resistance and struggle beyond the office?

MAURICE CULOT: Of course, that disturbs me. But well, with an office you do not always have a choice. And at least I have often managed to work with developers who were still willing to create streets in addition to the detached houses, to create an image of a village. Also, my office is specialized in traditional urbanism and in restauration projects which involve historical research, which I find very enjoyable. Also, I may have left Brussels in 1980, but I have never lost my militant side and I still write, for example, for Monts 14, an activist newspaper in Paris.

ISABELLE DOUCET: But if you contribute to ethically questionable projects, is that not an inacceptable compromise? Should we not refuse these kinds of projects altogether?

MAURICE CULOT: It is true that certain projects you just should simply not do. But these represent only a fraction of our work and when we do accept them, we do the best we can. A fake village is indeed not an ideal solution, but at least there is some kind of enjoyable everyday live theatre.

ISABELLE DOUCET: In the 1970s, you had already said that what matters is the urban scale, not architecture. But at the same time, you endorse Port-Grimaud in France because you believe that we have to build what people want and respect the taste of the inhabitants, not the architects.

MAURICE CULOT: At Port-Grimaud, François Spoerry was inspired by local architecture. He purchased old factories that had fallen into ruins and, during the night, he would send workers to disassemble the roofs and then use the tiles for the roofs in his project. So, this is what gives character to Port-Grimaud, where the roofs are made of tiles that were disassembled overnight and reassembled in the morning. This is not about what people want but about constructing streets and houses that give the impression that they had always been there. That is what I found so fantastic. I was born in the Walloon region in Belgium, in Charleroi to be precise, an industrial city where, in contrast to the grand factories, a taste for the picturesque can be found. Since childhood, I have had a taste for the small-scale, the picturesque. And then an architect, Spoerry, arrives, who creates a picturesque village! That touches on your personal history and your personal sensitivities. And, therefore, yes, I admit, I have a soft spot for the picturesque!

ISABELLE DOUCET: Ah! That is interesting. It adds still another dimension to what you called in the 1970s your "three façades"; the three dimensions activated simultaneously in your work: Cultural-historical, pedagogical 
and political action [Culot speaks of these three façades in Shane 1977, 189]. We can now add another dimension that is more personal.

MAURICE CULOT: To tell you the truth, I feel like I was born in 1900. I am more at ease in that period. I walk in Europe between the two wars, between 1920 and 1940. It is my favorite epoch, because it is when modernity is announced: The most beautiful cars and airplanes, the radio, cinema, the TSF. All these attributes of modernity that found expressions in garages, radio broadcasting buildings, cinemas and dance halls, swimming pools and bathing places. This was a time of promises, of a society that never arrived and instead disappeared in entropy and massification.

ISABELLE DOUCET: In London, you presented the work of Belgian Art Nouveau/modernist architect Antoine Pompe at the Architectural Association in the 1970s, while you also gave a lecture on the Brussels urban struggle. Do such different topics demonstrate the tensions between the work of the archivist and the activist?

MAURICE CULOT: What I recall from that period is that this duality was, in Britain, never really perceived as something strange. By contrast, in Belgium, one did not understand the coherence between my actions as a collector of architects' archives, such as the archives of Belgian modernist architect Louis-Herman De Koninck, and my criticism of contemporary architects. As far as I am concerned, I always experienced my work as an archivist as a gift, allowing for books and exhibitions. I like to walk in the footsteps of others, to discover where their ideas came from...

ISABELLE DOUCET: And this is probably a good time to conclude this conversation and thank you for your time.

\section{Notes}

1 This introduction by Isabelle Doucet was added for this chapter publication, and was not part of the originally published conversation in French (see also note 7).

2 One realization with direct affinities can be found in the Rue de Laeken in Brussels, where part of a historic street was reconstructed as a result of an architecture competition organized by the Fondation pour l'architecture in 1989. See Mierop and Deville (1995).

3 See for example our positioning paper Doucet, Gosseye, and Kockelkorn (2019).

4 For example, the Déclaration de Bruxelles is available for downloading through the website of the Foundation of the Urban Environment on https://www.ffue. org/2013/04/declaration-de-bruxelles-1978/.

5 Critical analyses do exist, including, among others, Doucet $(2015,2016)$, Ellin (1999), Ibelings (2004), Loosen (2017), Ockman (1981) and Till (1998); and there has also been a recent interest in architecture's turn to toward history (e.g., Moravánszky and Lange 2017).

6 A closer look into the counter-projects produced by the movement shows this shift in inspiration (Doucet 2013, Doucet 2015: 39-78). 
7 Originally published in French in A+ Architecture in Belgium, May 22, 2018; English translation published with permission. The translation to English was carried out by Isabelle Doucet and also includes some minor cuts and edits to the original version (Doucet and Culot 2018).

8 The Battle of the Marolle symbolized the working-class struggles for their Right to the City and was considered victorious in that it succeeded, in 1969, in halting the planned extensions to the Palace of Justice at the expense of a local neighborhood.

\section{Bibliography}

Anson, Brian. 1981. I'll Fight You for It. Behind the Struggle for Covent Garden. London: Jonathan Cape.

Barey, André, ed. 1980. Déclaration de Bruxelles. Brussels: Editions des Archives d'Architecture Moderne.

Borasi Giovanna, ed. 2015 The Other Architect / L'Architecte Autrement. Leipzig: Spector.

Brauman, Annick, Maurice Culot, and Michel Louis, eds. 1982. La Reconstruction de Bruxelles. Brussels: Editions des Archives d'Architecture Moderne.

Culot, Maurice. 1975. "La Longue Marche." Architecture d'Aujourd'hui 180 (JulyAugust): 18-29.

Culot, Maurice. 1976. "The Rally 5/23.” Recorded Lecture. Accessed October 19, 2019. https://www.aaschool.ac.uk/VIDEO/lecture.php?ID=864.

Culot, Maurice. 1980. "The Counter-Projects." In Contreprojets - ControprogettiCounterprojects, edited by Léon Krier and Maurice Culot, no page numbers. Brussels: Editions des Archives d'Architecture Moderne.

Culot, Maurice, and Léon Krier. 1978. "The Only Path for Architecture.” In Architecture Theory since 1968, edited by K. Michael Hays, 348-55. Cambridge, MA: The MIT Press, 2000. Originally published in English in Oppositions, Fall 1978. Translation from French: Maurice Culot and Léon Krier. 1978. "L'unique chemin de l'architecture." Bulletin des AAM, 14: 1-5.

Doucet, Isabelle. 2013. "Counter-Projects and the Postmodern User." In Use Matters. An Alternative History of Architecture, edited by Kenny Cupers, 233-47. London: Routledge.

Doucet, Isabelle. 2015. The Practice Turn in Architecture. Brussels after 1968. Farnham: Ashgate.

Doucet, Isabelle. 2016. "Aesthetics Between Provocation and Production: CounterProjects." Oase 97: 91-8.

Doucet, Isabelle. 2017. “De Belgische 'Counter' Episode 1965-1980. Stad en architectuur tussen denken, durven en doen." Stadsgeschiedenis 1, no. 12: 42-9.

Doucet, Isabelle, and Maurice Culot. 2018. "Interview de Maurice Culot. Une iconographie de résistance entre Archigram, Léon Krier, et François Spoerry." $A+$ Architecture in Belgium, 22 May 2018. Accessed October 19, 2019. https://a-plus. be/fr/interviews/cinquante-ans-apres-mai-68-une-iconographie-de-resistanceentre-archigram-leon-krier-et-francois-spoerry/\#.XNQgQy97E3i.

Doucet, Isabelle, Janina Gosseye, and Anne Kockelkorn. 2019. "From Le Droit à la Ville to 'Rechte Räume'. Legacies and Legends of the Movement for the Reconstruction of the European City." Published in online proceedings of the "Architecture and Democracy 1965-1989: Urban Renewal, Populism and the Welfare 
State" conference, organized by the Jaap Bakema Study Centre, TU Delft and Het Nieuwe Instituut Rotterdam, November 2019.

Ellin, Nan. 1999 [1996]. Postmodern Urbanism. New York: Princeton Architectural Press.

Ibelings, Hans. 2004. Unmodern Architecture: Contemporary Traditionalism in the Netherlands. Rotterdam: Nai Publishers.

Jencks, Charles. 1988. The Prince, the Architects, and New Wave Monarchy. New York: Rizzoli.

Krier, Léon. 1980. "The Reconstruction of the European City or Anti-Industrial Resistance as a Global Project." In Contreprojets - Controprogetti-Counterprojects, edited by Léon Krier and Maurice Culot, no page numbers. Brussels: Editions des Archives d'Architecture Moderne.

Krier, Léon, ed. 1978. Rational Architecture: The Reconstruction of the European City. Brussels: Editions des Archives d'Architecture Moderne.

Krier, Léon, and Maurice Culot. 1980. Contreprojets - Controprogetti-Counterprojects. Brussels: Editions des Archives d'Architecture Moderne.

Loosen Sebastiaan. 2017. "Le Monopole du Passéisme': A Left-Historicist Critique of Late Capitalism in Brussels." In Re-Framing Identities: Architecture's Turn to History, 1970-1990. East West Central. Rebuilding Europe 1950-1990 (Volume 3), edited by Ákos Moravánszky and Torsten Lange, 261-74. Basel: Birkhauser.

Maxwell, Robert. 1977. "Tafuri/Culot/Krier: The Role of Ideology." Architectural Design 47, no. 3: 186-8.

Mierop Caroline, and Françoise Deville, eds. 1995. Oproep aan de jonge Europese architecten. Brussels: Fondation pour l'architecture.

Moravánszky Ákos, and Torsten Lange, eds. 2017. Re-Framing Identities: Architecture's Turn to History, 1970-1990. East West Central. Rebuilding Europe 19501990 (Volume 3). Basel: Birkhauser.

Ockman, Joan. 1998 [1981]. "The Most Interesting Form of a Lie.” In Oppositions Reader: Selected Readings from a Journal for Ideas and Criticism in Architecture 1973-1984, edited by K. Michael Hays, 412-21. New York: Princeton Architectural Press.

Shane, Grahame. 1977. "Culot/Contextualism and Conscience." Architectural Design 47, no. 3: 189 .

Till, Jeremy. 1988. "Architecture of the Impure Community." In Occupying Architecture, Between the Architect and the User, edited by Jonathan Hill, 61-75, 67. London: Routledge. 


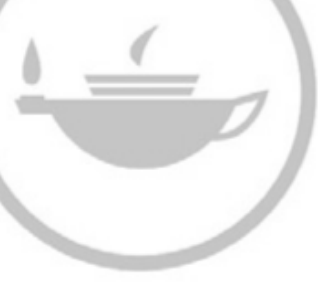

Taylor \& Francis Taylor \& Francis Group

http://taylorandfrancis.com 


\section{Part III}

Building and living ethically - conflicts over housing and architecture 


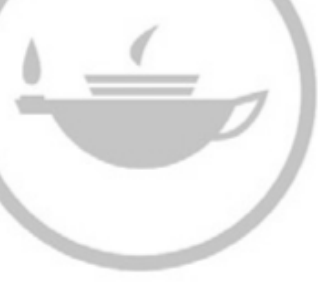

Taylor \& Francis Taylor \& Francis Group

http://taylorandfrancis.com 


\section{Shaping urban ethics \\ The "making-of" a collective housing project at Berlin's river Spree}

Max Ott

\section{Approaching an ethical project}

One evening in late summer 2015, Robert and I are standing in a boathouse on the Spree riverbank, once used by the GDR army to control the border territory between East and West Berlin. Robert, as a member of the newly built housing cooperative Spreefeld, is a part owner of this pragmaticlooking bunker, where he started the "innovator's club," a monthly public event, six months ago. Together with some of his fellow cooperative members, he wants to transform the use and meaning of the once inaccessible boathouse which is located in a neighborhood with many buildings under construction and a lot of new residents moving in: Robert now regards it as a place for old and new neighbors to get to know each other better.

While we are talking, Frank and Martin join us. Frank lives in Teepeeland, an informal settlement on a squatted property right next to the cooperative. Martin is a resident of Spreefeld just like Robert and a co-founder of the project. He runs a network agency focused on self-organized and collective housing in a small office in one of the cooperative's three buildings. It was established about 15 years ago after Martin had moved from Seattle to Berlin. I ask him about the numerous construction sites I had observed on my way to the boathouse and Martin tells me that the pressure of valorizing land is rising notably in this part of the inner-city district of BerlinMitte called Nördliche Luisenstadt. With a rather tortured smile, he gives an example and refers to the conversion of a prefabricated building from the 1970s in the immediate vicinity into a residential project with expensive condos, marketed under the slogan "Better dwelling - better living." So far, the status of the neighborhood as a formally declared area of urban renewal has curbed the valorization of properties, Martin explains. ${ }^{1}$ However, he has skeptical expectations for the future of Nördliche Luisenstadt. In his view, this neighborhood will look quite different in about ten years, when a lot of less profitable uses of the riverbanks will have been pushed out of the area. Martin then addresses the question whether his cooperative plays an active part in such a process of gentrification: He mentions a neighborhood initiative criticizing Spreefeld for the replacement of a popular improvised beach 
bar once located on its property. Nonetheless, he is convinced that this housing project is better than anything that realistically could have been built there instead. He points to its participatory planning process and to the public accessibility of ground floors, exterior spaces and the riverbank. "This is actually what we want to demonstrate here," Martin says: "You can build a house without being an asshole."

Whether one would approach this statement with theories of conscious ethical self-formation (Foucault 1997) or emphasize an "ethics of dwelling" resulting from the experience of relational being-in-the-world (Zigon 2014), Martin's strong way of formulating an aspiration to prove that developing buildings does not mean being a bad person may certainly be understood as an ethical positioning. It goes hand in hand with the problematization of a property valorization that threatens the heterogeneity he values. It is based on the attempt of marking a difference to such an exclusive spatial transformation by addressing Spreefeld as an inclusive project. It was made while Martin participated in an evening event where sharing a space with a broader public is supposed to serve the creation of "good neighborly relations" (Erfinderklub 2015). In this manner, Martin advocated the very project he lives in. However, he is also a planning professional who promotes collective housing in general, and he is far from being the only one to do so.

Even a cursory glance at current subjects of professional discourses in the field of architecture and urban planning reveals a high appreciation for collective self-organization and an increased interest in the architectural dimension of "living in communities" (Arch+ 2018; Bauwelt 2014; Bauwelt Einblick 2019; Becker et al. 2015; Dömer et al. 2014; Kries et al. 2017; Ring and SenStadt 2013). This interest may be considered in conjunction with a "return of the housing question" (Hodkinson 2012; Rink et al. 2015), as each of the publications above addresses dynamics of a competitive housing market, the challenge of rising rents and property prices, or the shrinking of subsidized and affordable housing in prospering cities. Against this background, which also served Martin to illustrate the risk of socio-spatial homogenization and segregation, collective housing is emphatically described as an expression of a "prefigurative desire to live in common" (Hodkinson 2012, 425). Its members are presented as "committed citizens per se," whose "individual initiative extends beyond their own four walls" (Bauwelt Einblicke 2019, 5) and, thus, allows for a creation of "spaces of commoning" (Arch+2018) that bears the promise of "building the diverse city" (Bündnis Junge Genossenschaften Berlin 2018). In contrast to a spatial development resulting from expectations of safe and quick financial profits, the architectures of such a city would mirror a wish for self-determined and solidaritybased forms of living and result from the "active involvement of its future users" who "show strong identification with their neighborhood" (Bauwelt Einblicke 2019, 5).

In these discourses, collective housing is regarded as a truly urban ethical alternative to a market-led "mainstream" (Hodkinson 2012, 426) - an 
alternative that vividly and tangibly expresses a strong sense of community and a commitment to the city. That is why I will approach the cooperative Spreefeld in the following as an "ethical project." However, with a view to the representations cited above, it is my aim to move beyond celebrating cohousing architecture above all as a stable outcome of joint efforts by likeminded altruistic people, who strive consistently toward what they have always considered to be "right and good." On the one hand, I will emphasize a rather mutual relationship: Instead of considering architecture only as ideals and values translated into a fixed object, I will use my empirical findings ${ }^{2}$ to discuss it as a process of "social creativity" (Graeber 2005) that starts well before plans are drawn and does not end with residents moving in. The theory of social creativity allows me to illustrate how this architecture in the state of becoming does not just reflect but also influences "ethical imaginations" (Moore 2011, 15) as well as attempts to define new social relations, and it helps to point out how the processual qualities of participatory planning and concrete spatial structures have a role in shaping urban ethics (Loo 2012; Ott 2019a, 77-81).

On the other hand, my contribution challenges the idea that collective housing owes itself to participants who are "per se" community-oriented and committed to the urban context of their home. This is also a question of the understanding of "pure" ethical motivations among critical observers: Recent contributions to a critical debate on objectives and methodologies of moral anthropology have addressed a risk of rather superficial discussions on ethics if people's orientations, positionings and actions are single-mindedly understood as expressing an essential and irreducible individuality. They argue that, from such a perspective, ethical positioning and practices are likely to be overlooked as being themselves "shaped by (...) structures of power and interest" (Kalb 2018, 69) and become portrayed as "self-generating" (Friedmann 2018, 182). Seen from this angle and in light of the old debate about the contexts of action and the logics of practice, it is compelling to note that Martin's positioning concerning Spreefeld also addresses allegations that the cooperative itself is contributing to valorization and replacement, and that he highlights the importance to "demonstrate" the good intentions of the cooperative's members. I seek to follow up this ambivalence, suggesting that ethical claims to develop spatial structures for an inclusive and "diverse city" may not be narrowed to boundless individual virtue. If the overall objective is a reflection on the "social place" (Jones 2009) of architecture, these claims have to be considered as deeply interwoven with both needs and options to justify spatial appropriation in the context of competitive processes of urban transformation.

I will, therefore, initially focus on the broader spatial context of Spreefeld's buildings and controversies about an urban development policy that, by the middle of the 2000s, started to frame parts of the inner-city Spree according to Creative City rationalities. These controversies revolved around the accessibility and use of the riverbanks, characterized by the heterogeneity 


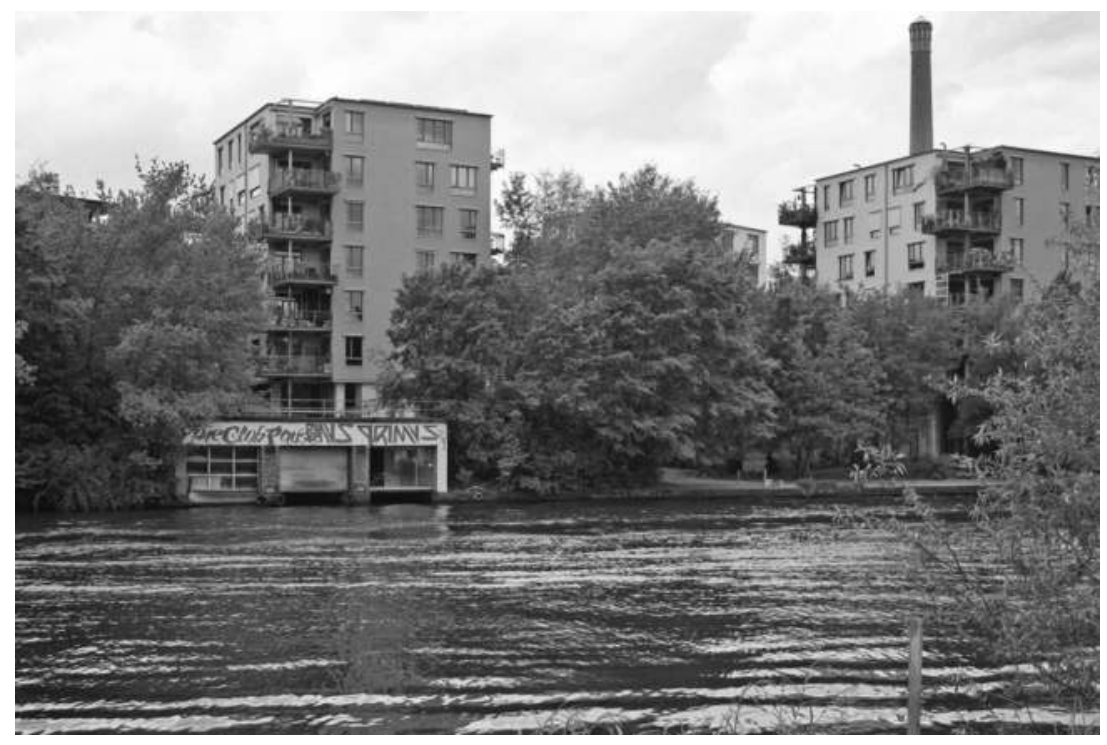

Figure 9.1 The buildings of the housing cooperative Spreefeld. (Max Ott)

of participants, and it is no coincidence they eventually became a point of reference for the housing cooperative Spreefeld (Figure 9.1).

\section{Between contestation and collaboration: transforming the spree riverbanks}

Broader debates about the future of the eastern parts of the inner-city Spree began in the middle of the 2000s when a private-public partnership called Regionalmanagement mediaspree (Regional Management Mediaspree) began to market the riverbanks as a potential location for media companies. Its campaign made use of the many informal appropriations of fallow land that had shaped the particular atmosphere of the former border area since the reunification of Berlin in 1990. It highlighted the river's creative ambience, produced by clubs, temporary bars and cultural venues, as a distinctive key factor for a new "mediaspree," but, nonetheless, emphasized the potential of massive spatial densification and new real estate development to attract private investors. The activities of the private-public partnership caused protests from political activists, artists and members of the cultural industries, as well as residents and stakeholders of the areas alongside the river. In 2008, the protesters were able to enforce a public referendum in the district of Friedrichshain-Kreuzberg and to secure a majority for three demands: The public accessibility of the riverbanks has to be ensured. New buildings have to keep a distance of 50 meters from the waterline. No 
high-rise buildings shall be built. In some cases, the referendum led to further negotiation processes, although a lot of already existing development plans were not substantially revised. Some ten years after the referendum, when I had just finished my fieldwork in the area, several "mediaspree" projects were still under construction or yet to be realized, and the fragmented appearance of the inner-city Spree riverbanks expressed the juxtaposition of separate decision-making processes.

Critical urban studies have recently investigated the controversies about mediaspree with an interest in emerging urban social movements. They discuss subjects and motivations of the participants, their confrontation with the objectives of official urban development policies and the different modes of negotiation and collaboration with policy makers and the city's administration (Holm 2011; Novy and Colomb 2013). Urban sociologist Andrej Holm, urban geographer Johannes Novy and planning sociologist Claire Colomb emphasize the heterogeneity of new protest movements whose members were not operating according to a consistent political ideology. They argue that the protesters were able to act together only because they shared the claim for unrestricted public availability of the Spree riverbanks, considering it a "Right to the City" (Lefebvre 1968). Holm particularly reflects on the binding force of this claim: In his view, it results from its reference to "legitimate ideas of social norms and obligations (that) meet broad public approval. Especially the claim for unlimited access to urban infrastructures has a universal quality" (2011, 96). Novy and Colomb, in turn, highlight another aspect by calling the "mediaspree" controversies a conflict about the "Right to the Creative City" (Novy and Colomb 2013). They refer to an urban development policy, which began to take shape in Berlin in the early 2000s, that celebrates the idea of creative, self-reliant and entrepreneurial urban citizens as a post-Fordist "creative class" (Florida 2003). In the competitive mindset of a Creative City, these subjects both contribute to the city's economic prosperity in times of fiscal austerity and actively produce extraordinary spaces, brought forth, for instance, by the bottom-up transformation of abandoned properties into vibrant locations (Colomb 2011, 222-69; Novy and Colomb 2013, 1822ff.). Novy and Colomb point out that exactly these "creatives" - embraced by normative Creative City discourses and simultaneously in fear of becoming replaced - played a crucial part in the protest movement (Novy and Colomb 2013, 1824). However, they also emphasize the heterogeneity of this movement as a whole. They suggest considering both the divergent backgrounds, levels of privilege and motivations of its members and the complexity of the protest itself, which assembled antagonistic struggles against gentrification, ethical claims for spaces of alternative self-realization, attempts to secure material interests and modes of pragmatically collaborating with the city administration (Novy and Colomb 2013, 1829-33).

In light of such observations, it is instructive to illustrate how the cooperative Spreefeld justified its spatial appropriation and to consider its social 
composition. Following Martin, the residents represent a favored type of urban subject in a Creative City quite accurately (Reckwitz 2010): "[A]lternative, creative, middle-class, $20 \%$ international." Above all, this applies to Spreefeld's initiators, who run offices with telling names such as "the coworkers" or "institute for creative sustainability," specialized in a "politics of bottom-up architecture" (Urban 2018) and in developing projects with full entrepreneurial responsibility and little to no public subsidies. ${ }^{3}$ While negotiating with the planning administrations, the founders of Spreefeld published a "project profile" that referred to the conflicts about "mediaspree" (Die Zusammenarbeiter 2010). It announced a "practical contribution to the latest and partly controversial debates about the further development of the inner city Spree area" and claimed an experimental approach, with rental apartments as an answer to the cuts of subsidized housing, a focus on "community and solidarity" and an integration of "cultural, local and social initiatives" for the benefit of a "collaborative neighborhood." The cooperative steered a middle course between contestation and collaboration: It promised to integrate the most prominent demand of the protest movements - the public usability of the riverbank properties - into their concept but simultaneously argued that privatization and spatial densification of properties on the riverbanks meant no harm as long as they were contributing to a "greater good" and not just self-serving. With respect to my intention to analyze the broader social framework of a self-described ethical project and its connection to power relations, the "project statement" is, thus, remarkable in at least two regards: First, because it illustrates how a group of people purchasing property within a contested area in transformation sought "broad public approval" (Holm 2011, 96) by referring to ethical values - values that match both urban policies promoting creative, collaborative and experimental self-organization (SenStadt 2007, 2011, 4) and the protesters' claims to a common access to spatial resources. Second, the project statement's wide range of offers more or less downsized the dilemma that more privileged representatives of the so-called "creative class" appropriated a property at the expense, it could be argued, of people with less economic and symbolic capital. In other words or asked rhetorically: Does a temporary beach bar have any chance of maintaining its entitlement to further use an empty property during the summer season as soon as the stage is taken by someone who prefigures opportunities for participation, relatively affordable rental apartments, publicly accessible riverbanks and cultural programs all at once and 365 days a year?

Both aspects address a strategic dimension of ethical positioning and, in the eyes of the critics of moral anthropology that I referred to in the first section, this might be their essence: Ethics or ethical rhetoric as a smooth way to harmonize conflictual negotiation, or a means to enforce one's own interests and to obscure a more powerful social position while simultaneously reproducing it (Kalb 2018). However, given the fact that the cooperative's initial statement is just one brick in the complex edifice of designing, building 
and appropriating architecture, there is more to tell about Spreefeld. I am not the only one suggesting that even though questions about securing social position are crucial for investigating collective housing as an ethical project, asking about its transformative potentials does not become dispensable (Gozzer 2019; Ott 2019a). In the following section, I will, therefore, elaborate how in this case, a cooperative architecture as a process of social creativity both expresses and influences ethical reflections and practices of creating meaningful "self-other-relations" (Moore 2011, 18).

\section{Social creativity and a process called architecture}

The origins of Spreefeld reach back to 2007 when a couple of architects took notice of a federal state-owned property held for sale. Since the property was difficult to access by road, its price was relatively reasonable, and Christopher, one of the architects, ${ }^{4}$ remembers that he had even been able to negotiate a long-term reservation with the owner. This provided time to specify an economic framework and gather enough stakeholders to buy the land before several years of designing, planning and forming the definite group of future residents followed. According to Christopher, an important moment during this time was the decision to develop the project under the legal form of a cooperative. The focus, thus, lay on planning a spatial structure where nobody possesses any parts exclusively, but everything is commonly owned. ${ }^{5}$ For Christopher, this had consequences for many of the participants' self-understanding and, therefore, for the architectural project: A shift away from the question "what is mine and what is yours?" had been essential to eventually build more spaces for collective use and to place more attention on the significance of exterior spaces as common spaces. As much as the "project profile" had made such a promise in 2010, and as much as the directives of an area of urban renewal since 2011 bound property owners to grant public access to the riverbank, the "cooperative drive" Christopher depicts appears as the prerequisite not only to keep this promise but also to define the specific way to physically articulate it. There is no hermetic border on the property between a public road, collective areas and semi-private spaces; instead, three seven-story buildings are arranged around a permeable structure of open spaces which can be entered day and night and create a passage to a sandy beach on the riverbank. The roof of the cooperative boathouse is designated as a public terrace, and the complete ground-floor level of the three buildings incorporates nonresidential functions. Each building has a spacious room at one corner, a so-called "option space," which is used collectively or for public events.

It is intriguing to reflect on the decision of founding a cooperative and the steps that follow while building a collective home as a "transformative praxis" - a situation where people "become something new" (Gozzer 2019, 63) by entering into a social contract that shifts their own perspectives, brings perceptible changes and opens up the possibility to further shape these 
changes together with others. Cultural anthropologist David Graeber has developed a theory on such "new social forms" (2005 407) based on examples taken from highly diverse cases from classic anthropology to the ethnography of activist circles, stressing the interconnection of social, material and processual dimensions. Graeber questions ideas about human subjects and collectives as being either sheer products of existing social conditions or an accidental accumulation of independent individuals whose interaction is motivated only by pragmatic calculation. Instead, he emphasizes collective processes of "social creativity" that bear the potential for social transformation. In his eyes, they are never completely predetermined but can also be driven by people's capability to reflect on relationships they value and create something together on that basis (Graeber 2005, 407-10). Graeber argues that processes of social creativity often have a considerable physical dimension, which he describes as a "fetish": A tactile product resulting from human interaction and expressing attempts to visualize an agreement on shared ideals (Graeber 2005, 410-14). However, Graeber goes even further. First, he assumes that a fetish does not just express "the creation of new social ties" (Graeber 2005, 424) but can constitute them in ways that are neither entirely controlled nor foreseen by those human subjects involved (Graeber 2005, 431). ${ }^{6}$ Second, he understands this relationship between objects and "new social ties" as an arrangement that may constantly be reflected, negotiated and renewed (Graeber 2005, 427). It is Graber's emphasis on the reciprocal and processual qualities of socio-material relationships that I want to take up in the following. Such considerations do not just enrich theories about architecture as a social "medium" (Delitz 2010). They also shape the mindset, value concepts and practices of members of the cooperative Spreefeld.

Objects that turn into fetishes through people's imagination, designation and practice often already exist in Graeber's examples. In the case of Spreefeld, however, a physical structure had to be designed in the first place. This became a collectively negotiated process after three different offices had been commissioned with planning the project. Each one focused on one of the three buildings, but the offices had to coordinate their work steps as they were asked to define one overall architectural approach. The architects translated the cooperative's wish for various apartment typologies into a simple primary supporting structure, which is characteristic of all three buildings and allows a broad range of floor plans to be incorporated - a means to react on both new needs and wishes emerging during the design process and changing constellations of dwelling in the future.

Martin, who had lived in cohousing projects ever since he moved to Berlin, was already convinced that shared apartments could stimulate a reconsideration of the true need for individually used square meters and personal goods, before he eventually joined Spreefeld. Robert, on the contrary, started to think in this direction only after he had moved into one of the huge cluster apartments, which provides space for 21 people who share a 
spacious kitchen and living room. The result here is a decline of individual square meters in proportion to space used collectively. While Robert showed me around his new home, he first talked about his previous apartment with a large private room, where his own furniture stood around everywhere. Then he reflected on what had changed since he moved in at Spreefeld: "At the end of the day, it was really satisfying to get rid of many things and to have a fresh start with minimal (...) individual possession and much more collective goods."

Robert describes the steps of forming a large group of flatmates as a long way of dealing with both spatial concepts and physical space, a way that "evolved," and, as could be argued in line with Graeber, cannot be captured in entirely rationalist ways, although it involved many steps of conscious planning. In the initial phase, he was not sure if he could procure enough money to become a member of the cooperative. Everyone willing to participate had to invest 1,000 euros for each square meter of his or her later share of an apartment, about $50 \%$ of the project's production costs per square meter. For Robert, who did not have the required equity capital, the cooperative eventually enabled private loans by offering its property as a security to the bank, a supportive means every financially weaker member of the group could rely on. He remembers this period as insecure not only in terms of financial issues but also in terms of a steady "coming and going" within the group and only preliminary considerations without any design drawings. When it became increasingly clear that the cluster apartment would consist of 21 people, the future flatmates got to know each other better. They started more intense discussions about the question "how do we actually want to live" and attempted to clarify this by participating in the design and planning process. Here, a spatial concept for living on two stories was developed, the open floor plan became visible, potential partitions with lightweight walls were drawn, and, eventually, as Robert puts it, "a decision" was made "to design large collective spaces and also broad hallways but rather small private rooms in return." While moving in, the inhabitants appropriated their new home by supporting each other in customizing the apartment and by giving it a differing appearance. "Some people plastered the ceilings of their private rooms and painted them white, some painted the pillars, some spaces now have wooden floors and some are screed-covered," Robert tells me. "Everything is feasible there and this is awesome. We could do it like that even though this is a rental apartment and that's really great." Meanwhile, the community of the cluster apartment has entered - in Robert's words - "the level of really living together." Robert considers this new relationship not as a 'final act' but as something in motion. One could repeatedly discover "new and different facets about some co-resident" while sitting at the large table in a kitchen shared by three generations. It took more than one year to notice that one stove was actually enough for the large group. From time to time, the kitchen is adjusted to changing uses and, in the near future, 
perhaps a more definite furnishing of the living area on the second floor will be considered.

Not only the cluster apartment illustrates the creation of social relationships as a process and its spatial articulation as not completed; the same applies to the exterior and the option spaces. More than two years after the cooperative moved in, it still appeared currently emerging and small modifications were made repeatedly. Some self-made seating furniture was added in between the trees and the positioning of large raised plant beds in the garden was repeatedly rearranged as if the residents were rethinking their possibilities of using the space between the buildings again and again. Only a little interior work was done in the boathouse and the option spaces on the ground floor. One of the latter was linked to a separated kitchen area and is used today for cooperative meetings or public workshops. Another one was still empty in early 2016 and served as a monthly venue for a Tango course for people with and without physical disabilities. "Although we have been living here for two years now," Robert told me in November 2015, "it is quite obvious how unfinished everything is." Martin explained that this appearance exemplifies a "process approach" to create "a small piece of a city" where not everything is "cast in stone" for all time. Robert specified that this characteristic may inspire "creative work" and help to establish a "social meeting place" for an area in transformation (Figure 9.2).

In view of such statements on a commitment to city and neighborhood and with Graeber's theories in mind, it is reasonable to reflect on the significance of "unfinished" processes for a specifically urban ethical dimension of the collective housing project. Spreefeld has a remarkable number of spatial thresholds to a broader public that are neither fully developed in terms of design interventions nor fully appropriated or controlled by a single fixed function for one specific group of people. Instead, these spaces are still considered accessible, adaptable, convertible and usable in a variety of ways and, in the eyes of Martin and Robert, it is exactly this "state of becoming" that may encourage further social negotiation processes. They can, thus, also support the creation of new relationships - even rather unpredictable ones, especially when interactions extend beyond the cooperative's "inner circle" and respond to the heterogeneity of an urban context. One example of this is encounters between cooperative members and occupants of the adjacent squatted property called Teepeeland, which were favored by the "porous" (Stavrides 2007) qualities of Spreefeld's spatial structures. Initially, the squatters had been invited to take wood waste from the cooperative's construction site and fetch tap water in one of the mostly unlocked option spaces. Since 2014, Martin has run an urban gardening project in joint responsibility with residents of Teepeeland to establish a connection between their properties. And every last Sunday of the month, the squatters host a public stand-up comedy evening in the boathouse and gather a lot of people who do not live in direct vicinity (Ott 2019b). Another example was the accommodation of two refugee families from Ukraine and Syria in one of the 


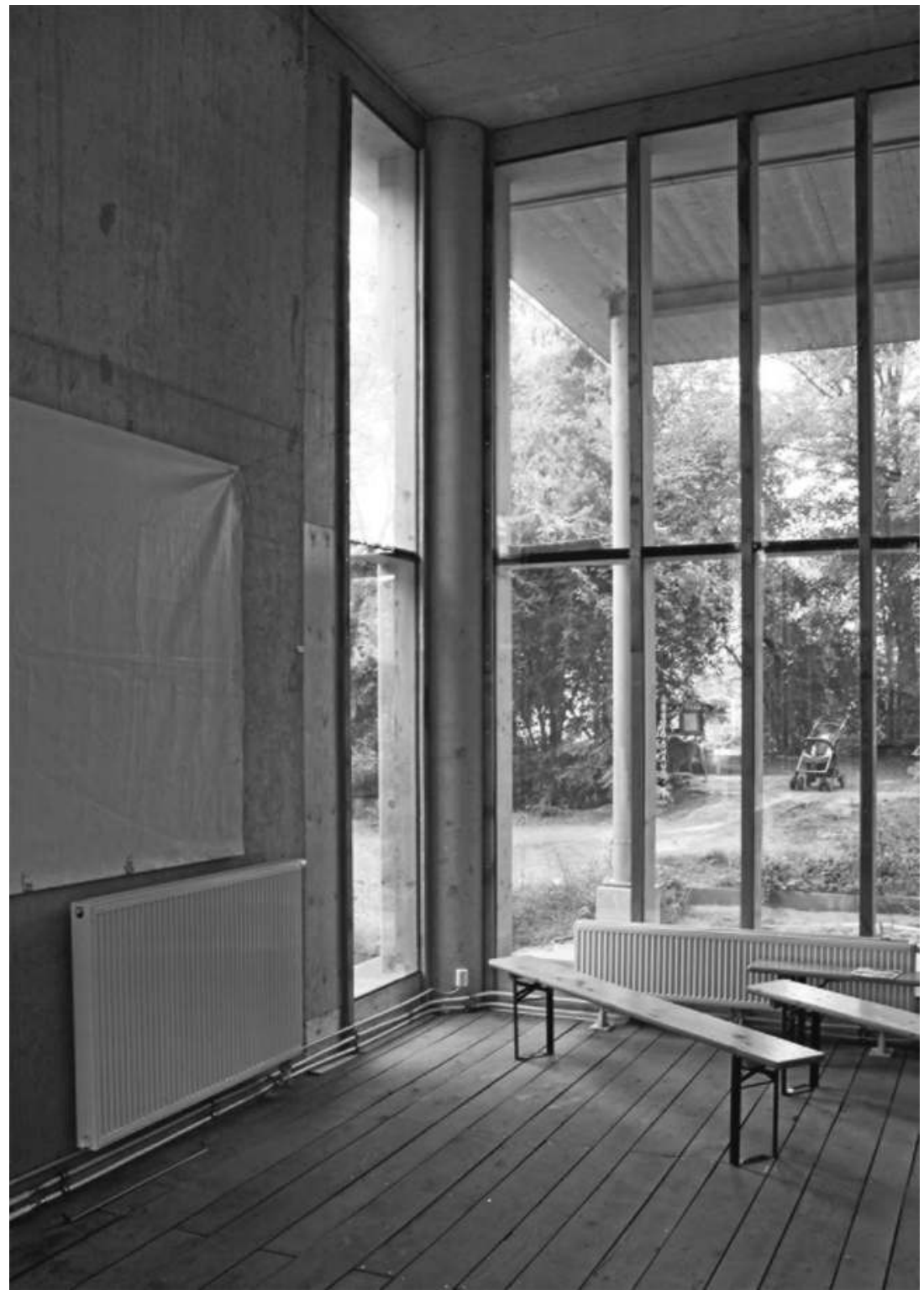

Figure 9.2 Inside an option space. (Max Ott)

cooperative buildings in late 2015. A place to give them shelter was already there, as the social arrangement of those spaces that came into question was, to put it with Graeber, not "fixed and permanent" $(2005,432)$ - it could be remade. 


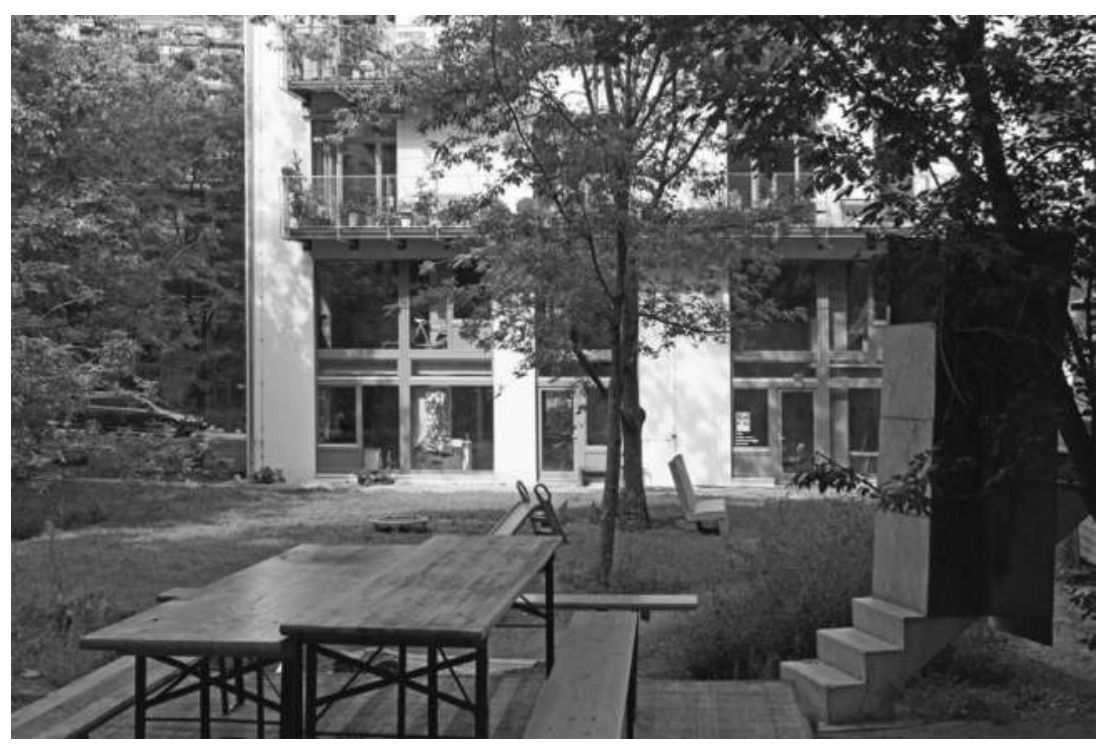

Figure 9.3 The spatial arrangements between the cooperative buildings. (Max Ott)

\section{An ambivalent assemblage}

Throughout this chapter, I have discussed the cooperative Spreefeld as an ethical project that claims to "demonstrate" - as its co-founder Martin put it - a commitment to the heterogeneity of an inner-city neighborhood in transformation. I chose two analytical approaches to illustrate what I believe contributes to a shaping of urban ethics and with a view to get past a rather normative and biased view on collective housing as a "good" response to a "bad" real estate market.

One approach was interested in the transformative potential of an ethical project: By combining my empirical observations with a theory of social creativity, I described architecture as an enduring process that does not just reflect but, moreover, constitutes both ethical imaginations and practices of creating new social relationships. I highlighted how Christopher, Martin and Robert give meaning to the steps of collectively conceiving, building and appropriating architecture, and followed the depictions of these three members of Spreefeld who are convinced that their project can establish an "inclusive culture" and provide spatial opportunities to live together beyond the pervasive goal of individual ownership. From this perspective, sincere and substantial urban-ethical intentions and actions are set against a spatial transformation driven by the competitive and, thus, exclusive logic of a free market.

The other approach was concerned with ethics in relation to existing power relations: Against the background of controversies about Creative 
City policies, I addressed the necessity of reflecting ethical positioning as a means of creative middle-class dwellers to legitimize their claim to contested inner-city properties. Considered from that perspective, the urban ethical project Spreefeld represents, above all, a successful strategy for acquiring scarce resources under given political-economic and discursive circumstances. The cooperative benefited from a policy of property privatization and, even though it criticizes the exclusionary impacts of urban development policies, it is highly attuned to a form of governance that both counts on the initiative of economically self-reliant subjects and promotes the "creative and solidary potential (of) people, who care for their neighborhood and district" (SenStadt 2011, 4). Given the fact that Spreefeld's property appropriation required the replacement of its prior users, it may be asked whether the cooperative's emphasis on inclusiveness and solidarity also represents an "unease" (Frank 2013); an unease of an urban middle class resulting from inner-city "processes of social rearrangement and segregation" (Frank 2013, 39), which are, on the one hand, experienced as threatening one's own wish of belonging to a diverse urban neighborhood and, on the other hand, have to be justified when it comes to participating in such processes.

I believe there is no great sense in trying to decide whether one of these two perspectives reveals more about Spreefeld's truth than the other. On the contrary, I am convinced that only a view from different angles makes it possible to come closer to analyzing this ethical project as what it is: A three-dimensional means to both fulfil "and" enforce particular housing needs, as well as to contest, negotiate "and" legitimize processes of urban transformation. It is, therefore, a complex and contradictory socio-material assemblage, and its ambivalence might be even intensified by a last observation that underlines why it would be shortsighted to understand collective housing as either simply representing the virtue of righteous urbanites contesting neoliberal urban policies with social creativity or only as a smooth product of joint efforts of a homogeneous "creative class." It is also a place that holds its own particular potential for conflicts among its members to play out and be negotiated.

Every cooperative has a constitution with binding rules, and Spreefeld's constitution includes one paragraph granting every resident the future right to transform her or his cooperative shares of the residential complex into private property (Spreefeld eG 2015, 11). This not only means that members of the cooperative have the chance to put an end to paying rent for the rest of their lives. They are also enabled to take advantage of an increasing financial value in a city under enormous pressure of growth by later trading their apartment on the free market; a turn of private profit made possible only by cooperative efforts undertaken to build this project. It is, thus, not surprising that the paragraph caused controversies between members of the cooperative who understand Spreefeld's complete spatial structure as a collective good and residents who announced to make use of their "right to buy." This conflict assembles both questions concerning the social place of 
ethical projects and processes of social creativity. On the one hand, it illustrates that, although the cooperative Spreefeld represents a particular social group, its members do not necessarily share the same focus. ${ }^{7}$ Nonetheless, Christopher, while depicting this conflict, argued against an impulse to see people who favor home-ownership as only self-interested and in opposition to a community-oriented project, and he expressed his conviction that they "also have good reasons" and will not "turn into bad investors" just because they might soon possess a private apartment. In fact, a different attitude concerning the question of ownership can be justified in ethical terms as well - as an "ethical alternative" (Fassin 2015, 188-96), where self-interest and commitment are intertwined and set against the broader context of rising housing costs: Whereas some understand the waiving of home ownership as a normative principle of true collaborative living, others may reflect on the positive consequences of having this safeguard. For instance, it ensures an inner-city domicile in old age and, thus, the possibility to maintain existing social ties. It offers the chance to take care of not only oneself but also others by eventually passing on this benefit to one's own children.

On the other hand, the conflict about private home ownership also affects the conceptual foundation of the cooperative and possibly a production of space that seeks to enable the creation of "new social forms" (Graeber 2005, 407). If it is true that a shift "away" from the question "What is mine and what is yours?" was important to create spatial structures and focus on their potential to be shared and commonly negotiated repeatedly, one could rightly ask whether another shift "towards" this question will put obstacles in the way of processes of social creativity, as soon as former cooperative members invest time and money only in their private apartments and no longer in the cooperative and its objectives. Somewhat ironically spoken, this conflict between future apartment owners and supporters of cooperative living may just be another renegotiation of existing social ties and may lead to the creation of new social relationships between different groups although I do not think this is the kind of social transformation Graeber has in mind. Robert, at least, seemed to be very interested in questions concerning the future evolution of Spreefeld. He told me more than once I should investigate Spreefeld again in ten years to find out what this project will really look like after a longer period of time. "Maybe we will still live together in this constellation, only more settled," Robert once answered to my question how he expected it to be then. "Maybe we'll keep having new ideas and keep testing new things. Or maybe we'll have encountered financial problems and things will have fallen apart."

\section{Notes}

1 German planning law allows city administrations to fix prices for land sales in such areas which limits the possible profits of private property exploitation until the urban renewal measures are completed. 
2 The data I refer to in this chapter is based on several participant observations and five qualitative interviews conducted between September 2015 and October 2016. Direct quotes are based on interview transcriptions and written field notes. I use pseudonyms to ensure the anonymity of the persons quoted.

3 Berlin's Senate Department of Urban Development framed such creative professionals as "Urban Pioneers" (SenStadt 2007) who created the liveliness and "Self-Made" aesthetics (Ring and SenStadt 2013) of a city suffering from financial scarcity and lack of investment by the middle of the 2000 s.

4 I call him by his first name here because it is typical for people to immediately be on a first-name basis in this context, which is different in other parts of the architectural field.

5 A cooperative member also does not own her or his apartment but a lifelong right to rent and use it exclusively.

6 Graeber states: "If fetishism is, at root, our tendency to see our own actions and creations as having power over us, how can we treat it as an intellectual mistake? Our actions and creations do have power over us. This is simply true" (Graeber 2005, 431).

7 A fact that is not surprising but often ignored in the majority of recent publications or media discourses celebrating collective housing.

\section{Bibliography}

Arch+. Zeitschrift für Architektur und Städtebau 51, no. 232 (July 2018).

Bauwelt 105, no. 39 (October 2014).

Bauwelt Einblick, no. 6 (June 2019).

Becker, Annette v., Laura Kienbaum, Kristin Ring, and Peter Cachola Schmal, eds. 2015. Building and Living in Communities. Ideas, Processes, Architecture. Basel: Birkhäuser.

Bündnis Junge Genossenschaften Berlin. 2018. "Wir bauen die Stadt der Vielfalt Ein Kooperationsangebot." Accessed August 29, 2019. https://www.bremerhoehe.de/media/Kooperationsangebot $\% 20 \mathrm{~B} \% \mathrm{C} 3 \%$ BCJGB.pdf.

Colomb, Claire. 2012. Staging the New Berlin. Place Marketing and the Politics of Urban Reinvention Post-1989. Abingdon: Routledge.

Delitz, Heike. 2010. Gebaute Gesellschaft. Architektur als Medium des Sozialen. Frankfurt am Main: Campus.

Dömer, Klaus, Hans Drexler, and Joachim Schultz-Granberg, eds. 2014. Housing for Everyone. Affordable Living. Berlin: Jovis.

Die Zusammenarbeiter. 2010. "Projektprofil Spreefeld Berlin (SFB)." Accessed August 29, 2019. http://coplaner.net/webdav/zusammenarbeiter/SFB $\% 20$ Spreefeld $\%$ 20Berlin/Pr\%c3\%a4sentation/Unterlagen/SFB_Projektprofil.pdf.

Erfinderklub. 2015. "Über uns.” Accessed August 29, 2019. http://erfinderklub.de/about/. Fassin Didier. 2015. "Troubled Waters. At the Confluence of Ethics and Politics." In Four Lectures on Ethics. Anthropological Perspectives, edited by Michael Lambek, Veena Das, Didier Fassin, and Webb Keane, 175-210. Chicago: HAU Books.

Florida, Richard. 2003. "Cities and the Creative Class." City \& Community 2, no. 1 (March): 3-19.

Foucault, Michel. 1997. "On the Genealogy of Ethics: An Overview of Work in Progress." In Michel Foucault. Ethics: Subjectivity and Truth. The Essential Works of Foucault 1954-1984, Vol. 1, edited by Paul Rabinow, 253-80. New York: The New Press. 
Frank, Susanne. 2013. "Unbehagen der Mitte. Die aktuelle Wohnungskrise und die urbanen Mittelschichten.” RaumPlanung - Fachzeitschrift für räumliche Planung und Forschung 169, no. 4 (July/August): 39-43.

Friedmann, Jonathan. 2018. "Situating Morality." In Moral Anthropology. A Critique, edited by Bruce Kapferer and Marina Gold, 182-98. New York/Oxford: Berghan Books.

Gozzer, Laura. 2019. "New Housing Cooperatives in Munich: Two Scenarios for an Ethnographical Class Analysis." In The Vulnerable Middle Class? Strategies of Housing in Prospering Cities, edited by Johannes Moser and Simone Egger, 49-67. München: utz Verlag GmbH.

Graeber, David. 2005. "Fetishism as Social Creativity: Or, Fetishes are Gods in the Process of Construction." Anthropological Theory 5, no. 4 (December): 407-38.

Hodkinson, Stuart. 2012. "The Return of the Housing Question." Ephemera: Theory \& Politics in Organization 12, no. 4 (November): 423-44.

Holm, Andrej. 2011. "Das Recht auf die Stadt." Blätter für deutsche und internationale Politik 8 (August): 89-97.

Jones, Paul. 2009. "Putting Architecture in its Social Place: A Cultural Political Economy of Architecture." Urban Studies 46, no. 12 (November): 2519-36.

Kalb, Don. 2018. "Why I Will Not Make It as a 'Moral Anthropologist'." In Moral Anthropology. A Critique, edited by Bruce Kapferer and Marina Gold, 65-76. New York/Oxford: Berghan Books.

Kries, Mateo, Andreas Ruby, and Ilka Ruby, eds. 2017. Together! Die Neue Architektur der Gemeinschaft. Berlin: Ruby Press.

Lefebvre, Henri. 1968. Le droit à la ville. Paris: Anthropos.

Loo, Stephen. 2012. "Design-ing Ethics. The Good, the Bad and the Performative." In Design and Ethics: Reflections on Practice, edited by Emma Felton, Oksana Zelenko and Suzi Vaughan, 10-19. Abingdon, Oxon: Routledge.

Moore, Henrietta. 2011. Still Life: Hopes, Desires and Satisfactions. Cambridge: Polity Press.

Novy, Johannes, and Claire Colomb. 2013. "Struggling for the Right to the (Creative) City in Berlin and Hamburg: New Urban Social Movements, New 'Spaces of Hope'?" International Journal of Urban and Regional Research 37, no. 5 (September): $1816-38$.

Ott, Max. 2019a. "Help Yourself, but Build the Right Thing. A Collaborative Housing Project in Growing Berlin.” In The vulnerable Middle Class? Strategies of Housing in Prospering Cities, edited by Johannes Moser and Simone Egger, 69-88. München: utz Verlag GmbH.

Ott, Max. 2019b. "A Threshold Space: Connecting a Home in the City with the City." In Home: Ethnographic Encounters, edited by Johannes Lenhard and Farhan Samanani, 133-144. London/New York: Bloomsbury.

Reckwitz, Andreas. 2010. "Der Kreative als Sozialfigur der Spätmoderne.” In Diven, Hacker, Spekulanten. Sozialtypen der Gegenwart, edited by Stephan Moebius and Markus Schroer, 248-60. Frankfurt am Main: Suhrkamp.

Ring, Kristien, and SenStadt - Senatsverwaltung für Stadtentwicklung und Umwelt Berlin, eds. 2013. Selfmade City Berlin: Stadtgestaltung und Wohnprojekte in Eigeninitiative. Berlin: jovis.

Rink, Dieter, Barbara Schönig, Daniel Gardemin and Andrej Holm. 2015. "Städte unter Druck. Die Rückkehr der Wohnungsfrage." Blätter für deutsche und internationale Politik 16, no. 6 (June): 69-79. 
SenStadt - Senatsverwaltung für Stadtentwicklung und Umwelt Berlin, ed. 2007. Urban Pioneers - Temporary Use and Urban Development in Berlin. Berlin: jovis.

SenStadt - Senatsverwaltung für Stadtentwicklung und Umwelt Berlin, ed. 2011. "Handbuch zur Partizipation." Accessed August 29, 2019. https://www. stadtentwicklung.berlin.de/soziale_stadt/partizipation/download/Handbuch_ Partizipation.pdf.

Spreefeld eG. 2015. "Satzung der Bau- und Wohngenossenschaft Spreefeld Berlin eG - Fassung vom 29.6.2015.” Accessed August 29, 2019. http://coplaner.net/webdav/ zusammenarbeiter/SFB SpreefeldBerlin/Präsentation/Unterlagen/150706_SFB Satzung A5_interaktiv.pdf.

Stavrides, Stavros. 2007. "Heterotopias and the Experience of Porous Urban Space." In Loose Space. Possibility and Diversity in Urban Life, edited by Karen A. Franck and Quentin Stevens, 174-92. Abingdon: Routledge.

Urban, Florian. 2018. "Berlin's Construction Groups and the Politics of Bottom-up Architecture." Urban History 45, no. 4 (November 2018): 683-711.

Zigon, Jarrett. 2014. "An Ethics of Dwelling and a Politics of World-building: A Critical Response to Ordinary Ethics." Journal of the Royal Anthropological Institute 20: 746-64. 


\section{Commitment - city - self \\ Ethical self-formations in \\ Munich's young housing \\ cooperatives}

Laura Gozzer

\section{Introduction}

"Nice prospects," Gute Aussichten, runs the headline of an article in the daily newspaper Süddeutsche Zeitung in August 2016. Its author writes,

No, it's not all fine yet - but there is hope! It is precisely in the unaffordable city of Munich where more and more housing cooperatives are coming into being. We need to ask ourselves whether we prefer human or profitable cities.

(Kastner 2016, 3)

The journalist presents recently established housing cooperatives as a beacon on the rather dark horizon of Munich's housing market. ${ }^{2}$ The question whether "we" want a "human" or a "profitable" city illustrates the argumentative level the discussion has reached: Housing is not only a problem in economic or juridical terms but also a topic of morality and values, a question of common humanity. The "moral problematization" (Foucault 1990; Gozzer 2017) of the local housing market is omnipresent in urban everyday life and conversations and practical struggles of countless denizens.

Cooperatives have experienced a "renaissance" in this highly moralized field of (future) urban housing in Munich (Anfang 2015). Defined by German cooperative law, Genossenschaftsgesetz, cooperatives are civil associations based on collective self-help. Their main purpose is not to maximize the profits but the well-being and support of their members, for example, to supply them with affordable housing space (Crome 2007, 211). The key principles of self-organization and self-responsibility go back to the mid-19th century when the first housing cooperatives were established in several European cities (Crome 2007, 212). The current reawakened interest in cooperative models from academics, politicians and civil society connects to various projects in search of alternative economic or social models, often summarized with the keyword "commons." People in Germany have founded new cooperatives not only in the context of housing but also, for example, in 
agriculture. The UNESCO committee added cooperatives to the list of UNESCO Intangible World Heritage in 2016 and describes them as:

community-based associations whose members work together on a voluntary basis for the benefit of all. Principles of self-help, selfresponsibility and self-administration as well as trust and reliability are their basis. They [...] contribute to the improvement of living conditions in various sectors such as culture, finances, nutrition or housing.

(German UNESCO Committee 2017, 50)

Academic studies about cooperatives and other forms of organization under the paradigm of shared commons often have an advocacy character (Helfrich and Heinrich-Böll-Stiftung 2012). As cultural anthropologist Ana Rogojanu remarks, commons are not only a field of research for many social and cultural scientists but also an "attractive promise" to "overcome the centralization of power and social hierarchies" and "a hopeful way in an autonomous future apart from market and state" (Rogojanu 2015, 179). Such evaluative approaches toward the cooperatives' potentials are undoubtedly useful, but this chapter has a different focus: It offers an ethnographic analysis of housing cooperatives as complex constellations of collective housing ideals and participants' socioeconomic strategies in order to look at the inherent ambivalences and contradictions within cooperative assemblages today.

The chapter discusses the case of the so-called young housing cooperatives, junge Wohnbaugenossenschaften, in Munich, which are (currently) 14 self-organized groups. WOGENO (founded 1993), Frauenwohnen (founded 1998) and wagnis (founded 2000) are perceived as pioneers of this generation. They have served as role models for 11 cooperatives that were established over 15 years later, between 2015 and 2019 (LH München N.D.). ${ }^{3}$ Their members own the building land and houses commonly. In addition to a membership fee, the inhabitants pay equity capital, Eigenmittelanteile, depending on the size of the flat and their income, and monthly rent. Thereby, they gain a lifelong rental right with the guarantee of stable rents. ${ }^{4}$ In the case of moving out, inhabitants receive their invested equity capital. Currently, there are only a few opportunities for cooperatives to take over already existing houses. Most of the time, commonly owned cooperative houses are new buildings that usually result from planning processes that have taken the wishes of future inhabitants into account. Young cooperatives emphasize specific ideals of living within the enclosed space and the wider city that they aim to incorporate in their houses. Closer neighborhood relations not only with the other residents of the cooperative but also with the inhabitants of the surrounding area are dominant goals that cooperative founders and residents approach by planning inner courtyards for neighborhood gardening, opening up cafés for the district or organizing sharing systems, for example, for bikes or food. In that sense, the negotiations and 
practices that are constitutive of housing cooperatives are also directed at specific visions of urbanity and city life - liveliness and community.

Housing cooperatives present one example for the ways in which inhabitants of Munich try to develop solutions for the housing problem through "ethical projects," projects for a better urban life. As conceptualized within the research group "urban ethics" (see introduction), ethical projects try to carve out, through discursive and other practices, an "ethical space" in which other rules, especially economic ones, are thought to be suspended. ${ }^{5}$ At the same time, young housing cooperatives are forms of self-help through which residents aim at securing or improving their own housing situation in the scope of the current economic order, especially in a high-rent city such as Munich. Media and political debates often present these two aspects as contradictory. Cooperatives are seen as either pioneers of an alternative, better and more just urban life or exclusive models of self-help by and for privileged and well-connected inhabitants who take responsibility for their own situation in times of neoliberal city governance. As a journalist states: "Most of them [the cooperative inhabitants] only want nice and cheap housing and do not want to hear much about participation" (Oberhuber 2016, 3). Motivations of self-interest and interest in the greater good are themselves debated in ethicized terms: Whereas the latter is presented as "good," the former is deemed morally suspect.

Even though the distinction itself made in the field of cooperative housing is meaningful, from an ethnographic perspective, the neat separation between the ethical and/or moral realm and other spheres of social action, such as "economic and political dimensions" (Fassin 2015, 177), is ultimately impossible to sustain. According to Didier Fassin, "moral and ethical realms are not pure - and can only be purified artificially. Emotions, benefits, strategies, ulterior motives, power games, social relations interact with values, principles and virtues" (Fassin 2015, 177). Consequently, the goal of an anthropological analysis of ethics is not "to single out what constitutes morality or ethics" but "to try instead to study them with their gangue and even in their vein in order to provide a distinct account and comprehension of their social meaning" (Fassin 2015, 176).

Following Fassin, the leading question for analyzing my ethnographic material ${ }^{6}$ is not whether housing cooperatives are authentically "ethical" or not but rather how ambitions for a "better" city life are produced and combined with a wide range of strategies, tactics, motivations and aspirations in the social field of housing cooperatives. The central arena where these negotiations and combinations develop cultural and social meaning is the self-formation practices of founders and residents. People reformulate their biographical aspirations, their socioeconomic situations and their relation to the city by becoming cooperative founders, residents or members. In doing so, they constantly negotiate ethical ideals and practical necessities, and they relate to them and, thereby, their own self, through processes of ethical subjectivation (Foucault 1990). What happens in these processes 
of ethical self-formation when the perceived need for self-help in times of a tense housing market intertwines with ambitions and visions for a "better" way of housing and urban life in a more general sense?

In following these questions, my research investigates the entanglements of self-interest and commitment to a greater good. It builds on conceptualizations of neoliberalism as proposed by Andrea Muehlebach, who uses the term "ethical citizenship" to show how current citizenship ideals incorporate both modes of individualization (self-oriented) and collectivization (other-oriented) (2012, 50). My main argument is that strategies and techniques that aim primarily at achieving individual economic security intersect and, in some ways, converge with ethical ambitions that aim at an alternative urban life. In this situation, with its tensions and convergences, specific forms of ethical self-formation and subjectivation become crucial. My argument unfolds in two steps: First, I shed light on the establishment of ethical ambitions for urban life that are constitutive of cooperative housing. They derive from an entanglement of future residents and founders, policies and regulations from the city administration and the groups' representational practices. Second, I analyze the negotiations of subject models ${ }^{7}$ of common ownership, community and commitment that emerge within the field of cooperative housing to show how residents, founders and members negotiate them in processes of ethical subjectivations, combining self- and other-orientation.

\section{Munich's young housing cooperatives in the making}

Cooperative housing presents a pragmatic economic solution for many residents and founders regarding their own housing situation. Negotiating their biographical visions and socioeconomic positions, interested parties need to check their budget, take on debt and invest. Many plan to start a family or are going to retire in the near future. Some had thought about private homeownership but could not afford it and saw their future in Munich endangered by unstable tenancies. Moving into a cooperative is not an easy way out; it is financially challenging for many. Even though most of the founders and residents possess a relatively high amount of cultural, social and economic capital (Bourdieu 1985), ${ }^{8}$ in light of the real estate and rental market in $\mathrm{Mu}$ nich, they also form a potentially vulnerable group (Frank 2013; Moser and Egger 2019). As this short characterization shows, the middle-class status of residents and founders, ${ }^{9}$ combined with their biographical situations, characterized their decision-making processes. Even though they "help themselves," they also receive financial support from the city administration because they can buy land at predefined, reduced prices. Therefore, they gain a higher position in the social field of the housing market (Bourdieu 1985) through processes of privatization of publicly owned space.

The cooperative's self-representations emphasize visions that go beyond or bypass such motivations of individual economic and housing security. 
The publicly represented ambitions to have an impact on city life, for example, through systems of sharing ecological transport or leisure activities for the neighbors, are closely intertwined with the city administration's policies. The rising number of new cooperatives in Munich goes back to political measures according to which the city sells up to $40 \%$ of publicly owned land that is being privatized to such collectives at predefined, reduced prices. Therefore, it is not the highest bidder who buys the land, but it is the applicant's concept that is decisive, according to the program of Konzeptioneller Mietwohnungsbau (LH München 2017). Apart from this, experts in the city-financed network Mitbauzentrale (Center for Co-building) have been helping people to initiate new projects since 2014 (LH München 2017, 95). This public support goes hand in hand with specific requirements for financing and constructing the houses. Most importantly, the city administration decides about the number of subsidized flats for people with low incomes that each project must include. Therefore, it defines the percentage of flats distributed via two different models of social housing (EOF-Wohnungen for low-income groups and München Modell for middle-income groups) for each house individually. This leads to a less homogenous constellation of cooperatives' residents compared to cities without such regulations aiming at a "social mixture" (see Ott in this book for comparison). Additionally, cooperatives that apply for publicly owned land need to present what they can offer to "the city," for example, by including spaces for social projects, offering gardens on the rooftops or promoting alternative forms of dwelling, such as so-called clusters. Cooperatives refer to a diffuse repertoire of ideals about what urban life should look like in the future and, therefore, take part in discourses about "sharing economy," "right to the city" and "urban mixture."

The following example illustrates this heterogeneous complex of economic interests, future visions, urban ideals, city politics and the allocation of building land. The city organization Mitbauzentrale recommends that the new initiatives constantly reinvest the capital acquired through rents and shares in providing housing space for a growing number of members. The administration advises cooperatives not to give inhabitants the possibility to hand over flats to friends or family to prevent nepotism. This recommendation is based on a critical perspective of older cooperatives, many of whom administer their existing housing stock without efforts to grow. Cooperatives oriented toward sharing their property with the wider urban society are positioned against rather static and, therefore, exclusive housing cooperatives from the older days. ${ }^{10}$ Moral arguments about working toward a "good" city based on values of inclusion and open access are expectations without being legally binding. During evenings for residents interested in cooperative housing at Mitbauzentrale, the host reminded the participants that they must shoulder some responsibility for the common good if they receive publicly owned land at reduced prices (Field note October 13, 2016). I understand this as an example of subtle forms of "ethicizing" governmental techniques that support cooperatives that the city administration (and 
the society it imagines and represents) benefits from rather than merely the individual residents of the houses. The political influence on young housing cooperatives is both (financially) supportive and (ideologically) demanding. The city administration responsibilizes ${ }^{11}$ the initiatives to provide flats for city-financed social housing programs and, simultaneously, to realize flagship projects that perform specific norms of the urban and the "good" city by choosing the projects according to their overall concepts and their urban-ethical surplus value.

The housing cooperatives' self-perceptions and -representations reflect these demands from the city administration to offer space, infrastructure, aesthetics, social housing and atmosphere to the district and city as a whole. Young cooperatives stress their role as pioneers of better urban dwelling in their internal and external communication and their spatial design. Some promote sharing systems between neighbors; others emphasize architectural innovation, such as the cooperative wagnis that won the German Urban Development Prize (Deutscher Städtebaupreis) for their latest building or Kooperative Großstadt that initiated an international architectural competition to choose the architecture of the future house. The rhetoric and semantics of the cooperatives' self-descriptions show a highly ethicized way of arguing. The first young cooperative WOGENO, founded in 1993, tells the founding story as follows:

In the city of Munich, which is witnessing an increasingly existential struggle around social policies and housing, there was a meeting of the founding members of WOGENO, whose shared intention was to send out a signal and develop concrete alternatives to isolation, the prioritization of shareholder value and social disruption.

(WOGENO N.D.)

The cooperative praises its active members who do something "for" the endangered city with an emphasis on publicly sending a political signal and on practical action. WOGENO defines its adversaries in terms of economic logics (shareholder value) and social problems (isolation, disruption). PROG$E N O$, founded in 2015, uses even stronger language:

For us, solidarity means to respect the dignity of every single person and to support each other. We worship and care for each other. We take responsibility for our neighbors and the house. We commit to the development of a lively urban quarter and support social, cultural and community-oriented initiatives. We take care of natural resources. These leading principles are important for us; we wish that all residents share them!

(PROGENO N.D.a)

According to this text, being a member of PROGENO means to live based on a whole fundament of values that go far beyond concrete questions 
of dwelling and housing co-ownership. The desirable resident agrees on "leading principles" and participates in developing a "good" urban life by acting responsibly, caringly and committed to wider goals of a good society. By doing so, the cooperatives legitimize their privileged position in receiving land at reduced prices by assuring the public that they will provide benefits for the city as a whole. In the following section, I will further develop how these ambitions to "offer something to Munich" relate to the actors' pragmatic-individualistic motivations to stabilize their housing situation.

\section{Connections and contestations: self-help and visions of a better Munich}

\section{Common ownership - taking a risk}

Common ownership presents an opportunity for the inhabitants to secure their own situation by gaining a lifelong rental right. Many people I talked to perceive cooperative housing as the only way out of their current, insecure tenancies, because they cannot afford private homeownership. During group meetings, people interested in becoming future inhabitants talked about their dissatisfactions with their current housing situations and their dismay regarding the local housing market. ${ }^{12} \mathrm{~A}$ woman in her early 30s introduced herself, her newborn child and her husband, with whom she was living together in a one-room apartment at the time. While looking for bigger apartments, they had been "confronted with the housing market in Munich for the first time in a long while," which they described as a "shocking" experience. The husband added that he increasingly wonders "what kind of world our children are growing up in, in these cities" (Field note February 9, 2017). The couple problematized the rising housing prices as a threat to not only their own future but also to the future of society. They articulated this in moral terms by emphasizing their emotional reaction and referring to the well-being of children. In such statements, insecurities about individual situations converge with concerns about social and political developments in Munich and "the world." In that sense, cooperative housing not only offered a solution for their current problem but also presented a way for them to act politically. They connected their own situation to the global speculation with housing space; they experience their own fate as intertwined with that of the city as a whole. By combining their personal insecurities and a more general search for justice regarding housing prices, the couple enacted subject codes of care and activation.

Some experience and narrate the process of becoming the co-owner of a house as risky in financial and social terms. Barbara, an interior designer in her 50s who lives in a cooperative house, talked retrospectively about her and her husband's decision to join the project. 
It was a big risk for us to say, we give our financial resources and, well, we will see from now on. Let's hope it goes well. Let's hope we will make it. [...] The possibility was there, that certain people say: "That is total crap and we do not want to continue any longer." They could have said: "I am not going to invest one more hour in this."

(Interview November 7, 2016)

Barbara's avowed feeling of instability focused on the reliability of other members whose commitment she described as unpredictable yet inevitable. The necessity but also difficulty to trust others was at the center of her narrative about cooperative housing as unknown terrain. Starting from here, she presented the cooperative's beginning as a success story that depended upon being brave and trusting of other members.

In the context of increasing housing costs, inhabitants regularly contrast their previous personal experiences in the real estate market under financialized capitalism with visions of a different economic model for urban housing in general. Due to perceived socioeconomic pressure, they move toward political-economic forms of small-scale collectivization and increasingly express attitudes critical of the principle of profit maximizing when it comes to real estate. The discourses and practices constituting and legitimizing common ownership evoke broader political changes. They also produce and are influenced by specific ideal subject models and, therefore, ethical subjectivations. In that sense, the ideal inhabitant of a cooperative is an active, critical urban citizen, who not only suffers from, but also rhetorically and practically opposes, speculation. This subject dedicates her or his financial resources, energy and time to collaboration and self-organization. To form a "good" subject in that sense requires virtues such as the ability to trust strangers; it entails risking one's own resources by pooling them with the group, by investing simultaneously in something very tangible and in a higher cause. Cooperative members often described their investment in the model of common property as risky but, at the same time, wise and voluntary, the only right thing to do. In these self-descriptions, a rationally wise, careful and, at the same time, caring subject emerges.

Founding or joining housing cooperatives presents a possibility for inhabitants to become active in the face of rising housing prices, a development that they experience as threatening for society at large and for their own status (Frank 2013; Schimank 2015; see also Ott in this book). Social and cultural sciences have interpreted "activation" as an aspect of "newly emerging neoliberal citizen-subjects" (Trnka and Trundle 2014, 137). In this line of thought, taking responsibility almost automatically presents "a facet of emerging neoliberal forms of governance that are portrayed by their proponents as enabling individuals' 'independence' and 'empowerment' " (Trnka and Trundle 2014, 137). Geographer Susanne Heeg (2013) critically conceptualizes the connection between the responsibilization of city dwellers and the financialization of housing space: The withdrawing 
welfare state forced people to care for themselves, which enhanced the perception of real estate as an investment that provides insurance against "age, sickness or other forms of economic insecurity" (Heeg 2013, 77). By trying to secure their status on an individual basis, urban residents became real estate investors themselves, an "indispensable wheel in the regime of financial accumulation" (Heeg 2013, 82). In the case of private real estate investment, responsibilization means individualistic self-help of middle and upper classes fearing social decline. When it comes to housing cooperatives, however, this critical conceptualization of "taking responsibility" cannot fully grasp the strategy of common ownership. Indeed, cooperative members see their own position endangered by neoliberal city developments. By joining or founding a cooperative, they take responsibility for their own fate. However, they do not (or cannot) follow the goals of autonomy, independence and marketization. The model of common ownership does not depend "on a single titleholder but on layers of social relations and mutual obligations" (Bruun 2015, 155-6). Like in the members' narrations, finding compromises, taking risks and trusting the group are central aspects. Consequently, a broader concept of responsibility proposed by Susanna Trnka and Catherine Trundle (2014) seems fruitful for the interpretation of cooperatives. These anthropologists state that diagnoses of neoliberal governance cannot sufficiently explain the various forms of responsibilities in everyday life, as subjects are "entangled within widespread ties, dependencies, and duties to others" (Trnka and Trundle 2014, 139). They emphasize that "new notions of 'community' and spaces for collective action and responsibility" (Trnka and Trundle 2014, 140) can arise from such relations. By initiating a cooperative, people also formulate ideas of how housing economies could work apart from responsibilization in the sense of individualization. Thereby, they can rely on values and practices that go back to the 19th-century cooperative movement: Collective self-help and common organization.

\section{Community - being a neighbor}

In addition to the financial aspect, many future cooperative inhabitants criticized the social life they associate with their current housing situation and expressed their hope of intensifying neighborly relations by joining a cooperative. As a representative example, Louisa, an anesthetist in her 50s attending one of the meetings to discuss a soon-to-be-built cooperative house, told the group that people in her current neighborhood, an area with single-family homes on the city outskirts, have built big fences so as not to see each other. She does not feel comfortable not knowing who is living around her, she said, and this is one of the reasons she is interested in moving into a cooperative together with her family (Field note February 9, 2017). Similarly, Tim, an IT-specialist in his late $20 \mathrm{~s}$ who is in the process of founding a cooperative, told me that there is not much contact among his current neighbors. When we visited an extant cooperative project, Tim was fond of 
a scene in the inner courtyard: Adults sat together for dinner, while children played next to them in the green grass. He expected less anonymous neighborhoods as safer and potentially supportive in everyday life with kids and talked about the idea of shifts for bringing them to school (Interview October 5, 2016).

Such visions of closer neighborhood communities connect to wider debates about "social disruption" (WOGENO N.D.), obvious in the selfdescriptions of cooperatives pleading for more familiarity in the city. Concepts of community, Gemeinschaftlichkeit, are omnipresent in current discourses about the urban, from city planning and activist groups to online neighborhood platforms. John Clarke (2014) observes a re-mythologization of community, also by academic research. He underlines the seductive power and ambiguous character of the term: Community occupies "the unstable space between description and aspiration" and works as a "keyword for exploring the forms in which people do, might, or should live together" (Clarke 2014, 46). Moritz Ege interpreted ambitions for closer neighborhood relations as "echoes of the discourses about the amoral city" and states that "ethical solutions for problematized urban lifestyles" often suggest lifestyles connected to idealized small town or village life (Ege 2018, 183-4).

In the research field of cooperative housing, the term "community" describes constant shifts between wishes for the future and current situations, between ideals and everyday life. The past also played a significant role in these conversations: People talked about the positive memories they have from growing up in villages and small towns that they imagine recreating in the urban cooperative. Other actors contested the notion of neighborhood community by foregrounding idealized forms of urban anonymity. Lukas, a cooperative founder, was concerned about the exclusive effects and the threat of urban freedom created by the installation of obligatory neighborhood communities. However, he added, a group of committed inhabitants is necessary for the cooperative's self-organization (Interview November 24, 2017). People constantly negotiate the ideal of community and its not only exclusionary but also productive potentials. These negotiations are influenced by visions about a better future urban sociality as well as memories of idealized village life. Imagining oneself as a "good" neighbor means to become part of a reciprocal system of give and take. Consequently, the ideal of neighborhood community relies on the implicit expectation toward members to commit to the group, as I will further elaborate in the following part of my analysis as the third subject model negotiated in practices of ethical self-formation.

\section{Commitment - investing oneself}

The realization of big goals - community, solidarity, ecology, architectural innovation, alternative economic models - is presented as hard work that requires personal commitment, "engagement." Commitment points to 
diverse contributions to the self-organization of the group not only during the construction phase but also after moving in. The processes that lead to the construction of cooperative houses are complex and can last several years. As soon as a project and its location take shape, possible inhabitants gather to deal with the loan for buying land, the details of the house and the implementation of community facilities. Discussions about individualized floor plans, windows and commonly used balconies or rooftops fill the group meetings in cooperatives that follow participatory planning ideals. An employee of Mitbauzentrale ensures future founders that most of their predecessors took these challenges with a certain ethos in establishing something new communally. They put their "heart and soul" into the projects; their "pioneer spirit" held the groups together (Field note January 25, 2017). Commitment is a form of capital to be invested in the field of cooperative housing, something that can "pay off," as Barbara put it retrospectively (Interview November 7, 2016). Commitment continues after moving in and becomes part of everyday life. In one house, residents agreed on a certain number of hours each inhabitant has to "work" for the community per month, and if they do not, they need to compensate with money. The tasks vary from keeping the hallway clean, maintaining the garden or building a room in the basement for kids to play (Field note October 7, 2016).

Another observation during a meeting for potential inhabitants of a soon-to-be-built project highlights the expectation of personal dedication. After the founders had introduced themselves, the cooperative and the housing project, they moved on to a general round of introductions for everyone present. The attendees sitting in a circle should articulate their aspirations regarding the planned house and explain what they can contribute. Even though the board members emphasized that nobody should feel like applying for a job, most stressed their own competencies when it was their turn. While a biologist stated that she can take care of the garden, and an engineer pointed out his expertise regarding the building process, a woman in her early 60s apologized for not having "such a cool profession" from which the others could profit. She emphasized that she can still engage in "multiple ways," for example, in the garden or by looking after children. She offered to invest a "lot of time" and "good spirit" to the common project (Field note February 9, 2017). Everyone present anticipated that he or she is asked to volunteer. The attendees adapted their introductions accordingly. The fact that university graduates mostly participated at the meeting led the last woman to apologize for not being able to contribute any expert knowledge. She perceived herself as an exception. There is no official definition about who can be included in the reciprocal relationship of cooperative housing, but subtle techniques define desirable and undesirable members. The implicit expectations became explicit due to the advertisement character of this introduction round, a situation where all present still perceive themselves as competitors for cooperative - and, therefore, secure - housing. 
Founders and residents describe their social and emotional commitment to the initiatives as demanding. A board member explained to me how "exhausting" it can be to "breathe life" into "concepts like sustainability and so on (laughs) and participation ... to give them common ground to some extent" (Interview October 7, 2016). This process comes with "a lot of different opinions in a lot of different directions." The board member pointed to difficulties in realizing the ideals in everyday life and emphasized that the willingness to compromise, Kompromissbereitschaft, is a necessary competency for residents. Even though (s)he presented committing to the project and the group as a challenging learning process, (s)he also pointed out that it should not be part of a top-down model but "has to come from the people themselves" (Interview October 7, 2016). The ideal subject constituted via ideals of personal commitment is a proactive, committed citizen who contributes his or her competencies to the group voluntarily out of idealistic motivations.

The goal of achieving closer neighborhood relations, in particular, entails the expectation that members dedicate their time and skills to the group voluntarily. As I have shown, the idealized neighborhood community relies on reciprocal relationships between residents. Consequently, commitment to the community worked as a distinguishing factor in multiple situations. The most explicit example of that differentiation is my conversation with Barbara. She seemed proud when telling me that many of her neighbors are extraordinarily committed to the cooperative idea and community. They volunteer in daycare for old or sick people or pay for architectural improvements with private money. She emphasized that this project would never have been possible without the engagement of a few pioneers who "really live the idea." In her eyes, the ones less engaged need to be "carried along" by active members (Interview November 7, 2016). When talking about less dedicated residents, Barbara referred to inhabitants of subsidized flats who did not choose to live in this specific house but received the offer via the city administration's social housing program after the house has been finalized. She added that she could not establish a general rule from this observation and that, nevertheless, the cooperative's goal is that different residents live together. During my research, many people implicitly referred to a possible tension between the ideal of social mixture and of committed residents. That shows how the different scales of economic necessity play a role in establishing subject codes and models. When commitment to the group should be - in the ideal subject model voluntary and based on idealistic motivations for a better, more active, more collective urban life, participation (only) out of economic pressure is suspect. Paradoxically, this stands in contrast to many middle-class cooperative residents' own economic fragility regarding rising housing prices and their subsequent strategic interests. These cases show a contradiction between their own needs to secure their housing situation, which they share in many ways with lower-income residents, and the subject model 
they uphold, that is, being a dedicated, idealistically motivated cooperative member.

\section{Conclusion}

The ethical ambitions and ideals in cooperative housing develop in a complex intersection of governmental techniques by the city administration, the cooperatives' strategies as actors on the housing market and the personal aspirations, ideals and needs of members and founders. Most of the latter share the perception that their own (individual) needs connect to those of others. By investing money, time, one's own personality and ideas into the group, by risking resources and trusting others, cooperative members aim at secure and better dwelling and, on a broader level, an improved urban life.

My analysis of ethical self-formations offered insight into the combination of ethical, economic and political motivations and legitimation practices at work in ethical projects. It showed that social and financial reciprocity is a key value in the cases I researched on the level of common ownership as well as on the level of imagined closer neighborhood communities. Therefore, the question of individuals' commitment to a larger idea lies at the center of ethical self-formations as inhabitants of cooperatives. On the one hand, self-interest and interest in the common good, the group and/or the city are constantly being combined and almost inextricably fused in conversations and everyday life, very much in line with Fassin's overall arguments about ethics and politics (see above). On the other hand, the narratives surrounding young housing cooperatives in Munich remain characterized by a dichotomous distinction between individualistic (financial) interest and the commitment to a greater good. This tension is constitutive for the ethical project of cooperative housing and enables diverse forms and ways of ethical subjectivation. These develop in negotiations among the residents, between the cooperatives and the city administration, between the initiatives and a public that is increasingly concerned about future housing in Munich, and in the self-formation of the residents.

The ambivalence of the field of cooperative housing, its ethical, political and economic dimensions, its simultaneously collectivizing and individually self-optimizing force is not destabilizing but productive. The contradictions themselves constitute cooperatives as collectives facing an urban housing crisis; as new actors on the housing market; as individuals who search for solutions for their financial and existential insecurity. The connection of one's own situation with the wider conditions of dwelling in Munich particularly opens up a terrain for ethical self-formation. Even though cooperatives are a strategy for "surviving" in the current economic and social order, they also present a challenge to current economic and social norms that emphasize independence, self-activation and the sanctity of market mechanisms. Therefore, as my results show, it is too shortsighted to celebrate housing cooperatives as promising models that can solve the housing crisis, 
but it is also not enough to interpret them as just another result of neoliberal responsibilization through which already privileged residents can uphold their status. Self-interest, in the sense of self-help, can be part of practices that aim at changes on a more general level in the current sociopolitical context, where collective action is often perceived as oppositional to individualistic motivations.

\section{Notes}

1 All German quotes have been translated by the author.

2 The average rental price in Germany's "most expensive" city in the first quarter of 2019 was $17.98 € / \mathrm{m}^{2}$ (1.85 USD/sq. ft) (Statista 2019).

3 In the last ten years, cooperatives have built 1,000 flats and are currently planning 3,000 more (LH München N.D.). The size of the cooperatives varies from 6,000 members and 600 flats (140 in the process of being built) (WOGENO 2019) and 80 members in younger cooperatives (Hoben 2018).

4 An example of the costs of flats in a project of the cooperative PROGENO: Equity capital: $1,700 € / \mathrm{m}^{2}$ (175.17 USD/sq. ft); monthly rents: $12.60 € / \mathrm{m}^{2}(1.3 \mathrm{USD} / \mathrm{sq}$. $\mathrm{ft}$ (PROGENO N.D.b). Seventy-five percent of the flats in this project are subsidized by the city and can be rented at reduced prices for low- and middle-income groups.

5 The research was funded by the German Research Council (DFG) as a subproject of the research group "Urban Ethics" (FOR 2101) on civic engagement on housing and housing policies in Munich; supervised by Johannes Moser and Simone Egger at the LMU Munich.

6 The ethnographic research in 2016 and 2017 focused on imaginations and expectations during the cooperatives' formation phases. This offered a unique perspective of the actors' aspirations, their biographical and socioeconomic situations, the decisions they made, the reasons they gave and the vocabularies they used, as well as the rationalities on which their calculations were based. I gained insight into the perspectives of (future) residents and founders by accompanying the formation of a group of residents for a specific project, through participant observations in information evenings, in-depth interviews and informal conversations.

7 I use Andreas Reckwitz's concept of subject models that is based on specific "subject codes." These distinguish a "good," desirable subject from others that oppose dominant values in a given "culture of subjecthood" (Reckwitz 2006).

8 The inhabitants I got to know during my research had mostly an academic background and were, for example, engineers, working in the art sector, psychotherapists, architects or urban planners.

9 See Gozzer (2019) for a closer look at the notion of "class" for the research on young housing cooperatives.

10 However, the question whether younger cooperatives are more inclusive than their predecessors is not that easy to answer. Younger initiatives ask for far more equity capital than the older cooperatives due to the goal of constant reinvestment and the need to establish a financial stock (Oberhuber 2016). Some of the older cooperatives in Munich also showed interest recently in expanding their housing stock.

11 The concept of responsibilization is used in studies on governmentality "in the sense of the attribution of responsibility" (Buschmann and Sulmowski 2018, 282) onto citizens or associations as a form of governmental technique in neoliberal policies. 
12 At these meetings, (future) cooperative members received information on a specific soon-to-be-built housing project. Given the housing market situation, the evenings had an atmosphere of competition over flats, even though, in most cases, the financial plan for the building and the economic capital required for future residents were not yet clear.

\section{References}

Anfang, Sophie. 2015. "Diese Genossenschaften suchen Mitglieder.” Abendzeitung, October 28. Accessed October 10, 2017. http://www.abendzeitung-muenchen. de/inhalt.wohnungen-in-muenchen-diese-genossenschaften-suchen-mitglieder. 715659b1-43fd-4459-bd94-a9a172bd3f13.html.

Bourdieu, Pierre. 1985. "The Social Space and the Genesis of Groups." Theory and Society 14, no. 6: 723-44.

Bruun, Maja Hojer. 2015. "Communities and the Commons. Open Access and Community Ownership of the Urban Commons." In Urban Commons. Rethinking the City, edited by Christian Borch and Martin Kornberger, 153-70. New York: Routledge.

Buschmann, Nikolaus, and Sulmowski, Jędrzej. 2018. "Von 'Verantwortung' zu 'doing Verantwortung'. Subjektivierungstheoretische Aspekte nachhaltigkeitsbezogener Responsibilisierung." In Reflexive Responsibilisierung. Verantwortung für nachhaltige Entwicklung, edited by Anna Henkel, Nico Lüdtke, Nikolaus Buschmann, and Lars Hochmann, 281-96. Bielefeld: Transcript.

Clarke, John. 2014. "Community." In A Companion to Urban Anthropology, edited by Donald M. Nonini, 46-64. Wiley-Blackwell. doi: 10.1002/9781118378625.ch3.

Crome, Barbara. 2007. "Entwicklung und Situation der Wohnungsgenossenschaften in Deutschland." Informationen zur Raumentwicklung 4, no. 2007: 211-21.

Ege, Moritz. 2018. "Urbane Ethiken und das Normative der Urbanität - ein Diskussionsbeitrag." In Andere Urbanitäten. Zur Pluralität des Städtischen (=Ethnographie des Alltags, 3), edited by Brigitta Schmidt-Lauber, 162-92. Wien/Köln/ Weimar: Böhlau.

Fassin, Didier. 2015. "Troubled Waters. At the Confluence of Ethics and Politics." In Four Lectures on Ethics. Anthropological Perspectives, edited by Michael Lambek, Veena Das, Didier Fassin, and Webb Keane, 127-74. Chicago: HAU Books.

Foucault, Michel. 1990. The Use of Pleasure. Volume 2 of the History of Sexuality. New York: Vintage Books.

Frank, Susanne. 2013. "Unbehagen der Mitte. Die aktuelle Wohnungskrise und die urbanen Mittelschichten.” RaumPlanung 169, no. 4: 39-43.

German UNESCO Committee. 2017. Wissen. Können. Weitergeben. Bundesweites Verzeichnis Immaterielles Kulturerbe. German Inventory of Intangible Cultural Heritage. Berlin. Accessed May 22, 2019. https://www.unesco.de/sites/default/ files/2019-02/IKE_Verzeichnis_gesamt-einleger_190215.pdf.

Gozzer, Laura. 2017. "Am Rande des Münchner Wohnungsmarkts. Subjektmodelle und moralische Anrufungen in Reportagen zur Wohnungssuche." Österreichische Zeitschrift für Volkskunde 120, nos. 3+4: 209-33.

Gozzer, Laura. 2019. "New Housing Cooperatives in Munich: Two Scenarios for an Ethnographical Class Analysis." In The Vulnerable Middle Class? Strategies of Housing in Prospering Cities, edited by Johannes Moser and Simone Egger, 49-67. München: utzverlag. 
Heeg, Susanne. 2013. "Wohnungen als Finanzanlage. Auswirkungen von Responsibilisierung und Finanzialisierung im Bereich des Wohnens." suburban 1, no. 2013: 75-99.

Helfrich, Silke, and Heinrich-Böll-Stiftung, eds. 2012. Commons. Für eine neue Politik jenseits von Markt und Staat. Bielefeld: Transcript.

Hoben, Anna. 2018. "Genossenschaften: Gemeinsam zu den eigenen vier Wänden." SüddeutscheZeitung-Online, Febuary 23. Accessed May 28, 2019. https://www. sueddeutsche.de/muenchen/wohnen-genossenschaften-gemeinsam-zu-deneigenen-vier-waenden-1.3878690.

Kastner, Bernd. 2016. "Schöne Aussicht.” Süddeutsche Zeitung 183 (August 9): 3.

LH München. 2017. Wohnungspolitisches Handlungsprogramm. 'Wohnen in München VI’ 2017-2021. Aichach: Mayer \& Söhne Druck- und Mediengruppe GmbH \& Co. KG.

LH München. N.D. "Wohnungsbaugenossenschaften.” Accessed May 23, 2019. https://www.muenchen.de/rathaus/Stadtverwaltung/Referat-fuer-Stadtplanungund-Bauordnung/Wohnungsbau/Gemeinschaftliches-Bauen/Genossenschaften. html.

Moser, Johannes, and Simone Egger, eds. 2019. The Vulnerable Middle Class? Strategies of Housing in Prospering Cities. München: utzverlag.

Muehlebach, Andrea. 2012. The Moral Neoliberal. Welfare and Citizenship in Italy. Chicago, London: The University of Chicago Press.

Oberhuber, Nadine. 2016. "Vorwärts Genossen!" Frankfurter Allgemeine Zeitung Online, Febuary 16. Accessed May 22, 2019. https://www.faz.net/aktuell/wirtschaft/ wohnen/wohngenossenschaften-als-rettung-vor-hohen-immobilienpreisen-14068859. html?printPagedArticle=true\#pageIndex_2.

PROGENO N.D.a "Was uns wichtig ist." PROGENO website. Accessed November 30, 2017. https://www.progeno.de/ueber-uns/prinzipien.

PROGENO N.D.b "Freiham. Wohnungen. Zahlen.” PROGENO website. Accessed August 28, 2019. https://www.progeno.de/freiham/wohnungen/zahlen.

Reckwitz, Andreas. 2016. Das hybride Subjekt. Eine Theorie der Subjektkulturen von der bürgerlichen Moderne zur Postmoderne. Weilerswist: Velbrück.

Rogojanu, Ana. 2015. "Gemeinschaftliches Bauen und Wohnen zwischen Selbstorganisation, Solidarität und stadtpolitischen Interessen." Österreichische Zeitschrift für Volkskunde 118, nos. 3+4: 177-203.

Schimank, Uwe. 2015. "Lebensplanung!? Biografische Entscheidungspraktiken irritierter Mittelschichten.” Berliner Journal für Soziologie 25: 7-31.

Statista. 2019. "Städte mit den höchsten Mietpreisen für Wohnungen in Deutschland im 1. Quartal 2019 (in Euro pro Quadratmeter).” Accessed August 28, 2019. https://de.statista.com/statistik/daten/studie/1885/umfrage/mietpreise-inden-groessten-staedten-deutschlands/.

Trnka, Susanna, and Catherine Trundle. 2014. "Competing Responsibilities: Moving Beyond Neoliberal Responsibilisation." Anthropological Forum 24, no. 2: 136-53.

WOGENO. 2019. "Aufnahmestopp von Mitgliedern." WOGENO Website. Accessed May 28, 2019. https://www.wogeno.de/mitgliedschaft/mitglied-werden.html.

WOGENO. N.D. "Wie alles anfing - wie es weitergeht!" WOGENO Website. Accessed October 9, 2018. https://www.wogeno.de/ueber-uns/geschichte.html. 


\title{
11 Antagonisms and solidarities in housing movements in Bucharest and Budapest
}

\author{
Ioana Florea, Agnes Gagyi and Kerstin Jacobsson ${ }^{1}$
}

\section{Introduction}

Economic crisis, the financialization of real estate and the neoliberal restructuring of cities have affected households and provoked citizen mobilizations in cities around the globe (Aalbers 2008; Brenner et al. 2012; Jacobsson 2016). Disparities between rich and poor are particularly salient in the housing sphere. Nevertheless, housing is also a field in which multiclass alliances have been emerging in various parts of the world (Mayer 2013; Polanska 2016). This chapter explores relationships between contextual factors and emerging solidarities as well as antagonisms in mobilizations around housing in two Central and Eastern European capital cities: Bucharest and Budapest; both Hungary and Romania are among the European Union countries most severely struck by housing deprivation and overcrowding (Vincze 2017). The main focus is on the period after the 2008 crisis, which involved new developments in national policies in both Hungary and Romania, with profound impact on social relations and power structures.

Although both countries were severely hit by the financial crisis, its impacts on the housing sphere were different. Hungary experienced a severe mortgage crisis, with a high number of failed mortgages followed by evictions (Bohle 2014). This effect of the crisis was thematized politically both by the government and by social protests. In the aftermath of the crisis, Hungary's economy, including its banking and housing sector, was transformed by a new supermajority government, the policies of which aimed at creating protected capital circuits for national capital. Since 2015, Hungary has experienced a new boom in housing prices, housing investment and mortgages, driven by newly nationalized banks, domestic savings and state subsidies for housing mortgages. Meanwhile, housing continues to constitute a main factor of social polarization.

Housing precariousness in Romania has grown ever since 1990, in the context of national policies favoring housing privatization and restitutions and/or reprivatization of formerly nationalized properties. This process intensified in the years after the 2008 crisis, as the state not only withdrew from social housing provision but also limited the amount and accessibility 
of social benefits. After 2009, Romania experienced severe cuts in wages, social benefits and employment, leading to an increased burden on housing costs and overcrowding, followed by evictions. At the same time, especially after the crisis, policies, such as rehabilitation programs for privately owned apartment blocks, the continuous sale of public housing, state-backed private mortgage programs and deregulations in urban planning, benefited mainly the better-off and stimulated large real estate developments. In this process, evictions and symbolic cleansing of the poor became emblematicthe most visible housing conflicts accompanying property restitutions in gentrifying urban central areas.

The financial crisis exacerbated previous social inequalities in both countries, affecting especially poor rural areas in Hungary, and poor areas at the edge of larger cities in Romania. The effects of the crisis were used by various configurations of power ambitions on the part of political actors and local and international capital and evoked a range of citizen mobilizations.

In this chapter, we investigate housing contention in Bucharest and Budapest after 2008, based on the authors' original research and secondary materials on housing movements, housing markets and legislation. We analyze housing struggles in the two cities in the context of post-socialist transformation and post-crisis economic development to see how such economic and political conditions shape opportunities and/or constraints for movementbuilding, oppositions and alliances. There are examples of emerging multiclass alliances between middle-class and poor strata (including those struck by housing debt after 2008) in both cities (Florea 2016; Udvarhelyi 2010) and antagonisms and conflicts of interest between various groups. As expected, ethical considerations regarding urban politics vary widely across this landscape, evoking not only new-leftist solidaristic mobilizations but also conservative, neo-nationalistic ones and a continuously changing landscape of alliances and divergences. Our focus of attention is on the antagonisms and solidarities produced across different positions within mobilizations around housing since 2008. We draw on Crossley's $(2006,2013)$ "field of contention" notion to account for this complexity of housing contention and the way in which it is structurally produced. We propose that, rather than singling out certain actors, the whole field within which these actors emerge and meet each other needs to be considered. We argue that structural aspects of housing relations are relevant in understanding the alliances, solidarities, antagonisms and conflicts in the field of housing contention, as well as the ideologies and political values emerging within the dynamics between different actors in this field.

\section{A field of contention approach}

Ever since Castells' seminal work, it has been argued that urban problems are particularly conducive to cross-class alliances, as they typically affect - albeit to various degrees - all classes, such as environmental or 
transportation problems (Castells 1983; Mayer 2013). However, previous research has also highlighted the difficulties in achieving mobilizations across class divides or among groups with different social backgrounds or interests (Florea 2016; Lichterman 1995; Rose 2000). Differences in the social positionality of activists, ideological differences and movement cultures, as well as competition for resources, have been identified as factors impeding the formation of coalitions (Lichterman 1995; Staggenborg 1986). Nevertheless, previous findings highlight that exceptional environmental conditions, such as an economic crisis, may cause organizations and groups to set aside ideological differences (Borland 2010; Staggenborg 1986).

Many of these studies of movement coalition tend to assume a rationalist framework, conceiving coalition- or alliance-building as a deliberate strategy that groups or organizations embark on when it serves their interests as aptly illustrated in the title of Van Dyke and McCammon's (2010) edited book Strategic Alliances.

However, the activist groups we focus on herein do not necessarily form alliances based on a common agenda or joint strategy; yet, they are all part of an increasingly dense field of contentious action around housing. Thus, we need a theoretical approach that can conceptualize both the antagonisms and solidarities in urban mobilization, allowing us to capture a wider spectrum of scenarios, such as the formation of cross-group solidarities, the failure of such attempts and the parallel mobilization of different groups in the same social-structural context.

For this purpose, we draw on Crossley's (2006, 2013) understanding of social movements as "fields of contention," which "draws our attention to the numerous groups and agents who interact within the internal space of a 'movement' and to the relations, alliances and conflicts between those various groups/agents as they unfold through time" and "draws our attention to the embedding of social movement struggles within multiple differentiated contexts of struggle, each of which affords different opportunities for struggle but each of which makes different demands upon activists if struggle is to prove effective" (Crossley 2006, 552).

This approach recognizes emergent properties and field dynamics without making strong assumptions about common understandings among the actors. Moreover, it is as much interested in the unintended consequences of field dynamics as in the conscious actor strategies. More than Crossley, but consistent with his approach, we stress the structural factors that formulate the conditions of group formation and struggle, thus returning to the understanding of social movements as part of long-term structural processes (Castells 1983). However, structural processes do not translate directly into values or ideological positions but rather form the conditions that actors face and, on the basis of which, may try to act to change their situation. Our field of contention approach is one that recognizes both structure and collective agency, complex historical constellations as well as the role of factors and events beyond the local in shaping actors' problem thematization 
and alliances. We conceive of structural factors as elements of the field of contention that both produce the conflicts around which contention arises and influence relationship-making among actors, by both enabling and constraining collective action.

In thinking about how structural processes translate into movement formation and relationships of solidarity or antagonism within the movement field, we wish to preserve the heuristic value of social movement research tools focusing on the constitutive process of a movement and combine it with an attention to actors' positions within the structural process. We conceive the constitutive process as happening not only within a movement or its strategic/intentional interactions but also through the structural conditions of the field. How do actors' positions within long-term processes converge at a certain moment of mobilization? How do long-term political cleavages, national policies or economic crises influence movement groups' opportunity structures for alliance-making? Asking such questions, we propose to investigate the constitution of movement politics and alliance structures as part of a field of contention conceived as a historical social process.

\section{Structural contexts of housing contention}

Consistent with our structural approach, in this section, we discuss intertwining structural factors that create the conditions for housing needs and insecurities and for movement formation.

Socialist housing construction and distribution in both Hungary and Romania followed long-term patterns of social and geographical hierarchies along urban and/or rural, industrial and/or agrarian priorities. The distribution of different types of public housing (state-built and nationalized apartments) followed the hierarchy rank in redistributive power (Konrád and Szelényi 1979). Most of the population in rural areas was excluded from central housing policies (Misetics 2017a) or offered bank credits rather than state housing.

After 1989, under the influence of international financial institutions such as the World Bank and the International Monetary Fund (IMF), the privatization of state housing aggravated the inequalities of previous distribution and propelled spatial segregation (Günter 2000). Meanwhile, falling incomes and surging unemployment coincided with bringing energy costs to world market prices and decreasing public expenditure for housing benefits (Misetics 2017a, 268), which induced increased household utility costs (Bohle 2014, 117). The combined effect of rising unemployment, housing pressures and the disbandment of workers' homes led to a visible growth in homelessness. Until recently, housing policies tended to favor construction and ownership (available to middle and upper strata) over housing costs benefits that could prevent housing and energy poverty.

In Hungary, those hit by poverty were squeezed into urban segregated neighborhoods or further out from the cities, migrating toward rural areas 
and often turning their small privatization gains from selling their apartments in the city (which they could not sustain) into hopes of existence in cheaper locations. The rural areas they headed to, however, often turned out to be long-term repositories of unemployment and growing poverty.

In Romania, one of the first laws in 1990 facilitated the right to buy in state-built apartments. In 1995, tenants living in nationalized dwellings were also allowed to purchase them, often coming into legal conflict with the property restitution claimants. Moreover, under European Union accession pressure, the Romanian government passed the Law 10/2001, speeding up property restitutions to former owners. These privatization mechanisms fueled the real estate market and structural dispossessions. Roma tenants were disproportionally affected following long-term histories of housing inequalities.

In Hungary, after the first government of present Prime Minister Viktor Orbán (1998-2002) initiated a program of state-aided housing loans benefiting the upper 20\% segment of the income scale (Misetics 2017a, 275-6), the following socialist government reduced those subsidies and channeled housing mortgages toward foreign currency loans. A forex mortgage boom followed (largely in Swiss francs) and changes in currency rates were externalized to households. Following the global financial crisis in 2008, between 2008 and 2009, households' debt service on forex loans grew between 30 and $60 \%$ (IMF 2012), coupled with a new wave of unemployment and income decrease. In the face of the economic crisis, the socialist government took an IMF loan and implemented further cuts, including housing subsidies (Bohle 2014, 21).

In 2010, Fidesz, the conservative party, entered parliament with a supermajority. It started a program to tackle forex mortgage debts, framed within a larger program labeled as a national economic freedom fight against foreign capital (Wiedermann 2014). Building on the delegitimization of the foreign direct investment- and credit-led economic policies of the previous socialist and liberal parties, Fidesz stepped up ideologically into the symbolic role of the representative of national interests against Western powers.

The problem of debt spirals due to forex currency rate changes was mitigated due to the government's forex emergency package. Nevertheless, debt service rates of indebted households remained high in comparison to the rest of Europe. With no subsidies for tackling household maintenance costs and debts, the situation resulted in a further growth of household debts, evictions and homelessness (Misetics 2017a). While Fidesz made the decrease of household utility costs a central theme of its 2014 election campaign, the distribution of these subsidies was, in fact, hierarchical, with larger users acquiring bigger benefits. The most important housing policy package of the post-2014 cycle followed a similar distribution scheme, allocating funds only to families who could afford down payments for new homes. Since 2015, a new housing investment boom has been driven by renationalized banks, domestic mortgages and mortgage subsidies, favoring 
national capital (in construction and finance) and the better-off layers of society. While the Fidesz government criminalized homelessness through the Constitution, 4,000 households were expected to be evicted in 2018 due to failed mortgages.

The launch of the first private mortgage program in Romania after 2002 corresponded with the advancement of the real estate boom. At the same time, local authorities refused to allocate budgets for social housing, while engaging in selling their properties on the market. This was especially the case for Bucharest. The real estate market peaked in March 2008. During the first crisis year, prices fell by $41 \%$. In response, the Democratic Party government launched the state-backed mortgage program called "Prima Casă" (First Home) in 2009, in collaboration with several major banks. The main beneficiary group was the young and aspiring middle class. Although this category generally benefited from the socialist housing distribution (through housing support passed on by the previous generation), it aspired to higher benefits from privatization, expecting jobs generated by foreign direct investment and access to Western-like urban development. The program's immediate effect was the stabilization of the real estate market, limiting the dramatic drop in prices. That same year, the government took a loan of 20 billion euros from the IMF, the European Commission, the World Bank and the European Bank for Reconstruction and Development, conditioned by austerity measures and structural readjustments, involving administrative decentralization, the flexibilization of labour contracts, the expansion of the health system privatization, tax cuts for companies. In the last few years, the transnational creditors have been pushing for a diminishment of homeownership policies to enhance the corporate rental market and to make way for large rental developments. In this context, housing precarity affects $25 \%$ of the population; impoverished tenants are not sufficiently protected by law, thus being evicted from restituted properties, private rentals and public housing units. They are pushed into informal housing at urban peripheries, "tolerated" until real estate interests appear in the area and push them even further out (Vincze 2017).

\section{Antagonisms and solidarities around housing mobilizations in Budapest}

The most politicized aspect of housing privatization in Budapest was the appearance of urban homelessness. Coalitions between mobilizations by homeless people and experts and/or activists had a significant role in the establishment of an official system of homeless shelters and in shifting the issue of homelessness from policing to the sphere of social policy (Csongor 2010). In the 2000s, social worker activists funded the organization "Man on the Street," with the aim of breaking the issue of housing poverty out of the existing frames of charity, homeless shelter infrastructure and social policy, thematizing it instead as a political issue concerning all citizens and exerting 
pressure to legalize the right to housing (Udvarhelyi 2010). In terms of crossclass coalitions, an important step was taken in 2009 when homeless activists and activists of Man on the Street founded the organization "The City is for All." Their aim was to transcend the structural inequalities ingrained in society that silence the poor and to create an organization where management and leadership roles are held by homeless people (Udvarhelyi 2010).

The interclass coalition between "affected" and "ally" members became the group's central organizational and political characteristic. One illustrative group policy is that only homeless members can represent the group publicly. While people living in housing poverty can become members after attending three meetings, middle-class "allies" can become members only by invitation. Similar measures are applied to compensate for material aspects of volunteer work by homeless members. The group cultivates a sense of consciousness regarding the potential dominance of middle-class activists within the group (Misetics 2017b, 406-7). The City is for All proposes its own model of advocacy as an alternative to paternalistic and nonparticipatory models of social policy.

Since 2009, The City is for All has become one of the most influential activist organizations in the post-crisis waves of progressive activism. Utilizing a conscious policy of coalition-making and media communication, it continues to link the issue of homelessness to other forms of social oppression (participating at demonstrations linked to lesbian, gay, bisexual and transgender rights and to those linked to the Roma minority's role in the 1956 revolution) or aspects of housing inequalities (organizing the "Vacant Buildings March," which links the issue of homelessness to wider issues of financial speculation and irresponsible housing policy). Actions of The City is for All address various scales and actors of local or national politics, from nationwide issues, such as the criminalization of homelessness, to issues on local governmental level, such as evictions.

After 2008, a wave of debtors' mobilizations reacted to the forex mortgage crisis in a neo-nationalist political framework and produced a stream of housing activism different from that practiced by The City is for All. Organized typically in the form of small core groups with a strong personal leadership and hundreds to thousands of followers through social media, debtors' initiatives framed debt service to banks as a fight between financial exploitation and society defined as the Hungarian nation. Debtors' actions ranged from petitions and lawsuits to street occupations and picketing of banks or government institutions. While the biggest demonstrations were centered in Budapest, the groups were also based and acted in smaller cities.

Members of these groups can be characterized as excluded from the favors of all mainstream housing policies. Szabó (2018) notes that forex debtors' families acquired homes relying on state loans and self-building during socialism. This implies that they did not receive any of the benefits of housing privatization. For them, the 2000s mortgage boom appeared as a new chance to acquire housing. However, members of debtors' movements were 
not among the people who could benefit from this chance in the long-term. They became endangered by mortgage failure and evictions after debt service skyrocketed in the aftermath of 2008. As the Fidesz government's rescue packages were targeted to better-off families, these families remained outside the scope of government help. At the same time, the government campaigns' symbolic narrative that vindicated the role of savior to the Hungarian people against foreign banks effectively muted the voices of those still under pressure.

The groups' criticism against economic exploitation turned against Fidesz as the latter's economic policies benefiting national finance capital continued. The members claimed that an alliance with banks was behind the government's mortgage rescue. In 2013, debtor activist groups demonstrated in front of Viktor Orbán's home. In 2016, they demonstrated in front of the house of Sándor Csányi, president of the Hungarian OTP bank, to emphasize the conflict between debtors and the biggest Hungarian bank's benefits from the government's mortgage solution package.

In terms of their protest repertoires and symbolic discourse, debtors' movements carried forward the tradition of right-wing protests from 2006. Barricades, square occupations, slogans combined with national symbols, cars or small lorries covered with those symbols, and daily protest news were also features of protests in 2006 that were ridiculed by the (then dominant) liberal media. The protesters' discourse featured an eclectic mix of legal and financial technical critique of the forex lending practice, political arguments referring to justice and civic rights, and historical and mythical images about the Hungarian nation taking back control over its history. Ignored by studies focusing on protest culture and civil society similar to Western progressive models, these repertoires were a result of previous decades of right-wing counterculture, spread throughout the lower levels of the cultural industry (like pocketbooks sold on train stations, summer festivals or the rise of "national rock").

Despite the mainstreaming of many of this subculture's claims and symbols by the electoral success of the extreme right party Jobbik and by the politics of the Fidesz government, the complex subcultures of the New Right have seen a relatively autonomous development from these bodies, even after 2010. In the case of debtors' movements, these repertoires have been turned against Fidesz. From the position of parliamentary opposition, the right-wing party Jobbik made gestures in support of debtors' groups. Its criticism of Fidesz' measures to save debtors fit into the party's strategy to build its political campaign on a radical right framing of the social tensions aggravating since 2010. From the part of debtors' movements, however, Jobbik received criticism for "vote extortion," referring to the idea that the party seems to deliver electoral promises rather than standing up directly for the interests of debtors.

Debtors' groups formed an alliance called the "Debtors' Chamber" for the 2018 parliamentary elections. They formulated 12 points/demands for 
solving the situation of mortgage debt and invited opposition parties to sign them. Despite getting support from multiple opposition parties, this strategy remained unsuccessful due to another one of Fidesz' supermajority mandates.

If The City is for All's political goal is to conceptualize and put into practice the political equality between homeless and unaffected members, debtors' groups organize to protect themselves from the threat of becoming homeless. For the latter, this means not only the loss of the home but also the loss of all other characteristics of what they see as basic conditions of a "normal" life: a family, access to a regular income, integration into social systems, such as healthcare and education. This difference in structural position was added to political differences when members of The City is for All considered alliances with debtors' groups. Despite both streams of activism being oriented against the same structural processes of housing deprivation, The City is for All soon decided not to collaborate with debtors' groups. On the one hand, this was due to ideological differences, as The City is for All considered debtors' groups' views on hierarchy, gender or antisemitism unacceptable to them. Another cause was that homeless members of The City is for All experienced an explicit exclusion of their persona and their problems when debtor groups maintained that they represent homeless people.

We see a field of contention in the situation described above where, on the one hand, there is little ideological difference between debtors' activist groups and state power, but there is a strong contradiction in their material positions and interests. On the other hand, despite the fact that both debtors' groups and The City is for All address housing problems caused by the same structural processes and policies, there is no collaboration between these groups due to the way housing problems become politicized along different social positions, alliances and political traditions. Finally, beneath the politicized movement groups, there are individual stories of conflicts, most of which do not become visible in public debates. Activists of the leftwing housing rights group The City is For All observed that the way such stories come into contact with movement actors - whether individual families threatened by debt and eviction reach out to progressive or right-wing movement groups - is largely a matter of chance, as both The City is for All and debtors' groups are very small compared to the volume of housing problems across the country.

\section{(Un)making solidarities around housing mobilizations in Bucharest}

Characteristics of the field of housing contention in Bucharest are the lack of politicization of homelessness, the politicization of evictions in the frame of antiracist and Roma rights mobilizations, and fluctuating solidarities and antagonisms with other "discontented" mobilizations, such as the right to the city, the heritage protection movement and, specific to the post-crisis 
period, the anti-corruption movement. Since 1989, the most politicized aspect of housing transformations has been the massive and persisting eviction process associated with housing restitutions of buildings nationalized in the 1950s. This process intensified in the early 2000s after changes in the national legislation facilitated restitutions to prewar owners, their heirs or buyers of their legal rights. As most of the formerly nationalized buildings were located in central areas, with rising land value, and as most of their dwellers were impoverished former state tenants, including many of Roma ethnicity, the restitution process generated (violent) evictions without relocations, gentrification and increasing inequalities between the new class of owners and former state tenants.

At that time, the strongest Roma rights organizations raised a critical voice against evictions that affected Roma dwellers disproportionately (Fleck and Rughiniş 2008). The involvement of Roma advocacy organizations as actors in the field of housing contention was framed within the wider antiracist struggle beyond the local context. Moreover, the intensified evictions attracted the interest of a new generation of critical urban researchers, such as those around the Association for Urban Transition (organized in 2001), and Ofensiva Generozităţii (founded by theatre and arts students in 2005-2006). These young educated groups, with a marginal position in the Romanian intellectual world, initially pushed for a progressive social change in urban policies and more visibility for themselves in the public discourse.

The early 2000s saw the parallel emergence of several actors in the field of housing contention. In mid-2006, Ofensiva Generozităţii initiated a community art project in Uranus-Sabinelor, a micro-neighborhood close to the city center, stigmatized as a Roma neighborhood, marked by numerous restitutions of previously nationalized houses and by imminent evictions. Several self-organized new-leftist groups came into alliance with Ofensiva Generozităţii, giving support to the area's remaining dwellers who gradually self-organized as the La Bomba group (later a formal association). All these groups and organizations allied in 2006 with other anti-hate-speech organizations to collectively organize a 250-people-strong antiracism manifestation - which illustrates the centrality of antiracist solidarity for urban contender groups in the early 2000 s.

In early 2007, many of these groups formed the Platform for Bucharest, under the coordination of the Association for Urban Transition, which published a declaration for a better city with claims ranging from heritage protection to better housing conditions. Different groups concerned with urban issues showed adhesion to the claims in the declaration and joined the Platform. The alliance-building process developed around a loose ideal of a better city and was fueled by the desires for social change coming from diverse small "discontented" groups mostly not directly affected by deepening (re)privatization policies.

Before the local elections of spring 2008, the Platform worked to promote a policy document to guide Bucharest's booming urban development 
ethically. The local elections in 2008 corresponded to the start of the crisis and the dramatic fall of real estate prices. The following years were marked by frequent episodes of contention organized around the Platform for Bucharest. In mid-2009, certain protests were gathering more than 200 people and online groups had thousands of supporters. At that time, hierarchies among movement groups within the Platform became increasingly unequal, limiting access to resources and discursive legitimization. Positions of different movement groups varied according to professional status, level of education, age, class and access to more powerful social networks, with housing rights activists being less powerful. Under the pressure of the more powerful groups, the Platform's prioritized claim became the protection of architectural heritage against demolitions for new high-rise real estate developments. Most of these buildings with heritage value were also formerly nationalized buildings, now restituted or in the process of restitution.

The already precarious tenants of such buildings (mostly Roma) were increasingly labeled in the movement's internal and public communications as the destroyers of heritage value, while the impoverished in need of affordable housing were accused of ignorance regarding the cultural value of certain urban areas. The movement's initial cross-class alliance was breaking apart. The initial ideal of "the right to the city" was losing symbolic ground in front of a new vision: a competitive "city of culture" with historical identity embodied in its architectural heritage (Florea 2016).

Right-wing nationalist groups have strengthened within the Platform and within the growing heritage protection movement since 2010. Consequently, several initial supporters of the Platform have distanced themselves from it. Using the movement's frame, base and discursive legitimization, a new political platform was building up, later growing into Save Romania Union (Uniunea Salvați România) - the second most powerful political party in Bucharest.

In parallel, La Bomba's community center was evicted in 2011 following property restitution. This was an important event in the process of politicization around housing rights. Media attention sided with the evictees - which rarely happens. They also received support from those who previously participated in La Bomba community actions. Moreover, the locals managing La Bomba became even more involved and radical in their critique of housing policies, expressed in street protests sometimes gathering more than 100 people, press releases, requests for official meetings at the mayor's office, and in two collaborative theatre plays developed together with socially involved artists.

After the crisis, evictions from formerly nationalized buildings became emblematic for the making of solidarities and antagonisms in the field of housing contention. In the spring of 2012, a Roma family informally living in a recently restituted villa, administrated by a well-known member of the heritage protection movement, was evicted. The family's removal from this property in the city center was legitimized through their replacement with 
young artists who would establish as a cultural collective (Florea and Dumitriu 2017). Critical debates arose within several left-wing groups dedicated to issues of social justice. These debates intensified the antagonism between the heritage protection movement and the emerging alliances mobilizing in the field of housing, the latter becoming more articulated in their housing justice claims.

Since then, an increased level of interactions and alliance-building among tenants at risk of eviction, artists, academics, anarchist self-organized groups, Roma rights activists and NGOs have animated the field of housing contention. In this context, Frontul Comun pentru Dreptul la Locuire (The Common Front for Housing Rights, FCDL) was established in 2013. The FCDL was organized as a non-hierarchical group of people at risk of eviction and those working to advance housing justice - a cross-class coalition viewing housing precariousness in capitalism as a concern of the many. They have a loose network of about 2,000 supporters and its activities address various scales, ranging from the local (offering assistance with filing social housing applications at the municipality's housing administration departments) to the national (pushing for changes in the housing legislation) and international (actions of international solidarity and exchange).

Another violent eviction occurred in a restituted complex of buildings in Vulturilor Street, in the center of Bucharest, in the fall of 2014, which affected more than 100 people. The previous contact between the displaced tenants and the FCDL allowed the organization of a strong and visible opposition. The level of cross-class and multiethnic solidarity and alliance-building around the Vulturilor eviction case was unprecedented in the field of housing contention in Bucharest, involving actors ranging from wider Roma rights organizations to even members of the heritage protection movement. As in previous emblematic eviction cases, the politicization of the groups involved increased, in this case through protests initiated by evictees, meetings with municipal, parliamentary and ministerial decision-makers, reaching out to more people at risk of eviction, and activating the solidarity of some hitherto unpoliticized NGOs, such as those offering direct harm reduction and medical assistance to people affected by homelessness.

However, cross-class alliances and solidarity building in the field of housing contention reached a limit in 2015, when massive urban protests against corruption failed to address social issues and excluded any association with FCDL claims (Voicu 2017). Massive protests in late 2015 were sparked off in the aftermath of a deadly fire in a Bucharest music club. Mass media accounts and public debate arose around the corrupt authorities' guilt when it comes to, for example, the (lack of) appropriate spaces for cultural events and ensuring building safety in the city. Public rage was enhanced by the meritocratic presentation of some of the fire victims as young middle-class professionals. In this frame, the FCDL supported the protests, with an emphasis on the precarious lives of club workers (also among the victims) and the need for safe buildings in the city, especially housing. However, its 
messages of cross-class solidarity were not adopted by the protests, whereas Save Romania Union, with its urban professional image and its focus on protecting buildings, gained visibility and stronger influence.

Anti-corruption protests sparked off against the recently installed PSD (Social Democratic Party) government in January 2017. These were the widest and most publicized protests in the last two decades, gathering more than 200,000 protestors in Romanian cities for several months and challenging and affecting national political dynamics. At the same time, an illegal eviction of about ten Roma and non-Roma families was facilitated by the municipality in the city center in February 2017, while massive anticorruption protests for justice system reform were taking place not far away. The call for solidarity initiated by the FCDL and its Roma rights alliances highlighting evictions, housing injustice and economic inequality as important anti-corruption claims - was ignored by the movement groups.

This failed alliance illustrates an ideological difference. Despite challenging the same public authorities, anti-corruption protestors (some identifying with Save Romania Union) are advancing their own claims for more Westernmodeled development, while ignoring social justice and housing justice claims. Similar to the previous heritage protection protestors, they claim to represent the entire just society, thus silencing the critical voices of the housing movement. This failed alliance, as well as the previously broken "right to the city" alliance, also indicates a field of contention where members of different contender groups occupy different structural positions. Interestingly, the anti-corruption protestors organize against a government actually favorable toward the middle- and upper-classes. Despite benefiting from the last few decades of urban development, privatization and housing policies and being less vulnerable to post-crisis transformations, this recently organized "discontented" urban middle-class advances its interests even further, while rejecting alliances with the "deprived." On the other hand, cross-class solidarities around the FCDL and alliance-building with other movements and groups (feminist Roma, newleftist, harm reduction) continue to develop at the intersection of ideological affinities, unintended outcomes of participation in community and movement events, personal contacts and differently vulnerable structural positions.

\section{Conclusion}

This chapter addressed what we conceptualize as the field of contention over the issue of housing in Bucharest and Budapest, focusing specifically on how structural processes shape actors' positions and mutual relations in social struggles over housing and how their ideologies and actions intervene into this field. Following up on Crossley's (2006, 2013) proposition to think movements within a field of contention that comprises multiple levels of struggles, including unintended consequences and factors not reflected consciously, we proposed that tracing movement formation and mutual relations together with structural factors that formulate the conditions of 
ideological and strategic formation of activist struggles has a strong contribution potential to understanding urban movements.

Our field of contention approach allowed us to see how mobilizations may take unintentional directions (such as the split in "the right to the city" movement in Bucharest), are absorbed by wider power struggles (such as the anti-mortgage mobilization's critique being absorbed by governmental discourses in Hungary and the heritage protection movement in Bucharest being absorbed by gentrification processes) and mobilize around similar issues with opposing political logics (such as the right-wing anti-mortgage mobilization versus "housing for all" approaches in Budapest), all within the boundaries of the same overarching structural factors.

The cases discussed illustrate that attention to processes beyond short-term local movements is necessary for understanding how structural and political factors interact in a complex field of contention. In addition to contemporary policies and struggles on local and national levels, housing conditions in both countries are shaped by long-term processes of localized structural integration into the dynamics of financial markets and global competition.

Therefore, to properly understand how mobilizations (don't) shape around the issue of homelessness in our cases requires attention to such long-term processes, involving the downgrading of social housing and welfare services, the marketization of housing after 1989, the mortgage crisis in Hungary as an effect of housing financialization, respectively urban policies aiming to attract investment at the price of evictions in Bucharest.

We suggest that a field of contention perspective is useful for understanding actors' positions, politics and alliances, solidarities or conflicts within the present field of housing contention. Our analysis showed that relationships between actors in various social positions vary widely. We focused particularly on the relationship between middle-class political mobilization and those threatened by housing poverty. While the Hungarian group The City is for All and the Romanian Common Front for Housing Rights are built explicitly around cross-class alliances between those positions, contradictions between the positions, interests and political stances of actors in different positions become salient in other cases. Such was the case of the lack of support for those suffering evictions during a massive wave of middle-class demonstrations in Bucharest, or the case of the parallel activity of rightwing and left-wing housing activists in Hungary, who work on structurally similar issues but find it impossible to work together. In parallel, the heritage protection movement and the housing movement in Bucharest, although initially allied against real estate investors' power over urban development, split into antagonistic political positions, both trying to widen their niche in the dominant discourse and to penetrate the level of national politics.

A field of contention approach, informed by an investigation of historical structural processes within which movement actors operate, can provide a more complete understanding of movement formation and intra-movement alliances, solidarities and antagonisms, as it considers movements' own 
ideas, strategies and alliance-making together with parallel or "silent" elements of the field and relates the characteristics of field relationships to the positions of movement actors within structural processes. Our case studies of Bucharest and Budapest housing struggles showed that similar local problems induced by global processes provide a foundation for a process of movement formation that results in a landscape of groups with various political views, organized in complex patterns of alliances, solidarities and antagonisms. Rather than seeking a linear connection between broad structural process and movement response, we take the investigation of the complex relationships between localized forms of structural process, social positions of actors and the historical making of movement ideologies and alliance structures to be a key task in understanding the relationship between housing problems and housing movements today.

\section{Note}

1 The authors' names are in alphabetical order. This research is funded by the Swedish Research Council FORMAS (contract 2016-00258_3).

\section{Bibliography}

Aalbers, Manuel. 2008. "The Financialization of Home and the Mortgage Market Crisis." Competition \& Change 12, no. 2: 148-66.

Bohle, Dorothee. 2014. "Post-Socialist Housing Meets Transnational Finance: Foreign Banks, Mortgage Lending, and the Privatization of Welfare in Hungary and Estonia." Review of International Political Economy 21, no. 4: 913-48.

Borland, Elizabeth. 2010. "Crisis as Catalyst for Cooperation? Women's Organizing in Buenos Aires." In Strategic Alliances. Coalition Building and Social Movements, edited by Nella Van Dyke and Holly McCammon, 241-65. Minneapolis: University of Minnesota Press.

Brenner, Neil, Peter Marcuse and Margit Mayer. 2012. Cities for People, Not for Profit. Critical Urban Theory and the Right to the City. Routledge: New York.

Castells, Manuel. 1983. The City and the Grassroots. London: Edward Arnold.

Crossley, Nick. 2006. "The Field of Psychiatric Contention in the UK, 1960-2000." Social Science and Medicine 62: 552-63.

Crossley, Nick. 2013. "Fields of Contention." In The Wiley-Blackwell Encyclopedia of Social and Political Movements, edited by David A. Snow, Donatella della Porta, Bert Klandermans, and Doug McAdam, 265-7. Malden, MA.: Blackwell Publishing.

Csongor, Anna. 2010. "Húszéves a menhely alapítvány" [Twenty Years of Shelter Foundation]. Civil Szemle 7, no. 4: 29-54. Accessed January 2018. http:// ec.europa.eu/eurostat/statistics-explained/index.php/File:Distribution_of_ population_by_tenure_status,_2015_(\%25_of_population)_YB17.png.

Fleck, Gabor, and Cosima Rughiniş, eds. 2008. Come Closer. Inclusion and Exclusion of Roma in Present Day Romanian Society. Bucharest: National Agency for Roma.

Florea, Ioana. 2016 [2015]. "The Ups and Downs of a Symbolic City: The Architectural Protection Movement in Bucharest." In Urban Grassroots Movements in 
Central and Eastern Europe, edited by Kerstin Jacobsson, 55-78. London and New York: Routledge.

Florea, Ioane, and Mihail Dumitriu. 2017. "Living on the Edge: The Ambiguities of Squatting and Urban Development in Bucharest." In Public Goods versus Economic Interests. Global Perspectives on the History of Squatting, edited by Freia Anders and Alexander Sedlmaier, 188-210. New York and London: Routledge.

Günter, Jutta. 2000. "Social Consequences of Housing Privatisation in Hungary." South-East Europe Review 3: 23-34.

IMF: International Monetary Fund. 2012. Hungary 2011 Article IV Consultation and Second Post Monitoring Discussion. IMF Country Report, 12/13. Washington, DC: International Monetary Fund. Accessed January 2018. www.imf.org/ external/pubs/ft/scr/2012/cr1213.pdf.

Jacobsson, Kerstin. ed. 2016 [2015]. Urban Grassroots Movements in Central and Eastern Europe. London and New York: Routledge.

Konrád, György, and Ivan Szelenyi. 1979. The Intellectuals on the Road to Class Power. Brighton: Harvester Press.

Lichterman, Paul. 1995. "Piecing Together Multicultural Community: Cultural Differences in Community Building among Grass-Roots Environmentalists." Social Problems 42, no. 4: 513-34.

Mayer, Margit. 2013. "First World Urban Activism." City 17, no. 1: 5-19.

Misetics, Balint. 2017a. "Lakáspolitika és hajléktalanság.” In Társadalom-és szociálpolitika, Magyarország 1990-2015, edited by Z. Ferge, 267-86. Budapest: Osiris.

Misetics, Balint. 2017b. "Homelessness, Citizenship and Need Interpretation: Reflections on Organizing with Homeless People in Hungary." Interface 9, no. 1: 389-423.

Polanska, Dominika. 2016. "Neoliberal Post-socialist Urban Transformation and the Emergence of Urban Social Movements in Poland." In Urban Uprisings. Challenging Neoliberal Urbanism in Europe, edited by Margit Mayer, Catharina Thörn and Håkan Thörn, 309-32. London: Palgrave.

Rose, Fred. 2000. Coalitions Across the Class Divide: Lessons from the Labor, Peace, and Environmental Movements. Ithaca: Cornell University Press.

Staggenborg, Suzanna. 1986. "Coalition Work in the Pro-Choice Movement: Organizational and Environmental Opportunities and Obstacles." Social Problems 33, no. 5: 374-90.

Szabó, Natasa. 2018. "We Are the State, We Are the People: Forex Loan Debtors' Struggles for Citizenship in Hungary." MA thesis, Central European University, Budapest.

Udvarhelyi, Éva. 2010. "Man on the Street: Anthropology, Citizenship and the Fight for Housing Rights in Hungary." Practicing Anthropology 32, no. 2: 17-20.

Van Dyke, Nella, and Holly McCammon. 2010. Strategic Alliances. Coalition Building and Social Movements. Minneapolis: University of Minnesota Press.

Vincze, Eniko. 2017. "The Ideology of Economic Liberalism and the Politics of Housing in Romania." Studia Universitatis Babes-Bolyai Sociologia 62, no. 3: $29-54$.

Voicu, Ştefan. 2017. "In the Middle of the Night. Anti-communism, Anti-corruption and National Pride." EuroNomade. Accessed March 2019. www.euronomade. info/? $\mathrm{p}=8805$.

Wiedermann, Helmut. 2014. Sakkéspóker - Krónika a magyar gazdasági szabadsághar cgyöztes csatáiról. Budapest: Kairosz. 


\title{
12 Ethical contestation in architecture for a creative Singapore
}

\author{
Michaela Busenkell
}

The "Renaissance City Singapore" was one of Asia's most high-profile "creative city" programs. "Renaissance City" Singapore is initially an imagined identity that the Singapore Government developed and adapted locally based on global discourses (e.g., Florida 2002; Howkins 2001; Landry 2000) on "creative / cultural industries," "creative workforce," "creative cluster," "creative city" and "cultural capital." The initiative concerns mainly the formation of creative spaces, products, ideas and people. This top-down program was a major turning point for Singapore in politics, society and the built environment. It touches upon different policy fields and brought forth new governmental institutions, such as the Ministry of Information and the Arts (MITA) in 1990, the National Arts Council as a Statutory Board of MITA in 1991 and the Media Development Authority in 2003 (named Infocomm Media Development Authority since 2016), that control, regulate and license most cultural products and issues, such as arts, broadcasting, films, internet or the printed media.

Often described as a paternalistic city-state with a "soft-autocratic" style of governance, Singapore has a one-party dominant political system and meritocracy as a governing principle (Goh 2017; Jacobs 2012). Government intervention and a society "that is all too self-conscious of the absence of freedom in many areas of social life" (Huat 2007) go hand in hand with a successful private development industry. Whereas the global corruption index ranks Singapore at place three (Transparency International 2018), which means that it has the third-least corruption worldwide, the world press freedom index of 2019 ranks the island at place 151 out of 180 countries, as the "government is always quick to sue critical journalists, apply pressure to make them unemployable, or even force them to leave the country. The Media Development Authority has the power to censor all forms of journalistic content" (World Press Freedom Index 2019).

The connection of cultural and social values and ethics with urban architecture is particularly prominent in Singapore, despite or due to the repeated comprehensive governmental acts of urban redevelopment, based on the extensive demolition of public buildings and urban neighborhoods. Known as a financial center with a liberal business climate, the city-state's 
policies, especially regarding land and housing, also integrate a socialist component that can be seen as quite radical (Haila 2016, 20): The government owns $90 \%$ of the land and takes a major position in Singapore's social and economic development overall (Economic Development Board 1992). It regulates and controls land, urban planning and building to a high degree, preventing land speculation (Haila 2016) and providing affordable housing for most of the population.

When it comes to urban projects, such as Singapore's creative city ambitions, the ethical question "How should one live?" (Collier and Lakoff 2005; Faubion 2009; Foucault 1987) and its urban ethical version "How should one live in the city?" (see introduction) can be reformulated, from an architectural point of view, by asking about the manifestations and contestations of the "good life in the city" in the built space of this "creative city" project. Here, the question regarding the conditions of a good and proper life can be rephrased as "How should one build" for the good and proper urban life, in this case, in Singapore, a question that implicitly guides debates and practices and raises questions of power and authority. My interest in this chapter is to explore the ethical claims and positions of architects, institutions and/or authorities and other actors of the creative city program that underlie and nurture the design and erection of relevant buildings. By taking a close look at the planning process of the Esplanade - Theatres by the Bay, the first cultural flagship building of the creative city program, which opened in 2002, I want to point out the contradictory debates and conflicts about architectural space that came up in the specific context of Singapore at the beginning of the creative city initiative. What, at first sight, seems to be a discussion about the building's materiality and spatial design is deeply embedded in social issues, in controversies over the role of the arts, and for whom and what kind of art the spaces will serve. The entanglement of the different dimensions of space - social space, space of the arts and architectural space - becomes explicit in these controversies. They are embedded in a three-dimensional process of producing perceived, conceived and lived space (Lefebvre 1991 [1974]) for the creative city. I examine divergent ethical positions on the conception of architecture primarily by highlighting their entanglements with governance strategies and processes of subjectivation, to perspectivations of urban ethics (see introduction). The case study of the Esplanade reveals opposing ethical positions that relate to social, economic and creative issues and tensions. With the case study, I also present an example of the ways in which the discussion on architecture in Singapore refers to the politics of identity and questions of civil society, participation and freedom (Figure 12.1).

To gain a better understanding of the Singaporean context and the challenges and constraints it puts on architectural ethics, I first outline the emergence of the field of contestation over architecture and the trials of strength between governmental sanctions and architects' possibilities since the early years of independence. The second part tracks the development of 


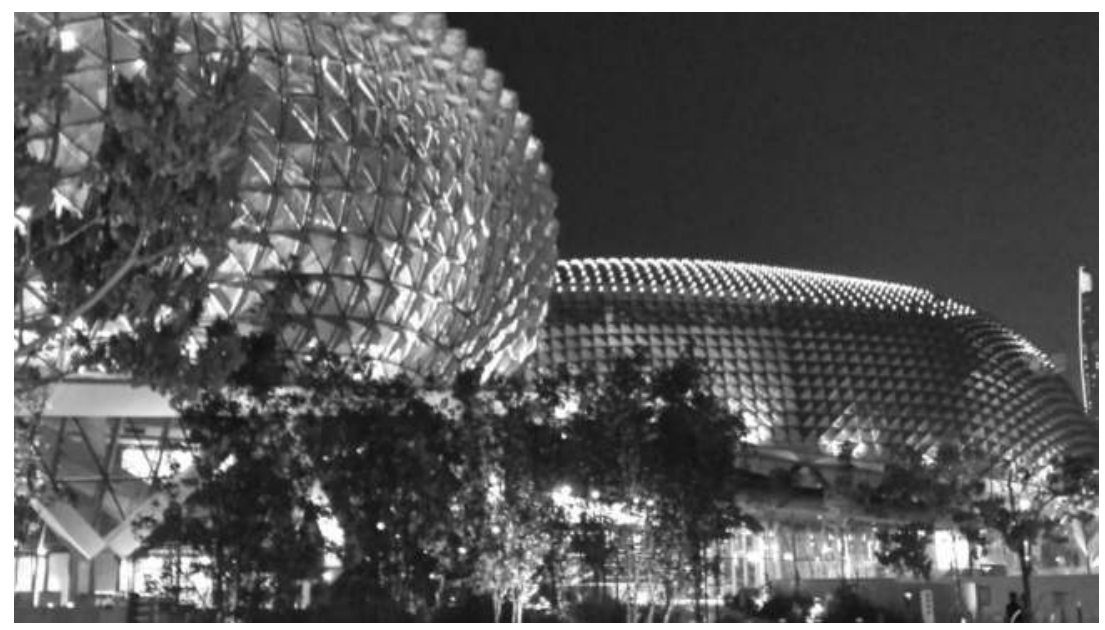

Figure 12.1 Esplanade - Theatres on the Bay. (Michaela Busenkell)

Singapore's creative city agenda. Regarding governance and subjectivation processes, I argue that this represents a case of ethicized discursive practice, as the authorities articulate the core values and attributions of meaning for the creative city and present their view of the "good life" in Singapore. Programs for the creative renewal of the urban environment were implemented in a top-down fashion, but a vibrant creative city cannot be realized without the participation and enthusiasm of people. Representations of ideal subjects for this urban space, thus, focus on a change of mindset for "creative people" to play an active part. At the same time, the activation of subjects also provides occasions and spaces for political expression. As the case study of the Esplanade in the third section illustrates, the new architectural manifestations of the city's cultural engagement need to be activated; they need to be socially appreciated, appropriated, used and enlivened; and consequently, at least to some extent, they open up a window of interference and participation.

\section{Theory and methodology}

This chapter is based on an approach situated at the interface of architecture and social and cultural sciences. Sociological accounts of architecture's role as a medium in social transformations (Delitz 2010) and Lefebvre's theory of the production of space provide a suitable point of departure (Lefebvre 1991) for revealing the implicit and explicit ethics in the discourses and practices around the architectural concepts, negotiations, implementations and appropriations within the framing of the creative and/or global city initiative. Architectural space is a socially produced space, a place molded by 
a specific set of social relations that interact at a specific location, so that the peculiarity of a place issues partially out of the traits of interaction which occur at that location (Massey 1992, 11). I apply Lefebvre's three interrelated dimensions of material, mental and lived space to this case study and, furthermore, extend his spatial triad with an actor- and actant-based approach, inspired by actor-network theory and Albena Yaneva's approaches described in The Making of a Building. A Pragmatist Approach to Architecture (2009) and Mapping Controversies in Architecture (2012). Yaneva's analyses of architecture as a dynamic process that takes place in interactive networks of human and nonhuman actors open up a new approach to complexity in the making of architecture. In this network of actors, controversies open up as well. To unfold the actors' controversies means to observe a "contradictory space" (Lefebvre 1991, 292ff) where arguments and contestations evoke ethics of architecture and space. Contradictions arise in discussion and in the buildings themselves. In practical terms, this examination of the ethics of the production of architectural spaces, practices of architects and other social practices is based on discourse analysis, interviews and participant observation: In addition to reading written documents, I visited Singapore's new cultural buildings and analyzed visual data of architectural and urban planning production, such as plans, models or sketches - all these are seen as contributions to the discourse on architecture and urban space.

Lefebvre, who conceived his theory of space as a critical instrument for changing society, perceived contradictory space as the space where social contradictions manifest; it is an important precondition for the generation of other spaces (Lefebvre 1991). In the case of the Esplanade, the networks of architecture involve the local and global, social and technical, economical and creative. I will also pursue social contradictions and tensions on freedom and civil society by pointing out contradictory positions on architectural space, implicit and explicit, among architects, officials, artists and other actors: Ethical rhetoric is used by government authorities as a technique of legitimation for new conceptions of (creative) values, norms and meaning; new (creative) identities are invoked by the politics of ethical conduct and new conceptions of economic and moral processes are also being established.

This requires some preliminary remarks on architectural ethics and the relationship between architecture and ethics (see also Isabelle Doucet and Max Ott's contributions in this volume). The question how to improve and enhance the life of the people for whom a building is planned is inherent in the practice and self-image of architects (Taylor and Levine 2011). Architects, as members of a profession, usually have an explicit code of ethics that, in most countries, is formalized in a set of rules and codes of conduct of the respective chamber of architects. They emphasize the responsibility toward developers and users, society, the environment and the profession; and toward "good" architecture, in the sense of a responsibility for well-thought-through (and in that sense "good") design and up-to-date 
professional knowledge in science and construction culture. In Singapore, these professional rules, codes of conduct and ethics are defined in the Architects Act, Chapter 12, Section 38 (revised version 2003). In addition to these codes of conduct, in current architectural discourse in many countries, there is a particular emphasis on wider ethico-political questions and rhetoric: Issues of architectural ethics are topics of exhibitions, publications and discussions in public and professional spheres. These discussions revolve around questions such as whether and in what sense reconstructions of historical buildings should be true and honest (Nerdinger 2010), the roles of architects in gentrification and, related to the latter, their contributions to investor profits and price increases (Holm 2006, 2010), and, of course, matters of sustainable planning (see Deutsche Gesellschaft für Nachhaltiges Bauen https://www.dgnb.de; Singapore Green Building Council https:// www.sgbc.sg). Under the label "building for despots," questions arise concerning for whom architects build (and should not build) (Chan 2013, 2014, 2015; Düchs 2011, 56). Participative design and construction processes have captured renewed interest, especially in the context of the social turn in architecture, related to issues such as inadequate housing supply or housing inequality (Arch+ 2013; Lepik 2010). In this chapter, however, ethics of architecture revolve primarily around the implications of the urban, cultural and social transformation of Singapore to become a creative city and the ways in which design, building techniques, materiality, scale, shading systems and architectural form are entangled with ethical questions. Thus, top-down expectations for Singapore's creative architectural performance meet alternative bottom-up ethics of architectural creativity, and it is the tensions arising that are analyzed here.

\section{Sociopolitical development, urban renewal and contestation in architecture and urban planning in Singapore}

Singapore has undergone continuous urban and social transformation since its detachment from British rule. Three political eras had a particularly significant impact on architecture, urban planning and the image of the city: The colonial period under British Rule (1819-1965); the early period of selfgovernance (1959) and independence (1965); and the "Renaissance City" development with the aspirations for a global city, respectively, for a "Distinctive Global City of the Arts" (Powell 1996). The Singapore Improvement Trust's Master Plan of 1958, led by a team of British planners, was the basis for the Singapore Concept Plan, drawn up by a team of UN experts with the state and city planning department and completed in 1971 as the framework for the country's physical development over the next 20 years. Priorities were the provision of housing and work. Local architects were able to open their own architecture studios and firms for the first time, an architecture program was installed at Singapore University and architecture competitions were opened (and sometimes restricted) to the participation of local 
architects (Lim 2005; Powell 2004). Western ideas of modern architecture were discussed and related to Asian traditions, to the specifics of local climate and culture, to issues of identity and the spirit of the Merdeka - of independence and freedom, as proclaimed by Lee Kuan Yew after the People's Action Party came into power in the general election of May 30, 1959.

Until 1965, political discourse focused on the evolution of a Malaysian identity and culture; architects envisaged a Malayan architecture with a local identity (Lim 2005, 146). This orientation was abruptly abandoned after the separation from the Malaysian federation in 1965, as a result of political tensions between Malaysia and Singapore culminating in racial riots in Singapore.

The most urgent questions facing the new sovereign state concerned economic development, state formation and national identity building (Lim $2005,143)$. It was a time of envisioning a new city-state and a new, independent society. After the traumatic Singapore moment of the expulsion from Malaysia and its aftermath, however, the question of survival was emphasized by Prime Minister Lee Kuan Yew as the "main theme underlying all analyses of problems and statements of policies and intent" (Chan 1971, 48).

Access to the US market was a critical factor for the economic miracle of Singapore. Social and political stability was regarded as essential for economic growth; the government exerted restrictions on individual freedom, the press and political debate (Kong et al. 1997). It took measures against political opponents and critics, such as journalists, theatre practitioners and other intellectuals, and began to license social activities (Lim 2005, 153), requiring official authorizations for assemblies, groups or associations with more than four people. The dissolution of the Singapore Planning and Urban Research Group (SPUR, 1965-1973), a collective of younger architects, planners and sociologists from Singapore's private and public sectors that acted as a "watchdog" over government projects, was the most famous and significant case of repression in architectural controversies (Hill and Fee 1995). SPUR's critical ideas and strategies had given rise to tensions with authorities, and the group was finally forced to dissolve. SPUR has been seen as an early venture in the direction of civil society (Hill and Fee 1995, 222; Lim 2005, 151). Under the conditions of an authoritarian state the SPUR case illustrates contestation and critical discourse on values in architecture and how they can open up a space for democratic participation, codetermination and freedom.

\section{"Renaissance City Singapore" - toward a global city for the arts}

In the mid-1980s, during the economic recession, Singapore's Economic Committee recommended the development of the arts as part of the service sector. Faced with a financial crisis in East Asia and Southeast Asia in the late 1990s more broadly, the Singapore government started to investigate 
new possibilities for an economy of the future with ambitions to develop the cultural assets necessary for Singapore. George Yeo, the Minister for Information and the Arts at the time, explained, "To be competitive in the next phase of our national development, we need to promote the arts" (Yeo in Kong and Yeoh 2003). The vision was for Singapore to become a global city as a center for banking, finance, manufacturing and commerce, and also a "global city for the arts." The Report of the Advisory Council on Culture and the Arts (ACCA 1989) and the Renaissance City Report and Plans (RCP II 2005; RCP III 2008 RCR 2000) outline the measures to transform Singapore into a "Renaissance City" and link art with commerce and national identity (Purushothaman 2016, 205). Good facilities and a "congenial environment" were seen as tools to attract talents, investors and businesses from all over the world (ACCA 1989, 12). This development of a cultural and creative economy in Singapore also calls for a newly "creative" population and a life and subjectivities in which a certain understanding of "culture" plays a much larger role than before. For that purpose, the government takes measures such as establishing new educational institutions, redesigning education plans for schools and changing the daily lives of citizens with artistic programs at the workplace, in the neighborhood, community centers and social clubs. It also entails new leisure activities that are partially offered free of charge, such as lunchtime concerts or free admission for Singaporeans to museums, and envisions major changes in the built metropolitan environment. Regarding the Singaporean trauma of endangered survival, the government argues that this "creative" transformation is essential for the city-state's social and economic viability. The report of the Economic Review Committee (ERC Report 2003) is framed by concerns over the small size and location of the country and, consequently, its future survival. The development of the arts should shift away from an "arts for art's sake" mindset toward a more "holistic perspective," in the sense of the creative industries' role in the nation's social development, the plans argue (RCP II 2005, 14). This also means that the arts as an imaginative space are shifted toward rationalized and measurable economic criteria. Today, for example, the arts and literature or music in Singapore are evaluated with a "key performance index system" imposed by the National Arts Council that measures the effectiveness of the use of funds which clearly locates arts and culture in the field of economics. In the context of this cultural policy and a broader economic ethic, the value of artistic and cultural production appears to be primarily derived from political-economic goals.

In programs like these, Singaporeans are addressed as one community, whose members are responsible for the collective destiny of the nation by way of economic advancement. This is an ethicized politics of behavior that relies on evoking and linking values that purport to be timeless, natural, obvious and incontestable and that are also taken to guide self-directed action. Framed as "Arts (f)or Survival" (Kong and Yeoh 2003, 162), the "Renaissance City" ideal calls on citizens to develop an interest in culture and 
the arts and thereby contribute to the survival of the nation. This discourse addresses citizen's conduct of life and, in that sense, ethics as subjectivation, as becoming a specific type of subjects living a specific "good" life, following the government's lead, but doing so out of their own volition (Collier and Lakoff 2005; Faubion 2009; Foucault 1987). As sociologist Nikolas Rose puts it, "ethopower" or "ethopolitics" works through values, beliefs and sentiments to facilitate techniques of responsible self-government and one's obligations to others (Rose 2000; on ethicization, see also Bogner 2011 and Moore in this volume).

At the same time, government documents suggest that the creative city will encourage individuals' further professional and personal development as well as criticism and public discourse: [Art and culture]

provide an avenue for Singaporeans to critique, analyze and discuss their experiences in an accessible and creative manner, thereby encouraging the development of views and positions on issues. This will be a society that is clear about its identity, confident and at ease with itself.

(RCR 2000, 3)

These promises have to be seen within the frame of survival, economics and creativity. Regarded in a general, theoretical sense, frames define the perspective from which specific topics - such as, in this case, the openness for public discourse and critique - can be problematized and work toward political legitimation. They are, therefore, crucial for structuring and negotiating conflicts (Bogner 2011).

While state planning called for citizens' greater responsiveness, new perspectives and ideas, the fear of losing power to an active and possibly contentious public embracing democratic ideas always loomed in the background: "The crux is how to do so without losing the efficiency, decisiveness and collective [state] action that has enabled Singaporeans to thrive" (Singapore 21 Committee 1999). There are other limits to this sense of creativity as well. In the "survival" frame and given the priority of economic goals, it is implied that art for the art's sake is ultimately irresponsible, unjustifiable and even "unethical," as it does not contribute to growth and could even undermine the city-state's well-being. The following case study will spell out these and other complications and ethical contestations.

\section{The esplanade - theatres on the bay}

Questions of national identity and of a contextual Singapore architecture have frequently been posed in the city-state's history. Public controversies about architecture and urban space were revived in the context of building for the "creative city" and particularly the cultural center of the Esplanade, a project collaboration between British architect Michael Wilford and DP Architects in Singapore. The discussion was polarized between a pragmatic 
governmental interest in economic indicators, global city status, creative city success and nation building and, by contrast, the visions of architects, artists, other cultural workers and citizens who promote a specific, contextrelated architectural "Singapore idiom." In this situation, buildings are highly contested spaces (Kong 2002).

Architecture can redefine the perception of social and spatial context and create new space for action, so that urban residents can see their city as a collectively produced place for living, activated by new urban imaginations and visions. The government in Singapore promotes an architecture that is oriented toward global images, in order to offer the adequate framing of Singapore as a location for multinational companies. A counter-model could show an evolutionary development from place- and context-specific qualities for a Singapore identity as a "city as oeuvre" (Lefebvre 1968). As anthropologists Susser and Tonnelat (2013) argue, a crucial meaning of urban artistic work and architecture lies in this potential for new urban visions, especially, in this case, in the ability to change perspectives on the "creative" in the creative city - as a space for diverse imaginations and practices. Singaporean architects and other citizens' orientation toward a local architecture idiom can be seen in this light. In their buildings, some Singaporean architects, such as Tay Kheng Soon, Wong Mun Summ and Richard Hassell (WOHA), Tan Kok Hiang and Ho Sweet Woon (Forum Architects), Yip Yuen Hong and Lee Ee Lin (ipli Architects) and others, explicitly seek new references and interpretations of the Tropical-Asian environment and identities with its multiple cultural and historical relations, articulating an ethic of adherence to local, regional and sustainable reference points. For many decades, however, there were few opportunities to implement these visions in government-administered cultural projects. Since the 1970s, most major projects were awarded to foreign architectural firms. This pattern also remained in place during the creative city transformation period, which provoked strong resentment (Powell 2004, 109).

The Esplanade was the initial project of the creative city program and the flagship for the political ambitions of a "global city for the arts" (Kong 2000; Yeoh 2005). The location, Marina Bay, literally constituted new ground on land reclaimed from the sea with spectacular new buildings for luxury hotels, a financial center and the Esplanade cultural center, embodying the connection of economy, tourism and culture promoted by the city-state's plans. The Esplanade was conceived in 1992, the design was exhibited in 1994, redesigned in 1995, construction started in 1998 and it opened in 2002. As sociologist Heike Delitz (2010) argues, architecture is a symbolic medium for the constitution and transition of society. In its new architecture, a society gains a new image of itself (Delitz 2010, 16). Its spaces associate artefacts, bodies and discourses. Indeed, the Esplanade presents a visual and spatial model of the transformation of Singapore in a creative city and society. A high symbolic value is attributed to it. At the same time, the Esplanade functioned as a catalyst for architectural contestation and an 
expression of social controversies (Yaneva 2012), relating design and materiality to questions of identity, scale to economy, local versus global art and architecture, or inclusivity and/or exclusivity to the role of art and architecture. As the model and plans were exhibited at the end of the design process in 1994, the design provoked serious critique from the public. For the first time in Singapore's history, a building was openly criticized over a period of a year in the press (interview with Gore 2016).

The first thread of critique related to the costs of the building and the question whether it was an elitist or inclusive building. In the eyes of many Singaporean "heartlanders," such an elaborate cultural building would benefit only a small elite, while it would be paid for by the taxpayers. This criticism was deflected by the Ministry of Information and the Arts by pointing to the fact that the construction costs of the Esplanade, publicly reported at S\$ 667 million/412 million euros, were financed mainly through the state lottery, the only form of gambling allowed in Singapore, and further supported by corporate sponsorship. The Esplanade's slogan "Performing Arts for Everyone" deliberately emphasizes its non-elitist character. It shows a mix of functions - the concert and theatre complex, shopping mall, rooftop terrace with bar-café, a library of film and theatre and a range of restaurants - that are intended to make it a lively place for a wide variety of people. Here and in general, "inclusivity" is an ethical argument; it suggests a "cultured" and "good" life for everybody. However, in the domain of the arts, the call to be inclusive is to be interpreted with caution, as it can also require artists not to be too difficult, to produce pleasing or entertainment products and eliminate more subtle or sensitive issues, as claimed in a 2015 newspaper article by Kathy Lai, CEO of the National Arts Council at that time (Lai 2015).

A second thread of the debate concerned the building's form and material but had much wider implications as well. The planned structure featured three organic glass bodies that integrate all functions. The design was described as composition that appears like lanterns in the night, reflecting the quiet residential architecture of Southeast Asia. As architect Michael Wilford commented, the glass-covered public areas of the Esplanade were designed as places of social intercourse to be open and visible in the daytime, while at night, people have a view from the interior over the city and the bay (Richards 2003). The extensive glazing of the buildings, however, caused a controversy regarding the appropriate materiality in the tropical Singapore climate and, finally, the building was deemed not to be an Asian design by critics (interview with Gore 2016). Harsh disputes led to changes of the built volume and the appearance of the building. An official decision was made to change the complex into two building phases and only phase one was to be built. After this decision, Wilford, the British architect, resigned, and the local partner firm, Singaporean DP Architects, took over the project. A young structural engineer of Atelier One in London developed a cladding façade system with a double space frame structure and triangular aluminum sun shields. The building's shell could now be seen as an allusion of the 


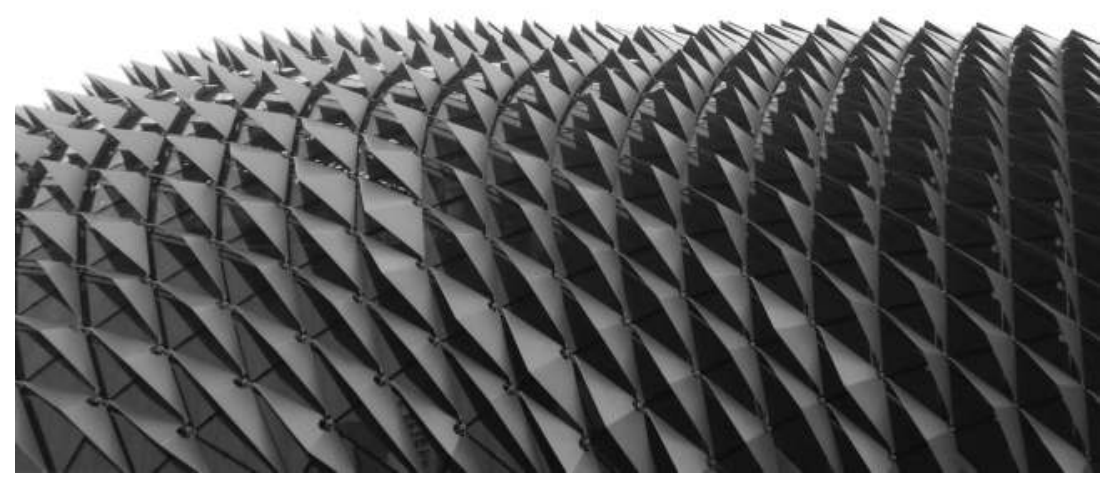

Figure 12.2 Shading shell of the Esplanade. (Michaela Busenkell)

Durian, the local stink fruit, a delicacy that is not allowed to be consumed in closed public spaces because of its intense smell. This allusion, which was not necessarily intended by the engineer, was adopted by the public as a context-related, Asian design (Figure 12.2).

But issues of identity went deeper; they also concerned the project's uses, programming and overall purpose. Critics, such as Tay Kheng Soon and many artists, questioned the Esplanade's size and, with this, the commodification of the arts and their distance from local society, as it was assumed that only famous international touring companies but not local groups could fill and afford the rent of the large halls. Within the community of local artists, the state's emphasis on economic goals had led to a general mistrust of its intentions in the arts. George Yeo, Minister for Information and the Arts during the planning and construction period of the Esplanade and chairman of the Steering Committee, explains the economic intentions quite bluntly:

The Esplanade represents the state's latest and, to date, most ambitious and expensive venture into the production of landscapes for the arts, and it represents what Singapore hopes most to achieve: The vision of a global city, acting as a hub not only for banking, finance, manufacturing, and commerce but also for the arts - thus helping to create new ideas, opportunities and wealth.

(Yeo 1995, 5)

Minister Yeo also states that Singapore is what it is because of its cosmopolitan orientation (Yeo 1994, cited in Kong 2000). In counterpoint, Kuo Pao 
Kun, Singapore's famous playwright, expressed what many others thought: "Can we have a Singapore Arts Centre by just bringing all the arts of the world to Singapore without our own education, without our own creativity?" (Kuo 1995). The debate about the roles of international versus local artists, on the one hand, thus, mirrors that about the roles of international versus local architects; on the other hand, it also brings out divergent priorities about the economy and different understandings of art and its role within local and wider contexts. As a reaction, the operators of the Esplanade developed a program concept including different events, target groups and ticket prices, with international and local orchestras, theatre groups and artists, ethnic festivals and free daily concerts in the entrance hall and in an open arena at the Waterfront. In June 2019, construction for a new mid-size theatre broke ground that will serve smaller local groups, designed by Singaporean 61 architects and targeted for completion in 2021 (see https://www. esplanade.com/about-us/the-next-stage).

\section{Conclusion}

In the Esplanade project, debates about the planning process, the place of local artists and the shape of arts and creativity, catalyzed a controversy over values and the ethics of building for a "good" life in Singapore - involving questions of inclusion and exclusion and the value of local artist productions versus global art and performance. This expanded into a fundamental debate about values in the arts and in architecture, related to identity and artistic autonomy. The new Marina Bay quarter, first of all, represents an official image of creativity and culture. Furthermore, it is one of the locations where Singaporeans, according to the plans for a "Renaissance City," are to form an audience of cultured and creative subjects. As architect Tay Kheng Soon comments, the concept and design of the Esplanade are seen by many as an official representation of a new, Asian identity for Singaporeans. In his opinion, however, it is easier for the government to buy international architectural design and art programs than to investigate regional architecture history and grow new sensitive and creative approaches (Tay 1994 cited in Kong and Yeoh 2003). The district, while symbolizing and promoting ideals of societal transformation toward a creative economy, can be interpreted in terms of techniques of governance and subject formation, the top-down prescription of a new urban ethics (Figure 12.3).

This official framing of creativity in the service of economics is problematized by a series of contestations over the question "how should one build" that involve symbolic and material elements of the project. These controversies pit different perceptions of creativity and the economic value of creativity against one another in a context of globalization and economic expansion (Kong 2000; Smith and Warfield 2008) that makes the local a particularly loaded topic, culturally and economically. Singapore's survival strategy is based on the idea of cosmopolitanism (Yeo 1994, cited in Kong 


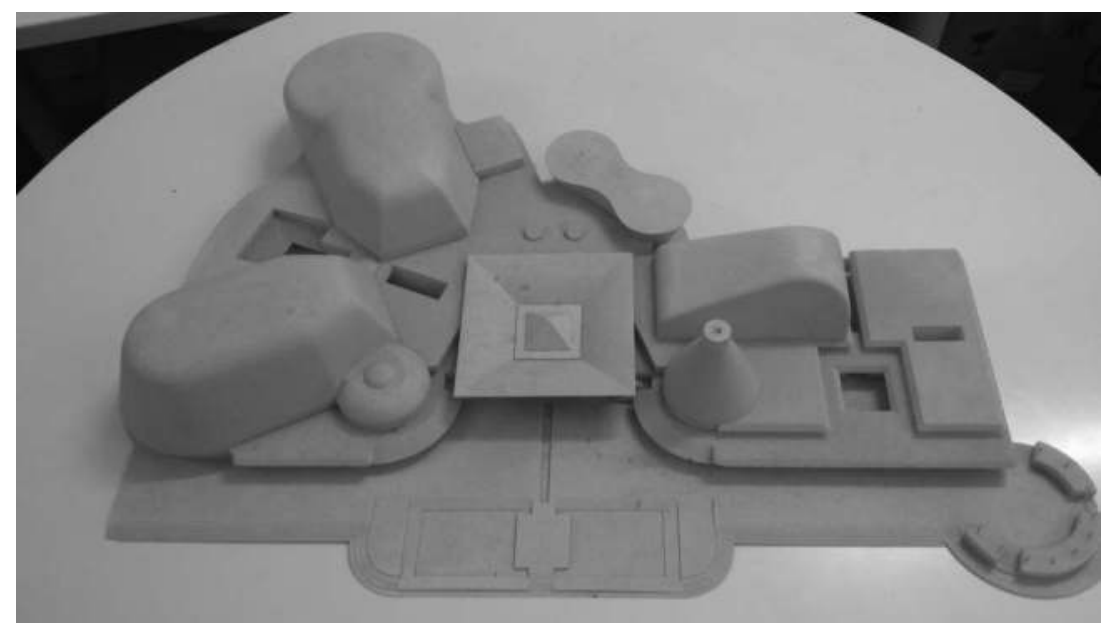

Figure 12.3 Competition model (DPA). (Michaela Busenkell)

2000), which is transferred to art, culture and architecture - an attitude that, for many years, left little room for local architects and reduced them to the role of the local partner agency of an international star architect. In official discourse, good architecture expresses an international modern style with Asian allusions and provides powerful images. However, spaces for negotiation opened up in the wake of governance and subjectivation processes for the creative city transformation. In this sense, architecture projects can act as catalysts in respect of social issues that have seldom been openly questioned in public before. With the Esplanade, a contradictory space opened up where social contradictions became manifest (Lefebvre 1991). After the dissolution of the SPUR group in the early 1970s, it was not until the first discussions over the Esplanade that massive, public architectural critique (published in the daily newspaper over a longer period of time) was voiced. Following Lefebvre, this is an important precondition for the creation of other spaces. The administration's reactions to the criticism of its plans for the Esplanade, the revision of some of the plans, the focus on the symbolically "local" in architecture and the new programming focus illustrate a limited but, nonetheless, effective responsiveness. However, critics still have good reasons to see this as primarily strategic rather than paradigmatic.

What started with the conceptualization of the Esplanade is still an ongoing process. Today, public architecture projects in Singapore are still primarily evaluated using numerical criteria, so that mostly big corporate firms are commissioned. With the licensing (i.e., censoring) system of the Info-communications Media Development Authority, the Key Indicator 
System and the funding grants of the National Arts Council, the government continues to possess strong instruments to regulate and control the art scene in this small country where most artists rely on financial support from the state. Still, to some extent, the "Renaissance" program, with its focus on the active participation of citizens, created a space of discussion and debate where the official framing of creativity and arts continues to be questioned openly. In that sense, the ethical contestations of the Esplanade, which raised complicated issues over cultural policy, for example, regarding inclusivity and commerciality, also encouraged open statements and criticism on other, subsequent construction projects; the public's voices and participatory approaches are, to a certain extent, increasingly integrated. Nevertheless, buildings for private investors and builders, such as hotels, office buildings or private residential buildings, are most likely where new approaches to architecture are tested today in Singapore. Local architects, individuals or small groups, initiate and commission projects that open up alternative models and values for material, social and creative space. They explicitly seek new references to and interpretations of the tropical Asian context, woven from diverse strands of histories and cultures, mediating between Asian and Western culture and create a specific amalgamation that might serve as a role model for the urban spaces of Singapore's future. Despite the power of Singapore's neoliberal "creative city" project, in fact, because of it, a window for interference and participation opened in which debates focused on the ethical question "how should one build"? (Figure 12.4).

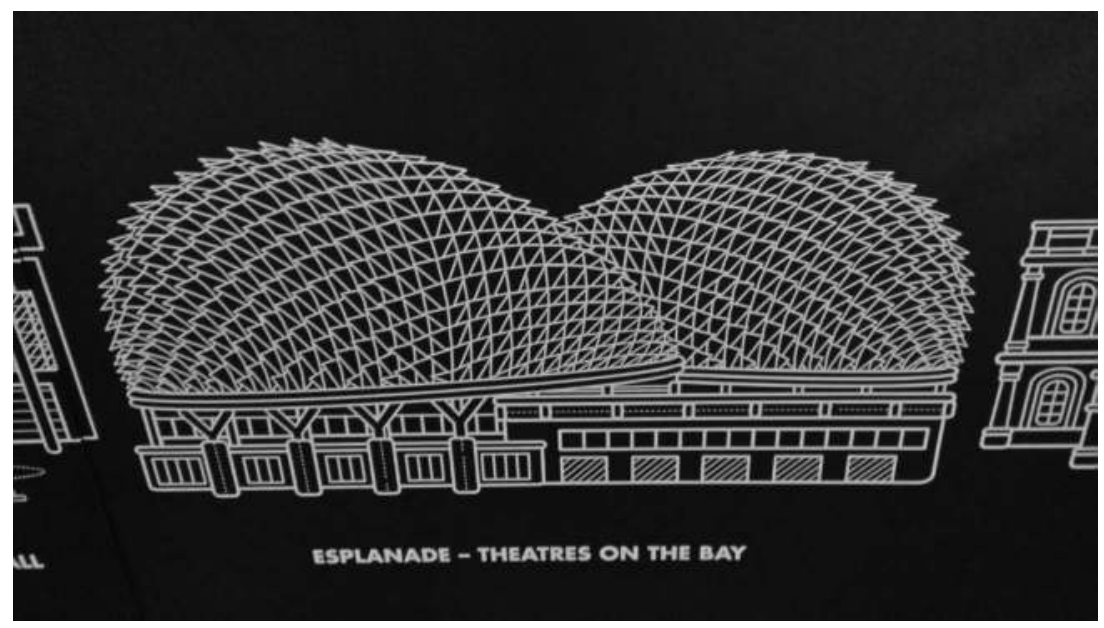

Figure 12.4 Section - Esplanade. (Michaela Busenkell) 


\section{Bibliography}

ACCA - Advisory Council on Culture and the Arts. 1989. Report of the Advisory Council on Culture and the Arts, Singapore.

Arch+. 2013. Think Global, Build Social. No. 211/212.

Architects Act. 2003. Chapter 12, Section 38; (revised version). Accessed January 2015. https://sso.agc.gov.sg/SL/AA1991-R2.

Bogner, Alexander. 2011. Die Ethisierung vonTechnikkonflikten. Studien zum Geltungswandel des Dissenses. Weilerswist: Velbrück Wissenschaft.

Chan, Heng Chee. 1971. Singapore: The Politics of Survival 1965-1967. Singapore: Oxford University Press.

Chan, Jeffrey K. H. 2013. "Teaching Ethics in Architecture: Contexts, Issues and Strategies." Journal of the NUS Teaching Academy 3, no. 3: 85-99.

Chan, J effrey K. H. 2014. "Planning Ethics in the Age of Wicked Problems." International Journal of E-Planning Research 3, no. 2: 18-37.

Chan, J effrey K. H. 2015. "Moral Agency in Architecture? The Dialectics of Spatializing Morality and Moralizing Spaces." In Architecture, Materiality and Society: Connecting Sociology of Architecture with Science and Technology Studies, edited by A. L. Muller and W. Reichmann, 198-214. London: Palgrave.

Collier, Stephen J., and Andrew Lakoff. 2005. "On Regimes of Living." In Global Assemblages. Technology, Politics, and Ethics as Anthropological Problems, edited by Aihwa Ong and Stephen Collier, 29-31. Malden, MA: Blackwell.

Delitz, Heike. 2010. Gebaute Gesellschaft. Architektur als Medium des Sozialen. Frankfurt am Main, New York: Campus.

Düchs, Martin. 2011. Architektur für ein gutes Leben. Über Verantwortung, Ethik und Moral des Architekten. Münster: Waxmann Verlag.

Economic Development Board, Ministry of Information and the Arts. 1992. Singapore - Global City for the Arts. Singapore: Tourist Promotion Board.

ERC Report. 2003. Creative Industries Development Strategy. Edited by the Ministry of Trade and Industry (MTI), Singapore. A Report by the ERC Service Industries Subcommittee Workgroup on Creative Industries. Accessed September 20, 2019. http://unpan1.un.org/intradoc/groups/public/documents/APCITY/ UNPAN011548.pdf.

Faubion, James D. 2009. "The Ethics of Fieldwork as an Ethics of Connectivity or the Good Anthropologist (Isn't What She Used to Be)." In Fieldwork Is Not What It Used to Be. Learning Anthropology's Method in a Time of Transition, edited by James D. Faubion and George E. Marcus, 155-64. Ithaca: Cornell University Press.

Florida, Richard. 2002. The Rise of the Creative Class: And How It's Transforming Work, Leisure, Community, and Everyday Life. Cambridge, MA: Basic Books.

Foucault, Michel. 1987. "Zur Genealogie der Ethik: Ein Überblick über laufende Arbeiten." In Michel Foucault. Jenseits von Strukturalismus und Hermeneutik, edited by Hubert L. Dreyfus and Paul Rabinow, 265-92. Frankfurt am Main: Beltz Athenäum.

Goh, Beng Lan. 2017. "Red Dot on the Map; Singapore, Size, and the Problems of Success." In Small Countries. Structures and Sensibilities, edited by Ulf Hannerz and André Gingrich, 105-22. Philadelphia: University of Pennsylvania Press.

Gore. 2016. Interview Michaela Busenkell. 
Haila, Anne 2016. Urban Land Rent. Sinapore as a Property State. Chichester/West Sussex: Wiley Blackwell.

Hill, Michael, and Fee, Lian Kwen. 1995. The Politics of Nation Building and Citizenship in Singapore. London, New York: Routledge.

Holm, Andrej. 2006. Die Restrukturierung des Raumes. Stadterneuerung der 90er Jahre in Ostberlin. Interessen und Machtverhältnisse. Bielefeld: transcript Verlag.

Holm, Andrej. 2010. Wir bleiben alle! Gentrifizierung - Städtische Konflikte um Aufwertung und Verdrängung. Münster: Unrast-Verlag.

Howkins, John. 2001. The Creative Economy. Ringwood: Penguin.

Huat, Chua Beng. 2007. "Foreword." In The Asian Modern: Culture, Capitalist Development, Singapore, written by C. J. W.-L- Wee. Hong Kong: Hong Kong University Press, vii-ix.

Jacobs, Andrew. 2012. "As Singapore Loosens Its Grip, Residents Lose Fear to Challenge Authority.” New York Times, 16 June, 2012.

Kong, Lily. 2000. "Cultural Policy in Singapore: Negotiating Economic and SocioCultural Agendas.” Geoforum 31, no. 4: 409-24.

Kong, Lily, and Brenda Yeoh. 2003. The Politics of Landscapes in Singapore: Constructions of "Nation". Syracuse, New York: Syracuse University Press.

Kong, Lily, Martin Perry, and Brenda Yeoh. 1997. Singapore: A Developmental City State. Chichester/New York: Wiley..

Kuo, Pao Kun. 1995. Art vs. Art: Conflict and Convergence: The Substation Conference 1993. Singapore: Substation 1995, p. 145.

Lai, Kathy. 2015. The Straits Times, November 7, 2015: The tough balancing act of ATS funding. https://www.straitstimes.com/opinion/ the-tough-balancing-act-of-arts-funding.

Landry, Charles. 2000. The Creative City. A Toolkit for Urban Innovators. London/ Sterling, VA: Earthscan.

Lefebvre, Henri. 1968. Le Droit de la Ville. Collection "Points". Paris: Anthropos.

Lefebvre, Henri. 1991 [1974]. The Production of Space. Oxford: Blackwell.

Lepik, Andres. 2010. Small Scale, Big Change. New Architectures of Social Engagement. New York: The Museum of Modern Art.

Lim, William S. W. 2005. Asian Ethical Urbanism. A Radical Postmodern Perspective. Singapore: World Scientific Publishing.

Massey, Doreen. 1992. For Space. London: Sage Publications, p. 11f.

Nerdinger, Winfried. 2010. Geschichte der Rekonstruktion - Konstruktion der Geschichte. München: Prestel.

Powell, Robert. 1989. Innovative Architecture of Singapore. Singapore: Select Books.

Powell, Robert. 1996. "Urban Morphology: Values Embedded in the Singapore Landscape." Journal of Southeast Asian Architecture 1: 46-59.

Powell, Robert. 2004. Singapore Architecture. Singapore: Periplus Editions.

Purushothaman, Venka. 2016. "Cultural Policy, Creative Economy and Arts Higher Education in Renaissance Singapore." In Higher Education and the Creative Economy. Beyond the Campus, edited by Roberta Comunian and Abigail Gilmore, 201-20. London: Routledge.

RCR. 2000. Renaissance City Report. Culture and the Arts in Renaissance Singapore. Ministry of Information and the Arts (MITA), Singapore. RCP II (2005) Renaissance City Plan II. Edited by the Ministry of Culture and the Arts (MICA), Singapore. 


\section{Michaela Busenkell}

RCP III. 2008. Renaissance City Plan III. Hrsg. vom Ministry of Information, Communications and the Arts (MICA), Singapore.

Richards, Kristen. 2003. http://www.archnewsnow.com/features/Feature101.htmSa'at, Alfian (1998): One Fierce Hour. Landmark Book, Singapore, p. 41ff.

Rose, Nikolas. 2000. "Community, Citizenship, and the Third Way." American Behavioral Scientist 43, no. 9: 1395-411.

Singapore 21 Committee. 1999. Together, We Make the Difference, Government of Singapore, p. 49-51.

Susser, Ida, and Stéphane, Tonnelat. 2013. "Transformative Cities: The Three Urban Commons." Focaal - Journal of Global and Historical Anthropology 66: 105-21.

Smith, Richard, and Katie Warfield. 2008. "The Creative City: A Matter of Values." In Creative Cities, Cultural Clusters and Local Economic Development, edited by Philip Cooke, Luciana Lazzeretti, Creative Cities (Hg.), 287-312. Cheltenham/ Northampton: Edward Elgar.

Taylor, William M., and Michael P. Levine. 2011. Prospects for an Ethics of Architecture. London/New York: Routledge.

Transparency International. 2018. Corruption Perceptions Index: Singapore. Accessed June 1, 2019. https://www.transparency.org/country/SGP.

World Press Freedom Index. 2019. Accessed June 1, 2019. https://rsf.org/en/ singapore.

Yaneva, Albena. 2009. The Making of a Building. A Pragmatist Approach to Architecture. Pieterlen/Bern: Peter Lang AG, Internationaler Verlag der Wissenschaften.

Yaneva, Albena. 2012. Mapping Controversies in Architecture. Farnham, Surrey: Ashgate.

Yeo, George. 1995. Singapore: Global City for the Arts 1995:5. Ministry of Information and the Arts, Singapore.

Yeoh, Brenda S. A. 2005. "The Global Cultural City? Spatial Imagineering and Politics in the (Multi)cultural Marketplaces of South-east Asia." Urban Studies 42 May, nos. 5/6: 945-58. 


\section{Part IV}

\section{Environmental justice, ethics of care and the spectacle of urban sustainability}




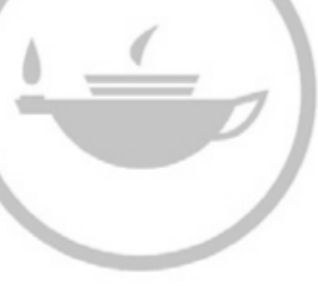

Taylor \& Francis Taylor \& Francis Group

http://taylorandfrancis.com 


\title{
13 Reimagining urban environmentalisms
}

\section{A comparative framework}

\author{
Julie Sze
}

\begin{abstract}
Discourses and policies on "urban sustainability" have exploded in recent years. This growth has many roots. Sustainability now commands unmatched attention and presumes unprecedented importance. It enjoys a degree of political traction and invokes a sense of urgency, which often seems automatic and universal. Spurred by climate change, urban growth and environmental degradation writ large, understanding and promoting sustainability seem omnipresent. Calls for sustainability convey imperatives and an agenda for action. The urban dimension is connected to what Neil Brenner and Christian Schmid (2014) identify as the "Urban Age thesis," which posits that for the first time in history, more than half the world's population lives in cities. The "Urban Age" thesis frames global urbanization as a phenomenon of the planetary ecological dimension.
\end{abstract}

The very demise of humanity on the planet seems plausible, if not inevitable, but cities are feted as possible solutions to climate and environmental crisis. However, the growth of the city as the solution to sustainability and its underlying pillars are often under-analyzed. Rather than an inevitable solution to climate and environmental crisis, discourses and practices of urban sustainability must be understood as products of social dynamics. These dynamics - moral logic and aspiration (ethics) and struggles over power (politics) - are important, yet often unstated components for understanding how calls for sustainability and urban environmentalism are produced and reproduced.

Sustainability is malleable and ubiquitous and appears to lack explicit politics (Sze et al. 2018). However, politics is present, including conflicts inherent in eco-modernization - related to greenwashing, inequality and justice - and the underlying power relations that shape 21st-century ecological urbanism (Müller and Mattissek 2018). Seghezzo argues that it is the ambiguity of the term that has contributed to its large-scale acceptance as a framework for environmental and social action (2009). German linguist Uwe Pörksen, in his Plastic Words: The Tyranny of a Modular Language (1988), describes "plastic words," such as "development," "growth," "health," "model" and "quality." He argues that they share several key features. Showing no trace of their origins, "plastic words" are derived from 
the sciences and are "building blocks of the industrial state." They are "ciphers" that transmit messages of emptiness; "they are idols, magical and empty" (Pörksen 1988). He wrote in a historical context before sustainability exploded, but his idea of plastic words is, nonetheless, applicable here. Sustainability is a "plastic word," linked loosely to environment. It connotes without precise definition, and therein lies its seductive appeal and political power. Recent scholarship has focused on highlighting the justice turn in sustainability (Agyeman 2013; Agyeman et al. 2003; Sze et al. 2018).

At the urban scale, environmental discourse is a factor in displacement and gentrification (Checker 2011). Sociologist Miriam Greenberg identifies "the sustainability edge," which she defines as sustainability discourses being promoted by entrepreneurial urban growth coalitions of major cities around the world as a form of branding to support urban economic growth (Greenberg 2015). This chapter focuses on how sustainability projects align with real estate development and top-down authoritarian approaches to urban planning. Urban land-use development is one sector where sustainability contravenes economic justice, and where ethics and long-standing community ties lose out in the face of marketization and real estate ventures.

Based on my research on eco-city discourses in Shanghai (Sze 2015) and environmental justice and activism in New York City (Sze 2007; Sze and Yeampierre 2018), I propose a comparative transnational framework through which to analyze the emergence of spectacular urban sustainability projects and their ideological limits. By spectacular, I mean the "spectacle" of sustainability, which is often rendered through images and imaginaries on the local scale. Spectacular sustainability connotes images and imaginaries associated with "organic" and "green." It overlaps with recycling and bicycling, zerowaste, carbon neutral and solar panels. My case studies in Shanghai and New York show how a global and a temporal and/or spatially situated "sustainability justice" framework is essential for making sense of the recent proliferation of discourses, social movements and policies across geographic space. Specifically, this chapter explores how urban sustainability projects construct new consumerist citizen identities and destabilize old conflations of place and identity by interweaving urban and rural landscapes in new forms that are not well understood. The turn to sustainability erases the political implications of various development projects and makes issues of ethics and justice less visible in its wake. The turn to sustainability relies upon "ethical" urbanity as a spectacle, while erasing the political implications of various development projects, and makes actual ethical demands and demands for justice, especially on the community scale, less visible in its wake. I argue that the turn to sustainability in global urban environmentalisms is an unstable and deeply contested terrain of differential notions of spatial and temporal justice.

Political struggles over urban sustainability plans that appear to be simple conflicts around the structure and enactment of a "good" and sustainable city are, in fact, struggles over the formation of ideal (or improved) citizens and collective environmental goods that take place in the context of extreme 
economic inequality and forecasts of the imminent dangers of climate change that will hit specific places and the peoples that inhabit them particularly hard. These are often, but not always, less politically powerful communities. Sustainability is not universal but, in fact, deeply particular. "Whose sustainability, in other words" (Sze et al. 2018). Whose ethics? How are different communities impacted? Who is responsible for what and how? Notions of sustainability are shaped by class, political identity, migration and/or movement, race and gender (among other factors). Sustainability is shaped through and by corporate capitalism "as well as" counter-hegemonic struggles against the worst excesses of global capitalism and urban development.

\section{Beyond consumer citizenship: ethics and justice}

China has undergone urban rebuilding in the last three decades that constitutes the largest destruction of property in human history. Land use and/ or space and identity have been radically transformed in the historical and political context of China's incorporation into the global economy since the 1980s. The transformation of Shanghai since the 1990s has been particularly dramatic, as befits its world city status and global ambitions. In Shanghai, several ecologically themed development projects, including major naturethemed suburbanization projects and at the 2010 World Expo, represented what I called the apotheosis of eco-desire, or the fusion of desire, projection, profit and fun, particularly top-down versions of eco-development (Sze 2015). My articulation of eco-desire was borrowed from anthropologist Lisa Rofel, who argues that desires do not stem from a lack of material objects but are the "productive force" that creates neoliberal subjects unleashed by the capitalist machine (Rofel 2007). The eco-desires that these Shanghai projects represent are green or sustainable capitalist discourses in the Chinese political context. This discourse and policy suggest that capitalist means are the best solution to environmental problems.

Part of the equation of eco-desire in China are in two distinct but interrelated areas: The "capitalization of nature," primarily through technology, and the "transformation of citizens." Shanghai's economic, urban and environmental policy worked together to produce the improved city that promises a "Better City, Better Life," according to the official World Expo slogan. A strong "vision" of nature and environment is a key component to the city's recent urban development history.

The capitalization of nature functions in these ways. First, technology "transforms" historically degraded "rural spaces" into highly desirable "ecological places." While rural spaces remain poor, "ecological" places retain the virtues of rural spaces (i.e., clean environments), while increasing their economic and cultural value (i.e., investment capital opportunity) long associated with urbanization. The "natural capital" and ecological discourse that saturated the Shanghai eco-developments I examined (which are common in many parts of China) represent the desire to add economic and 
social "value" to economically depressed rural spaces. Eco-desire (value $=$ rural + technology = spectacular sustainability) was also a recurrent theme at the Shanghai World Expo. This "capitalization" of nature is particularly acute on Chongming Island, which is governed as part of Shanghai, but which is distinct from the city historically and culturally. Chongming is a large part of the city's land base (20\%) but economically "backward" (6\% of the city's gross domestic product). Chongming Island was the site of the first proposed $100 \%$ zero waste and carbon-neutral city called Dongtan. Although that project failed, Chongming Island remains a hotspot for the capitalization of nature and the preferred site for the transformation from rural poverty to ecological prosperity in Shanghai (Sze 2015).

Second, ecological and sustainable development in China shows how the wide-scale, top-down transformation of China has been operationalized and aimed at three great changes: from rural to urban, savers to consumers and/or spenders and from communists to state-sponsored capitalists and/ or communists. These transformations are national policies and cultural discourses simultaneously. My interest is in how ecological and/or sustainability discourse functions within these broader political and economic contexts. What is being worked "out" and "through" these ecologically themed and branded urban land-use development projects and at the World Expo is the ideological formation and construction of middle-class Chinese consumers within new political visions and identities. These work synergistically to create new ecological subjects who embody and live sustainably (i.e., within the framework of good and ethical behavior) within a broader national, environmental and social context of the expanded Chinese Communist Party capitalism. Whether economic land-use development and environmental "harmony" can co-exist remains an unsettled and unsettling question.

Thus, what the Shanghai ecologically themed developments I studied reveal are the efforts of the Chinese Communist Party to transform its subjects into ideal citizen-consumers, using discourses and policies that are resonant globally. Environmental sociologist Andy Szasz (2008) identifies that USbased middle-class environmentalism is founded through consumption of things, such as bottled water, buying or growing organic food, and the use of nontoxic materials. Middle-class political and economic subjects identify through their self-identified ethical purchasing decisions and lifestyle choices, although the national context may differ widely. Schlosberg and Craven (2019) call the growth and development of sustainable food, energy and fashion systems "sustainable materialisms." In many ways, this shift toward a globalized middle-class urban sustainability through consumption and/or consumer citizenship is reminiscent of Bourdieu's notion of distinction, taste and social capital (1986).

However, as many scholars have identified, the hegemony of individualism and consumer choice is in line with neoliberal ideology (Harvey 2007; Mukherjee and Banet-Weiser 2011). The "goodness" of such activities, such as "urban greening," is under doubt (Angelo 2019). Neoliberalism is "the 
doctrine that market exchange is an ethic in itself, capable of acting as a guide for all human action" as David Harvey describes (2007). Scholars across social science and humanities fields have used neoliberalism as their predominant analytic in the last two decades as the impact of neoliberal policies after 1970 has become increasingly clear. The valorization of marketization and the retrenchment of the state and public sectors feel, in many areas, nearly complete (or, at least, hegemonic).

Others have highlighted how sustainability has become increasingly aligned with upper-income and wealth amenities, visible through "green" images of trees and through practices such as organic consumption and recycling. Sociologist Miriam Greenberg (2018) and her colleagues distinguish between market, justice, vernacular, ecotopian and eco-oriented sustainabilities (Critical Sustainabilities nd). Market-oriented sustainability in this iteration is sold and seen as a "choice" that indicates a moral position rather than a socially understood good or resource. Sustainability has become an arbiter of morality, just as food scholars have shown that "good" eating is connected to the construction of "good citizens" and a sense of cultural and national belonging (Biltekoff 2013) that is blind to biases related to class, immigration status and/or race, and social difference writ large (Guthman 2011).

This construction of sustainability as a universalized "good" or morality does, in fact, embody politics and ideologies. Sarah Jaquette-Ray suggests in her The Ecological Other: Environmental Exclusion in American Culture (2013) that discourses of the environmental body draw on normative notions that link the wilderness with body, wholeness, and health. These normative notions are linked to histories of early conservationism and its links to and the discursive development of wilderness and bodily ideals and their relationship to race and gender in the Progressive Era. Concurrent crises of "masculinity," "race" and "nation" at the turn of the 20th century led to aggressive consolidation of wilderness ideologies, identities and policies, best embodied through President Theodore Roosevelt and his rapid expansion of the national park system (on land expropriated from Native American tribes). Many US-based environmental historians have documented that the rise of environmental discourse and conservation policy a century ago was triggered through national anxieties over extreme social change related to urbanization, immigration and demographic transition. Just as the United States was becoming more urban, more "non-white" and facing changing gender roles, shifting notions of nature and wilderness were becoming dominant and impacting policy and practice.

What I am suggesting here is that the global urban sustainability wave is predicated on similar, albeit slightly different, anxieties and within the contexts of neoliberalism and marketization. The focus on sustainability cannot be separated from the climate crisis and the Great Acceleration of environmental indicators of ecosystem collapse. At the same time, climate crises "discourses" need serious examination, just as global anxieties relate to new formations of power, politics and economics. The rise in authoritarian political leaders is part and parcel of a reaction to changing 
demographics (whether around "racial" or "refugee" bodies) and economic crises (the global crises in 2008). The rise of political authoritarianism as a response to political upheavals has the impact of blunting demands for change and justice, socio-ecological, climate or otherwise.

What social movements, such as Occupy Wall Street, Right to the City and Black Lives Matter, argue in part is that "rights and responsibilities," including the right to claim and belong - "identity, space and/or housing" and "life" itself - should not be predicated on the ability to pay. The lead poisoning in Flint, Michigan, is a particularly egregious example of privatization, where the poor and majority Black population was lead poisoned en masse as a direct result of neoliberalism. In addition, residents still face high levels of debt and water shutoffs as a result of poisoned water (Sze 2020). Social movements, such as those in Flint, are responding to the hegemonic adoption of neoliberalism as the global governing ideology of the last three decades. These movements and activists argue that citizenship and belonging are not just political questions and cultural identities but, in fact, justice-oriented and moral imperatives. In the global urban sustainability context, the transformation of rural space and people into environmental and/or sustainable plus capitalized space and people may be antithetical to ethics and justice for those critical of the authoritarian and neoliberal turn in global and urban politics.

Sociologist Daniel Aldana Cohen (2016), writing about the Sao Paulo drought crisis, argues for a revitalization "in a socioecological and crisissensitive form (of) Manuel Castells's concept of collective consumption politics: namely, contests over how states provide, or facilitate, the goods and services that sustain urban living" (143). Cohen's contribution to sustainability literature is to broaden what is perceived as sustainability projects by using a collective (rather than an individual) consumption lens. Thus, worker struggles for affordable housing and cheaper public transportation can be understood as democratic politics or counter-hegemonic sustainability justice-oriented struggles.

These efforts and struggles contrast sharply with the spectacular sustainability projects that are popping up as a central feature of the high-end global urban landscape. In other words, sustainability is not a "good" (as in moral and/or ethical choice or behavior) or understood as an individualized consumer act whether based on housing (installing solar panels) or buying and/or consuming food (choosing local and organic). Sustainability can be thus thought of as a set of political struggles "over collective goods" (space, mobility, belonging) rather than a set of consumerist objects or behaviors.

\section{Beyond place and/or identity and/or space: toward spatial justice}

The branding of urban sustainability as what Greenberg (2018) calls a "marketoriented" sustainability is a global phenomenon, but one that is particularly intense in "world cities," and in those cities where conditions of spatial 
and economic inequality and gentrification have surged. Scholars have argued that these trends represent environmental gentrification (Checker 2011). Sociologists Kenneth Gould and Tammy Lewis' book Green Gentrification: Urban Sustainability and the Struggle for Environmental Justice (2016) analyzes how "greening" projects and politics trigger gentrification, looking at empirical case studies from four different Brooklyn neighborhoods. Parts of Brooklyn have become the poster case studies of extreme displacement and gentrification in the last two decades, with select neighborhoods costing more to live in than high-end areas of Manhattan. Green Gentrification highlights the negative social consequences of green growth coalition efforts to both "green" and "grow" the global city and suggests policy choices to address their contradictions. Gould and Lewis argue that while most of the neighborhoods in Brooklyn have already completed the gentrification cycle, Sunset Park represents the "last best hope" for achieving truly sustainable urban greening. Sunset Park's unique situation is because of the efforts of UPROSE, an environmental justice organization in Sunset Park that foregrounds a community revitalization strategy based on green jobs, a politically left vision and a racial justice analysis. This organization is focused on environmental justice and climate justice and rejects the symbolic and/or spectacular symbols of sustainability and climate resiliency that are being promoted by real estate developers (Hum 2014).

The Bay Area of California has been hit hard by the tech industry. The tech boom is a large factor in struggles over housing access and displacement. Gentrification is the overarching reality that structures contemporary sustainability and land-use struggles. Greenberg examines, for example, how a market-oriented sustainability project displaced a long-standing recycling center in San Francisco. The spectacular images of nature are a central component of high-end and top-down economic and land-use development throughout California (Jocoy 2018; Knuth 2016).

What a comparative analysis between these diverse urban geographies shows is that sustainability is not, in fact, neutral or universal. Rather, sustainability is used by real estate developers in Shanghai, in the context of China's national economic goals, to create more consumers and middle-class urban populations to relate the "environmental" as something "beyond" the rural and/or ecological. Sustainability is used to trigger gentrification in California and in New York City. However, in Brooklyn, environmental justice groups reject the high-end notion of sustainability as a lifestyle imperative that ushers in working-class and racial minority displacement, centering climate resilience instead, that takes working-class and racial identities seriously.

In doing so, UPROSE is rejecting green gentrification as inevitable and natural. A comparative framework allows for an analysis of the global city sustainability of Shanghai and New York City connected to their positions in the world economic system but different in terms of possibilities for a democratic sustainability agenda. In Shanghai, spectacular sustainability 
is on the rise, as disavowal of industrial identity reigns. Manufacturing is understood as a vestige of a polluting past. In New York City, protecting the industrial economy and a manufacturing identity is seen by a local environmental justice group as central to rejecting the unfettered marketization of land use, the neoliberalism that leads to the displacement of working-class communities from a racially minoritized space.

In the Sunset Park, Brooklyn, case, real estate developers took over what was historically known as the Bush Terminal, seven massive buildings on the waterfront that were the iconic site of Brooklyn's industrial development. The developers, called Jamestown, partnered with other investors to buy a controlling interest in the site from the previous owners who defaulted in the wake of the massive damage of Hurricane Sandy (Sze and Yeampierre 2018). Hurricane Sandy devastated many waterfront neighborhoods; it flooded a large expanse of land, leading to over 47 deaths, caused US $\$ 19$ billion of property damage, shut down the stock exchange and took out the power grid and the transportation infrastructure throughout the Northeast. In New York City, the damages were immense and are related to a central fact: Waterfront trade is what built major cities historically, but that proximity to water makes the cities central to global finance particularly sensitive to sea-level rise and intensified flooding related to climate change.

Sandy's harm to Sunset Park was, thus, in stages. The actual physical threats related to the flooding and damage came first. Second, the financial fallout on both micro- and neighborhood scales occurred (Bush Terminal and/or Industry City, see de Mause). Some refer to these post-Sandy plans for climate resiliency using "strong" language that seeks to "tame nature" (Lang 2016; on gendered environmental discourses, see MacGregor and Seymour 2017). The real estate developers are most well known for Chelsea Market in what used to be a dilapidated meat-market district of Manhattan but is now an extremely high-end residential area. The developers renamed the site "Industry City" and sought to brand the area through artisanal food, "innovation economy" companies, and through events such as large DJ dance parties (Berger 2014).

"Innovation," like sustainability, is a plastic word that evokes the cutting edge of technology and growth. The ironies abound. First, the company's name "Jamestown" itself evokes the first permanent English settlement in Virginia (1607).

Activists critique the Jamestown developers as an illustration of colonizers with the tagline "There's nothing innovative about displacement," with the flag of "IC" (Industry City) replacing Columbus' flag in the famous 1946 paining by John Vanderlyn at the US Capitol (this line explicitly references the developer's call to nurture "innovation" and creative industries at the site; Hum 2015).

The allocation of space and its uses is, thus, supremely fraught and shaped by temporal concerns. These include the backdrop of the industrial 
polluting past (and, indeed, of colonialism) and the uncertain future of waterfront cities facing extreme sea-level rise as both a political anxiety and ecological outcome of climate crisis. A global comparative framework that takes space and time seriously allows for the critical analysis of urban sustainability agendas. Such an analysis involves a serious understanding of neoliberal ideology and how countermovements make diverse claims to space and life itself.

\section{Conclusion: toward an ethical and justice-oriented urban sustainabilities framework}

Thus far, we have seen how the case studies in Shanghai and New York City show that global urban sustainability has been constructed in marketoriented frames and has (in the New York City case) also been contested as such. As Aldana Cohen writes, "The perpetuation of unequal ecologies defers political uncertainty, the pursuit of democratic ecologies begins with them" (2017, 283). An ethically framed urban sustainability is necessarily contingent and uncertain, although it is not relativistic. Explicit articulation of the ethics and justice in urban sustainability ensures that the "forms" that sustainability takes are not in the service of capital, specifically marketization and privatization.

Rather, an ethical urban sustainability that centralizes issues of temporal and spatial justice necessarily invites a different politics from the dominant mode of spectacular urban development projects that is largely symbolic and imaginative. A democratic urban sustainability contains different politics than those proffered in the service of capital. It is only through a comparative spatial and temporal frame that we can imagine a future in which urban climate crisis is not inevitable and that sustainability is not just a plastic word.

\section{Bibliography}

Agyeman, Julian. 2013. Introducing Just Sustainabilities: Policy, Planning, and Practice. London: Zed Books.

Agyeman, Julian, Robert Doyle Bullard, and Bob Evans, eds. 2003. Just Sustainabilities: Development in an Unequal World. Cambridge: MIT Press.

Angelo, Hillary. 2019. "Added Value? Denaturalizing the 'Good' of Urban Greening." Geography Compass 13, no. 8. Accessed September 6, 2019. doi: 10.1111/ gec3.12459.

Berger, Erica. 2014. "Gentrification Inc.” August 7. Fast Company. Accessed September 6, 2019. http://www.fastcompany.com/3033870/gentrification-inc.

Biltekoff, Charlotte. 2013. Eating Right in America: The Cultural Politics of Food and Health. Durham: Duke University Press.

Bourdieu, Pierre. 1986. "The Forms of Capital." In Handbook of Theory and Research for the Sociology of Education, edited by J. Richardson. 241-58. New York: Greenwood. 
Brenner, Neil, and Christian Schmid. 2014. "The 'Urban Age' in Question.” International Journal of Urban and Regional Research 38, no. 3: 731-55.

Checker, Melissa. 2011. "Wiped Out by the 'Greenwave': Environmental Gentrification and the Paradoxical Politics of Urban Sustainability." City \& Society 23, no. 2: 210-29.

Cohen, Daniel Aldana. 2016. "The Rationed City: The Politics of Water, Housing, and Land Use in Drought-Parched São Paulo.” Public Culture 28, no. 2: 261-89.

Cohen, Daniel Aldana. 2017. "The Other Low-Carbon Protagonists: Poor People's Movements and Climate Politics in a Global City." In The City is the Factory, edited by Miriam Greenberg and Penny Lewis, 140-57. Ithaca: Cornell.

Critical Sustainabilities. N.D. Accessed June 20, 2016. https://critical-sustainabilities. ucsc.edu/sustainabilities-2/.

de Mause, Neil. 2015. "As Industry City Promises a New Sunset Park, Some Residents Fight to Maintain the Old One." City Limits Magazine. October 27. Accessed September 6, 2019. https://citylimits.org/2015/10/27/as-industry-city-promises-anew-sunset-park-some-residents-fight-to-maintain-the-old-one/.

Greenberg, Miriam. 2015. "The Sustainability Edge': Crisis, Competition, and the Rise of Green City Branding." In Sustainability in the Global City: Myth and Practice, edited by Cynthia Isenhour, Gary McDonough, and Melissa Checker, 105-30. Cambridge: Cambridge University Press.

Greenberg, Miriam. 2018. "Situating Sustainability in the Luxury City: Toward a Critical Urban Research Agenda." In Sustainability: Approaches to Environmental Justice and Social Power, edited by Julie Sze, 180-95. New York: NYU Press.

Gould, Kenneth, and Tammy Lewis. 2016. Green Gentrification: Urban Sustainability and the Struggle for Environmental Justice. New York: Routledge.

Guthman, Julie. 2011. Weighing In: Obesity, Food Justice, and the Limits of Capitalism. Berkeley: UC Press.

Harvey, David. 2007. A Brief History of Neoliberalism. Oxford: Oxford University Press.

Hum, Tarry. 2014. Making a Global Immigrant Neighborhood: Brooklyn's Sunset Park. Philadelphia: Temple University Press.

Hum, Tarry.2015. "Thereis Nothing InnovativeaboutDisplacement." Gotham Gazette. October 21. Accessed September 6, 2019. http://www.gothamgazette.com/index. php/opinion/5942-there-is-nothing-innovative-about-displacement-industry-city.

Jaquette-Ray, Sarah. 2013. The Ecological Other: Environmental Exclusion in American Culture. Tucson: University of Arizona Press.

Jocoy, Christine L. 2018. "Green Growth Machines? Competing Discourses of Urban Development in Playa Vista, California." Urban Geography 39, no. 3: 388 412. doi: 10.1080/02723638.2017.1333238.

Knuth, Sarah. 2016. "Seeing Green in San Francisco: City as Resource Frontier." Antipode 48, no. 3: 626-44.

Lang, Steven. 2016. "Promise or Peril: Incorporating Resiliency into Sustainability Planning for the Post Hurricane Sandy New York City Waterfront." Conference Presentation, Association for American Geographers, see https:// critical-sustainabilities.ucsc.edu/aag-2016/.

MacGregor, Sherilyn, and Nicole Seymour, eds. 2017. "Men and Nature: Hegemonic Masculinities and Environmental Change." Rachel Carson Center Perspectives: Transformations in Environment and Society 2017, no. 4. doi: 10.5282/ rcc/7977. Accessed September 6, 2019. http://www.environmentandsociety. 
org/perspectives/2017/4/men-and-nature-hegemonic-masculinities-andenvironmental-change.

Mukherjee, Roopali, and Sarah Banet-Weister, eds. 2012. Commodity Activism: Cultural Resistance in Neoliberal Times. New York: NYU Press.

Müller, Simone M., and Annika Mattissek, eds. 2018 "Green Cities: Explorations and Visions of Urban Sustainability." Rachel Carter Center Perspectives: Transformations in Environment and Society no. 1. doi: 10.5282/rcc/8462. Accessed September 6, 2019. http://www.environmentandsociety.org/perspectives/2018/1/ green-city-explorations-and-visions-urban-sustainability.

Pörksen, Uwe. 1995. Plastic Words: The Tyranny of a Modular Language. Harrisburg: Penn State Press.

Rofel, Lisa. 2007. Desiring China: Experiments in Neoliberalism, Sexuality and Public Culture. Durham: Duke University Press.

Schlosberg, Davis, and Luke Craven. 2019. Sustainable Materialism: Environmental Movements and the Politics of Everyday Life. Oxford: Oxford University Press.

Seghezzo, Lucas. 2009. "The Five Dimensions of Sustainability." Environmental Politics 18, no. 4: 539-56.

Szasz, Andrew. 2007. Shopping Our Way to Safety: How We Changed from Protecting the Environment to Protecting Ourselves. Minneapolis: University of Minnesota Press.

Sze, Julie. 2007. Noxious New York: The Racial Politics of Urban Health and Environmental Justice. Cambridge: MIT Press.

Sze, Julie. 2015. Fantasy Islands: Chinese Dreams and Ecological Fears in an Age of Climate Crisis. Berkeley: UC Press.

Sze, Julie. 2020. Environmental Justice in a Moment of Danger. Berkeley: University of California Press.

Sze, Julie, Anne Rademacher, Tom Beamish, Liza Grandia, Jonathan London, Beth Rose Middleton, Liza Grandia, Louis Warren, and Mike Ziser. 2018. "Introduction.” In Sustainability: Approaches to Environmental Justice and Social Power, edited by Julie Sze, 1-25. New York: NYU Press.

Sze, Julie, and Elizabeth Yeampierre. 2018. "Towards a Just Transition: Climate Justice, Development and Community Resilience." In Just Green Enough: Urban Development and Environmental Gentrification, edited by Winifred Curren and Trina Hamilton, 61-73. Abingdon, Oxon/New York: Routledge. 


\title{
14 Handling waste through consensus, care and community in Auckland, Aotearoa New Zealand
}

\author{
Jeannine-Madeleine Fischer
}

\section{Introduction}

Caring for the environment and, notably, battling climate change are key issues in contemporary global debates. Cities are particularly being held accountable by the public for threatening levels of pollution and global warming. Environmental initiatives involve both governments and communities. Eco-friendly ways of urban planning and "green" lifestyles have become important features to evaluate the quality of modern cities. This is also evident in the approach of C40Cities, a network that was founded in 2015 and today connects 94 "megacities" around the world (C40Cities 2019, n.p.). Cities generate more than $70 \%$ of global carbon emissions and, thus, have to be taken into account to tackle climate change, the network states. It aims for a collaboration between the participating cities to improve political efficacy, since "their power only grows when they work together" (C40Cities 2019 , n.p.). C40Cities argues that global responsibility is located in today's cities. The network intends to help mayors run their cities in a less polluting way by sharing effective policies. Auckland joined the network in 2015 and two years later received an award for encouraging local communities to reduce urban waste. The award honored the city's large Waste Management and Minimisation Plan and "crowned [it] zero-waste world champion" (Our Auckland 2017, n.p.). The scheme asks for more awareness about waste production and separation in private households and communities. Governing the improvement of urban environments directly addresses the everyday conduct of life in the city. Public and private responsibility converges in the city's goal to reduce urban waste production to zero by 2040: Achieving the goal of nonpolluting forms of city life means asking for local collaboration between councils and citizens.

Auckland is located in a national setting that presents itself globally as "clean and green," but, at the same time, Aotearoa New Zealand is one of the world's most wasteful countries per capita (Blumhardt 2018, 13). Vast natural areas and landscapes rich in variety contribute to a perception of a country of ecological awareness. In public debate, however, it is often this condition of omnipresent, beautiful "nature" that is assumed to be a reason 
for "less" environmental care: Given the size, gestalt and low population density of the country, the environmental impact from daily life is not immediately visible. This, however, is different in the densest agglomeration of the country: Auckland, with a population of more than 1.4 million, is home to one-third of the national population. The city is estimated to send around 1.5 million tonnes of waste to landfills each year (Recycle 2019, n.p.), from which $65 \%$ could have been avoided through waste separation (Auckland Council n.d., 3). Without furthe $r$ interventions, the amount of waste produced is likely to double within ten years in Auckland alone (Recycle 2019, n.p.). Meanwhile, public awareness of waste and media coverage of the topic keeps growing. The New Zealand Herald covered a study in April 2019 that reveals Aotearoa New Zealand as the country consuming the second largest amount of plastic in the whole Asia-Pacific area (New Zealand Herald 2019, n.p.). Around 252,000 tonnes of plastic are disposed to landfills nationwide. Packaging makes up a huge part of that quantity (Recycle 2019, n.p.).

During my fieldwork, initiatives for a change of waste behavior were omnipresent in the city: Waste educators, public cleanups and stickers on wastebins are present in all of its areas. "Changing mindsets" and people rethinking their personal habits and those in their area are crucial goals of the city's efforts to become "zero waste." They are clearly directed against a "normalization" of waste production and point toward a "problematization" of waste itself (Kettle 2014, 3). Thus, waste is no longer to be considered a natural by-product of current lifestyles but rather as "wrong" and imperatively necessary to avoid. In this local discourse, like in many other cases, dealing with waste is presented as an ethical question about urban life: About the "right" way of being in and connecting with the city on different levels (Hawkins 2006). Urban waste is not only a practical problem to be solved by the council through policy but also a personal "concern" of caring citizens that "want" to keep their local environment clean and beautiful. Foregrounding personal responsibility shifts the environmental care to the civil society. At the same time, caring for the environment transforms into forms of care for the city and is, thus, closely connected to other social relationships and interactions. Ultimately, the ways in which ecofriendliness is performed as a local priority also relate to waste reduction as a "consensual" practice of caring for the environment and the city: The need for environmental care is regarded as undeniably good; the way it is implemented, however, remains controversial.

In this chapter, I first contextualize waste policies in Auckland and then introduce an example showing how local ideals of environmental care actually take shape in a neighborhood initiative. I examine how a community project aiming to improve local waste behavior and, thereby, the local environment involves particular urban power processes. The "right" way to deal with waste is performed as an enactment of the "clean neighborhood" and its "responsible citizens." Nonpolluting practices are directed toward 
not only nature but also the city itself, in its material and social dimensions. In the first part of my analysis, I consider how waste, ethical subjecthood and community interrelate in the neighborhood initiative and show how the collaboration between local community and local government takes shape as a project of "intimate governance" (Agrawal 2005). In the second part, I examine how caring for waste interrelates with caring for the local community and includes ideals of social relationships and interactions, in this case on a suburban level. As I will argue, the enactment of an ethics of care can reinforce urban power and representation processes and is closely interrelated with neoliberal policies in the city.

This analysis is based on a subproject of the interdisciplinary research group "Urban Ethics. Conflicts around good and right urban lifestyle in the 20th and 21st century (2015-2018)" (FOR 2101, funded by the DFG). The research focused on environmental ethics in Auckland and was conducted under the supervision of Eveline Dürr. Empirical fieldwork for this analysis was carried out during three phases between 2012 and 2016, for a total of 11 months. I applied participant observation, qualitative interviews and group discussions with a range of different stakeholders. I followed city dwellers through their daily practices of environmental care, created round tables to discuss local ideas of urban environmentalism and talked with council staff about current changes in city politics.

\section{Situating waste dynamics in Auckland}

The 1980s were marked by a growing concern for environmental issues worldwide. The environmental impacts of industrialization and urbanization became increasingly visible and called for action. In this period, Aotearoa New Zealand became known for its strict antinuclear attitude, symbolically marked by the sinking of the Rainbow Warrior in 1985 (Gundry 1993, 4). Civil society groups lobbied strongly for improving environmental policies; these claims evoked environmental reforms and the establishment of the Ministry for the Environment as well as the Department of Conservation (Taylor 2013, 18). Another major environmental reform took place in 1991 with the Resource Management Act, which collapsed a variety of existing regulations into one single piece of environmental legislation. Regarding waste, however, the Resource Management Act provided general considerations rather than specific objectives (Taylor 2013, 24). The same period, the 1980 s, was also marked by a clear shift toward free market reforms, "Rogernomics." The paradigm of the neoliberal government continued in different phases and with different emphases. Since the late 1990s, however, neoliberal strategies became accompanied by a characteristic "partnering ethos" in governance that is considered as a type of Third Wayism specific to the country. By linking up central government, local institutions, communities and volunteers, "multi-level collaborative arrangements" were created to support local development (Larner and Craig 2005, 407). 
Waste management in Auckland should be considered in this context: Large parts of Auckland's waste infrastructure became privatized between 1990 and 1997. Private ownership of transfer stations and landfills made an increase of landfilling economically rational, which inspired critics that took form in the Zero Waste New Zealand Trust, established in 1997 (Davies 2008, 121). The trust ran campaigns to redefine waste as a local resource and present alternative models of treating it. The national New Zealand waste strategy was developed in 2002, followed by the Waste Minimisation Act in 2008. Both informed the Auckland Council Waste Management and Minimisation Plan in 2012 (Auckland Council 2012b; Kettle 2014 , 6). In this document, the council presented a hierarchy of concerns that placed waste minimization at the top. This marked a paradigmatic shift from waste disposal toward reducing, reusing and recycling unwanted materials. The Auckland Plan, the city development plan of 2012, phrased "zero waste" by 2040 as one of the ambitious goals for becoming the "the world's most liveable city" (Auckland Council 2012a). In that process, the approach to waste shifted from technical to social terms: Solution strategies are not primarily sought in new infrastructures and, for example, machines, but rather in changing the waste "behavior" of urban dwellers. The new Auckland Waste Management and Minimisation Plan was introduced in 2018. It strongly emphasizes the role of communities, networks and collaborations. This is also illustrated in the plan's layout: The front page pictures a group of smiling children, dressed in reflective wests and helmets, subtitled "Working together for Zero Waste" (Auckland Council 2018).

The administrative division of the city complicates urban waste policies. Before the amalgamation to the supercity in 2010, many of the now 21 local boards used to be independent and each region had its own waste regulations. The revised urban waste management aims to align the various systems to a common waste strategy across Auckland by 2021; the changes, however, take effect in the suburbs according to different schedules. A new three-bin service will provide a free recycling bin, a free food wastebin and a charged bin for general rubbish. Through a "pay-as-you-throw" system for landfill waste, city dwellers will have a financial incentive to reduce their individual waste production. The Southern suburb Papakura was the first to establish the three-bin system in March 2018; in the first month alone, 70 tons of food scraps were collected and processed in composting plants (Our Auckland 2018, n.p.). To enhance efficiency, the council employs community members to support the reform by informing the inhabitants about proper waste behavior throughout neighborhoods and institutions.

This major change is accompanied by the introduction of community recycling centers to replace the usual bulk waste collection, which also introduces new cultural framings of waste. These infrastructures are designed as a local system of reuse and up-cycling. "Local" people are employed to process "local" rubbish, which is then sold again "locally" to create an efficient circuit within the communities. In doing so, responsibility for and power 
over the community's waste stream shift to the community itself (Auckland Council 2012a, 68). But more than that, the centers are also intended to become community hubs that strengthen social ties. Waste disposal should play out as a community activity and be embedded in, rather than isolated and shut out from, local social life. The ideal is to make discarded items visible, to redefine their value and to render them a connecting link in the community. Unlike landfills and the old recycling yards, the community recycling centers are attributed with positive meanings, such as creativity and community building, rather than pollution and nuisance. Thus, these centers are considered as "good" infrastructure in an environmental, social and, to some extent, aesthetic sense, in contrast to utilitarian common waste facilities. Re- and up-cycling are fit with a framework of creative, constructive and progressive practices that connect modern waste behavior with social cohesion and a responsible, up-to-date urban lifestyle. Here, waste is not something to get rid of but something to connect through and with. Collectively engaging with waste is a means to build, encourage and strengthen local communities. In the context of these new waste policies, rubbish is considered an urban potential that can create value and change. This definition shifts the static condition of waste toward dynamic processuality (see also Reno 2009, 30). The question is not what waste is but rather what it can "become." This is connected to a new understanding of temporality in this context - the dynamic potential of waste requires people to think ahead. Waste transcends its actual shape and points to the future. Simultaneously, disposed objects preserve their past; the historicity inscribed in them contributes a large part to their popularity. While the old recycling yards were used for a quick disposal, the new institution asks for multiple ways of "getting in touch." Waste is not hidden away here; it is visible, haptically perceivable and physically consumable. The meaning of re- and up-cycling goes beyond aesthetics; the disposed items are considered not only in their visual appearance but in light of common sensual experience. By creating a realm of shared experience, city dwellers are not only interacting with bulk garbage but also with each other. In the logic of environmental local governance, the community recycling center is created to transform the materiality of waste and the quality of local social relationships simultaneously.

Nevertheless, ascriptions that have for a long time dominated the cultural meaning of waste, such as pollution and poverty, are still at play; the meanings of waste are marked by coexisting and contradicting attributions (Reno $2009,40)$. In part because of these ambivalences, waste works as a powerful agent in the socio-material environment of the city. Oscillating between connotations of the valuable and the non-valuable, the ambiguity of waste is closely tied to moral imaginations about the "good" and the "bad" that go far beyond the effects of individual practices. Ways of dealing with waste are framed as "good" behavior within an overall more ethical conduct of life. Handling waste is not only an ordinary routine but a practice, a performance of the self and a form of disciplining one's own behaviors that reveals 
attitudes and ethical values of individual city dwellers. Forms of "good" or "proper" and "bad" or "wrong" conduct are clearly defined and even measurable - through the visible amount of waste citizens produce.

These programs feed into the new paradigm that gives priority to the social dimension of waste. By connecting community and waste, city dwellers are asked to alter their attitudes toward rubbish and to shoulder responsibility for their waste behavior - not only in their personal household but also in their community more broadly. The imperative to take accountability for "good" ways of dealing with waste extends toward one's neighbors and other community members. The waste behavior of each single city dweller is considered as a contribution to or against a better city and neighborhood life. "Care for the city" means that personal accountability relates to a wider community responsibility and agents partly take over accountabilities from the local government. The project to achieve a better, nonpolluting city is considered much more than only an idea promoted by the Auckland Council; it is reconceptualized as both a personal and a community endeavor. The consensual agreement to act for the "good" is connected to a subtle acceptance of a neoliberal framework that asks citizens to shoulder responsibility for the city. The next section will show how care for the city can take shape in a community project: Local agents are tackling the infrastructural dimension of Auckland's waste management system directly to create and implement a revised version of taking care of waste streams in their neighborhood (see also Dürr and Fischer 2018).

\section{A neighborhood sets about waste}

Lynn Keith (name changed) has been a passionate activist for a long time. She is $P \bar{a} k e h \bar{a},{ }^{1}$ is around 50 years old and has resided in a suburb in the southern part of Auckland for many years. She feels personally tied to the place. The southern part of Auckland is marked by prejudices: Local and national media represents these suburbs as the most ethnically diverse and socially deprived area of the city, which is associated with a high rate of criminality and with frequent incidents of waste dumping. The neighborhood I focus on in this section, however, is a middle-income suburb in southern Auckland where mainly Pākehā live. Lynn and I meet several times during my research. When explaining changes in the waste management system, she is clearly annoyed by the widespread ignorance - regarding waste issues in the city. Her critique addresses both the council and the local community.

For Lynn, the handling of soft plastics is an issue of special concern. At the time of our discussions, the soft plastic bins at the supermarkets which have widely been removed by now - are still a novelty. Soft plastics are normally used to wrap vegetables and food and are, therefore, widely consumed. Until recently, soft plastics were sent to landfills as they cannot be processed by common plastic recycling machines. Some supermarkets have been equipped with extra bins for soft plastics by the council, which 
means that citizens have to get their soft plastics to the public bins by themselves. Given this inconvenient way of disposal, urban dwellers are likely to throw soft plastics into the general household waste. This way of separation has recently collapsed for global reasons: Since China refused to import further plastic waste imports, many of the collection bins around Auckland were removed in December 2018 and citizens were asked to dispose of their soft plastics to landfills until a local solution for processing has been found (Shaw 2019, n.p.).

While acknowledging that the bins are potentially helping to reduce landfill waste, Lynn reports that the public bins are often misused and filled with other kinds of waste by customers. At one of our meetings, she tells me how she started sorting the bin in the supermarket by herself one day. She recalls that many people passed by, watching her with wide eyes. She spoke to an assistant and asked the supermarket's employees to check what kinds of plastic customers throw into the bin and, most notably, to provide them with information and education. The council supplied the bins but did not provide any on-the-spot directions for how to use them.

As Lynn considers this service dysfunctional, she started organizing a separate soft plastic collection point in her community. Taking turns with her friends, she offers her home for a community collection and, once a week, delivers the rubbish to an upcycling company nearby. In doing so, she not only takes over the collection but also checks the contents of the rubbish sacks and, if necessary, clarifies the rules. With this small-circle system, Lynn and her friends elaborate an improved form of waste management on a local level that enhances the council's program. Their service provides an alternative to public collection points that is more accessible for neighbors in both local and social terms.

One of the practices that Lynn and her team aim to establish in their local neighborhood is to take good care of waste. They have invented an education program to teach their neighbors how to handle waste in their own homes. In addition to their own revised small-scale waste management system, they organize six-week challenges to educate people about waste separation. Andrea Miller (name changed), a member of Lynn's group, usually hosts these events. The courses start by collectively sorting out the rubbish bags of the participants in Andrea's backyard. Neighbors bring their rubbish from the previous week, weigh it, scoop it out on a blanket and arrange the waste items according to their proper destination. After that process, the remaining landfill rubbish is weighed again to demonstrate the enormous difference and to motivate the participants to continue separating their waste according to Andrea's explanations and information sheets (Figure 14.1).

After six weeks, the whole group comes together again for afternoon tea on Andrea's veranda where everybody has the chance to report on experiences, challenges and future visions. The end of this waste minimization program is marked symbolically by presenting certificates that honor neighbors who have successfully absolved the challenge as "waste champions." 


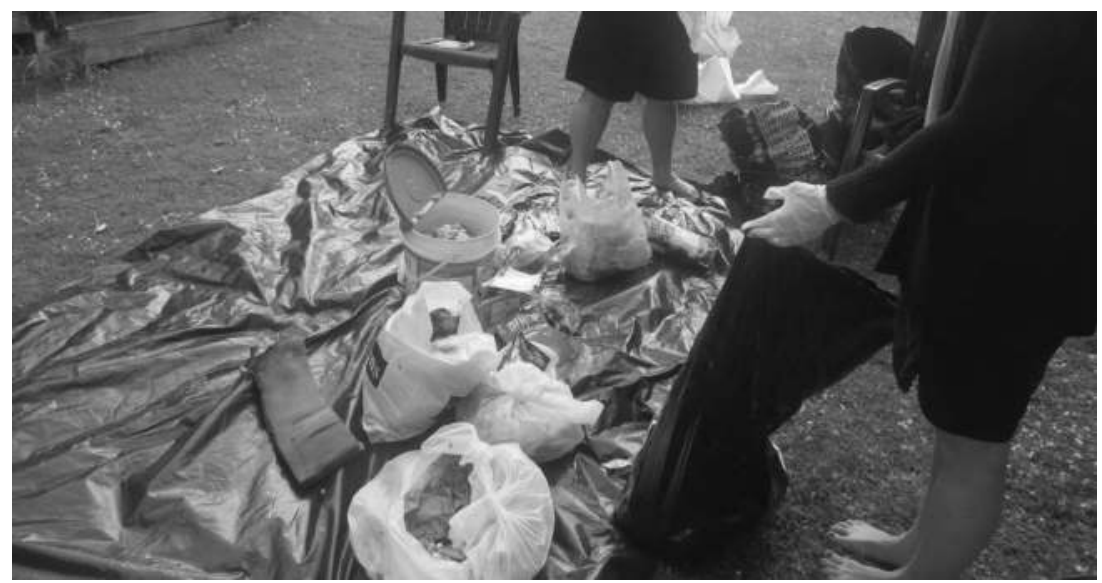

Figure 14.1 Communal Garbage Sorting. (Jeannine-Madeleine Fischer)

The reduced waste volume can be considered in its materiality, in a visual and haptic sense, while these documents literally turn the participants' accomplishments into "good" objects. Ideally, of course, this success is not confined to the duration of the challenge but integrated into daily life. By turning practices of waste separation into a routine, the neighbors contribute to local change in the suburb. Again, these practices are visible semipublicly and publicly - ultimately, it is the number of garbage bags disposed weekly that informs the local public about individual waste behavior in the suburb. Attending this program, then, is more than a personal challenge: The participation also works as an outward representation of "good" individual behavior and a demonstration of local belonging. After all, the challenge is a locally defined practice: Lynn and Andrea are firmly approaching "neighbors" and, thus have, an exclusive focus.

Lynn and Andrea rent a stall at the weekly market and prepare leaflets to distribute in the mailboxes within their local neighborhood to acquire more participants to join their activities. They do not mind making this effort in addition to their full-time jobs; to the contrary, they tell me that they are looking forward to their volunteer work, since caring for the local community and environment makes them feel good and proud. They are also considering other strategies, such as walking through the streets during curbside collection days and checking which households bring out particularly large amounts of waste. This would allow them to specifically approach those neighbors who are producing the most waste. They see such attempts at neighborly social control as a direct way to change the appearance, aesthetics and, finally, the atmosphere of their suburb. Four points are particularly important for thinking through the relationship of waste, community and the local state here, as the next section will show. 


\section{Subjecthood, community and collaborations}

Lynn and her group are not inventing global visions of environmentalism; they take care primarily of the local community they connect with and feel emotionally close to. Belonging to the place and the community is performed by accepting responsibility for the local environment, which also means living up to the call for eco-friendliness in the city.

First, recycling practices exceed the personal space of private households and serve as a public visualization of values and linked belongings. Public enactments of recycling such as Lynn's, therefore, almost inevitably also exhibit ethical subjecthood. Recycling is not only a way to improve the environment but also one's self-representation in the community (Hawkins 2006, 95). Ethically infused subjectivities and models of "good" subjecthood take shape through collectively performed practices: Lynn and her friends can, in that sense, be seen as recycling and composting agents who identify as active, participating, responsible, empathic and relational city dwellers. Lynn communicates both her personal attitude toward waste and her active role in the community by arranging a local collection point. In the context of Auckland's policies and public imagery, Lynn also enacts the role of a good Auckland citizen by engaging with the urban environment. She shows herself as self-guided, self-reliant and responsible. In doing so, not only does she try to live up to the city's claims herself, she also calls on her neighbors to embrace an ethical responsibility to care for the environment by taking part in her initiatives. These activities are well aligned with a broader local consensus on eco-friendliness and community, where the ideal of the self-responsible subject is extended to a subject that accepts liability for "self-and-other-together" (Held 2006, 12). Lynn describes her initiative as a "better" way of urban community life and enacts collective responsibility in her group. In the frame of community, personal accountability segues into collective responsibility, in this case on a neighborhood level, and spaces for a specific form of collective action are created (Rose 1999, 172).

Second, waste activism is particularly closely intertwined with (idealized) social relationships. Lynn told me that she does not want to live in a dirty neighborhood and wants to provide a clean and joyful environment for her children here and in a wider sense: "Rubbish is definitely about future. I don't want my children growing up on leaching landfill ground and raising their children there." She is emotionally connected to the place she has made her home for the last few decades. However, to invest a lot of time and energy is not her only motivation; she also considers her efforts to be an effective way of keeping the community together and of strengthening social ties. She told me, "When you care for waste, you kind of care for the community. We want to keep it the way it is and better." Waste separation is, thus, performed as a social, community activity that strengthens feelings of belonging to the neighborhood. For that reason, Lynn and her friends also organize community cleanups on Sunday afternoons and picnics in summer. They told me 
that waste is a great way to connect people, since everybody has to deal with it in daily life and everybody enjoys a clean environment. Caring for waste expands to caring for the community, which is primarily experienced as a social commitment.

The third aspect connects back to wider questions of urban governance and ethics: When it comes to waste reduction, the ideals of local inhabitants and communities get interlinked with aims of the council. Agrawal argues that this process of merging interests creates a realm of "intimate governance" $(2005,19)$. Unlike "governance at a distance," "intimate governance" takes shape within the community and mingles various interests, stakeholders and diverse levels of power. The government does not appear as an external authority that introduces unfamiliar ideals and goals but as an internal part of local communities. These processes are decentralizing care for the environment "by dispersing rule, scattering involvement in government more widely, and encouraging careful reckoning of environmental practices and their consequences" (Agrawal 2005, 19). Imaginations of the "good," of ethical urban-environmental behavior and being are co-constituted in the interaction between council and inhabitants rather than only or even primarily implemented by strong authorities. Agrawal describes this process as a "joint production of interests" $(2005,19)$. Social agents adopt corresponding attitudes and ideals by getting involved in environmental practices such as recycling. The community serves as a pool of ideals and values, and social agents appropriate the "good" by participating in the community. According to Agrawal, and very much in line with what this case study illustrates, appropriations of attitudes, conducts and ideals also feed into processes of subject formation $(2005,16)$. Here, too, "good" subjectivities emerge from the intermingled collaborations of council and local community. Furthermore, the aspirations of "the community" are aligned with the demands of the council in "intimate governance": Motivation may differ, but the practices that agents employ in order to reach their objectives converge (Agrawal 2005 , 18). The council might favor a sense of community in the city to increase efficiency and limit its own spending efforts or to improve urban environmental behavior; meanwhile, local inhabitants like Lynn aim to establish a certain atmosphere and define the character of places where they live. Both vectors, the aims of the council and of the community, flow into one another and create shared initiatives. The joint frame articulates common values that are locally performed in these collaborative arrangements. Many city dwellers, Lynn included, consider such activities as forms of local self-empowerment. Working with the council's approaches is a way to get actively involved in city politics and to integrate one's own imaginations of local transformation processes.

Fourthly, residents connect the handling of waste to belonging to a certain place. The ethical demand to take care of nature also merges with a sense of responsibility toward the city as a whole and the local community in particular. Environmental care and waste behavior are framed in terms 
of locality, of local communities and used to define ways of belonging in and to the city. In this vein, citizens can connect the city's project with their own plans and ideals, such as modeling the character and reputation of one's suburb. The suburb itself gains prominence by promoting specific initiatives and is symbolically and practically demarcated from other parts of the city. This will become clearer in the next section, where I take a closer look at how the idea of "caring" that is performed in the community interrelates with neoliberal city politics and broader power dynamics in the city.

\section{Caring for waste, responsibility and representation}

Caring for waste and caring for the community are merging into a joined concern, as Lynn's statements illustrate. I consider care as a specific kind and quality of relating to one another: Caring connections are marked by an ideal of reciprocal attention and looking after each other. As an ethic, care has the potential to create new relationships and institutions for "mutuality and well-being" (Lawson 2007, 1). This is what Lynn and her friends aim to establish "inside" their neighborhood: Strong, resilient connections among the community to keep the local environment sustainably clean and enjoyable for themselves and future generations. Lynn says, "You can see a difference in the community. And the change will spread." The community works as a space of interaction for instigating change locally. Social connections are tied to expectations of a more considerate, mindful attitude and caring behavior. By propagating care as a basis of "good" social relations in the suburb, local identity is co-constituted through these ideals and their performance. Caring for the environment and reducing waste become markers of belonging to the local community as a social group that is guided by this ethic of care.

Lynn's project obviously has empowering and community-strengthening effects in her neighborhood. Nevertheless, I want to emphasize two critical processes that emerge from the connection of a community ethics of care to neoliberal city politics. First, the sense of responsibility is relocated: The strong community commitment relieves the state of some of its responsibilities. Lynn's initiative cannot be reduced to neoliberal conduct; her community and neighborhood ideals also go beyond these entanglements. Without denying the positive effects of work such as Lynn's, it should be noted that enactments of active subjecthood also take effect as a passive consent with neoliberal strategies of responsibilization and the hegemonic economic system (Perkins 2009, 403). The recycling services of the council are evidently insufficient; filling this gap through a community-based initiative means to agree to a shift of accountabilities. Finally, the suburbs, with fewer activists, remain underserved and disadvantaged.

By actively becoming involved in waste reduction, eco-activists like Lynn also render themselves "responsible" subjects who tackle urban challenges through their own initiatives - or, seen from a different perspective, 
they are rendered as such through specific forms of governance. Neoliberal ideals of active citizens "who will not burden the state or demand entitlements without accepting corresponding responsibilities" (Jessop $2002,465)$ resonate well with the set of caring practices to form "good" waste behavior in the city. Urban waste and environmental degradation are not reinterpreted primarily as tasks of the (local) state but more as private affairs that ask for "personal 'sensitivity' toward others" and reposition urban environmental matters, to a large degree, in the field of selfgovernance (Hamann 2009, 40).

Second, caring for waste also becomes a tool of delineation and serves as a means for reproducing local power hierarchies in the city. The professed consensus about "good" eco-friendliness empowers wealthier neighborhoods that can draw on other resources than people in poorer and more polluted suburbs. By promoting specific initiatives, the suburb itself gains prominence and is symbolically and practically demarcated from other parts of the city. Taking care of waste also contributes to defining local communities in a relational sense: Lynn often refers to the deprived neighborhoods in southern Auckland as a counter-image of her ideal. This delineation is particularly powerful because of the negative associations mentioned above. Pointing to media reports about the dumping problem in the southern suburbs of Auckland, she also suspects people from the girdling neighborhoods of dumping their waste on the terrain of "her" community. In statements like these, talking about waste behavior supports and helps legitimate a powerful demarcation line between "good" and "bad" areas. The attributions of "good" and "bad," however, evoke various connotations and meanings. Waste serves as a publicly visible marker of a suburb's wealth, quality of life and, to some extent, ethical value. Lynn's neighborhood is one of few middle-income suburbs in this area and is, thus, perceived of as a major contrast to the surrounding residential districts. The localized waste initiative further strengthens this contrast.

Eco-friendly practices are often associated with characteristics such as ethnicity or social milieu. In this imaginary, the "right" way of caring for Auckland's environment is embodied by specific types of good citizens. It becomes entangled, therefore, with other patterns of inclusion, exclusion and inequality. Caring for a privileged suburb and excluding the disadvantaged, surrounding neighborhoods perpetuate social imbalances and unevenly distributed services in the city (see also Murphy 2015, 19). In a broader sense, it can be argued that care always remains focused on a vulnerable "object" that has to be cared for and, thus, operates as a "selective mode of attention" (Martin et al. 2015, 627) that entails power relations. In that sense, here, too, processes of exclusion are attached to "good" and eco-friendly engagement.

Inequalities and the role of the state in reproducing these inequalities are less visible behind the powerful demand for more environmental care and responsibility that is performed as undeniably "good." This meshes with the logic of responsibilization, as the demand for good, caring and active 
citizenship that shifts the role of the local state from providing infrastructures and support for citizens to encouraging and empowering citizens to provide for themselves. Consequently, a lack of activism can be blamed when deprived communities do not seem to be caring enough for their local environment, rather than unequal structures (see Hyatt 2001, 212).

\section{Conclusion}

Framed as community practice, the commitment to environmental care becomes increasingly obligatory: Getting involved is performed as a way of, maybe even a means to belonging to a certain neighborhood; local, social and ethical connections contribute to the binding character of eco-activism. Neoliberal politics of a shrinking state support the shift of responsibilities to nongovernmental agents and are also decentralizing the handling of environmental problems. Environmental amenities, such as green space, and nonpolluted neighborhoods are seen as aspects of an urban quality of life to be achieved by local residents rather than as something that is to be provided by the council.

Common waste practices are woven into the everyday lifeworlds of city dwellers: The commitment to joint ideals of "good" waste behavior has an affective dimension and is much more familiar to citizens than the acceptance of an authoritatively imposed code of values. The call for communality in Auckland fits into local imaginations of the "good" city life: Many quarters have developed strong identities, consider themselves as communities and articulate future visions that are primarily focused on maintaining or establishing close local social ties. To acknowledge commonly lived values is to respect the jointly created community. Furthermore, the connections that link waste activists with government bodies take shape as "multi-partner governance" (Agrawal and Lemos 2007). These hybrid forms of government profit from the synergies that evolve from joint collaboration, but at the same time, conflicts of interests are less visible and the local government becomes less contestable. In that context, critique and rejection may be more difficult to express; for example, to criticize social effects of exclusion and to suggest more sophisticated approaches that prioritize tackling pollution in deprived, rather than in privileged, neighborhoods. Potential counterconcepts are not directed toward the government but toward neighbors and social agents that share common relationships and activities.

The local community initiative has positive impacts on the reduction of landfill waste in Auckland but, at the same time, social inequalities and established hierarchies among the suburbs are reproduced and reinforced. The neoliberal approach of urban waste politics ultimately re-empowers the powerful and fosters inequalities regarding access to infrastructure and local reputation in the city. Care and community are always intermingled with multilayered dependencies - and these get easily veiled beneath environmental consensus. 


\section{Acknowledgments}

I thank all my interlocutors in Auckland sincerely for participating in this research. I give thanks to the Social Sciences Department at AUT University for supporting this project in the field. Further I thank my supervisor Eveline Dürr for her profound support and feedback during the whole project. I thank our interdisciplinary research group "Urban Ethics. Conflicts over the 'good' and 'proper' life in cities of the 21st century" at LMU Munich for our discussions and colloquia. I thank the Deutsche Forschungsgemeinschaft (DFG) for the financial support for this research.

\section{Note}

1 Pākehā is the Māori term for New Zealanders descending from the first European settlers.

\section{Bibliography}

Agrawal, Arun. 2005. "Environmentality. Community, Intimate Government, and the Making of Environmental Subjects in Kumaon, India." Current Anthropology 46, no. 2: 1-23.

Agrawal, Arun, and Maria Carmen Lemos. 2007. "A Greener Revolution in the Making? Environmental Governance in the 21st Century." Environment 49, no. 5: 36-45.

Auckland Council.n.d. "Here's Your Rubbish and Recycling Guide.” Accessed May 8, 2019. http://www.makethemostofwaste.co.nz/media/1349/rubbish-and-recyclingguide-web.pdf.

Auckland Council. 2012a. "The Auckland Plan." Accessed May 8, 2019. http:// theplan.theaucklandplan.govt.nz/pdfs-and-maps/.

Auckland Council. 2012b. "Auckland Waste Management and Minimisation Plan. Getting Auckland's Waste Sorted." Accessed May 8, 2019. https://www.aucklandcouncil.govt.nz/plans-projects-policies-reports-bylaws/our-plans-strategies/ topic-based-plans-strategies/environmental-plans-strategies/Documents/wastemanagement-minimisation-plan.pdf.

Auckland Council. 2018. "Auckland Waste Management and Minimisation Plan 2018." Accessed May 10, 2019. https://www.aucklandcouncil.govt.nz/ plans-projects-policies-reports-bylaws/our-plans-strategies/topic-based-plansstrategies/environmental-plans--strategies/docswastemanagementplan/ auckland-waste-management-minimisation-plan.pdf.

Blumhardt, Hannah. 2018. "Trashing Waste: Unlocking the Wasted Potential of New Zealand's Waste Minimisation Act." Policy Quarterly 14, no. 4: 13-26.

C40Cities. 2019. "The Power of C40Cities.” Accessed May 6, 2019. https://www.c40. org/cities.

Davies, Anna R. 2008. The Geographies of Garbage Governance. Interventions, Interactions and Outcomes. Burlington: Ashgate Publishing Limited.

Dürr, Eveline, and Jeannine-Madeleine Fischer. 2018. "Tackling Pollution with Care: Everyday Politics and Citizen Engagement in Auckland, New Zealand." In The Routledge Handbook of Anthropology and the City, edited by Setha Low, 204-15. London: Routledge. 
Gundry, Pat. 1993. Devonport. Auckland: Devonport Books.

Hamann, Trent H. 2009. "Neoliberalism, Governmentality, and Ethics." Foucault Studies 6: 37-59.

Hawkins, Gay. 2006. The Ethics of Waste. How We Relate to Rubbish. Lanham: Rowman \& Littlefield Publishers Inc.

Held, Virginia. 2006. The Ethics of Care. Personal, Political, and Global. New York: Oxford University Press.

Hyatt, Susan Brin. 2001. "From Citizen to Volunteer. Neoliberal Governance and the Erasure of Poverty." In The New Poverty Studies. The Ethnography of Power, Politics, and Impoverished People in the United States, edited by Judith Goode and Jeff Maskovsky, 210-35. New York/London: New York University Press.

Jessop, Bob. 2002. "Liberalism, Neoliberalism, and Urban Governance: A State Theoretical Perspective." Antipode 34, no. 3: 452-72.

Kettle, Elizabeth Elaine (Betsy). 2014. "Daylighting Waste. Can Community-Based Recycling Depots Become Parts of Auckland's Everyday Life?" Master thesis in Landscape Architecture, Auckland: Unitec.

Larner, Wendy, and David Craig. 2005. "After Neoliberalism? Community Activism and Local Partnerships in Aotearoa New Zealand." Antipode 37, no. 3: 402-24.

Lawson, Victoria. 2007. "Geographies of Care and Responsibility." Annals of the Association of American Geographers 97, no. 1: 1-11.

Martin, Aryn, Natasha Myers, and Ana Viseu. 2015. "The Politics of Care in Technoscience." Social Studies of Science 45, no. 5: 625-41.

Murphy, Michelle. 2015. "Unsettling Care: Troubling Transnational Itineraries of Care in Feminist Health Practices.” Social Studies of Science 45, no. 5: 717-37.

New Zealand Herald. 2019. "NZ's Green Image Let Down by Its Huge Plastic Waste Consumption: Study.” Apri1 9, 2019. Accessed May 6, 2019. https://www.nzherald. co.nz/nz/news/article.cfm?c_id=1\&objectid=12220755.

Our Auckland. 2017. "Auckland Crowned Zero-Waste World Champion.” December 6, 2017. Accessed May 6, 2019. https://ourauckland.aucklandcouncil.govt.nz/ articles/news/2017/12/c40-cities4zerowaste-award/.

Our Auckland. 2018. "Auckland's New Food Scraps Collection Leads the Way in Food Recovery." June 1, 2018. Accessed May 6, 2019. https://ourauckland. aucklandcouncil.govt.nz/articles/news/2018/6/auckland-s-new-food-scrapscollection-leads-the-way-in-food-recovery/.

Perkins, Harold A. 2009. "Out from the (Green) Shadow? Neoliberal Hegemony through the Market Logic of Shared Urban Environmental Governance." Political Geography 28, no. 7: 395-405.

Recycle. 2019. "Waste Starts with Us and Ends with Us!” Accessed May 6, 2019. https://www.recycle.co.nz/problemsize.php.

Reno, Joshua. 2009. "Your Trash Is Someone's Treasure: The Politics of Value at a Michigan Landfill." Journal of Material Culture 14, no. 1: 29-46.

Rose, Nikolas. 1999. Powers of Freedom. Reframing Political Thought. Cambridge: Cambridge University Press.

Shaw, Aimee. 2019. January 23. "Soft Plastics Recycling on Hold for Another Three Months, Shoppers Urged to Send Bags to Landfill.” January 23, 2019. Accessed May 6, 2019. https://www.nzherald.co.nz/business/news/article.cfm?c_id= 3\&objectid=12194766.

Taylor, Gary. 2013. "Environmental Policy-Making in New Zealand, 1978-2013." Policy Quarterly 9, no. 3: 18-27. 


\section{Part V}

Protest between ethics and politics

Collective agents of urban change 


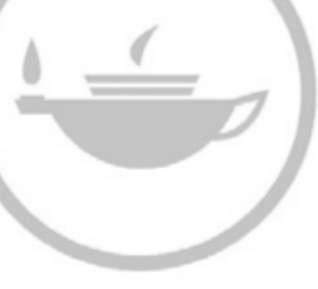

Taylor \& Francis Taylor \& Francis Group

http://taylorandfrancis.com 


\title{
15 Keep the city clean
}

\author{
The ambivalent ethics of \\ ownership in urban routine and \\ non-violent protest in Moscow
}

\author{
Alexander Bikbov
}

\section{Bodily and binding vs. digital and optional: how different institutional ethics in top-down urban interaction produce different effects}

Over the past decade, Moscow and St Petersburg - as well as other large Russian cities - have seen their urban space rearranged, essentially, in a top-down fashion. Since the mid-2000s, public discussions have invariably emerged as belated responses to faits accomplis created by city managers, whether the issue was a projected skyscraper threatening to protrude from a cityscape, the remapping of a historical district or the construction of a spacious commercial area. In all of these cases, public participation and rightto-the-city claims have been distinctly reactive, expressing anger at changes already underway or imminent: "You cannot do this to us!" In Moscow, the mayor's office has taken unilateral action, avoiding any preliminary public debate, on measures such as building massive inner-city motorways and junctions, planning the demolition of millions of square meters of "outdated" housing ${ }^{1}$ or destroying thousands of square meters of small retail structures (between February and August 2016).

Although top-down, such transformations allow for certain limited forms of public participation and expertise. The authorities began to stage two distinct modes of interaction in successive steps: Citizen consent and expert proposals. The first format was introduced in 2003 in the form of public hearings for construction and demolition projects to be implemented (Figure 15.1). These hearings involve recording the consent of residents living in the district concerned and holding them is mandatory for all such projects. ${ }^{2}$ The second mode takes the form of an annual Moscow Urban Forum established in 2011 - a large meeting held jointly by the municipal government, businesses and noncommercial associations - as well as a digital voting platform for expert proposals called Active Citizen that was launched in 2014 (https://ag.mos.ru). Together with several other city-level tools of governmentality, this provides city managers with "advisory" options meant to readjust their general vision, rather than to accept or abandon individual projects. 


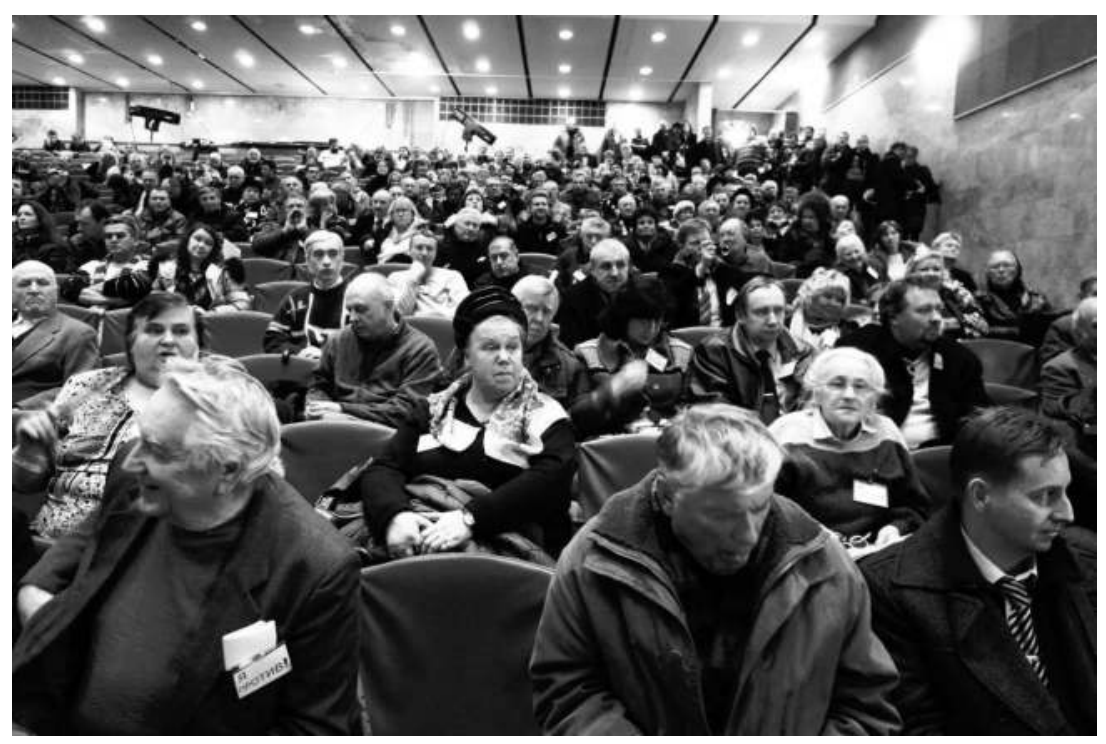

Figure 15.1 Public hearing in Moscow. (Alexander Bikbov)

The two modes differ not only in their instrumental status but also in the temporality and bodily experience that they imply. The collective bodily presence at - legally required - public hearings is a socially different experience from the optional and individual digital expression of suggestions by nonprofessionals. Although the former experience is in no way "nice," it connects urban ethics inseparably with a particular emotional-aesthetic regime of participation.

District-level public hearings are often held in closed, stuffy rooms. Exchanges quickly become noisy, nervous and heated. Communication is de facto unregulated, even though a formal procedure is in place. Attendees often deliberately interrupt presenters and each other. Exclamations of disagreement, impulsive questions and verbal aggression are common. A face-to-face NIMBY ("not in my back yard") confrontation with projects presented by a municipal office is fundamentally a reactive setting where indignation is the dominant mood on all sides, including among the city officials present.

Nonbinding forms of participation, on the contrary, tend to favor proactive (rather than reactive) visions of urban change. Yet, they also encourage rational self-control and distance: Spatial distance in the case of digital voting and discursive distance in the case of professionally moderated debates and forums. This regime is "nicer" and, at the same time, more alienating on a social and cognitive level, pushing amateurs to rely on the judgments expressed by professional experts more closely associated with long-term, anticipatory urban planning. There is a robust literature that explores how 
aestheticizing the urban interactions to a class transformation of city space and, to some degree, excludes the lower classes from that space (Duncan and Duncan 2004; Longhurst 2012; Pow 2009; Walks 2006). This is echoed by similar changes in nonphysical urban space induced by communication technologies. Rendering exchanges on urban issues "nicer," the nonbinding tools simultaneously strongly influence who (what social status groups) participates in these exchanges more often and most effectively. The collective, bodily and spontaneous reactions to what is happening just outside one's home that dominate the binding format of public hearings mobilize residents across various segments of society, including those lacking special social skills and cultural capital. As a rule, participants in public hearings are also older than those taking part in digital exchanges on urban issues. According to data from the mayor's office, only 12\% of those registered with the Active Citizen platform were aged over 45 (Voronov and Sidorov 2015). ${ }^{3}$ By contrast, according to the 2010 census, $42 \%$ of Moscow residents were older than 45 .

These class and age effects are closely associated with the temporality and criteria of success implied by the binding mode. Startled into action, amateurs tend to mobilize and cooperate as activists for a period of one to three months. This is distinctly longer than the duration of online campaigns on social media, and the direct impact on the administration can be stronger thanks to the involvement of participants experienced in dealing with red tape and steering clear of bureaucratic traps. At the same time, the more physical and emotionally demanding nature of this form of participation renders it highly dependent on achieving clear-cut victories, and collective trust clearly depends on the personal reputations of the most active participants rather than the communication framework as such.

Despite the lack of continuity in district-level mobilization, the legal obligation for the administration to take the results of the hearings into account enables residents to exercise a form of law-abiding, procedural resistance. As was to be expected, the rise in dissenting votes requiring adjustments to urban planning projects has increasingly come to be perceived by the authorities as an annoying constraint that slows down top-down city development. Repeated parliamentary debates, as well as draft laws introduced in the fall of 2016 and the spring of 2017, have called for this mechanism to be canceled and replaced with online expressions of opinion that would have no binding force.

While the (ongoing) managerial reform of urban governance and federal legislation initially provided an institutional framework for public participation and negotiation on urban development, the legally binding and emotionally taxing regimes of participation have more recently tended to be replaced by "softer" and "nicer" ones. The political effects produced by this shift were anticipated in the feedback framework for Moscow's "renovation" scheme. Residents of every building earmarked for demolition as part of that scheme were given a very short window of time (May-June 
$2017)$ to vote on the plans. The vote took place largely on the Active Citizen website, and anyone who did not vote was, by default, counted as consenting to having their building demolished and being resettled.

Thus, steps taken to make it easier - technically and emotionally - to express individual opinions on top-down city planning projects ended up primarily facilitating the executive management of the projects being promoted, rather than fostering spontaneous grassroots initiative and residents' creativity. As the deputy mayor of Moscow, the key promoter of the digital platform, declared: "This project lets us improve the efficiency of management in practice" (Byt' 2015). A comment by the head of IT for the Moscow government states the objectives even more precisely. In response to the question "Why can't citizens submit an initiative directly?" he states, "We put to a vote only what we can really fully implement" (Gorodskoy sovetnik 2015).

Moreover, even bracketing out widespread and probably well-founded accusations of behind-the-scenes manipulation and vote rigging, establishing a mechanism that channels interaction on urban issues into a distanced and optional format paradoxically, but quite deliberately, aligns Russian top-down city management with the key formula of neoliberal governmentality as a reduction of "the excess of government" (Dean 2010, 69-74). Digitalizing and "nicefying" citizen consent speed up feedback (each vote is limited to a one-month period), reach large audiences at low procedural costs $(200,000-500,000$ votes) and add to the general legitimacy of the mayor's office by offering a choice of options, mainly concerning service provision. ${ }^{4}$

However, the effects of these ultramodern governmentality tools are often obscured by the fact that they are being used alongside "archaic" backroom decision-making and directive city management. In the case of Moscow, ethical concerns about the relationship between the authorities and residents established within the top-down model of city management are primarily expressed in the language of "arbitrariness" and "dishonesty," rather than social injustice or discrimination against minorities. The city administration is typically accused of being economically corrupt, neglecting the interests of Moscow residents, favoring corporate interests, servicing the Kremlin's authoritarianism and violating smallscale private property rights. Critiques are also sometimes tinged with regional bigotry, especially directed against Sergey Sobyanin, Moscow's mayor since 2010, who is originally from the Khanty-Mansi ethnic minority region. He is regularly qualified as an "indifferent newcomer" or, in a racist version of the same resentment, as a "reindeer breeder" or "reindeer," while the mayor's office and the municipal bureaucracy are simply described as corrupt. ${ }^{5}$

These sensibilities generated by institutionalized interaction in a large Russian city need to be kept in mind as the background to residents' ideas of ownership, which I will now proceed to examine. 


\section{Locating an apolitical "place of one's own" in urban space}

The managerial shift toward nonbinding public support and expert lobbying in institutionalized urban interactions coincided with a mass protest movement that began to unfold in large Russian cities starting in December 2011. Triggered by vote rigging in the parliamentary elections, for the first time since the early 1990s, the protests brought more than a few dozen or, at best, a few hundred people onto the streets of Moscow. A typical weekend demonstration would draw approximately 30,000 , sometimes exaggerated to about 120,000 in media reports. ${ }^{6}$ The protests did not produce a grassroots organization active on the national scene, but it did usher in broader involvement in municipal council elections. In Moscow, according to a rough calculation, out of the 1,817 municipal councils members elected in March 2012, 21 were civic activists or opposition figures and another 250 had no affiliation with administrative agencies or the ruling party (Vinokurova 2013) - figures that are high by Russian standards.

Council member positions come with highly circumscribed mandates, so the newcomers were not attracted by any potential to make a big political impact. They were more driven by a desire to test themselves by "defending my district and its residents, by overcoming when they [the city authorities] are doing whatever they want." 7

The fundamental concept here is "my/our district." This term has a number of implications regarding local ethics and small-scale ownership, responding to trends that have developed - asynchronously - since the late 1980s. The idea that every house, industrial plant or plot of land should have a "real master/owner" was already a linchpin of debates in late Soviet city planning; later on, this was seen as a fundamental condition for deliberative democracy to function. ${ }^{8}$ In practice, throughout the 1990s, the idea of urban ownership never went beyond individual flats. The mid-2000s were marked by a tentative expansion of neighborhood activities relating to shared spaces. This primarily took the form of planting flowers (not trees, which were always managed by the city authorities) and otherwise decorating courtyards of large blocks of flats; in the Soviet era, the courtyards had been the responsibility of the municipal authorities. Residents would, thus, engage in a soft aesthetic reappropriation of neighborhoods, while on every other level, ownership of these neighborhoods was slipping away from them. This was part of a growing concern about the "cleanliness" and "neatness" of shared staircases, courtyards and streets that developed from below but was also fostered by the mayor's office. For a long time, the vision of a "clean city," together with the slogan "private ownership means quality," both explicitly referring to an imaginary Western model, was part of a consensus that turned Moscow, at least, into a showcase of a privatized urban economy.

Arguments in favor of privatization were still highly popular in the early 2000s. A Moscow newspaper advocating a reform of municipal services accused them of "socialism": 
Actually, the market has not really developed: Those 700 private organizations that have begun to serve us have not yet solved the problem of giving us a choice. Housing and communal services are still dominated by ZhEKs [public utilities offices] that do not have real competitors. As you can see, the mode of production, so to speak, remains socialist.

(Kuznetsova 2002)

The next step was a definitive commercialization of Moscow's municipal services. Conducted in 2004-2005, under the mottos of improving the quality of services provided, it caused an ultimate shift in the previously fixed perceptions of what constituted "interior" and "exterior" spaces in the city. Issues such as structural repairs, regularly repainting outer walls, replacing pipes and lifts, creating parking spaces and green spaces were no longer the undivided responsibility of the city government (and, thus, external to individual households): They now had an impact on family budgets.

Between 2001 and 2014, the cost of basic utilities such as water and electricity rose eight- to fifteen-fold in nominal prices. ${ }^{9}$ The cost of buying or renting property grew at a similar speed, as did the cost of public transport and parking. In the first set of interviews conducted at the protests in December 2011 (see below for details), municipal services were spontaneously mentioned by several participants as one of the most palpable problems, along with general corruption, the low quality of education, the absence of rule of law and several others.

The steady and tangible growth of fees for services and utilities, as well as the lack of direct feedback from the municipal administration to residents' complaints about quality flaws and corruption, put logistical problems in even greater relief, leading to a growing interest in "one's own" urban space. There have been regular conflicts in Moscow with, and trials of, facility and waste management companies. St Petersburg has seen annual public campaigns against municipal cleaning services incapable of deicing pavements in winter. Several large cities have experienced protests against city managers legalizing abusive construction and encroachments on green spaces. All of these protests have increasingly been framed as critiques of "how they are spending our money." Once again, most such cases of mobilization are short-lived and precarious, failing to establish permanent self-governed bodies. Moreover, only a small minority of residents in each district have had any direct experience with participation. Nevertheless, these cases managed to generate more widespread ethical concerns through word-of-mouth communication and especially the mainstream media picking up these issues. Thus, the notion of "one's own district" forged in defensive activism ended up becoming a widespread term, denoting not so much a common space created through cooperative grassroots interaction but rather a typified experience of infrastructural issues pre-shaped by city management.

The context for these struggles by an active minority was a universal desire for private comfort. As early as the 1990s, this expressed itself in a 
pervasive grassroots appropriation of (communal) landings in blocks of flats. People started installing massive iron doors to shut off these landings and porches for protection against frequent robberies (Figure 15.2). Over the past decade, shared courtyards have been appropriated in a similar fashion: Enclosures prevent outsiders from using them to circumvent the decrease of parking spots in the city. Spontaneous privatization is, thus, shifting from addressing concerns of personal security to being about neighborhood comfort. As a result, most of the critiques voiced by Moscow urban activists have not been aimed at a radical revision of the established administrative order. Their objective is rather to protect the comfort already acquired from arbitrary intrusion. Even the most successful and professionalized participants of pro-neighborhood campaigns acknowledge that Moscow's urban activism is clearly defensive. ${ }^{10}$ It is not simply a manifestation of a latent bourgeois libido exclusive to property owners; it is a larger substitutive desire typical of those aspiring to property ownership who wish to master a widening "private space." This desire persists even when these aspirations are questioned by other residents or violated by private developers or the city authorities themselves.

It is worth mentioning another, albeit secondary, factor that contributes to how "one's own" space is implicitly shaped in the city. For the past 15 years, local media have been promoting a meaning of "our district" as mostly focused on properly functioning urban facilities and a safe environment, rather than on citizen cooperation or political deliberation. In

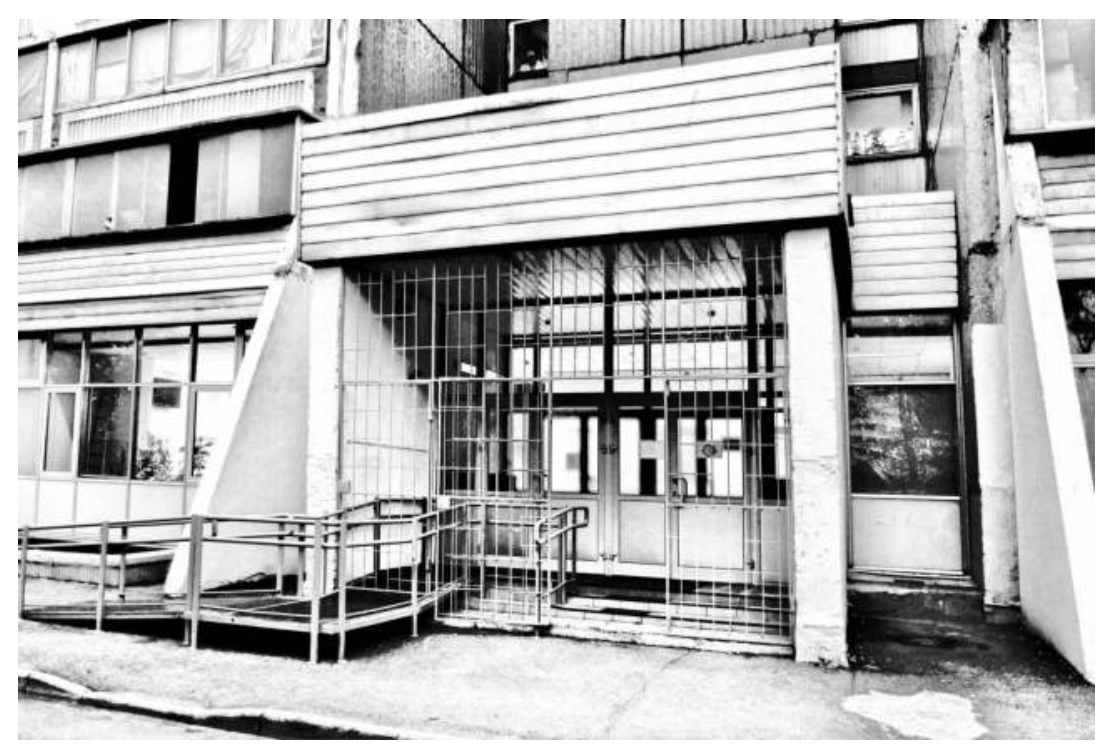

Figure 15.2 Protective bar on entrance door. (Alexander Bikbov) 
Moscow, free municipal weekly newspapers that saw a massive increase in borough-level circulation by the mid to late $2000 \mathrm{~s}^{11}$ have been covering news about local executive offices and infrastructure renovation, issues of flat rental and maintenance, public and private transport, health and local human-interest stories. ${ }^{12}$ Written in a paternal tone, these articles presume a moderate and extremely reasonable audience of petty flat owners and shape the identity of "our district" from an apolitical and mostly top-down perspective of thoughtful and efficient management. The way political news is avoided can be seen in the first 2011 post-protest publications. The only mention of the contested parliamentary elections, for instance, in the newspaper of the south-west borough, where protest voting is usually the highest, was a short 150-word note presenting the official results and titled Such is the people's will (Ivin 2011).

Although the status of free municipal newspapers as a source of valuable information is questionable, the administration makes ample use of them in preparation for conflictual public hearings and to address a growing demand for practical information on local fees and social benefits. On the opposite side, critical grassroots leaflets and publications published over the same period that deal with specific district-level or urban issues have approached these issues in ways similar to the municipal media. Their agenda and language typically avoid connecting local concerns with civic activism and political protests, given the risk of a dramatic loss in credibility. The divide between urban and political matters, which maintains a defensive vision of what is "one's own," has been reproduced on various occasions, including a rule that only neighborhood groups, but no political party representatives, be allowed to speak on the stage of a protest against Moscow's "renovation" (demolition) scheme in May 2017.

Summing up the ethical and (a-)political meanings of the concept of "my/ our district," as well as of "one's own" space in the city, the following point is worth noting: While local urban activism around issues of "corruption" and "lawlessness" opposes residents "who care" to a local inefficient bureaucracy, the issues of "cleanliness" and "neatness" command a broad consensus and are seen as politically unquestionable.

This means that the idea of "one's own" space serves as the foundation for two discursive and practical frameworks that appear, at first sight, to be completely independent of each other and even mutually opposed, yet, in fact, express the same basic attitude. The first framework expresses an adherence to positive values. In standing up for "our" local park in the face of an aggressive commercial developer or the Church, contesting abusive construction in "our" neighborhood or defending some other common space, amateur and short-term activists often appeal to an image of a comfortable and neat life in their district. They might talk about the quality of the environment and the neighborhood for consumers, the accessibility of family recreation and childcare institutions, about quiet courtyards and fresh air, about decent neighbors and respectable relationships. Yet, the 
same normative expectations articulated in a negative form might express themselves in resolutely objecting to the construction of a residence for migrant workers or a shelter for drug users, ${ }^{13}$ as well as in explicitly xenophobic and homophobic attitudes or, as already mentioned, in mocking the nonMuscovite origins of Moscow's mayor. In fact, these are not two distinct forms of political sensibility - one communitarian and salutary and the other racist and regrettable. Both embody the same vision of "one's own" seen foremost from the perspective of petty flat owners whose experience of the city is shaped by top-down urban management.

\section{Requesting normality and cleanliness in protest actions}

This convergence is put to the test in situations in which the routine of urban life is interrupted. This happened most visibly in street demonstrations and in the self-governing (leaderless) Okkupay camps that were set up in May 2012 in Moscow, St Petersburg and several other large cities by protest participants. ${ }^{14}$

Since the first mass protests against the fraudulent elections in December 2011, mass demonstrations in Moscow have gone on to address issues such as corruption, political repressions, human and civic dignity, media lies and the Russian military's involvement in the war in Ukraine. This thematic variation hides a broader dissent unveiled through sociological interviews recorded by the NII mitingov initiative in 2012-2018. ${ }^{15}$ As opposed to Arab, West European and American movements in 2010-2012 that subjected the existing institutional order to severe criticism and contested it through alternative, often community-based, projects, Russian protest has mostly aimed at normalizing individual claims to "repair" existing public institutions, in particular fair elections, a law-abiding police force, fair justice, an efficient army and some others. Participants have repeatedly bridged their differences through attempts to moralize political issues: To render protest as "kind," "cute" and strictly law-abiding, as well as to explicitly avoid the propagation of political or, worse, revolutionary viewpoints.

This consistent pro-institutional and nonviolent attitude might well have to do with the overrepresentation among protestors of people with university experience $(60-80 \%)$, often employed in the tertiary sector or in academia. The determining role of culture for participants' identity is indirectly confirmed by the high frequency with which, in the first few months of protests in 2012, they spontaneously mention the low quality and poor public management of education among major social issues. ${ }^{16}$ It finds further confirmation in the clear-cut opposition between "civilized" protest and "rude" and violent state power that is regularly held up in interviews throughout the period studied. Taken together with the explicit denial of one's own social and economic vulnerability attested in both the interviews and in media reporting about the protests ${ }^{17}$ this promoted an implicit class identity of the protestors as mostly well-off and self-restrained. 
No less importantly, the overwhelming majority of those interviewed reported that their involvement did not disrupt their habitual lifestyles or their friendship and professional networks. Civic associations and opposition parties experienced a short-lived growth in membership between December 2011 and February 2012, followed by a tacit disengagement. From an anthropological perspective, the street protests as well as the Okkupay camps were dominated by self-discipline and a laissez-faire attitude.

Even though the actual shifts in protestors' lifestyles were minor, this did not prevent them from making claims about their unity as prefiguring a future utopian society: "It is as though the whole [political] spectrum were represented here, and all kinds of people stand peacefully shoulder to shoulder. This is how a normal society should be organized" (female, about 50 years old, higher education, chief accountant). In such declarations, the explicitly experimental and reflexive vocabulary of "testing," "seeing what is happening," "witnessing" that educated protest participants employed to explain their motivation is combined with a demand for normality and things to work in a natural way. The latter shines through in criticism of "the dishonest people in power," "society feeding on corruption," "a complete disorder in legislation" and "a regime unlike European democracy." These are only some of the points from a long list of social and political dysfunctions that serve to ground an ethical, but explicitly apolitical, motivation to take to the streets. ${ }^{18}$ Protestors' utopianism expressed itself in a moral expectation that once all these dysfunctions are resolved, normality will settle in. As summarized by one participant, "[What do I expect?] That everyone should become accountable. That the laws simply work, that courts be fair, the army strong ... Well, that is, that everything works and function normally" (male, about 30 years old, higher education, engineer).

The call for normality most spectacularly translated into direct corporal experiments in urban space, testing the limits of an order seen as abnormal and repressive. This took the form of, for example, unapproved demonstrations, such as collective weekend walks, engaging in election observation at polling stations in order "to personally witness if vote rigging really is that bad" or refusing to leave when a demonstration is being dispersed by the police. Such tests can have a wide variety of outcomes, from a growing feeling of personal empowerment, collective cohesion or festive Okkupay spirit, all the way to the evident threat of detention and sometimes bodily harm by the police. The gesture of personal witnessing is generally closely connected to a desire to behave in an ethically "normal" way in response to a range of institutional deficiencies tested in person, without intermediaries or representatives (Figure 15.3). ${ }^{19}$

The following short samples from interviews recorded at the first protest demonstrations illustrate how this particular regime of involvement merges with an idea not only of ethical purity but also of spatial cleanliness, all summed up in explicit calls for normality. 


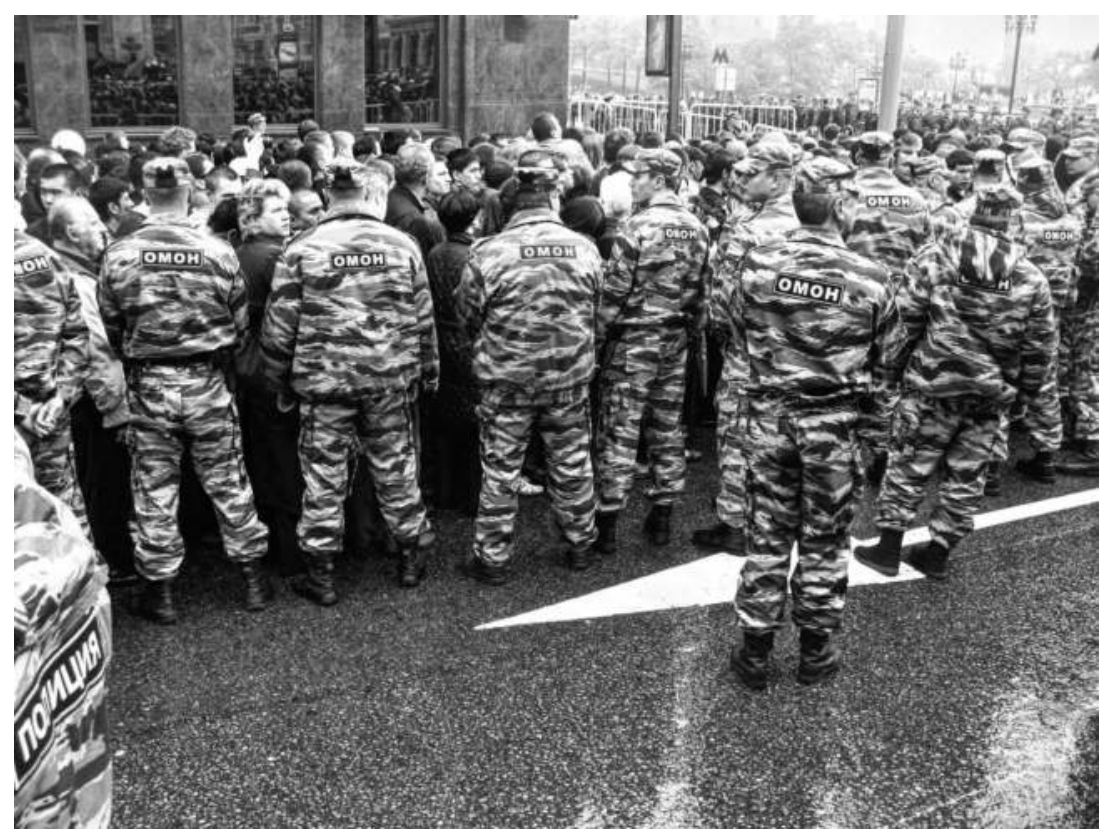

Figure 15.3 Queue for WWII victory celebrations. (Alexander Bikbov)

[What can I do personally?] I can do the right thing [laughs]. Abide by the laws, be good to the people around me. Anybody can do that.

(female, about 25 years old, secondary education, IT worker)

I simply support civil responsibility every day. I yield my seat to the elderly; I help them by carrying their bags. I think one should be just and simply human.

(male, about 25 years old, higher education, employed in the tourism industry)

Not to litter, not to spit cigarette butts onto the ground.

(female, about 30 years old, higher education, post-production producer)

We can bring up our cool son so he becomes a good person.

(female, about 35 years old, designer)

Explaining what she could personally do to change the situation, one of the participants sums it up by saying, "To do all the right things." This generalized language of "right things," which, in practice, often translates into a rather trivial form of commitment, is discursively opposed to a violent, 
corrupt and perverted political reality. More broadly, the ethics of these protests imply a strong libido of normalization expressed as a critique of both dysfunctional, corrupt institutions and an entire "abnormal" society based on corrupted relationships.

When participants mention specific intentions and projects produced by this attitude, they refer to an ethic of "small deeds": Catering to local needs that have not been satisfied by the municipal or federal government. Among them, those best articulated were cleaning up the streets of Moscow in a voluntary, self-organized effort, cleaning up a small lake near Moscow together with local residents, and cleaning up and beautifying one's neighborhood. The two key concepts that were regularly used in describing those projects were "by ourselves" and "to clean." This is identical to what could be observed in routine attempts at grassroots urban beautification that preceded the protest cycle.

Expressed mostly by young (22- to 35-year-old) educated professionals, such intentions rarely translated into practical action but fit the sensibility of small property owners exercising authority over their "own" city perfectly. One of the ethically "correct" collective activities considered most important during the Okkupay protest camp in May 2012 was a joint regular cleanup of the territory by those who were staying in the camp overnight. The Moscow (and St Petersburg) Okkupay camps did not formulate a political claim for urban space, in contrast to some other city occupations, such as those by the Spanish indignados or the US Occupy camps. Instead, its collective self-governance tasked itself with maintaining what was temporarily its "own" territory as a neat neighborhood. Generally speaking, Moscow's protest ethics, based on a widely shared, yet, always individually experienced view that political life is "abnormal," explicitly mandates cleaning, which the protestors understand as a way to return to normality.

\section{Tidiness and repression in Okkupay space}

The curatorial practices of protestors" "own" space in the Moscow Okkupay camp were constrained by two factors. On the one hand, they self-imposed an ethos of responsibility. On the other hand, residents of the central Moscow neighborhood where the camp was located criticized the noise and messiness it produced, and this criticism was amplified by pro-Kremlin media. The result was that camp participants engaged in practices such as collective waste removal in the mornings, planting new flowers to replace broken ones in the park's flower beds, sweeping the whole park at least once a day and using a considerable fraction of the crowdfunded common budget to install and maintain composting toilets. Those practices were coordinated by the core team in charge of the camp's "household" zone for approximately two weeks. In part, this concern for cleanliness was rooted in the organizers' professional socialization. A young restaurant chef who was managing food distribution several times a day imposed a professional hygiene code, so that 
volunteers were obliged to wear thin latex gloves while serving food. This focus on hygiene also served as a response to repressive attempts by the city authorities to shut down the camp as posing a threat to public health and safety (Figure 15.4).

However, many of the cleaning practices at the camp were totally unrelated to participants' professional background and were rather derived from the shared vision of "one's own" space analyzed above. The "household" zone volunteers included a professional human rights activist, a former police dog trainer, the owner of a small tourist business, a sound engineer working in media production who declared an individual hunger strike, and a shopkeeper and long-standing activist of a far-right movement. Managing to steer around their political differences and avoid conflict, they worked together on the "economic" task of maintaining the shared space. One vivid expression of this consensus was the fact that they jointly distanced themselves from the camp's assemblies, which were based on procedures set up by far-left activists but drew many participants who did not have any particular political affiliation. In interviews, some participants of the "household" team asserted that the assemblies "speak too much and lack the capacity to solve real issues." 20 This seems to distinguish the Russian camps considerably from Occupy-type assemblies in Spain and the English-speaking world,

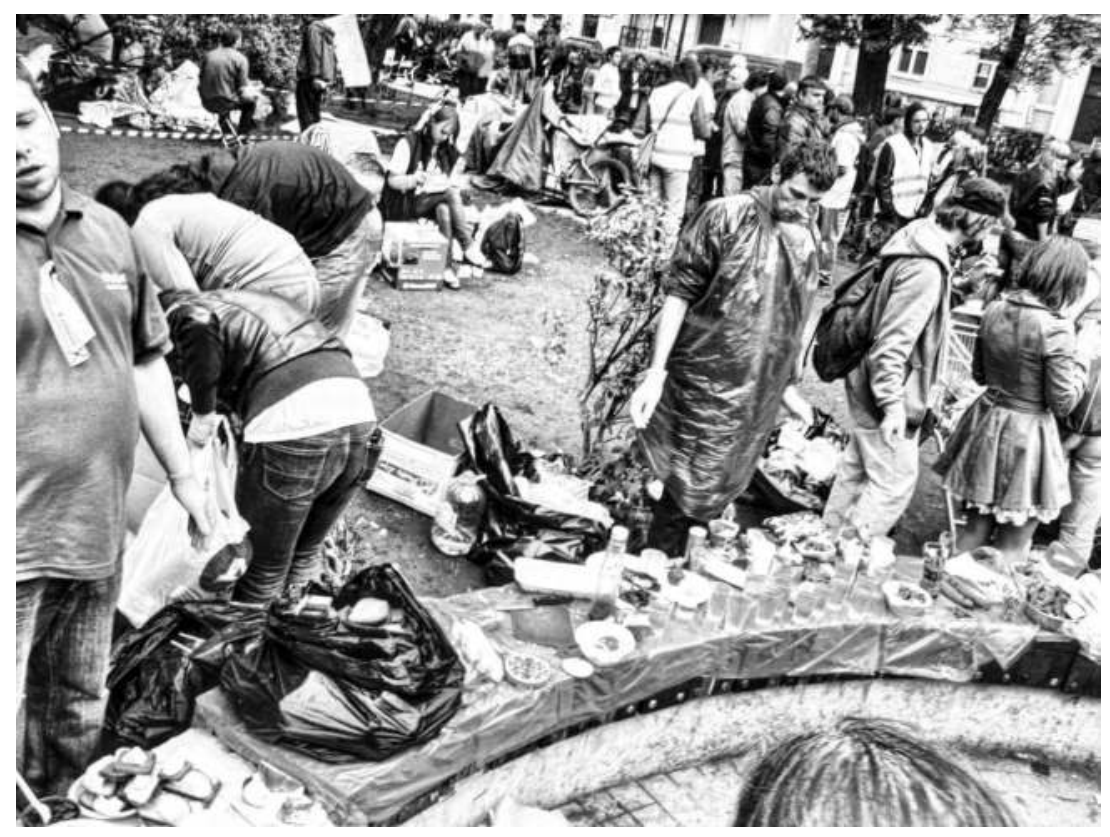

Figure 15.4 Okkupai camp. (Alexander Bikbov) 
where no clear distinction could be drawn between the "economic" management of the camp and deliberative consensus seeking.

Constituted as politically neutral, the space of the camp provided visitors who shared this "neutral" horizon with a sense of rational and empowering reciprocity:

It's cold [here], but it is perfectly organized. [...] Well, actually, there are squad people who are responsible for security, and people in the kitchen, in charge of the food. [...] This is going very well, you can go to the kitchen to bring your food, but even if you don't you will still get some from the common supply. And then, when it turned out that the mats that someone donated for sleeping at night [on the ground] weren't enough, within an hour someone brought large rolls of this. That's it. And everyone who needed got one.

(male and female, about 20 years old, students in the humanities)

The transparency of interaction was closely connected with the desire for a peaceful neighborhood. Participants frequently positioned the camp in the city by asserting that "in reality [and as opposed to some opponents' claims] we are not disturbing local residents." A widely shared image showed old (presumably apolitical and morally old-school) babushkas who sympathized with the protestors and were bringing them hot borscht and homemade pasties. The claim to normality exemplified in such external figures was part of a more general attempt to make the camp's use of urban space appear as "normal" as possible.

This peaceful image contributed to neutralizing politics. Soon after the creation of the Okkupay camp and following an inevitable phase of testing out and rotating roles, far-right (neo-Nazi) activists found their permanent place in the camp's structure as the security team. Instead of simply making the far left angrily leave the camp, this produced a division of labor and of subspaces, which was welcomed as an expression of natural, unobstructed human solidarity:

[Here in the camp] we even talk with nationalists, that is, we just chat and walk along with them. And it's OK. [...] We have decided to unite for a while. We have realized that we do not need any quarrels, because, just to say, when there is a common enemy, we need to come together, and the more of us there are the better. That's why now all the prejudicesleft, right— - have been put aside.

(female, 19 years old, student of choreography, anarchist)

While forging a new relationship with one's usual political opponents might be a specific issue, participants also explicitly base their ideas of a harmonious relationship with the neighborhood and with "ordinary people" on the same generally shared vision: 
The local [neighborhood] residents are treating us really well. They're bringing us clothes, they're bringing us food, they're asking what we need. They came to us today and said, gosh, it's really cool that you're here, because now there are fewer robbers, fewer alcoholics, they even said less garbage [in the neighborhood]. Our guys reported that [the nearest café] Shokoladnitsa allowed them to get boiling water. Here, it is poured into a vacuum flask and then you have tea, coffee and everything you need.

(the same interviewee)

On several occasions, Okkupay participants asserted that even troublemakers are approached in a similarly peaceful fashion:

Oh, and in emergency situations, when there are drunk people or something else of the kind, we contact the security team in order to remove them. Not physically, we simply ask them to leave.

(male, 20 years old, student in design, a freshly enrolled liberal activist)

Shared space kept tidy and managed peacefully seems to be the universally shared definition of what protest "is."

Aside from rare cases of patent conflict, this general model was widely upheld by various participants. However, at least one exception could be regularly observed in the common space constituted by the camp, consistently undermining the declared universalism of its utopian inclusive ethics. The figure of the homeless was met with rigid intolerance and criticized by both camp regulars and occasional visitors. Homeless people were consistently chased from the camp by its far-right security volunteers. A similar attitude could be observed at the St Petersburg Okkupay camp, which was smaller in size and had a narrower range of "household" practices but gave a similar importance to cleanliness. Similar to the phrase about "fewer robbers, fewer alcoholics" cited earlier, harmony between the neighborhood and the protestors was generally conceived here as a spontaneous consensus around the dominant vision of urban normality shared by both participants and nonparticipants.

One argument against homeless people specific to the protests was directly connected to the precarious existence of the camp. Homeless people were seen as a key factor in the negative public image that might put pressure on protestors:

They give the camp a bad name. If a pro-government TV channel comes to produce a story, they will show homeless people in order to say: "Look who the protestors are!" or "Here you find no one else but them." (male, about 55 years old, owner of a medium-sized business)

Here again one can observe how concerns of tidiness and self-defense are connected to symbolic or physical oppression. Another protest-related (though not protest-specific) argument claimed that the homeless were 
abusing common (spatial and financial) resources that should be used exclusively by protestors: "They are here all the time to get free food, they are just using and abusing our camp" (female, about 30 years old, participant in the camp "kitchen"). Other arguments transcended the camp, for example, when homeless people were portrayed as causing hygiene issues: "They are dirty and could spread their diseases among normal people." Rooted in a dominant sensibility that was simply projected on interactions at the camp, this attitude was further confirmed in demands for a general social selectivity that would prevent urban degradation:

These [homeless] people should not make themselves visible in the streets. They are always untidy and drunk. They just corrupt the city with their look and conducts. We need a clean and neat city.

(female, about 40 years old, higher education, homemaker)

Inherited from a longer late-Soviet and early post-Soviet imaginary of a sanitized place "of one's own" and further shaped by an intrusive amalgam of neoliberal technologies and top-down paternalism in city management, the grassroots ethics of cleanliness ultimately implies a restrictive vision of the commons. A range of behaviors, most notably revulsion to the most vulnerable urban figure - the homeless - show that the experience of protest did not radically restructure the dominant urban sensibility and replace it with idyllic universalism. The extraordinary appropriation of space by the Okkupay camps translated the risk of direct political reprisals into a growing demand for normalization, where the protestors' desire for a physically tidy and symbolically pure urban space maintained socially exclusionary and repressive connotations.

\section{Notes}

1 This refers to the so-called "renovation" scheme launched in Moscow in the spring of 2017 (see below).

2 Pavlycheva (2017) provides an outline, in English, of the basic legal framework for these public hearings.

3 Though this figure should be approached with caution, as age is an optional category in user profiles.

4 The 58 issues put to a vote in January-August 2017 on the Moscow portal Active Citizen (http://ag.mos.ru/results) can be summarized as follows: offers and quality evaluation of paid services provided to families or the city (38), streamlining administrative procedures and services (7), rating the best Moscow professionals in fields such as medicine or culture (5), embellishing public spaces (4), choice of logos and place names (3), and endorsing decisions previously approved by the city parliament (1).

5 All the themes listed in this paragraph can be observed, for example, in the Facebook group Muscovites against demolition (against the law on renovation) (facebook.com/groups/605672769637972), that contributed to street and media mobilization in 2017.

6 For the political context and an overview of the protests, see Gabowitsch (2017, especially Chapters 1 and 5). 
7 Interview with a young female municipal council member (Moscow, May 2012).

8 Indeed, the assertion that the Soviet people are masters of the country and its welfare was one of the pivotal formulas in Soviet-era solemn rhetoric. In the late 1980s, that claim was reappropriated for a critique of the system:

Why do you think party and workers' meetings have become active, why do people speak out openly and frankly? [...] For a long time, the idea that the worker is the master was repeated over and over, but in real life it was the administration that ruled. [...] Now the reins of government are in the hands of the entire collective.

(Editorial 1988)

9 Over that period, the cost of electricity grew by a factor of 8.6, gas by 12.5 and hot water by 14. Calculation based on Arkhiv postanovleniy (2016).

10 Interview with a female opposition municipal council member (April 2, 2017).

11 Since 1991, Moscow has been divided into ten municipal boroughs (okruga), and three new boroughs were added in 2012.

12 The first weekly newspapers of this kind were established by municipal boroughs in the late 1990 s and early 2000 s, with a circulation of $30,000-50,000$ paper copies each. In 2017, they had a circulation of 300,000-500,000 copies for approximately 1.4 million residents in the largest boroughs, thus reaching barely every household's letter box.

13 These are some examples of different neighborhood self-defense initiatives that I observed between 2013 and 2016.

14 In Moscow, the camps were held during several weeks as daily (mostly evening) open-air gatherings and debates in three major spots in central Moscow, with constant police restrictions and pressure.

15 For a detailed description of the research design and data set, see Bikbov (2012).

16 In response to the following open-ended question: "Which social issues do you personally consider most important in today's Russia?" By contrast, explicit questions on issues such as labor rights, immigration policies and social assistance frequently elicited replies such as "no particular opinion" or "have not reflected on that previously."

17 "This is not a rally of hungry people," said a historian, male, about 25 years old, repeating the dictum of a television presenter.

18 These interviews were recorded at a rally in Moscow on December 24, 2011.

19 The protestors' propensity for self-representation was indirectly confirmed by the fact that professional activists were unsuccessful in their attempts to create representative institutions for the protest movement. For a more detailed analysis, see Bikbov (2017).

20 Another sign of this functional division was that the "household" zone was physically fenced in, in order (the team members explained) to protect the belongings of the camp's permanent residents and to ensure that food was prepared in hygienic conditions.

\section{References}

Arkhiv postanovleniy. 2016. Arkhiv postanovleniy REK goroda Moskvy. Accessed September 27, 2019. http://depr.mos.ru/tarifs/archive-of-tariffs-for-communalservices-for-the-population-of-moscow.

Bikbov, Alexander. 2012. "The Methodology of Studying 'Spontaneous' Street Activism (Russian Protests and Street Camps, December 2011-July 2012)." Laboratorium. Russian Review of Social Research 2: 130-63. 
Bikbov, Alexander. 2017. "Representation and Self-Empowerment: Russian Street Protests, 2011-2012." Russian Journal of Philosophy and Humanities 1, no. 1: 43-54.

Byt'. 2015. "Byt' 'Aktivnym grazhdaninom': Anastasiya Rakova o rabote elektronnyh referendumov." Moskva 24 May 20, 2015. Accessed September 27, 2019. http:// m24.ru/articles/73786.

Dean, Mitchell. 2010. Governmentality: Power and Rule in Modern Society. London: Sage.

Duncan, James, and Nancy Duncan. 2004. Landscapes of Privilege: The Politics of the Aesthetic in an American Suburb. London: Routledge.

Editorial. 1988. Sotsialisticheskaya industriya. February 25, 1988.

Gabowitsch, Mischa. 2017. Protest in Putin's Russia. Cambridge: Polity Press.

Gorodskoy sovetnik. 2015. "Gorodskoy sovetnik. Aktivnyy grazhdanin." Ekho Moskvy November 8, 2015. Accessed September 27, 2019. http://echo.msk.ru/ programs/tochka/1653580-echo.

Ivin, Maksim. 2011. "Takova narodnaya volya." Za Kaluzhskoy zastavoy 43 December, no. 710: 2 .

Kuznetsova, Yuliya. 2002. "Ne tak strashna reforma, kak ee malyuyut." Moskovskiy komsomolets February 26, 2002.

Longhurst, Andrew. 2012. "Aestheticization and Consumption in Advanced Capitalism: The Woodward's Redevelopment as a Landscape of Class Power." Trail Six: An Undergraduate Journal of Geography 6: 2-15.

Pavlycheva, Olga. 2017. "A Public Hearing as a Form of the Public Participation in the Urban Planning." MATEC Web of Conferences 106, 01018 SpbWOSCE-2016. Accessed September 27, 2019. doi: 10.1051/matecconf/201710601018.

Pow, Choon-Piew. 2012. "Neoliberalism and the Aestheticization of New MiddleClass Landscapes." Antipode 41, no. 2: 371-90.

Vinokurova, Ekaterina. 2013. "Oppozitsiyu otfil'truyut ot Moskvy." Gazeta. ru June 5, 2013. Accessed September 27, 2019. http://gazeta.ru/politics/2013/06/ 05_a_5368573.shtml.

Voronov, Aleksandr, and Dmitriy Sidorov. 2015. “AAktivnogo grazhdanina' podozrevayut v fiktivnosti. V Mosgordume trebuyut otmenit' slushaniya v internete." Kommersant October 23, 2015. Accessed September 27, 2019. http://kommersant. $\mathrm{ru} / \mathrm{doc} / 2838141$.

Walks, Alan. 2006. "Aestheticization and the Cultural Contradictions of Neoliberal (Sub)urbanism.” Cultural Geographies 13, no. 3: 466-75. 


\title{
16 Guardians of Torfjanka Park
}

\author{
The fight for "our Moscow" \\ and the understanding of \\ "ordinary people" in the \\ current conjuncture
}

\section{Olga Reznikova}

Thousands of people in Nizhny Novgorod, Chelyabinsk, Krasnoyarsk, St. Petersburg, Ekaterinburg, Moscow and other cities in Russia have protested in the last ten years against newly built churches on land that was previously used as public parks or squares. These church building projects are a part of an aggressive policy of the Russian Orthodox Church (ROCH) that is implemented in close collaboration with local and federal governments. The ROCH sees the construction and reconstruction of churches as an important part of its mission of an "orthodox revival." Patriarch Kyrill has promoted this mission in numerous talks, arguing it is necessary to "revive Russian spirituality" after "communist tyranny." This revival is a part of the transformation of the Russian Federation into a post-secular formation. ${ }^{1}$ The city and references to the church's moral role in it figure crucially in this project: During a conflict in Ekaterinburg in May 2019, for example, the Patriarch's press secretary, priest Alexander Volkov, argued that "a Russian city without a church is not a city. It loses its essence, its substance, its backbone. It disintegrates, falls apart, it becomes some kind of stone jungle."

These church constructions were among the few issues that mobilized people in Russia to the streets in the years between 2013 and 2018. Local protests and disputes over the construction projects were intensified by corruption scandals involving the $\mathrm{ROCH}$ and news stories about the commercial usage of officially sacral buildings. This extensive, interregional fight has apparently hit a raw nerve of current Russian society.

These protests have a similar agenda and structure. It is important for most activists to emphasize that they are not against the Orthodox church, "only" against construction in green areas. ${ }^{3}$ They argue that the cityscape and quality of life will deteriorate and they make ecological arguments. In most cases, the moment of greatest outrage among protesters arises when the administration dismisses citizens' complaints and demands. In concert with other recent protests in Moscow (e.g., against the construction of shopping malls, the destruction of residential buildings and against the opening of welfare centers for homeless people), this has led to a critical rethinking 
of the role of local government and to new speaker positions: People living in the neighborhood of a conflict increasingly refer to themselves as mestnyj zhitel' [local residents]. This self-designation, which emphasizes the right of local people to have a say in matters that concern them locally, is also adopted in descriptions of these protests by other protest groups, journalists and researchers and circulates widely.

In this chapter, I examine one such protest against the construction of a church in a Moscow park and reflect on the political meanings of the visions of a good city and being an ethical subject in that context. The analysis is based on in-depth interviews with protesters, their opponents and other actors on a local and city scale, and long-term ethnographic participant observation (2015-2017). ${ }^{4}$ In the context of the wide-ranging literature on urban social movements, there are powerful frameworks to contextualize such protests and their political potentials toward a more just city. This wave of local protests in Moscow is directed against an authoritarian government and a conservative, religious social backlash, and it exhibits many of the features of protests that are usually theorized in rather optimistic and emphatic terms of the "right to the city" (Harvey 2008) or "urban commons" (e.g., Susser and Tonnelat 2013) or, on the other hand, through a critique of NIMBY activism (e.g., Devine-Wright 2009). However, I argue that they and their role in social and political processes cannot satisfactorily be described in these terms and typologies. Instead, these protests and the emergence of mestnyj zhitel' and prostoj mestnyj zitel' [ordinary local resident] as speaker positions and cultural-political figures should primarily be understood in the context of a contradictory conjuncture ${ }^{5}$ in the present historical moment, particularly in Russia, rather than exemplifying an overarching political force.

\section{Torfjanka, its "park guards" and "occupiers"}

Residents of the commuter neighborhood that surrounds Torfjanka Park in the North of Moscow have been protesting against the plan to build a church in this park from the summer of 2015 until today. The first attempt to begin construction occurred during the night of June $18,2015 .{ }^{6}$ Neighbors noticed that fences were being set up in the park. Residents came out and averted further construction. These residents later founded the activist group of "park guardians." On June 19, "orthodox activists" came to the park in order to shield the construction site and then stayed there for two years. Most of them were right-wing orthodox activists from the group "Sorok Sorokov," but also militant Cossacks and professional boxers organized by right-wing forces (Figure 16.1). Local residents noticed right-wing symbols, even swastikas. ${ }^{7}$

The "park guardians" of Torfjanka declared that their protest is directed against all types of construction in the park, including the construction of a church. In cases like these, land for a church is donated by city authorities 


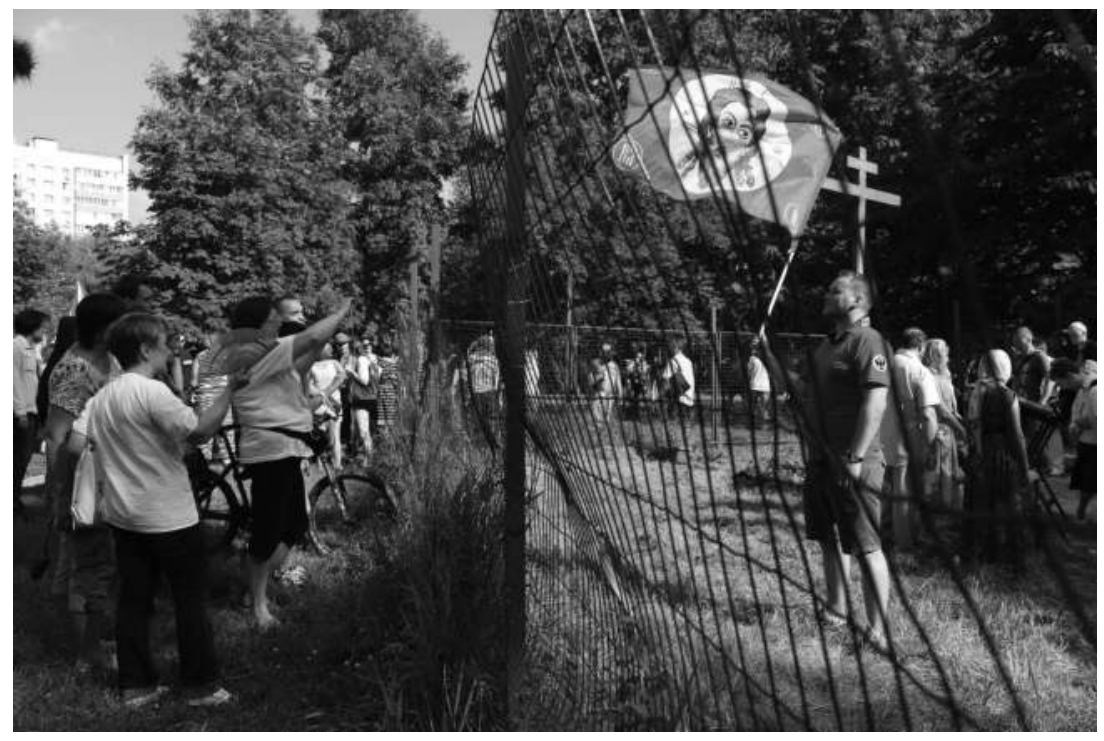

Figure 16.1 Confrontation between the "guardians of the park" and orthodox nationalists, June 26th, 2016, (Ute Weinmann).

and, after a few years, becomes the property of the ROCH. In the end, public spaces become clerical and privatized. The situation in Moscow is particularly virulent. The construction project in Torfjanka is part of the municipality's "200 Churches' or "Church in walking distance" program. This program was approved by the city government in 2012 and includes free land for 200 churches and financial assistance for sanitary facilities, communications, infrastructure and so on (Pinkevič 2018; Schnirelmann 2017). The Torfjanka protests soon received considerable attention in both the liberal and local press, most notably because of the confrontation between the zaščitniki parka ("guardians of the park") ${ }^{8}$ and their opponents, who began to call themselves zaščitniki chrama ("church defenders"). These confrontations often resulted in violence initiated by the latter and police detention of the former. Activists in other local protests in Moscow expressed their solidarity, mainly because the Torfjanka residents were "defending their park against the fascists."

The activists in Torfjanka combined a variety of strategies and tactics. They organized demonstrations and other protest actions (e.g., narodnye schody [popular/folk gatherings] in the park); they took "protest walks" in the park and through the center of Moscow; they led an information campaign and wrote about the problem to municipal authorities. They also took the legal route by addressing the prosecutor's office and filing a lawsuit. In 2015, they repeatedly confronted and blocked vehicles carrying building 
materials with a "shield" of their bodies and were able to prevent construction. From the perspective of the park protectors, their activities at the site itself were central. They organized watch shifts in front of the fence, staying around the clock in a small, homemade plastic tent, even in winter (Figure 16.2). During the early phases of the protest, their main practical concerns were to appropriate a part of the park with the tent and for gatherings, the surveillance and control of "what is going on behind the fence," 10 and physically preventing the construction work. Activists experienced many attacks by the police and right-wing thugs during that time. The tent was destroyed and then rebuilt numerous times. Later, at the end of 2016, activists moved into an old pickup truck, "GAZelle," where they continued to guard the site. Over a period of three years and, so far, successfully, local activists have managed to prevent construction. Such tenacity and long-term viability are atypical for this form of local protest, in Moscow and elsewhere. Torfjanka is a remarkable and, in some ways, singular case: It is one of the first widely discussed local protests in Russia; the long-term commitment has radicalized many activists, some of whom have taken up roles in local politics and other protests.

Several accounts of motivations for the protest were present in the group. Some protesters stated in interviews that this was primarily about ecological questions, because of trees being cut down for the church and green spaces disappearing. Some also professed the relevance of real estate prices that would decline due to new developments and smaller parks, that is, the potentially depreciating value of their property. For others, the protest was primarily about problems of corruption and represents a call for the rule of law, like in many other recent Russian protests. The protest was also, in

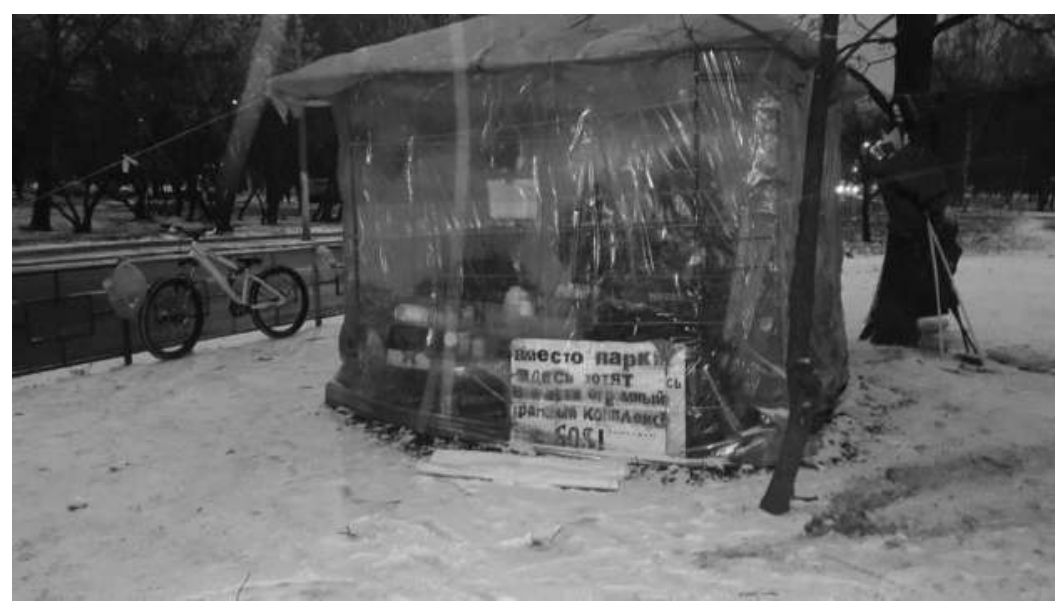

Figure 16.2 Watch shifts in front of the fence, November 15th, 2015. (Olga Reznikova) 
some ways, directed against the enforcement of religious, patriotic and neoconservative ideology, notwithstanding that some activists also supported an anti-orthodox Russian nationalism. The commonly shared argument of all "park guardians," however, was that Torfjanka was a unique park that belonged to local residents, it had to be guarded against construction projects and they had a right to decide about the park's future. While activists elaborated slightly different versions of this argument over time, the first mobilization emerged from the residents' strongly affective response to the initial events. A 76-year-old participant, Anna Kirilovna, ${ }^{11}$ called "Aunt Anja" in the group, for instance, remembers the first night of the protest as follows: "We all came out [from the apartments]. It was a very strong feeling. Rage and rage again. Our park would be occupied".

"Occupy" is a crucial, evocative word that, in the context of the Torfjanka protests, has primarily two meanings. On the one hand, it connotes narratives about the "Great Patriotic War" (World War II). In that sense, when protesters talk about occupation, the men behind the fence are associated with "German fascist invaders." This implies a struggle over the park as "soil" and a defense of one's soil based on national belonging, which is transferred to the local level. On the other hand, "occupy" is used positively for the activists' own actions, similar to other protests in which public squares or buildings are "occupied" and "occupy" becomes a shorthand for a type of protest. In that sense, the places where the activists set up their tent or held meetings and protest walks were also understood as "occupied spaces." The word and similar themes surface in other interviews as well, and they also play a prominent role in spontaneous slogans, appeals and speeches during the demonstrations and in the "protest ditties" that activists wrote and sang in the evenings. These usages of "occupation" illustrate an ambivalence of the local protest and the goal of "protecting our park" in a more general sense: For protesters, the park needed protection as a public space. In that sense, "our" means that it was owned by ordinary people, rather than elites and institutions. At the same time, it suggests that an "occupied" park is defiled by "enemies from the outside," outside here being defined as not living in the neighborhood, so that the first-person plural refers to a territorially exclusive self, in analogy with state territory. I will return to these dialectics of spatio-political inclusion and exclusion below.

In this regard and more generally, Torfjanka illustrates tendencies prevalent in many local urban protests. In these protests, for the first time in the history of post-Soviet Moscow, public space is conceivable as a space for overt, longer-term political contradictions and struggle (see Erpyleva 2019). The current local protest movement can be seen as an answer to neoconservative policies of the government and church during the current political and economic crisis. It also is shaped by its complex relationship to a wider landscape of opposition. The remainder of this chapter elaborates two aspects of the Torfjanka protest to explain what this entails: (a) the speaker position and subjectification of the activists in Torfjanka as nonpolitical "ordinary people" 
and, closely related, the creation of public space in the course of the fight for the park; and (b) the motif of "roots" in the context of controversies and arguments about Moscow as a "good city" from the protesters' viewpoint, which relates to emergent understandings of locality in the Torfjanka group.

\section{Social protest by ordinary people and the question of politicization}

A sense of locality is produced in the Torfjanka protests primarily by emphasizing the "ordinariness" of the "park guardians." Protesters publicly and in internal communication stressed that they understood themselves as prostye ljudi [ordinary people] or prostye mestnye žiteli [ordinary local residents], "ordinary Muscovites" who care about "their park." The fight against "occupiers" is staged as an explicitly unpolitical issue. Not being political was crucial in defining the "common agenda" amongst residents of the neighborhood who otherwise held highly discrepant views on religious and political matters and ideologies.

These statements resonate with a broader context: The "politicization of ordinary local residents" is presented critically in the pro-government press as an "instrumentalization" of dissatisfied ordinary people by opposition parties or foreign forces. The question to which extent local (or also workers') protests were politicized (or could become politicized) was and continues to be prominent in oppositional media and critical protest movement research. Anti-Putin activists and opposition members, who speak out against war and repression, and focus on political representation, placed great hope for democratic transformation on the "politicization of ordinary people." 12 Opposition leaders tended to evaluate local protests (but also worker or ecological protests, which they summarize as "social protests") ${ }^{13}$ according to the degree to which the prostoj narod ["ordinary people," but also "ordinary folk"] are and can be "politicized," that is, critical of Putin and the power structure, rather than by how vital their actual problems and demands are. The intelligentsia's old dream of creating "one big movement," an alliance between narod [the people/folk] and intelligentsia against vlast' [the state/state power], reappears in a contemporary guise in this idea of "politicization." In the current conjuncture, however, this alliance is complicated by a primarily negative, anti-populistic sense of "ordinary people" among the intelligentsia, where local activists and workers are generally suspected of being pro-Putin, indoctrinated by television and in need of education and enlightenment. Different ideological positions and interests are pragmatically held together against the "Putin system" in the political opposition itself, that is, among those who organize and regularly attend anti-government protests. Uniting all "social protests" and the political opposition remains a general aim among those who subscribe to the anti-Putin consensus. "Popular" social problems addressed by local protests almost inevitably remain invisible within this consensus. 
Such discussions take place in the context of not only the failure of the political opposition to challenge Putin and his government during that time but also economic crises and declining living standards. From 2015 to 2018, demands for social justice and local matters played a much more critical role in the landscape of Russian protests than they had in the years before when there were larger anti-Putin mobilizations. ${ }^{14}$ Ensuing discussions about the relationship between "social protests" and "political protests" went along with this shift in the agenda from political representation to social and local concerns. On the other hand, "political" and "politics" are negatively connoted terms within local, "social" protests. In terms of coalition building, it is important for many who protest about specific issues in their neighborhoods or at the workplace to separate protests with a local agenda or other social demands from protests with a general agenda "against Putin." This is true for Torfjanka activists as well: They resisted attempts by different political activists to create an alliance and to "politicize" them. In their internal discussions, activists were strongly concerned about "being used." "It's not about something big, it's about our little problem," a Torfjanka activist commented (interview, September 2015). They associated the world of "politics" (government, parties, activists with "political demands") with manipulation, corruption and dirt. In that sense, "local activists" and members of the political opposition movement share a view in which the local agenda is "below" the agenda of political protesters, but they judge this differently.

Considering the British case, John Clarke (2010a, 2013) has analyzed "ordinary people" as an object of governmental desire and discussed this figure's relationship to politics and populism. Observing similar narratives to those outlined above, he notes that the figure of "ordinary people" appears as simultaneously "above" and "below" politics. Clarke shows that this aversion to politics and politicians is embedded in a discourse of antielitism that can be used by "regressive populists" who rhetorically valorize and compliment "ordinary people" because they are "not political" and keep a distance from "actually existing politics" (Clarke 2010a). The rhetoric of the Putin government and Moscow City administration is similar to that of Clarke's "regressive populist," in that it valorizes ordinary people by contrasting them to misled "political activists." In the Russian case, state propaganda resonates with widespread complaints in local and social protests about liberals and political activists as "manipulators" intent upon instrumentalizing ordinary people. Today's references to "ordinary people" also evoke the expression "ordinary soviet people," 15 who are widely understood as not being against the government per se and by no means dissidents. However, in the current moment, belonging to the "ordinary people" means, first of all, to define politics through rejection. In that context, the strong distinction and hierarchy between "local/social protests" and "political protests" made by anti-Putin liberals activists and their emphatic notion of the political unwittingly reinforce this populist definition of "ordinary people." 
However, I want to argue that the terminology of the political cannot simply be given up when speaking about protests like that in Torfjanka. Regardless of this figuration of emic understandings of the (un-)political, the figure of the mestnyj zhitel' can be vital for understanding the transition between the pre-political and the political in a different sense, as elaborated by Hannah Arendt $(1958,1965)$. In her view, the political is created through acting (deed, action, and speech) in public space. The precondition for a political act is the possibility of interacting with different others about issues that are negotiable and critical for various individuals. This means that to deal with such matters connects people and separates them, which for her is the crucial characteristic of public space. Arendt mourns the loss of a sense of public space in modernity. According to her, the reason for this decline is that people no longer care about the political and the connections to (and separation from) each other.

In a concrete sense, to be "ordinary local people" in the Torfjanka protest camp was also a way to define a park as a public space. The latter made it possible to have exchanges between people regarding, among other issues, the effects of the conservative clerical turn in Russian society. Women's meetings took place regularly in September 2015 during night shifts. There, activists discussed the experiences of the older generation of women who had had abortions and the fear of moral judgment regarding abortion and sexuality prevalent in the younger generation. This is "political" in Arendt's sense but not "politicization" as envisioned by liberal opposition politicians. This form of discussion and solidarity became possible only in the context of the Torfjanka activists' fights against the privatization and clericalization of the parks and their creation of public space. Here, public space indeed serves as a place for the articulation of the idea of society as it should be.

\section{"This is our park": the role of "roots" in the definition of a good city}

The Torfjanka "park guardians" by representing themselves as "local residents," as "active" people who challenge city authorities, as people who are no longer passive, give a lot of importance to the local, urban arena and, in a sense, they create not only public space but also the city as something to fight over and for. However, and maybe counterintuitively, this is often connected with a nostalgic imagination of Moscow as a village-like city.

In the summer of 2015, activists had placed the protest tent at the entrance of the park. Because of their concern that at any given moment, construction materials would be delivered and the church would be built, the tent had to be occupied continuously. Twenty-four hours were segmented into six or seven shifts, each with at least three people. My calculation is that approximately 300 people were "on duty" at least once. In the evening, more people came to exchange news, to solve organizational problems and to chat; some stayed longer to join friends on duty at night. These were 
unusual, neighborly encounters, as many remarked, illustrating the sense of a public space and becoming-political in Arendt's sense. Between July and September 2015, I took over three or four shifts per week, supporting the protest, doing participative observation and becoming acquainted with protesters' backgrounds and the ways in which they theorized their own actions and collectively established their meanings. Importantly, it was not until after the ROCH's attempt to build a church and, thereby, privatize common space that the park became a crucial symbol of belonging for many residents. One participant, for example, explained this in an interview.

OR: You said, "our park." You, but also other activists use this label (...). What does it mean?

VERA: I never thought about this before, what this means, "our park," why it is important. The park was always there. And now, I understand this is important, that we have our park, for everyone, not only for the people who have PGM [literal: "orthodoxy of the brain," an expression used by atheists to ironically refer to the beliefs and supposed thoughtlessness of the followers of the orthodox church as a pathological syndrome]. I have lived here for more than 30 years. My daughter's whole life has been here. My granddaughter was born here. And the children used to climb trees here (...). The children skied and went sledding in the winter here (...). I was a single parent and my daughter also. But the trees in the park were like second parents for the children.

Vera Alekseevna, a 50-year old activist, held watch shifts four times a week and stopped by the tent almost every day in the first year of the protest. In the interview, she emphasized twice that only the confrontation and protest have shown her that the place is a public place (she used the world obšcestvennoe mesto, which can be translated as public or as commonly owned place) and that it must stay one. Again, it should be stressed that these claims are a new situation for Russian cities. Vera and her story illustrate the personal and biographical depth of such claims (Figure 16.3).

After perestroika, Russians cities underwent a process of privatization of public estates where assets were given to the elite, to institutions (such as the $\mathrm{ROCH}$ ) and, in the case of apartments, to the broader population, whom it helped deal with the upheaval and economic decline of the 1990s. Like other Moscow residents, many Torfjanka protestors own privatized apartments that they or family members had lived in during Soviet times. Following the analysis of sociologist Michael Burawoy (2001), privatization in Russia during the 1990s led to a broader and quite brutal societal, economic and cultural "great involution." Burawoy uses this term to indicate that transition to market economy did not mean transition to democracy. In that situation, people were so busy with their survival and the wider upheaval that they did not care much about public estates or public spaces. Burawoy links the apparent depoliticization of post-Soviet Russia to the political transition from the party-state 


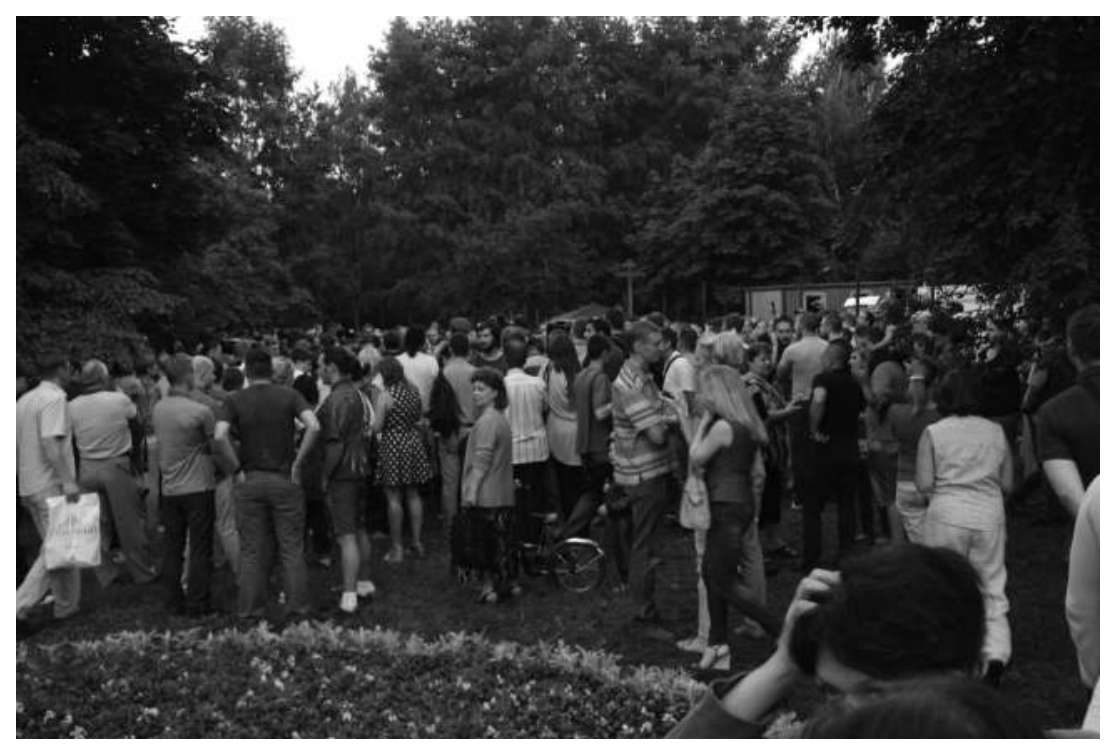

Figure 16.3 Gathering against the construction of the church, July 11th, 2015. (Ute Weinmann)

to what he calls a form of "neo-feudalism." The effects of this are still relevant; Moscow still cannot be wholly understood as a neoliberal city because it is also, structurally, a neo-feudal city: Similar to other cities in Russia, the political elite, to some extent, treats Moscow as its property, particularly as the property of the mayor and his family. This political-economic context is crucial also for the meanings of these subject positions and cultural figures.

References to the local in local protests revolve around the new urban figure mestnye ziteli [local residents], as I have shown, but they also intersect with the interpellation of the city dwellers as activnyj graždanin [active citizen] by the city administration: Whereas mestnye žiteli are figured as ordinary people who fight for the right to have a voice at the municipal level, the city's digital program activnyj graždanin offers residents the opportunity to vote on small issues or to voice complaints. In that sense, this program-like other "quality of life" projects for a "better" Moscow - is intended to provide an answer to such challenges. This constellation illustrates Moscow urban politics' "non-simultaneity,"16 as activnyj graždanin can be understood as a typically neoliberal responsibilization and activation strategy where a demand for communal representation overlaps with techniques of effective governance (see Clarke 2013). However, the results of the vote in Moscow are constantly distorted in the interests of the city's quasifeudal political elite, as they were in this case as well. ${ }^{17}$

These ambiguities of the local have another important aspect, the prominence of the idea of rootedness, organic belonging and the references to 
legitimate privileges of those who are locally established. In the quote above, for example, Vera talks about the trees in the park that have played the role of a second parent for her children. Trees and roots are significant and complex metaphors for the Torfjanka activists in general; the same is true for other local initiatives against construction projects. Trees in parks, for example, as activists stated, can be seen as necessary not only for ecological reasons but also because they prevent the city from further "overfilling." In narrations about the "good city," trees are often seen as a symbol for a time when the city did not "have so many people" and its residential areas had a village-like character. ${ }^{18}$ Speaking about trees can also provide a metaphor for speaking about one's own "roots" as local residents. In one conversation, for example, Maxim Koršunov (a 45-year-old activist) complained: "It is important to have roots, and now they [the city administration, but also the 'powerful people'] try to uproot us (...) Then soon, all of Moscow will be renewed, and then only 'rootless' people will live here" (August 2015).

In the following excerpt, Maxim and Maria elaborate on this.

MAXIM: Do you want to research about what "a good city" is?!

OR: Yes, I am researching about social protests in Moscow. And I'm interested in how you imagine and describe Moscow as a good city.

MARIA: I think good Moscow existed in the Soviet time ... Not all the people could come here, because the city was closed [Maria refers to controls on internal migration from the periphery]. ${ }^{19}$ It was a city for Muscovites. Really for us, not like now.

MAXIM: Or more specifically, the city belonged to us.

OR: What does this mean?

MAXIM: You asked what the "good city" is. The good city is our city! A city where the Muscovites make decisions ${ }^{20}$ where municipal policy is oriented towards their [Muscovites'] needs.

OR: Did I understand you correctly? Your idea is that the city should be closed to migrants and that the hard propiska [residence registration in the Soviet Union and in Russian Federation regulation] would be implemented again. Isn't it?

MARIA: Yes, of course!

MAXIM [NOT AGREEING WITH MARIA ENTIRELY]: It is not about migrants per se. Our concern is, we are living here, and the city administration has to organize life here comfortably. [...] We would like to have clean air; we would like to have our land, our parks and normal infrastructure.

There are numerous and shifting references, antagonists and priorities in such conversations. The Mayor of Moscow, Sergey Sobyanin, for example, whom Maxim indirectly referred to when he spoke about the municipality, was usually assumed to be corrupt, but also to "deal in the interests of migrants," not in the interests of "rooted Muscovites." His origins from an "ethnic," not primarily Russian, province was often pointed out in that 
context. In the new political subjectivation as "local resident," then, people become (or make themselves) responsible for their local community and they lay claims to public space and democratic rights. In Torfjanka, it primarily stood in opposition to the "occupiers" from the outside but also, as in Maxim's statement, to people who "don't have roots" or "don't have roots in Moscow." Other than politicians from peripheral regions, the groups that local activists cast in these roles were migrant workers and Jews, in some cases explicitly, in line with racist and anti-Semitic imaginaries. Residents of a workers' hostel in the vicinity, most of whom were labor migrants, were eyed suspiciously and sometimes seen as a security threat, as were migrant street cleaners working for the city ${ }^{21}$ and Jewish protest activists. While many protestors did not advocate such views in explicit terms, pejorative references to "rootless" people, or people that are "not rooted in Moscow," were so dominant a theme in these discourses that I do not think these evocations of the rights of "local residents" can realistically be separated from them, even if such a disarticulation would, of course, be conceivable. Torfjanka is not a particularly exceptional case in this regard, however. I encountered similar sentiments and rhetoric in different protests with a comparable structure, that is, a strong emphasis on "ordinariness" and spontaneous, affective mobilization.

\section{Conclusion}

Such observations should hamper political enthusiasm about localist claims to the commons and the "good" city. They should not be downplayed, as I believe they often are in the urban social movement literature, even if they can also be countered in such protests. The point I want to focus on in the end, however, is not to measure the Torfjanka protests with a catalog of "-isms." Instead, I want to return to the question that motivates my overall research in Moscow: What these urban protests and their visions of the "good" city tell us about the conjunctural circumstances in contemporary Russian society? What is going on when people protest passionately against the construction of a church in a park for four years, are beaten up but consistently return? What are they doing when they develop a concept of a "good" urban life as local citizens? How do the locals imagine "their city" and its roots?

It must be stressed that local residents here are primarily calling into question clericalization, the privatization of parks and squares, and authoritarian structures. In doing so, they recreate a democratic concept of urban citizens where subjects collectively negotiate important issues (the role of the church, ecological responsibility, participation in local planning, the powers and responsibilities of citizens) with other local citizens whom they consider their equals. In this, they advocate progressive values, open up spaces for debate and can be seen as a force of civil society empowering itself against the state in the context of the neoconservative turn. However, this "equal" subject's power to act ethically and politically is also based on categorical 
hierarchies and exclusions. It is predicated on exclusions of people who do not have to have a voice - in this case, especially non-Russian migrants. In this sense, it is neither surprising nor coincidental when references to equality and the creation of a place of contestation and negotiation are inseparable from references to and institutionalization of "roots," from which the right to participation is drawn. In the absence of critical challenges, political citizen-subjects, like those constituted here, require counter-figures, such as Jews and migrants.

These arguments should be considered together with the difficulties of establishing articulations with other movements that could potentially counteract these problems of localism. This is the bad news about today's conjuncture in Russia: Serious struggles against the neoliberal and/or neo-feudal transformations in Moscow mainly have two positions: (a) The anti-populistic one of the "political" opposition, which has a strong promiddle-class bias, and (b) the creation of ethnically inflected vocabularies of "ordinary people" for the articulation of local concerns. Moreover, the understanding of active, local citizens that was shaped in that context comes quite close to the understanding of the active citizen that the city has propagated in order to facilitate more modern forms of governing under a neoliberal paradigm, even if there are many frictions. The good news is that in the present conjuncture in Russia, local activists have turned spaces of the city into valuable, emphatically public (and secular) places for which people are ready to fight. Russian cities, thus, constitute a concentration of conflicts with an open-ended outcome. This is a necessary, if not sufficient, condition for an emancipatory movement.

\section{Acknowledgments}

The author would like to thank Christian Noß, Vildan Seçkiner and Carol Del Vitto for their thoughtful comments on earlier drafts of the chapter and to Ute Weinmann for permission to use her photos.

\section{Notes}

1 One notable landmark for this transformation is a meeting between President Vladimir Putin and members of the Council of Bishops on February 1, 2013. In this meeting, the President talked about the necessity of backing out of the "vulgar understanding of secularity" and the need for expanding the power of the ROCH in society (see the video of the meeting at http://kremlin.ru/events/president/news/17409/ st, accessed June 12, 2019). For more about the question of the transformation of secularity in the Russian Federation, see Lunkin (2017) and Pinkevič (2018).

2 See the interview with him under https://ria.ru/20190528/1555044209.html, accessed June 3, 2019.

3 Many banners in Ekaterinburg's city square (2019), in the Torfjanka Park in Moscow (2015-2019), in Chita (2016) and in many other places have a similar statement: "We are not against building a church, we are against building a church on the green area." 
4 Research was funded by the German Research Council (DFG) as a sub-project of the research group "Urban Ethics" (FOR 2101) on the urban ethics of protest and the violence of ethics in Moscow (EG 371/1-1); the project was supervised by Moritz Ege at the University of Göttingen.

5 For discussion about conjunctural analysis, see classically Stuart Hall et al. (2013), and the new discussion driven by John Clarke (2010b), Moritz Ege and Alexander Gallas (2019), Jeremy Gilbert (2019), und others.

6 In 2013, Moscow's mayor, Sergey Sobyanin, signed a resolution on the church construction in Torfjanka. A small group of activists started a petition and litigated against the decision at that time, but most of the locals were surprised about the construction work on this day.

7 "Sorok Sorokov" is a Moscow right-wing orthodox group. Like other similar groups, it does not officially act on behalf of the ROCH but is financed and informally supported by it. The name can be translated as "Forty times forty," which means that members of this group want to have 1600 churches in Moscow "again." The group was formed in 2013 by Andrej Kormuhin in Novospassky Monastery. On behalf of the monastery, he recruited dozens of professional boxers for the physical enforcement of the construction of new churches. The group is also partially connected with a small militant right-wing group that acts violently against migrants and anti-fascists under the name of "Molot" (Hammer), and generally with the right-wing scene. "Sorok Sorokov" positions itself as "orthodox patriots," using symbols from a mixture of German Nazism and the Russian right-wing movement with references to neo-pagan and orthodox symbols at the same time. For their own purposes, they do not exclude physical confrontation with "enemies of the Orthodox Church." Activists from Torfjanka were the first who noticed the problem and went public with it. "Sorok Sorokov" became famous for their activity in Torfjanka but was also involved in confrontations about the building of churches in several other places in Moscow (2016/2017), Nizhny Novgorod (2019) and Ekaterinburg (2019), and it supported the war in Ukraine, in which some of its members were involved. This note is based on the analysis of the investigations of activists from the group "For the Park of Torfjanka" (online at https://vk.com/park.torf2016, accessed September 23, 2019), as well as collected materials of Mitrokhin (2015) and my press review of $2015 / 16$. For an overview of the relevant right-wing actors close to $\mathrm{ROCH}$, as well as for the analysis of the contradictory relationship to the government, see Nikolai Mitrokhin (2006) and Victor Schnirelmann (2017).

8 The "orthodox activists" and official ROCH call the local activists bogoborzy [God-fighters]. Protestors initially fought against this insult. However, later, it was ironically reclaimed by some activists as a self-designation.

9 This is what an activist from an initiative against the construction of a sports complex in Moscow "Park Družby" called the Torfjanka activists in an interview with me (September 2015). This view can be considered as typical for other local Moscow protests.

10 A quotation from the interview with an activist a month after the beginning of the protest.

OR: "What is the most important thing now?"

ALENA: "To know what is going on behind the fence [she laughs]. To know, then we can act."

Behind the fence, the right-wing groups were continuously present, often insulted local activists and attempted to deliver the building materials. In addition, on Sundays, a priest and some parishioners from the neighborhood also attended self-organized "public prayers." The rest of the time, they stayed in a construction wagon around the clock. After half a year, the heated confrontation phase 
between "park protectors" and "orthodox activists" ended and they visited each other in the respective camps.

11 I use pseudonyms here and throughout the text.

12 For discussion of the critical sociology and cultural studies, see about local protest and direct democracy: Clément and Zhelnina (2020), Erpyleva (2019), and Zhuravlev et al. (2020).

13 The most relevant discussion occurred when truck drivers went on strike (20152017). Discussions about the ecology and the city evolved among others regarding the protests against waste dumps in the Moscow region. On the politics of terminology, such as "social" protests, see also Reznikova and Ege (2019).

14 For statistics, see Bizjukov (2016).

15 Prostoy sovetskij čelovek [ordinary soviet people] refers to the pre-revolution expression malen'kij čelovek [small people] and denotes the soviet population, people who were seen to be free from capitalist suppression in the new socialist era and heroically managed their everyday life.

16 The expression "non-simultaneity" was coined by Ernst Bloch (1985), who tries to explain German "backwardness" and defines the "non-simultaneity" as a general characteristic of modernity. In view of 21st-century Russia, I use the term to refer to the simultaneity of neoliberal and neo-feudal forms of government.

17 The city government tried to solve the conflict in Torfjanka through the program called activnyj graždanin. In September 2015, a digital poll was announced. Many protesting mestnye žiteli of the neighborhood were against this poll because it only offered the options of choosing between building the church in Torfjanka or in another place (in Anadyrskij Proezd). Most, nevertheless, participated. The results and the decision of the Moscow authorities were announced in October 2015: The new church construction was allocated to Anadyrsky proezd, where, in 2016, a temporary, quickly erected wooden church of St. Macarius was built. However, after that, the fence in Torfjanka was not dismantled and the land transfer from the city to $\mathrm{ROCH}$ was not annulled.

18 The negative nickname of Moscow as a "big village," which was used in the 19th and 20th centuries mainly in the context of comparisons between Moscow and St Petersburg, is now appropriated by some local activists as a nostalgically description for "lost Moscow."

19 About continuity and fractures of Russian migration policy, see Malachov and Simon (2018).

20 In the course of the conversation, Maria also speaks about rights to the city of korennye moskviči [rooted Muscovites], people whose grandparents lived in Moscow.

21 The gatherings in the protest tent were also sometimes used to discuss "controlling the quality of migrants' work in the neighborhood." Two people of the group in summer 2016, for example, regularly controlled the cleaning work on the stair landing or leaf picking in the park and entered into conflicts with the workers.

\section{Bibliography}

Arendt, Hannah. 1958. The Human Condition. Chicago: University of Chicago Press. Arendt, Hannah. 1965. On Revolution. London: Faber \& Faber.

Bizjukov, Pjotr. 2016. "Trudovye protesty v Rossii: pričiny, formy, aktory." Vebinar Yabloko. Accessed June 3, 2019. https://www.youtube.com/watch?v=aPKyxGQ8Bik. Bloch, Ernst. 1991 [1935]. Heritage of Our Times. Cambridge: Polity.

Burawoy, Michael. 2001. "Transition without Transformation: Russia's Involutionary Road to Capitalism.” East European Politics and Societies 15, no. 2: 269-90. 
Clarke, John. 2010a. "Enrolling Ordinary People: Governmental Strategies and the Avoidance of Politics?" Citizenship Studies 14 (6): 637-50.

Clarke, John. 2010b. "Of Crises and Conjunctures: The Problem of the Present." Journal of Communication Inquiry 34, no. 4: 340-1.

Clarke, John. 2013. "In Search of Ordinary People: The Problematic Politics of Popular Participation.” Communication, Culture \& Critique 6: 208-26.

Clément, Karine, and Anna Zhelnina. 2020. "Beyond Loyalty and Dissent: Pragmatic Everyday Politics in Contemporary Russia." International Journal of Politics, Culture and Society 33, no. (2): 143-162.

Devine-Wright, Patrick. 2009. "Rethinking NIMBYism: The Role of Place Attachment and Place Identity in Explaining Place-protective Action." Journal of Community and Applied Social Psychology 19, no. 6: 426-41.

Ege, Moritz, and Alexander Gallas 2019. The Exhaustion of Merkelism: A Conjunctural Analysis. New Formations 96 (Special Issue: This Conjuncture): 89-131.

Erpyleva, Svetlana. 2019. "The Local Activism in Russia: Biography, Event and Culture." Academic dissertation at Helsinki University, online at: Accessed June 10, 2019. https://helda.helsinki.fi/bitstream/handle/10138/301023/THENEWLO. pdf? sequence $=1$.

Gilbert, Jeremy. 2019. “This Conjuncture: For Stuart Hall.” New Formations 96 (Special Issue: This Conjuncture): 5-37.

Hall, Stuart, Chas Critcher, Tony Jefferson, John Clarke, and Brian Roberts. 2013. Policing the Crisis: Mugging, the State, and Law and Order. New York: Macmillan.

Harvey, David. 2008. "The Right to the City.” New Left Review 53: 23-40.

Lunkin, Roman. 2017. "Svetskost' kak oružie. Začem v Rossii chotjat peresmotret" osnovy svetskogo gosudarstva?" InVictory October 13, 2017. Accessed June 3, 2019. http://www.invictory.com/columns/2816/.

Malachov, Vladimir, and Mark Simon. 2018. "K genealogii migrazionnoj politiki v Rossii: Stolknovenie dvuch pravitel'stvennych razional'nostej." Voprosy teoretičeskoj ekonomiki 1, no. 2: 58-72.

Mitrokhin, Nikolai. 2006. Russkaja pravoslavnaja cerkov': Sovremennoe sostojanie $i$ aktual'nye problem. Moscow: Novoe literaturnoe obozrenie.

Mitrokhin, Nikolai. 2015. "Rokovye Sorok Sorokov." Anticompromat. Accessed June 2, 2019. https://anticompromat.org/tserkovniki/40_sorokov.html, last visited 02.06.2019.

Pinkevič, Vasilij. 2018. "Transformacija ponjatija 'svetskosti' i graždanskij activism." ITNOW 3: 82-7.

Reznikova, Olga, and Moritz Ege. 2019. "Ethische Politik oder moralische Ökonomien? Arbeiter- und Mittelschichtsproteste in Moskau." In Wirtschaften. Kulturwissenschaftliche Perspektiven, edited by Karl Braun, Johannes Moser, and Claus-Marco Dietrich, 343-54 Marburg: Philipps-Universität Marburg.

Schnirelmann, Victor. 2017. "Oskorblenie čuvstv: nepredvidennye posledstvija odnogo zakona." In Religii i radikalism v postsekuljarnom mire, edited by Elena Filippova and Jean Radvanyi, 280-91. Moscow: Gorjačaja linija - Telekom.

Susser, Ida, and Stèphane Tonnelat. 2013. "Transformative Cities: The Three Urban Commons." Foccal 66: 105-21.

Zhuravlev, Oleg, Natalia Savelyeva, and Svetlana Erpyleva. 2020. "The Cultural Pragmatics of an Event: The Politicization of Local Activism in Russia." International Journal of Politics, Culture, and Society 33, no. (2): 163-180. 


\title{
17 "They are stealing the state" Commoning and the Gilets Jaunes in France
}

\author{
Ida Susser
}

In the context of the political polarization in Europe following the 2008 recession, the extreme right has been energized, while new progressive parties have also been formed. Analysts have described changing global relationships and the massive impacts of financialization (Kalb 2015; Smith 2011). However, there is a need to investigate the social transformation in the practice of democracy that may be occurring. We need to understand the efforts of young people and others who are occupying squares, similar to \#OccupyWallStreet in the United States, 15M in Spain or Nuit Debout in France. These have been widely regarded as progressive movements or organizations of the left (Casas-Cortés et al. 2014; Castells 2012; Milkman 2014; Susser 2017; Susser and Tonnelat 2013). Here, I concentrate on the Gilets Jaunes protests of 2018/2019, which include all generations from youths to middle-aged people and pensioners, many from the provinces and the urban peripheries of France, joining mass demonstrations in the streets of Paris. Where do they fit in an analysis of alternative democratic processes in this polarizing moment?

I focus on what I and others have called "commoning" (Stavrides 2015; Susser 2017), to consider the ways in which these forms of contestation may be transforming urban ethics and reconfiguring democracy. ${ }^{1}$

First, how do we understand contemporary efforts at progressive social transformation? Is there a new political bloc or a working class with consciousness or agency emerging? To answer these questions, we might turn to the work of an earlier generation. These are some of the questions that were raised by British social analysts when they formed the New Left Review after their disillusionment with the Soviet Union (Susser 2016). In their search for the analysis of new social formations, Stuart Hall, E.P. Thompson, Raymond Williams and Eric Hobsbawm, among others, drew on Gramsci (1971) and his writings on folk culture and the question of the formation of a new political bloc. Hall and Thompson both followed Gramsci's fluid discussion of political blocs and the dialectical interactions of culture and class formation (Hall 1986; Thompson 1963).

Gavin Smith (2011) asked a key question about the form of revindication movements under the contemporary regime of financialization. He asks 


\section{Ida Susser}

how social movements were structured in terms of what he calls "selective hegemony." Smith sees the latter as a reconfiguring of the state directed against the narrowing of inclusiveness accompanying financialization. This might be understood in terms of the shredding of the welfare state and the abandonment of marginal groups, such as immigrants. Thus, Smith rethinks the concept of governmentality in terms of regimes of accumulation. However, as I mentioned in a comment on his article (Susser 2011), he focused on the processes of financialization rather than new forms of class and agency. Today, faced with an array of protests and social movements, how do we theorize agency or possibilities for social transformation within financialization and the accompanying narrowing of the state?

\section{The precariat and austerity: fragmentation and cohesion among subaltern groups}

Guy Standing (2011) theorized a group he labeled "the precariat" as a new social formation resulting from the long-term changes regarding work and inequality. In contrast to a definition of precarity which "speaks to conditions that threaten life beyond one's control" (Butler 2009, i), analysts of the precariat focus on agency and, for example, the ways in which refugees and immigrants may try to build a movement across citizenship lines by linking their situation to the contemporary insecurities of capitalism (Jørgensen 2016).

Standing sees the precariat as composed of three distinct groups of insecure workers - migrants, the dislocated industrial working class and educated underemployed youth (2011) - and the Occupy movement as providing a crucible for the recognition of a class of precarious workers incorporating these three groups. He has been accused of papering over the differences between educated middle-class youth, poor migrants and members of the displaced working class. Scholars note that he includes a grab bag of disconnected groups in his definition with no particular relationship to the means of production and lacking any agency for change (Means 2017; Seymour 2012). In addition, critics argue that although the educated, underemployed youth may no longer be protected by the benefits of the welfare state, they are still able to strategize as entrepreneurs with start-ups or artists in an artisanal space (Scott 2017). With elite educations and some financial backing from families, they retain the options and aspirations to achieve in the contemporary regime of capitalism. Nevertheless, a lot of literature suggests that the squares are mainly populated by underemployed millennials (Casas-Cortés et al. 2014; Milkman 2014).

Other researchers have noted that precarity has been the ongoing experience of working people in capitalism, and the affluent worker of the welfare state was the exception. In this case, the movement among the "precariat" can be seen as composed of postindustrial insecure workers who were recently stably employed in industrial society along with women and 
minorities who had never been given much opportunity for security (Federici 2012). At this point, it may be more useful to talk of subaltern groups, the culturally diverse disadvantaged groups analyzed by Antonio Gramsci (1971; Hall 1986).

Rather than assume, as Guy Standing has suggested, that particular sectors of precarious workers form a cohesive political group that could be called a precariat, I prefer to trace a wide variety of subaltern groups, some of whom may be defined as the precariat, to explore whether they are forming a new political bloc (Gramsci 1971).

Austerity policies can be seen not simply as a consequence of the Great Recession or corporate corruption but rather as a reflection of the widespread destruction of a particular kind of state (Smith 2011). The modern industrial state underwrote the corporate world by subsidizing the education, health and stability of a large proportion of workers. The traditional working classes in the centers of capital no longer have the power to maintain the benefits that they fought for throughout the 19th and 20th centuries. Such traditional workers' struggles established the particular forms of social reproduction originally reified in the welfare state. The idea, for example, of "a fair day's wage" encompassed the costs of the patriarchal, heterosexual family for the reproduction of men with their wives and children. Thus, the stable working class emerged alongside and in interaction with lower and precarious standards of reproduction for minorities, migrants and other historically subordinate groups and women, as well as the uneven development of colonialism. The flexible economy (Harvey 1989), including the exportation of industry and the deregulating of manufacturing and civil service work, often through subcontracting, not limited to the gig economy, has been long in coming. A new working poor has been recognized since the 1990s (Susser 1996). The question now is whether a new working class is fighting for the regulation of work in the flexible workforce.

The emergence of different forms of social movements can be seen as an attempt to redress the assault on customary living conditions, life cycle security and aspirations. I would suggest that this is also an attempt to redefine workers to include the previously neglected minorities as well as new family and identity configurations. The new forms of worker protection will have to consider new forms of relationships within families and new kinds of work/leisure routines to address issues that some categorize as identity politics (such as feminism and LBGT rights) (Figure 17.1).

Such new worker configurations also require a platform beyond factories and other stable workplaces for organizing. Consequently, these social movements engage people in central squares, neighborhoods, streets, highways, roundabouts and many more places yet unimagined. I suggest that this is where we need to analyze the new movements such as $15 \mathrm{M}$, Occupy, Nuit Debout and the Gilets Jaunes. To quote the well-known preface from E. P. Thompson's The Making of the English Working Class as a framework for this crucial endeavor: 


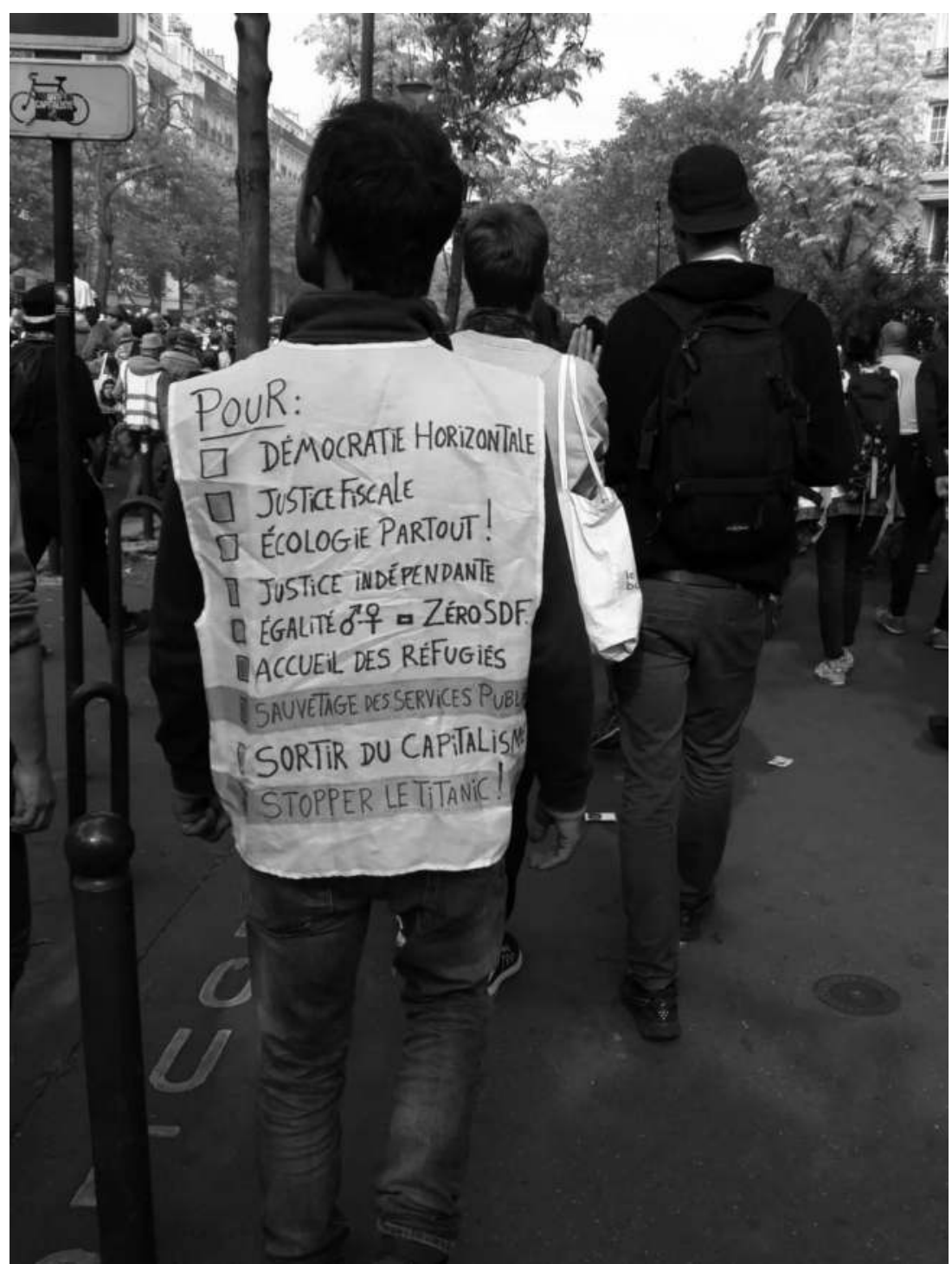

Figure 17.1 Gilets Jaunes protest. (Ida Susser)

This book has a clumsy title, but it is one which meets its purpose. Making, because it is a study in an active process, which owes as much to agency as to conditioning. The working class did not rise like the sun at an appointed time. It was present at its own making. Class, rather than classes, for reasons which it is one purpose of this book to examine. (There is, of course, a difference. "Working classes" is a descriptive 
term, which evades as much as it defines. It ties loosely together a bundle of discrete phenomena. There were tailors here and weavers there, and together they make up the working classes.) By class I understand an historical phenomenon, unifying a number of disparate and seemingly unconnected events, both in the raw material of experience and in consciousness. I emphasize that it is an historical phenomenon. I do not see class as a "structure", nor even as a "category", but as something which in fact happens (and can be shown to have happened) in human relationships.

(Thompson 1963, 2)

Thompson includes changes among field laborers, weavers, artisans, Methodists and many others. He looks at childhood, aging, politics and the Peterloo massacre and points out that these things cannot be understood simply in demographic or sociological terms. He talks of a process in which people saw themselves as members of a new formation that came to be understood as the working class. This is the way I conceive of this contemporary analysis of social movements on the shifting grounds of transformative relationships in the era of financial capitalism. Such movements can be seen as progressive when they are inclusive and incorporate demands such as the restructuring of gender, colonized inequalities and racial exclusions. They can be classified as right-wing when they rely on exclusivity, nationalism and the institutionalization of patriarchy and hierarchies of color and sexuality. Since we are talking about processes, a movement may be progressive at one moment and right-wing in a different historical conjuncture.

The Gilets Jaunes whom I discuss here present a conundrum. Unlike the various Occupys and specifically, in France, Nuit Debout, which have been seen as having progressive aims, there is a lot of dispute among analysts as to whether the Gilets Jaunes represent a progressive alternative. They are certainly not made up primarily of the predictable groups of left parties and organizations and precarious youth manifest in these earlier events. The Gilets Jaunes include people who are longtime leftists, but they also include pensioners and civil service workers as well as many people from the provinces. They were initially energized in opposition to the gasoline tax that Emmanuel Macron, President of France, had highlighted as an ecological measure. In addressing the Gilets Jaunes, Macron and the media interpreted this opposition as a right-wing refusal to pay for his ecology program. As people from the provinces and urban periphery, they were also immediately suspect as more conservative than cosmopolitan Parisians.

Some have feared that the Gilets Jaunes, if not anti-Semitic or homophobic themselves (as much of the media has discussed both in France and internationally; Nossiter 2018), are made up of groups promoting a form of disorder that may precipitate intolerance and provide a justification and reinforcement to right-wing movements. The late Hannah Arendt, a controversial figure in terms of right and left, has been referred to in, for example, 


\section{Ida Susser}

the Guardian (Williams 2017), making this argument about disruptive protests and violence as precipitants of fascism before World War II.

Two points of view were starkly contrasted at a conference ("Debat sur le mouvement Gilets Jaunes," Columbia Global Centers, January 16, 2019) in Paris, where two of the main speakers were Antonio Negri and Etienne Balibar. Negri hailed the emergence of an autonomous movement and saw the lack of leadership and clear demands as a reflection of the focus on horizontality and the avoidance of hierarchy or continuous leadership so prevalent among contemporary protesters. Etienne Balibar saw the same amorphous lack of leadership and clear demands of the Gilets Jaunes as a unpredictable situation that might turn, in a flash, into rage about immigration or other right-wing issues. At this moment, with the growing power of right-wing national governments in the European Union, these are serious considerations.

An ethnographic perspective on the Gilets Jaunes and previous activist movements in Paris begins to reveal the makeup and consequences of such protests and might help to illuminate this question.

\section{Paris - Nuit Debout}

In 2012, Francois Hollande took office as the first socialist president in France since 1995. Meanwhile, the extreme right National Front party was gaining voter support. In 2015, in response to a series of assassinations in Paris by Muslim extremists (the Charlie Hebdo assassinations in January, followed by the murders of many people at cafés and elsewhere in November 2015), President Hollande declared a state of emergency. Given the tragic events in Paris in 2015 and the rise of the National Front, it is all the more surprising that less than six months after the terrorist assaults, while Paris was still officially in a state of emergency, on March 31, 2016, 100,000 marchers occupied La Place de La République (see Susser 2017). Nuit Debout spread rapidly, with many squares occupied throughout France.

Nuit Debout then united with the Left unions who had been organizing for several months in opposition to the efforts of the Socialist Party government to change the labor laws. The government's aim was to allow employers more flexibility to dismiss workers. Throughout the next five months, through the height of the tourist season, unions went on strike on air and train transportation routes. Meanwhile, still occupying La Place de La République, Nuit Debout joined strikers and organized numerous marches to the banlieues (poor suburbs). They joined with migrants who were being evicted from a public park in Paris, and they supported strikes among bus drivers, domestic workers and many other groups. Left unions, in a fragile collaboration with Nuit Debout, called massive demonstrations in June that drew over 300,000 participants. Students and faculty from Paris 8, the university campus in St. Denis, led their own campus occupation and panels against racism at the same time as Nuit Debout. 
The 2017 French national elections reflected the disappointment with the Socialist Party outlined above. The National Front led by Marine Le Pen achieved a measure of mainstream respectability and made it through the first round. The Socialist Party, which people saw as abandoning their constituency in their efforts to change the labor laws, dwindled to less than $7 \%$ of the vote. Meanwhile, a leftist, Jean-Luc Mélenchon, previously in the Socialist Party, formed his own party, La France Insoumise, and unexpectedly won $20 \%$ of the vote, with the journalist Francois Ruffin elected as a deputy (Clarke and Holder 2017). Highlighting the disarray of the traditional postwar party structure, Emmanuel Macron, who had never run for office, formed a mainstream party and defeated both the traditional parties (conservatives and socialists) in the first round. Consequently, he entered the run-off against Le Pen. New political parties, such as those led by Macron and Mélenchon, were more successful than most traditional parties, similar to the shake-up in political configurations in Spain and elsewhere.

Many Nuit Debout activists whom I interviewed abstained from the second round of elections. They saw Macron, former treasurer of the Socialist party, as a leader of the attack on the labor law. Massive protests against Macron were predicted by many people I interviewed in May 2017. Although some, in the end, voted for Macron, they felt manipulated into voting to stop a fascist threat represented by the National Front. When Macron finally won the elections, he vowed to make the very changes in the labor law and cuts in the welfare state against which Nuit Debout and the left unions had organized.

Nuit Debout, as an occupation, lasted for about ten months, becoming smaller over time. Many subsidiary movements resulted from the groups or commissions that had formed in the squares (Susser 2017; 2020). Some groups began to organize in specific neighborhoods, such as Place des Fêtes. Massive strikes quickly followed the election of Macron, and many of the organizers had first met in Nuit Debout.

In spring 2018, student strikes, including a months-long occupation of the Sorbonne, opposed Macron's new policies, known as ParcourSup, constraining admissions to university nationwide. This later became one of the many concerns of the Gilets Jaunes. Railroad strikes, also in spring 2018, continued for many months, supported by the student strikers. Railroad workers from all over France, some walking hundreds of miles in protest, came to speak at meetings in Paris attended by both railroad workers and striking students.

Thus, when the Gilets Jaunes appeared in November 2018 they were a new part of the growing disquiet and fury at the Macron regime. Protesters all over France built cabanas at crossroads, occupied highways and "liberated" toll booths. They also prepared Cahiers de Doleances that they presented to municipal governments, in self-conscious modeling of the French Revolution, when such lists of grievances were collected over a few months in 1789 (Wahnich 2018). Perhaps presaged by the railroad workers who marched to 
Paris in spring 2018, on November 17, 2019, masses of protesters from the provinces come together in Paris to voice their outrage.

Many left activists have been meeting in the squares of the poorer sections of Paris since Nuit Debout, working to create weekly neighborhood forums. When the Gilets Jaunes appeared, these neighborhood forums, from Montreuil, Belleville, Place de Fetes and elsewhere, marched together to join the mass protest at the Bastille, Paris, which supports Negri's view of the Gilets Jaunes as a progressive movement.

However, in support of Balibar's caution, followers of Marine Le Pen were evident on the streets in the first weeks of the Gilets Jaunes. In addition, in current French politics, there is some possibility that if Macron fails, a wide avenue will open for Marine Le Pen. However, there is no indication that the Gilets Jaunes are focused on immigration and exclusion in the ways represented by the party of Marine Le Pen.

\section{The Gilets Jaunes and commoning}

I would suggest that the Gilets Jaunes might be a group in which the process of class-making or self-conscious class formation is currently taking place. Nothing is predetermined. The direction of this new movement, progressive or right wing, is being negotiated among the participants in the process of the months of protests (see also Chaillet 2019).

As an anthropologist, I participated in the protests on Saturdays in Paris and elsewhere from January 2019. I talked with members of the Gilets Jaunes on the marches, in assemblies and other situations, such as the occupations of crossroads and the building of cabanas, and also conducted a number of more lengthy interviews with members of the Gilets Jaunes of different ages and occupations.

As a nonreligious woman of Jewish descent and an immigrant in several continents, I was particularly concerned about the growth of right-wing movements and issues of anti-Semitism, racism and anti-immigrant exclusivity. As a longtime researcher of the United States, I have also been analyzing the context of the election of Donald Trump in the United States (see Susser 2018, forthcoming). The question of inclusivity versus exclusivity was one of my primary concerns in analyzing the Gilets Jaunes uprisings. Unfortunately, the Guardian and the New York Times, two influential news sources outside France, have hardly covered Gilets Jaunes activities other than moments of violence. In February 2019, an incident of anti-Semitism, in which a Jewish French intellectual was shouted at in the street, became international news (Nossiter 2019). While the breaking of windows around the Champs-Élysées and street disruptions of the Gilets Jaunes have hit the front pages, little has been published on their overall demands, the many civil service strikes in France and the unprecedented maiming of protesters. As an example of misleading coverage, the Guardian (Willsher 2019a) and many other papers published an official government report that the Gilets Jaunes 
had attacked a hospital in Paris. This seemed, at the time, both outrageous and unimaginable, as the Gilet Jaunes had been protesting in support of the health worker strikes over the reduction of services. The next day it emerged that protesters had rushed into a nearby hospital seeking protection from a police tear gas attack. A retraction appeared in the French media and in the Guardian, but the incident was still believed by many (Willsher 2019b).

After almost a year of demonstrations, the Gilets Jaunes are now made up of a wide variety of groups. Many do not want to be seen as part of a left progressive party, although others are associated with Mélenchon's party, France Insoumise. What might be a decreasing minority are associated with Marine Le Pen. Hard evidence on this point is difficult to get. Le Pen supporters were not openly visible at any of the Paris demonstrations I observed. Some of the Gilets Jaunes I interviewed said they had seen Le Pen supporters in the first few weeks but that they were no longer welcome or evident. When I talked with some of the Gilets Jaunes from outside Paris, they said that they were aware of some right-wing members in their district, but they did not discuss the subject. On a demonstration in June 2019, I met a young unemployed man who had been brought to Paris by the Gilets Jaunes among the wounded protesters, and he was enthusiastic about Trump. When I spoke with his mother, a teacher, she was less enthusiastic.

Many of the people who came to the protests gave me detailed political analyses. At the same time, they gave me the examples from their daily life that had led them to become Gilets Jaunes. In May 2019, I spoke with a nurse from just outside Paris, who had been demonstrating since November the year before. She told me that she felt she was representing all the nurses and other health workers who could not leave their work to come to the protests. Her clinic was on strike, but they still had to work to make sure the patients were all right. Then she told me her son and daughter were going to be prevented from attending university in September 2019 because of ParcourSup (instituted by Macron to reduce student admissions to overcrowded universities). ParcourSup was written on the back of her Gilet Jaune and was clearly a prime concern for her. She told me she had not brought her son and daughter with her because she was afraid of the police violence.

On a demonstration in January 2019, I met a woman in her early 60s wearing a Gilet Jaune as we were both trapped by police while we marched peacefully up a boulevard near the Champs-Elysees. In a subsequent interview, she explained that she was Jewish and was born in Belleville in the 1950s. Her mother had escaped from Poland just before World War II and come to live with relatives in Belleville. She said she came to the protests, sharing rides from outside Paris every weekend, because she was living on her pension and could not afford to stay in Paris, her lifelong home. She was also concerned that her son, a chef, was not able to earn enough in his job to pay his rent and for food.

Similarly, I met another woman in her 60 s at a crossroads occupation set up in a mall outside Paris. The wife of a police officer, she said that although 
she and her husband were comfortable economically, her children, well educated and supported through their parents' efforts, could not afford to buy a house or send their own children to college.

A grandmother whom I met on another demonstration and later interviewed more fully told me of her daughters' difficulties. One daughter was a nurse and the other a teacher. She said she thought of herself as representing the needs of her daughters and grandchildren, as her daughters did not have the time or the money to come to the protests. She described the brutalizing conditions of work at the clinics and said that her daughter who had been a teacher had to quit work because of a burnout.

Showing the central significance of health care, another Gilet Jaune, a courageous young woman, wrote and talked about her neglect in hospital while she was living through cancer. She saw this experience as leading to her recognition of the Gilets Jaunes as her new "family," after many years of leftist participation. Her description of the anomic and upsetting conditions in health care paralleled shockingly the account of the nurse's experiences related by her mother.

To add to this portrait, I also met many young men and women on the demonstrations and building cabanas who came from the areas surrounding Paris and sometimes as far away as Brittany. Some were clearly politically left, while others were much less politically explicit but angry. Some told me that they wanted to fight back physically as well as in peaceful demonstrations. They claimed that it was the only way to get attention from the media. Many had been arrested, some even before they arrived at the marches, and kept in prison for several days or weeks dealing with complicated legal charges and unable to defend themselves. When they were let out of prison, they were far from home in unfamiliar environs. Local Gilet Jaunes groups attempted to provide support for the people arrested both in court cases and finding their way home. However, this intimidating experience, in itself, led many to abandon the protests.

a Stealing the state and the growing rage

Although aware of the growing gap between rich and poor (as described by Picketty 2014), most of the Gilets Jaunes seemed more concerned with the degradations of public services, the privatization of health care and their own daily challenges than with abstract inequality. The Gilets Jaunes on the marches and in assemblies repeatedly used the phrase "they are stealing the state." People regard public services as a right and see the services as belonging to the state and the state as paid for by their money and belonging to them. When the state privatizes a service, it is seen as "stealing the public money."

The history of France is significant at this point. Just to point out, lacking an in-depth historical materialist analysis, Louis XIV said, "L'état c'est moi," and the French Revolution was fought to establish that this was not true. The understanding that the state belongs to the people is a central 
understanding among the Gilets Jaunes. The Gilets Jaunes are reflecting and demanding the maintenance of what we might term a moral economy of the state and the ethics of a just city. They are framing the state as belonging to them, paid for by them and answerable to them. They see the lack of investment in public transportation outside Paris and the declining support for provincial services as illustrating the "stealing of the state." They are claiming their rights to state services, such as health, education, retirement, care for the handicapped and dealing with the problems of the frail elderly. A just city or a moral state would be one that responds directly to the voices of the people and maintains services in a humane way that serves all the people.

b The creation of community as a source of resilience

In daily life, under current economic conditions, while services are no longer adequate for the sick and those in need, people also no longer have the time to supplement such needs. Women are out working; people work longer hours and cannot assist family and friends on a daily basis. In addition, women particularly, who used to do much of the preparation of social gatherings, no longer have as much time and people have less money to fund such social occasions. In other words, not only have the public services been eroded but social life has been affected, leaving many people alone. Even people with families find themselves alone in their daily challenges. Thus, the problems of the shrinking state are also the problems of the degradation of social life.

Under such conditions of neoliberalism, where people have less time to care for others, individualism is promoted as a prime value and the collective action of unions and others is undermined, the Gilets Jaunes are recreating a community. People told me that it was extremely important to them, and almost exhilarating, when they first saw the Gilets Jaunes. As examples (my translations):

"When I saw the Gilets Jaunes, I realized that I was not alone in my experiences."

Other people said: "It changed my life."

"It was the best experience of my life."

One can see this phenomenon in the building of the cabanas. At one cabana I visited in the Val de L'Oise, everyone came to the cabana on the weekend for barbecues and films and to see their family and friends. An organizer said: "The cabana is more popular than the village square." Since the post office and other amenities of the village have mostly disappeared, this is hardly surprising.

On another occasion, on a religious holiday (Saints Day), I observed men and women building a cabana in an abandoned truck lot in the workingclass suburbs of Paris. The group was diverse in age and background, including a number of men and women of color, and may have been part of a larger effort in which truck drivers were engaged. Over several days, participants organized barbecues, children were running around and the Gilets 
Jaunes had also built a little house for the children to play in. The cabana lasted only a week before it was destroyed by the police. However, although it was only for a week, participants were very sad after it was hacked to pieces, not simply because of the destruction of a symbol of the battle for the Gilets Jaunes but also for the community which had been so short-lived and temporary.

It is experiences such as this that I see as the "commoning" process of the Gilet Jaunes. The movement is both enraged and resilient: Enraged at the loss of community and public and social services over time, and resilient in the commoning efforts to create a new community.

\section{c Questions of Violence}

Saturday, March 16, 2019, was a major Gilet Jaunes weekend. This march, which combined the Gilets Jaunes with the Climate Change movement, was particularly significant due to the charges by Macron, echoed in the press internationally, that the Gilets Jaunes were opposed to ecological concerns. The event was arranged by the two groups to demonstrate that the Gilets Jaunes were not opposed to climate regulations, simply to bearing the burden in their gas taxes when corporations were generating high profits and not being asked to bear this burden. The climate march began at Opera. At this spot, in spite of the thousands of people, almost no police were in evidence (perhaps there were police in plainclothes, but they were not confronting marchers in inflammatory ways).

Later, as a parade of the Gilets Jaunes left Opera, the police surrounded them in full protective gear, on motor bikes and accompanied by paddy wagons. When the whole march joined together at La Place de la RepubliqueGilets Jaunes and climate demonstrators - it felt a little like a "be-in" from the late 1960s (including the tinge of marijuana). However, the speeches were becoming very angry as people felt ignored, erased and effaced. There was a general claim that the Gilets Jaunes were going to turn to other forms of peaceful resistance (not hurting people, only property), including blocking highways and trains and general disruption.

Around 6:15 pm, as dusk set in, the police started to surround La Place de la Republique in full protective gear and to arrest nearby demonstrators, unpredictably. As some protesters had described their views of violence to me, there was an explosive response by the demonstrators to the ensuing arrests. Within 15 minutes, there were radio reports of massive violence at $\mathrm{La}$ Place de la Republique, windows broken, people arrested and cars turned over. The buses were rerouted, and the metro stop at Republique was closed.

The levels of police violence at the Gilets Jaunes protests have been well documented and tracked by scholars in France (Bertho 2019), who have formed an organization, Nous Accusons. They have launched a petition, marched behind a banner and initiated media coverage on the extreme wounding of protesters. The violence perpetrated by the police on demonstrators met invariably with a disruptive response from some demonstrators. 
However, the police are armed with LBD-40s, a controversial gun that fires rubber bullets and is banned in the United Kingdom and elsewhere. Some protesters break windows, set motor bikes and cars on fire and push back at the police, but they are not in full army protective gear and do not carry lethal weapons. The number of permanently wounded marchers and bystanders in terms of the actual loss of an eye, a hand or a foot has been increasing. In France, police are not legally allowed to fire LBDs at the eyes or genitals. However, there are over 174 court cases pending against French police for illegal use of violence (Willsher 2019c). Recently one protestor drowned as, along with other protesters, he fell off a bridge in Nantes as the police charged. This almost predictable escalation in casualties has precipitated ongoing demonstrations.

\section{d The building of a broader movement}

The Gilets Jaunes may be the latest and most powerful, most supported of a variety of movements that have emerged since 2016. They link many of the uprisings and strikes from different sectors (such as railroads, teachers and health workers) and the smaller uprisings among hospital aides or the sanspapiers as well as the climate change activists and left-wing organizations.

In 2018/2019, as the Gilets Jaunes protested every Saturday in the streets of Paris and in towns and roundabouts around France, many strikes were taking place. At the Gilets Jaunes marches in Paris, I met primary school teachers who were out on strike, health care workers whose emergency clinics were on strike, civil service professionals, artists, actors and students and faculty from universities around Paris. Actors and artists, long- standing members of a precariat, had formed a group called "The Yellow Submarine" and were widely represented among the protestors. However, in addition, the Gilets Jaunes joined and supported many other demonstrations as diverse as strikes among nurses' aides in the suburbs and the widespread pension protests of September 2019, which closed down the metro and the buses for a day and involved massive demonstrations in the streets.

Because of the weakness or failure of many unions, the Gilets Jaunes are also inventing new methods, such as the occupation of the ronds points, the building of cabanas and the freeing of toll booths. In these ways, even though the original mass marches in Paris may have become smaller, the Gilets Jaunes are attempting to forge a new set of resistances and generating the support of the public from the banlieus to the provinces.

\section{Conclusions}

When people talk of the destruction of the state, they talk not only of the privatization and dismantlement of public services but also, as we saw above, of the crisis of daily life, the family, education, health care, the aged, the handicapped (highly visible at protests on crutches and in wheelchairs) and 
the students, who feel they are "losing their futures," as one protester said to me. The Gilets Jaunes have emerged as one of the most forceful movements of the current era against this transformation of the state and the accompanying degradation of social life. Although the French have defended the welfare state longer than the United Kingdom or the United States, it now seems to be under threat.

Perspectives such as among the Gilets Jaunes in France, in which people frame the state as theirs, are not universal, certainly not in Western liberal democracies. In the United States, even many on the left do not identify with the state; in fact, much of the left strongly distrusts the state. In the United States, protesters may make many claims upon the state, for housing, for employment, for quality education. However, these demands are not framed as if they are the state. In the United States, people pay lower taxes and often do not imagine they have a right to public services. Rather, they expect to pay for services and see services, in some cases, as a form of charity, not a right (Morgen and Erickson 2017). In France, people pay taxes and they expect to receive public services when they need them. The idea that the "state is Us," so particular to France, may explain the unusual, powerful resistance to privatization policies there. The Gilets Jaunes are the latest and possibly among the most inclusive, as well as the most enduring and disruptive of this resistance.

In France, Nuit Debout and the Gilets Jaunes represent transformative spaces where people in the current era of financialization and globalization are struggling to work out new strategies. Activists envision Occupy and other consciously horizontalist movements as an effort to develop innovative forms of protest to counteract the increasing inequality, authoritarian tendencies and hardened boundaries of the new global regime. Such progressive representation strives for inclusivity and the breakdown of established hierarchies of gender, race, immigration and class, among others. My research suggests that the Gilets Jaunes are, through their commoning processes, generating such approaches or a new form of urban ethics.

If we see contemporary social movements as responding in fragmented and conflicted ways to the crisis of the state, we see such movements coming together in the contemporary demonstrations, the Nuit Debouts and Gilets Jaunes. These liminal moments of solidarity seem, at least, to offer inspiration for a progressive transformative movement.

The ragged and chaotic new progressive movements are an attempt to counteract the nationalist nostalgia inherent in the right-wing reaction to austerity and to chart a new direction and a new political bloc to confront the increasing power and mobility of capital. Perhaps rather than prefigurative (Graeber 2013), we can see them as experimental, incremental and also perhaps momentarily constructing a cohesive political bloc of subaltern groups the displaced through housing, migration and ecological stress, the neglected who have lost employment in the industrial core, the longtime excluded, such as poor women, and the recently downwardly mobile, in fact, the $99 \%$. 
The Gilets Jaunes, made up of working-class people on the urban periphery, including many pensioners and families who cannot make ends meet, may now be joining this emerging bloc. Each of these groups has to be understood in the context of their own history and social movements. The participants in Nuit Debout were not the same as the Gilets Jaunes. However, just as E. P. Thompson looked at the weavers, the farm laborers, the artisans and other groups of workers in other parts of England, and then documented when they began to see themselves as one working class, we need to analyze the multiple histories of subaltern groups and observe the moments when they begin to recognize themselves as part of larger political bloc, or not.

Instances such as Nuit Debout and the Gilets Jaunes in France represent approximations in the emergence of a progressive political bloc. As Balibar cautioned, such movements are contingent and contested and are reflective of a rage against the destruction of living standards and aspirations for a generation. Such rage could be expressed in frighteningly fascist ways. There is the possibility that Hannah Arendt was correct and that riots and disruption can also fuel the Right. However, I would argue that the protests that we see today are also a hopeful sign in their inclusive progressive inspirations. In the commoning and the construction of an inclusive critical community, they are a fragile but promising bulwark against the growing fury that is also fueling nationalism and exclusivism.

\section{Acknowledgments}

I would like to thank La fondation Maison des Sciences de 1'homme for a 2015 Fellowship Award as well as the National Science Foundation Award 1759658, the LAIOS-IIAC (CNRS-Ehess) for their help during my research as well as Hunter College for their support of my research on social movements.

\section{Note}

1 In using this term, the emphasis is on the process of becoming rather than on a static image of the "commons."

\section{Bibliography}

Bertho, Alain. 2019. "Retour sur le rapport du mouvement à la violence." l'atelier des Ronds-points, Maison des sciences de l'Homme, Paris Nord.

Butler, Judith. 2009. "Performity, Precarity, and Sexual Politics." Revista de Antropología Iberoamericana 4, no. 3: i-xiii.

Casas-Cortés, Maribel, Sebastian Cobarrubias, and John Pickles. 2014. "The Commons.” In The Urban Companion to Anthropology, edited by Don Nonini, 449-70. Chichester, UK: Wiley-Blackwell.

Castells, Manuel. 2012. Networks of Outrage and Hope: Social Movement in the Internet Age. Malden, MA: Polity Press.

Chaillet, Raphael. 2019. "Ethnographie des ronds points en Lorraine.” L'atelier des Ronds points, Maison des sciences de l'Homme, Paris Nord, May 28, 2019. 


\section{Ida Susser}

Clarke, Seán, and Josh Holder. 2017. "French Presidential Election May 2017 - Full Second Round Results and Analysis." The Guardian, May 26. Accessed September 28, 2019. http://www.theguardian.com/world/ng-interactive/2017/may/07/ french-presidential-election-results-latest.

Federici, Sylvia. 2012. Revolution at Point Zero: Housework, Reproduction, and Feminist Struggle. Oakland: PM Press.

Graeber, David. 2013. The Democracy Project: A History, a Crisis, a Movement. New York: Spiegel \& Grau.

Gramsci, Antonio. 1971. Selections from the Prison Notebooks. Edited and translated by Quintin Hoare and Geoffrey Nowell Smith. New York: International Publishers.

Hall, Stuart. 1986. "Gramscsi's Relevance for the Study of Race and Ethnicity." Journal of Communication Inquiry 10, no. 2: 5-27.

Harvey, D. 1989. The Condition of Postmodernity. Oxford: Blackwell.

Jørgensen, Martin Bak. 2016. "Precariat - What It Is and Isn't - Towards an Understanding of What It Does." Critical Sociology 42, nos. 7-8: 959-74.

Kalb, Don. 2015. "Introduction: Class and the New Anthropological Holism." In Anthropologies of Class: Power, Practice and Inequality, edited by James Carrier and Don Kalb, 1-27. Cambridge: Cambridge University Press.

Means, Alexander J. 2017. "Generational Precarity, Education, and the Crisis of Capitalism: Conventional, Neo-Keynesian, and Marxian Perspectives." Critical Sociology 43, no. 3: 339-54.

Milkman, Ruth. 2014. "Millennial Movements: Occupy Wall Street and the Dreamers." Dissent 61, no. 3: 55-9.

Morgen, Sandra and Jennifer Erickson. 2017. "Incipient Commoning in Defense of the Public?” Focaal, 79 December: 54-66.

Nossiter, Adam. 2019. "Anti-Semitic Taunts Prompt French Soul-Searching." February 18, New York Times. Accessed September 28, 2019. https://www. nytimes.com/2019/02/18/world/europe/france-antisemitism-yellow-vests-alainfinkielkraut.html.

Picketty, Thomas. 2014. Capital in the 21st Century. Cambridge, MA: Harvard University Press.

Scott, Michael. 2017. "'Hipster Capitalism' in the Age of Austerity? Polanyi Meets Bourdieu's New Petite Bourgeoisie.” Cultural Sociology 11, no. 1: 60-76.

Seymour, Richard. 2012. "We Are All Precarious - On the Concept of the 'Precariat' and Its Misuses." New Left Project 10, n.p.

Smith, Gavin A. 2011. "Selective Hegemony and Beyond-Populations with 'No Productive Function': A Framework for Enquiry.” Identities 18, no. 1: 2-38.

Standing, Guy. 2011. The Precariat: The New Dangerous Class. London/New York: Bloomsbury Academic.

Stavrides, Stavros. 2015. "Common Space as Threshold Space: Urban Commoning in Struggles to Re-Appropriate Public Space.” Footprint 9, no. 1: 9-19.

Susser, Ida. 1996. "The Construction of Poverty and Homelessness in US Cities." Annual Review of Anthropology 25, no. 1: 411-35.

Susser, Ida. 2011. "Comment on Gavin Smith 'Selective Hegemony'." Identities 18, no. 1: 54-62.

Susser, Ida. 2016. "Considering the Urban Commons: Anthropological Approaches to Social Movements." Dialectical Anthropology 40, no. 3: 183-98. 
Susser, Ida. 2017. "Commoning in New York City, Barcelona and Paris: Notes and Observations from the Field." Focaal 79: 6-22.

Susser, Ida. 2018. "Re-envisioning Social Movements in the Global City: From Fordism to the Neoliberal Era." In Worldwide Urban Mobilizations, edited by Don Kalb and M. Mollona, 208-22. New York/Oxford: Berghahn Press.

Susser, Ida. 2020. "Popular Mobilization: Rescaling as a Consequence of Nuit Debout/Occupy." In The Tumultuous Politics of Scale. Unsettled States, Migrants, Movements in Flux, edited by Donald M. Nonini and Ida Susser, 236-54. Abingdon: Routledge.

Susser, Ida. (forthcoming) "Right Wing Movements in the United States and the Election of Donald Trump." Anthropological Theory.

Susser, Ida, and Stéphane Tonnelat. 2013. "Transformative Cities: The Three Urban Commons." Focaal 66: 105-21.

Thompson, Edward Palmer. 1963. The Making of the English Working Class. London: Victor Gollancz.

Wahnich, Sophie. 2018 "The Structure of Current Mobilizations Corresponds to the Sans Culottes." Mediaparte December 9, 2018. Accessed September 28, 2019. https://www.versobooks.com/blogs/4160-the-structure-of-current-mobilizationscorresponds-to-that-of-the-sans-culottes.

Williams, Zoe. 2017. "Totalitarianism in the Age of Trump: Lessons from Hannah Arendt." The Guardian. February 1, 2017. Accessed September 28, 2019. https:// www.theguardian.com/us-news/2017/feb/01/totalitarianism-in-age-donaldtrump-lessons-from-hannah-arendt-protests.

Willsher, Kim. 2019a. "Paris Hospital Attacked by May Day Protesters, Say Officials." The Guardian May 2, 2019. Accessed September 28, 2019. https://www. theguardian.com/world/2019/may/02/paris-hospital-attacked-by-may-dayprotesters-say-officials.

Willsher, Kim. 2019b. "French Interior Minister under Pressure over Hospital Attack Claim." The Guardian May 3, 2019. Accessed September 28, 2019. https://www.theguardian.com/world/2019/may/03/french-interior-ministerchristophe-castaner-may-day-paris-hospital.

Willsher, Kim. 2019c. "Injured Gilets Jaunes Protest in Paris against Police Violence." The Guardian June 2. Accessed September 30, 2019. https://www. theguardian.com/world/2019/jun/02/injured-gilets-jaunes-protest-againstpolice-violence-march-of-the-mutilated.

Wolf, Eric R. 1969. Peasant Wars of the Twentieth Century. Norman: University of Oklahoma Press. 


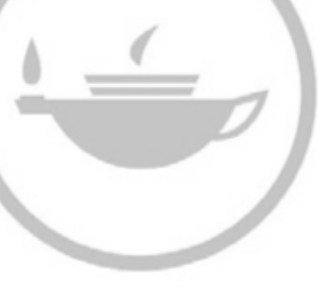

Taylor \& Francis Taylor \& Francis Group

http://taylorandfrancis.com 


\section{Index}

Note: Italic page numbers refer to figures and page numbers followed by " $n$ " denote endnotes.

A+ Architecture in Belgium 141n7

Abram, Simone 55

Abulafia, David 71

Active Citizen platform 243, 245-6, $258 \mathrm{n} 4$

African identity 40

Africanness 40

African urbanism 28

Agoranomos 82

Agrawal, Arun 235

Ahmed, Sarah 53, 58-9

Alekseevna, Vera 269, 271

al-Maqrîzî, Taqiyy al-Dîn Ahmed b. 'Alî 83

al-Shayzarî, 'Abd al-Rahmân b. Nasr 83

Altan, Çetin 105

ambiguous colonial and postcolonial rediscovery of Hisba 91-2

ambivalent assemblage 158-60

amoral familism 69

Ancient Greece 72

antagonisms around housing mobilizations in Budapest 185-8

anti-immigrant exclusivity 284 anti-orthodox Russian nationalism 265

anti-Semitism 284

Archigram 134-41

Architectural Design 135, 136

architecture: contestation in 200-1;

Delitz on 204; Malayan 201;

Mediterranean 75; social creativity and 153-8

Archives d'Architecture Moderne (AAM) 130-4

Arendt, Hannah 268, 281, 291

Armenian Hospital Surp Pırgiç 102
Art Net lecture series 131

Asian urbanism 43

Association for Urban Transition 189

Association of the Conquest of Istanbul (Istanbul Fetih Cemiyeti) 103

Atelier de Recherche et d'Action Urbaines (ARAU) 132-9

Athenian democracy 68

Auckland, Aotearoa New Zealand: caring for waste, responsibility and representation 236-8; and collaborations 234-6; and community 234-6; handling waste through consensus, care and community in 226-8; neighborhood sets about waste 231-3; overview 226-8; situating waste dynamics in 228-31; and subjecthood 234-6

Auckland Council Waste Management and Minimisation Plan 229

Augé, Marc 119

austerity $278-82$

Austin, John L. 52

authentic peasant: as deserving poor

104-6; and urban threat 104-6

authoritarian nationalism 11

Aymard, Maurice 69

Badiou, Alain 22n6

bad Istanbulites 101-2

Bahnhofsklatscher ("train station clappers") 6

Balibar, Etienne 282, 284, 291

banal consumerism 11

Barey, André 130

Battle of the Marolle 135, 142n8 
Baudelaire, Charles 73

Benjamin, Walter 66, 72

Ben-Yehoyada, Naor 71

Berger, John 98

Berlant, Lauren 53, 55, 58-9

Berlin 54; as a Creative City 56, 59; cultural transformation of 54; "SelfMade" aesthetics 161n3; Senate Department of Urban Development 161n3; "Urban Pioneers" 161 n3

Berndt, Heide 68, 76n1

Black Lives Matter 220

Bloch, Ernst 275n16

Bocquet, Denis 66, 70

The Book of Istanbul 103

Bourdieu, Pierre 218

Braudel, Fernand 69, 76n6

Braudelian Mediterranean 69

Brenner, Neil 215

British Rule 200

Bucharest: Centrul Civic vs. Centrul Vechi 114-18; field of contention approach 181-3; old town in transition 118-23; overview 112-14, 180-1; structural contexts of housing contention 183-5; (un) making solidarities around housing mobilizations in 188-92

Budapest: antagonisms around housing mobilizations in 185-8; field of contention approach 181-3; overview 180-1; solidarities around housing mobilizations in 185-8; structural contexts of housing contention 183-5

Bugay, Umut 106

Building and Dwelling. Ethics for the City (Sennett) 5

The Bulletin 133, 135

Burawoy, Michael 269

Byzantine administrative heritage 82

Byzantine land wall 18, 103

C40Cities 226

Cahiers de Doleances 283

Cansever, Turgut 104

capitalism: corporate 217 ; early liberal 14; financial 281; financialized 171 ; neoliberal 75; state 12

capitalist urbanization 10

caring for waste, responsibility and representation 236-8

Carol I of Romania 115

Cassano, Franco 73-4

Castells, Manuel 76n7, 136, 181-2, 220

Castex, Jean 130
Ceaușescu, Elena 113

Ceaușescu, Nicolae 113

Çelebi, E. 88

Centrul Civic vs. Centrul Vechi 114-18

Centrul Vechi: Centrul Civic vs. 114-18; governmentality and 114

Chambers, Iain 72-4

Charlie Hebdo assassinations 282

Chinese Communist Party 218

Christianity 101

Christians 88, 104

city: defined 66; different modalities of and attachments to promises $52-5$; as a form of life 28-9; Mumford on 66; practices and objects of desire 52-5; as "promissory assemblage" 51; scenes of 49-55; scenes of promise and 49-55

"The City as a Self- Help Book: The Psychology of Urban Promises" 49

city as a setting for collaboration: outlook 58-9; overview 47-9; promissory collaboration in urban project work 55-8; scenes of the promise and the city $49-55$

The City is for All 186, 188, 193

Clarke, John 173, 267, 274n5

classical urbanitas 66-7

Cohen, Daniel Aldana 220, 223

Cold War 102, 104

collaborations: Auckland, Aotearoa New Zealand 234-6

collaborative neighborhood 152

collective consumption politics 220

collective housing 147-9, 153, 156, $158-9,161 \mathrm{n} 7$

Collier, Stephen 13-14

Colomb, Claire 151

colonialism, European 17, 71

commitment: emotional 175; to environmental care 238; investing oneself 173-6; personal 175; social 175,235

commoning 277; Gilets Jaunes and 284-9

common ownership 170-2

community: Auckland, Aotearoa New

Zealand 234-6; being a neighbor

172-3; and collaborations 234-6; and subjecthood 234-6

Congrès Internationaux d'Architecture Moderne 67

Constitutional Revolution of 1908100

consumer citizenship 217-20

consumerism 8, 75, 119

Cook, Peter 135-6 
cooperatives: defined 164; purpose of 164

cosmopole 71

cosmopolitan ethics 6

cosmopolitanism: European conceptions of 71; imperial 71; Mediterranean 71, 75 ; origins of 71

Council of European Urbanism 133

Counterprojects (Krier and Culot) 130

Craven, Luke 218

Crossley, Nick 181-2, 192

"cruel optimism" 53

Csányi, Sándor 187

"The Culture of Cities" (Mumford) 66

Cumhuriyet 102

Cuny, Cécile 49

d'Alembert, Jean-Baptiste 66

Dan, Nicuşor 126n22

De Boeck, Filip 42

"Debtors' Chamber" 187

Déclaration de Bruxelles 130-2, 138, $141 \mathrm{n} 4$

De Koninck, Louis-Herman 141

Delitz, Heike 204

democracy: Athenian 68; electoral 20;

European 252; municipal 68

Derviş, Suad 102

Deutscher Städtetag (Association of German Cities) 67

Diderot, Denis 66

"Distinctive Global City of the Arts" 200

Doinas, Stefan Augustin 124n2

Dolan, Catherine 38

DP Architects 203, 205

Duany, Andrés 138

Duizings, Ger 125n14

Dürr, Eveline 228

Eastern Europe 12

"eco- cities" 7

École Nationale Supérieure

d'Architecture et des Arts Visuels (La

Cambre) 132-4, 136, 138

The Ecological Other: Environmental

Exclusion in American Culture

(Jaquette-Ray) 219

Eigenmittelanteile 165

Ekaterinburg 261, 273n3, 274n7

Encyclopédie 66

Enlightenment 65

environmentalism: global visions of 234 ; middle-class 218

Erdoğan, Recep Tayyip 107
Ergin, Osman Nuri 89

ethical events: and promise of open cities 5-7

ethical imagination 40, 42-4; and cultural invention 31 ; defined 30 ; and problematization 30-4

ethical projects 7-11; approaching 147-50; exemplary 8-9; improving urban life 7-11

"ethical substance" 4, 13

ethical urban sustainabilities framework 223

ethics: of civilization 99-101; cosmopolitan 6; demolishing the abject or participating in universalism 99-101; and governmentality 39; and justice 217-20; and normative dimension of urban life 12-16; of urban heritage and moral landscapes 97-9

Ethics of the Urban 22n6

Euro-American exceptionalism 28

Eurocentric universalism 75

European Bank for Reconstruction and Development 185

European colonialism 17, 71

European Commission 185

European Economic Community 133

European Orientalists 83

European postmodern urbanism 134

European Union 5, 10, 180, 282

fantasy $31,33,42$

Fassin, Didier 3-4, 15, 166, 176

Fidesz conservative party $184-5,187-8$

"field of contention" 181

15M 277, 279

First Ottoman Army 100

First World War 102

Foucault, Michel 12-15, 30, 32, 39, 97, 99

Foundation of the Urban Environment $133,141 \mathrm{n} 4$

France: fragmentation and cohesion among subaltern groups 278-82; Gilets Jaunes and commoning 284-9; Nuit Debout 282-4; overview 277-8; precariat and austerity $278-82$

France Insoumise 283, 285

Frauenwohnen (self-organized group) 165

French Revolution 283, 286

Frontul Comun pentru Dreptul la Locuire (The Common Front for Housing Rights, FCDL) 191-2

functionalist urbanism 67,130

future urban 41-4 
Gallas, Alexander 274n5

Gaudefroy-Demombynes, Maurice 83

Gemeinschaftlichkeit 173

Genossenschaftsgesetz (German cooperative law) 164

German Nazism 274n7

German planning law 160n1

German Research Council (DFG) $177 n 5,274 n 4$

German Research Foundation 17

Gilbert, Jeremy 274n5

Gilets Jaunes protests of 2018/2019 21, 277, 279, 284; and commoning 284-9; fragmentation and cohesion among subaltern groups 278-82; Nuit Debout 282-4; overview 277-8; precariat and austerity $278-82$

Giraudoux, Jean 80

Global North 34, 44

Global South 28, 33, 40, 74-5

global urban environmentalisms 216

global urban sustainability 219-20, 223

Goldziher, Ignaz 83

good Istanbulites 101-2

good life, city $3,10,17,21,28,65,74$, 197, 198, 203, 205, 207

Gould, Kenneth 221

governmentality 9, 13-14; Centrul

Vechi and 114; contemporary 22n7; ethics and 39; neoliberal 12, 246; responsibilization and $177 \mathrm{n} 11$; ultramodern 246

Graeber, David 154-7, 160, 161n6

Grama, Emanuela 125n11

Gramsci, Antonio 74, 277, 279

Greater Romania 115

Great Patriotic War 265; see also World War II

Great Recession 279

Greek antiquity 66

Greenberg, Miriam 216, 219, 220

Green Gentrification: Urban

Sustainability and the Struggle for

Environmental Justice ( Gould and Lewis) 221

Grumbach, Antoine 130, 138

Guardian 282, 284-5

Gutmenschen 6

Habermas, Jürgen 4, 121

Habib, Alan 52

habitat of the subject: city as a form of life 28-9; ethical imagination and problematization $30-4$; future urban 41-4; imaging others $34-40$;

livelihoods and inequalities $34-40$

Hall, Stuart 274n5, 277

Hamurarwe 37

Harvey, David 80, 219

Hassell, Richard 204

Häußermann, Hartmut 68

Heeg, Susanne 171

Heidegger, Martin 73

Herron, Ron 137

Hippodamus of Miletus 69

Hisba 81-6; ambiguous colonial and postcolonial rediscovery of 91-2; colonial scholars and 91; as Koranic principle 81; and moral economy 83; principles 87-9; treatises 82-3, 85

Hobsbawm, Eric 277

Hollande, Francois 282

Holm, Andrej 151

Horden, Peregrine 69, 76n6

Ho Sweet Woon 204

Huet, Bernard 130, 138

humanitarianism 6

Hungarian OTP bank 187

Hungary 180; socialist housing construction and distribution in 183; state-aided housing loans in 184; urban segregated neighborhoods in 183-4

Hurricane Sandy 222

Husserl, Edmund 15

Huxley, Margo 97-8

Ibn Khaldun 83, 85

Ibn Khaldun manuscript 84

İhsan, Ahmed 96-7

Ilbert, Robert 70-1

imaginations: moral 230; Occidental 66; social 99

inequalities and livelihoods 34-40

"institutional morality" 117

International Monetary Fund (IMF) 34, 183,185

Ioan, Augustin 113, 119

İşcan, Haşim 104

Islamic nationalism 102-4

Islamic theology 17

Islamic-Turkish Ottoman civilization 103

Istanbul, land walls of (1910 to 1980):

authentic peasant as deserving poor and urban threat 104-6; demolishing abject or participating in universalism 99-101; ethics of civilization (1910-1953) 99-101; ethics of urban heritage and moral 
landscapes 97-9; Istanbulites, good and bad 101-2; landscape of a new moral 106-7; overview 96-7; symbolic turn of 1953 102-4; from universalist to Ottomanist and Islamic nationalism 102-4

Istanbulites: good and bad 101-2 Italian Renaissance cities 66

Jacobs, Jane 68, 80, 132

Jaquette-Ray, Sarah 219

Jews 88, 104, 272-3

Jobbik (extreme right party) 187

justice: ethics and 217-20; -oriented urban sustainabilities framework 223

Kakuzo, Okakura 5

Keith, Lynn 231-7

Kenya 36, 39

Kirilovna, Anna 265

Kompromissbereitschaft 175

Konzeptioneller Mietwohnungsbau 168

Kormuhin, Andrej 274n7

Koršunov, Maxim 271

Koutsoumpos, Leonidas 22n10

Krier, Léon 130-1, 134-9, 134-41

Kroll, Lucien 137, 139

Kuo Pao Kun 206-7

La Bomba group 189-90

Laconte, Pierre 130

La France Insoumise 283

Lai, Kathy 205

Lakis, Asja 72

Lakoff, Andrew 13

La Méditerranée et le monde méditerranéen à l'époque de Philippe II [The Mediterranean and the Mediterranean World in the Age of Philipp II] (Braudel) 69

La Place de La République 282

La Reconstruction de Bruxelles 138

La Reconstruction de la Ville européenne 130, 138

La Tour Ferrée. Projets dans la Ville. Projets réalisés à La Cambre, Bruxelles, de 1975 à 1978136

League of Nations 91

Le Bateau d'Élie. Contributions aux luttes urbaines et projets opportunistes, La Cambre 1971-1975 136

Le Bulletin des Archives d'architecture moderne 138

Le Droit à la Ville (Right to the City) 132
Lee Ee Lin 204

Lee Kuan Yew 201

Lefebvre, Henri 17, 72-4, 80, 132, 136, 198-9, 208

Left unions 282-3

Le mani sulla città (Hands over the City) $76 \mathrm{n} 7$

Leontidou, Lila 74

Le Pen, Marine 283-5

Levinas, Emmanuel 5

Lévi-Provençal, Evariste 85

Lewis, Tammy 221

life, city as a form of 28-9

Light, Duncan 124n3

livelihoods and inequalities 34-40

Lopez, Roberto S. 70

Lotus 135-6

Lucan, Jacques 130

luttes urbaines (urban struggles) 131

Macron, Emmanuel 281, 283

The Making of a Building. A Pragmatist Approach to Architecture (Yaneva) 199

The Making of the English Working Class (Thompson) 279

Maniu, Iuliu 120

"Man on the Street" 185-6

Mapping Controversies in Architecture (Yaneva) 199

market-oriented sustainability 219-21

"masculinity" 219

Matless, David 99

Maxwell, Bob 136

McCammon, Holly 182

McCann, Eugene 114

Medieval Islamic societies 81

Mediterranean Anthropology 69

Mediterranean cosmopolitanism 71, 75

Mediterranean culture 73

Mediterranean mégapoles 70

Mediterranean metropolises 66

Mediterranean urban ethic 17

Mediterranean urbanity 17; Mediterranean flavor 66-8; overview 65-6; re-considering a protean concept 75-6; varieties of 68-75; in western scholarly discourse 65-76

mégapole méditerranéenne 70 mégapoles 70

Mehmed the Conqueror 104

Mélenchon, Jean-Luc 283, 285

Menderes, Adnan 104, 106, 108n7

Middle Ages 82, 116

middle-class environmentalism 218 
Middle East 91

Miller, Andrea 232-3

Mitbauzentrale (Center for Co-building) 168,174

Mitrokhin, Nikolai 274n7

modernity: Baudelaire on 73; defined 73; non-Modern 71; Western 73

Monts 14140

moral anthropology 4, 149, 152

"moral economies" 15

moral problematization 164

Moscow 249-50; bodily and binding vs. digital and optional 243-6; institutional ethics in top- down urban interaction 243-6; locating an apolitical "place of one's own" in urban space 247-51; repression in Okkupay space 254-8; requesting normality and cleanliness in protest actions 251-4; tidiness in Okkupay space $254-8$

Moscow Okkupay camp 254

Moscow Urban Forum 243

Mostafavi, Mohsen 22n6

Mouffe, Chantal 22n6

Muehlebach, Andrea 167

muhtasib 82-3, 85-7

Mumford, Lewis 66-7

Munich Lichterkette 22n1

Munich young housing cooperatives

(junge Wohnbaugenossenschaften) 165; being a neighbor 172-3; commitment 173-6; common ownership 170-2; community $172-3$; connections and contestations 170-6; ethical selfformations in 164-77; in making 167-70; overview 164-7; self-help and visions of a better Munich 170-6 music 35-7, 202

Nadi, Yunus 102

Nairobi, Kenya 17, 18, 38-9, 42

nation 219; in 20th century 219;

Orthodox Church and 120

nationalism: authoritarian 11; Islamic 102-4; Russian 265

Negri, Antonio 282

neighborhood: Auckland, Aotearoa New Zealand 231-3; waste disposal and 231-3

"neo- feudalism" 270

neoliberal capitalism 75

neoliberal governance: and improving urban life 7-11 neoliberal governmentality 12, 246

neoliberal ideology 11, 218, 223

neoliberalism 167, 218-19, 220; as global governing ideology 220; individualism and 287; late- modern 13; "Third Way" 10

New Left Review 277

New Right 187

"new social forms" 154,160

New Urbanism 133, 138

"new urbanity" 68

New York City 19, 216, 221-3

New York Times 284

New Zealand Herald 227

Nicolet, Claude 70

Nicolin, Pierluigi 130, 136, 138

NII mitingov initiative 251

NIMBY activism 262

non-governmental organizations

(NGOs) 9, 18, 38-9, 122, 191

"non-Modern modernity" 71

"non- simultaneity" 275 n 16

non- Western modernity 73

Nördliche Luisenstadt 147

Northern anti-urbanism 74

Nous Accusons 289

Novgorod, Nizhny 274n7

Novospassky Monastery 274n7

Novy, Johannes 151

Nuit Debout 277, 279, 281-4, 290-1

Occidental imagination 66

\#OccupyWallStreet 277

Occupy Wall Street movement 220, 278, 279

Ofensiva Generozităţii 189

Ogan, Aziz 101

Okkupay camps 251-2, 254, 256-8

Ong, Aihwa 43

"The Only Path for Architecture" (Culot and Krier) 130

open cities: ethical events and promise of 5-7

Orbán, Viktor 184, 187

"orthodox activists" 274n8, 275n10

Orthodox Church 120-1, 261, 274n7

Ottoman Algeria 91

Ottoman Egypt 91

Ottoman Empire 71, 86-9, 117

Ottoman heritage 103-4

Ottoman imperiality 86-90

Ottoman Iraq 91

Ottomanist 102-4

Ottoman Palestine 91 
Ottoman Syria 91

Ottoman Tripolitania 91

Panerai, Philippe 130

ParcourSup 283, 285

"park protectors" 264, 275n 10

Pavlycheva, Olga 258n2

People's Action Party 201

perestroika 269

Petrescu, Dragos 117

"plastic words" 215-16

Plastic Words: The Tyranny of a

Modular Language (Pörksen) 215

Plater-Ziberk, Elizabeth 138

Platform for Bucharest group 189-90

polyrhythmy 72

Pompe, Antoine 141

Pörksen, Uwe 215

porosity 72,75

"porous modernity" 74

Prague Spring 117

"the precariat" 278-82

Preissing, Sonja 49

presentism 12-16

Price, Cedric 131

problematization 32-3; economic changes and 32; ethical 13, 21; ethical imagination and 30-4; moral 164; political changes and 32; social changes and 32; socio-material practices of 48 ; urban as a $33-4,41,43-4$

PROGENO 169, 177n4

Progressive Era 219

promises: different modalities of and attachments to 52-5; practices and objects of desire 52-5; scenes of 49-55

Prost, Henri 101

"public prayers" 274n10

Purcell, Nicholas 69

Putin, Vladimir 266-7, 273n1

racism 282, 284

Rainbow Warrior 228

Rajak, Dinah 38

Rancière, Jacques 22n5, 22n6

Rational Architecture 138

rationalism 4

Reckwitz, Andreas 177n7

Reconstruction of the European City model 131-3

Régulier, Catherine 72

Renaissance 65

Renaissance City Report and Plans 202
"Renaissance City Singapore" 196, 200, 201-3, 207

The Report of the Advisory Council on Culture and the Arts (ACCA) 202

repression in Okkupay space 254-8

Resource Management Act 228

rhapsode, defined $76 \mathrm{n} 6$

Right to the City 20, 74, 80, 132-3, 142n8, 151, 168, 190-3, 220, 262

Rofel, Lisa 217

Rogojanu, Ana 165

The Roma 102, 104

Roma advocacy organizations 189

Roma ethnicity 189

Roman antiquity 13, 66

Romania 180; Law 10/2001 184; socialist housing construction and distribution in 183

Romanian Common Front for Housing Rights 193

Romanian National Bank 115

"Romanian revolution" 113

Romanian socialism 113

Roman urbanitas 66

Roma rights mobilizations 188

Roma rights organizations 189, 191

Roosevelt, Theodore 219

Rose, Nikolas 203

Rosi, Francesco 76n7

Rottier, Philippe 133

Ruffin, Francois 283

Russian nationalism: anti-orthodox 265

Russian Orthodox Church (ROCH) 261, 263, 269, 273n1, 274n7, 275n17

Salin, Edgar 67-8

Sao Paulo drought crisis 220

Save Romania Union (Uniunea Salvați România) 190, 192

Sayer, Andrew 12, 15, 22n10

Schlosberg, Davis 218

Schmid, Christian 215

Schneider, Matthias 52

Schoonbrodt, René 136

Scott-Brown, Denise 138

Second World War 74

Seghezzo, Lucas 215

Sennett, Richard 5-6, 22n3

Servet- $i$ Fünun 96

Shanghai 19, 221; eco- city discourses in 216; economic, urban and environmental policy of 217 ; global city sustainability of 221-2; transformation since 1990s 217 
Shanghai World Expo 218

Siebel, Walter 68

Singapore: Economic Committee 201; Economic Review Committee 202; esplanade - theatres on the bay 203-7; National Arts Council 202; overview 196-8; "Renaissance City Singapore" 201-3; sociopolitical development 200-1; theory and methodology 198-200; urban renewal and contestation in architecture and urban planning in 200-1

Singapore Concept Plan 200

Singapore Improvement Trust's Master Plan of 1958200

Singapore Planning and Urban Research Group (SPUR) 201, 208

Singapore University 200

Situationist International 16

Smith, Gavin 277-8

Sobyanin, Sergey 246, 271, 274n6

social creativity 149,154 ; and architecture 153-8

social disruption 173

socialism: Romanian 113; Romanian national identity during 116

social movements 9, 20, 182-3, 216, 220, 278-9, 281, 290-1

social protests: defined 266; by ordinary people and the question of politicization 266-8; and "political protests" 267

societal heterogeneity 17

Society of Preservation of Old Monuments 101

Soleri, Paolo 137

solidarities, around housing mobilizations in Budapest 185-8

"solitary contractuality" 119

"Sorok Sorokov" 262, 274n7

Southern urbanism 74-5

Soviet Union 271, 277

Spanish indignados 254

spatial justice 220-3; beyond place and/ or identity and/or space 220-3

Spoerry, François 134-41

Spree riverbank, Berlin: between contestation and collaboration 150-3; transforming 150-3; unrestricted public availability of 151

Stan, Lavinia $124 \mathrm{n} 3$

Standing, Guy 278-9

Starck, Philip 139

Strategic Alliances 182 "strategic detachment" 59

subjecthood: active 236; Auckland, Aotearoa New Zealand 234-6; culture of $177 \mathrm{n} 7$; ethical 228

Süddeutsche Zeitung 164

sustainability: explicit politics and 215; global urban 219-20, 223; marketoriented 219-21; upper- income and wealth amenities 219

"the sustainability edge": defined 216

Swyngedouw, Erik 10

Szabó, Natasa 186

Szasz, Andy 218

Tan Kok Hiang 204

Tanpinar, Ahmet Hamdi 102

Tanzimat 88-9

Tay Kheng Soon 204, 206, 207

technocratic urbanism 67

"Third Reich" 68

"Third Way" neoliberalism 10

Thompson, E.P. 21, 81-2, 277, 279, 281, 291

tidiness in Okkupay space 254-8

Tismăneanu, Vladimir 118

Tonnelat, Stéphane 204

Torfjanka Park, North of Moscow: overview 261-2; "park guards" and "occupiers" 262-6; social protest by ordinary people and question of politicization 266-8; "This is our park": the role of "roots" in the definition of a good city 268-72

Totelecan, Silviu 126n19

Tourism Directorate of Istanbul 103

Trnka, Susanna 172

Trump, Donald 284-5

Trundle, Catherine 172

Tunnard, Christopher 67

"200 Churches' or "Church in walking distance" program 263

ultramodern governmentality 246

Ulubatl1, Hasan 103

Un Bucuresti Frumos (A Beautiful Bucharest) 118

UNESCO 165

UNESCO Intangible World Heritage 165

UN Habitat 39

United Nations 104

United States 219; New Urbanism in 133; \#OccupyWallStreet in 277; protesters in 290; public services in 290 
universalism: demolishing abject or participating in $99-101$; Eurocentric 75

universalist 102-4

(un)making solidarities around housing mobilizations in Bucharest 188-92

UPROSE (environmental justice organization) 221

"Urban Age" thesis 215

urban anthropology 48-9

"urban crisis" $65,73,76 \mathrm{n} 7$

urban environmentalisms: beyond consumer citizenship 217-20; beyond place and/or identity and/or space 220-23; ethical and justice-oriented urban sustainabilities framework 223; ethics and justice 217-20; overview 215-17; reimagining 215-23; toward spatial justice $220-23$

Urban Ethics 177n5, 228, 274n4

urban ethics: ambivalent assemblage 158-60; beyond presentism 12-16; and construction of local dimension of Ottoman imperiality 86-90; between contestation and collaboration 150-53; ethical events and promise of open cities 5-7; ethical project, approaching 147-50; ethical projects 7-11; ethics and normative dimension of urban life 12-16; improving urban life 7-11; neoliberal governance and post- politics 7-11; overview 3-5; social creativity and architecture 153-8; transforming, Spree riverbanks $150-3$

"urban eutopias" 74

"urban greening" 218

urbanism: African 28; Asian 43;

European postmodern 134; functionalist 67, 130; Southern 74-5; technocratic 67

urbanitas 66; in classical antiquity 65-7; classical Roman 66

Urbanité romaine 66

urbanity: and classical Greek and Roman antiquity 66; Mediterranean 17, 66-8; mégapole 70-1; and modern cities and metropolises 65; new 68; Southern 76; Western 17

urbanity as an ethic: ambiguous colonial rediscovery of Hisba 91-2; and construction of local dimension of Ottoman imperiality 86-90; Hisba 81-6; Islamic roots 81-6; overview
80-1; postcolonial rediscovery of Hisba 91-2

urbanization: Africa's 28-9; capitalist 10; environmental impacts of 228 ; of Turkey 105; "Urban Age" thesis and 215

urban life: ethical projects 7-11; ethics and normative dimension of 12-16; improving 7-11; neoliberal governance and 7-11; post-politics and 7-11

urban modernity 65,89

urban project work: non-collaborative aspects of promissory collaboration in $55-8$

urban sustainability $215-16$; branding of 220-1; democratic 223; ethical 223; global 218-20, 223; globalized middle-class 218; political struggles over $216-17$

urban threat: authentic peasant as deserving poor and 104-6

US Occupy camps 254

Valéry, Paul 70

Van den Broeck, Jan 42

Vanderlyn, John 222

Van Dyke, Nella 182

Verdery, Catherine 116, 124n9

Volkov, Alexander 261

voluntarism 4

Vossen, Joachim 125n13

"vote extortion" 187

wagnis (self-organized group) 165, 169

Ward, Kevin 114

waste activism 234

waste dynamics in Auckland 228-31

Waste Minimisation Act 229

Western civilization $66,70,75$

Western liberal democracies 290

Western modernity 73

western scholarly discourse:

Mediterranean urbanity in 65-76

Western urbanity 17

Weszkalnys, Gisa 55

Wiet, Gaston 87

Wilford, Michael 203, 205

Williams, Raymond 98, 277

WOGENO (self-organized group) 165,169

Wohl, Richard 65, 76n1

Wong Mun Summ 204

World Bank 34, 183, 185

World Trade Organization 10 


\section{Index}

World War I 91, 115, 123

World War II 18, 265, 282, 285; see also

Great Patriotic War

Wright, Frank Lloyd 137

Yale University 67

Yaneva, Albena 199
"The Yellow Submarine" 289

Yeo, George 202, 206

Yip Yuen Hong 204

Young, Craig 124n3

Zero Waste New Zealand Trust 229

Zigon, Jarrett 112, 117, 123 